\title{
O problema da subsequência comum máxima sem repetições
}

\author{
Christian Tjandraatmadja
}

\author{
DiSSERTAÇÃO APRESENTADA \\ $\mathrm{AO}$ \\ Instituto De Matemática e Estatística \\ DA \\ UnIVERSIDAde DE SÃo PAUlO \\ PARA \\ OBTENÇÃO DO TÍTULO \\ $\mathrm{DE}$ \\ Mestre em CiÊnCIAS
}

\author{
Programa: Ciência da Computação \\ Orientador: Prof. Dr. Carlos Eduardo Ferreira
}

Durante o desenvolvimento deste trabalho o autor recebeu auxílio financeiro da FAPESP através do processo 07/57149-5

São Paulo, julho de 2010 



\section{O problema da subsequência comum máxima sem repetições}

Esta versão definitiva da dissertação contém as correções e alterações sugeridas pela Comissão Julgadora durante a defesa realizada por Christian Tjandraatmadja em 26/7/2010.

Comissão Julgadora:

- Prof. Dr. Carlos Eduardo Ferreira (orientador) - IME-USP

- Prof. ${ }^{\text {a }}$ Dr. ${ }^{\mathrm{a}}$ Yoshiko Wakabayashi - IME-USP

- Prof. ${ }^{a}$ Dr. ${ }^{a}$ Marie-France Sagot - UCBL-FRANÇA 



\section{Agradecimentos}

Agradeço à minha família, em especial meus pais, pelo sempre presente apoio e pelo extensivo esforço em me ajudarem a chegar onde estou.

Agradeço a todos os meus amigos, pela companhia, apoio, diversão e amizade em geral que me trouxeram todos esses anos. Tenho muita sorte por conhecer os amigos que conheço. Em particular, agradeço ao Jan M. P. G. e ao Stefan T., dois grandes amigos de inúmeras qualidades que muito me influenciaram de forma positiva nestes últimos anos. Aprecio também as interessantes discussões de programação inteira que tive com o Alexandre da S. F. durante o mestrado.

Agradeço aos meus professores, em particular,

- ao prof. Carlos Eduardo Ferreira, excelente orientador e professor, sempre disposto, com bastante interesse e entusiasmo, a me oferecer ótimos conselhos e ideias e a me guiar na superação dos desafios que surgiram neste trabalho; aprecio também seu esforço para tornar possíveis viagens para conferências e cursos que certamente contribuíram para minha formação;

- à prof. ${ }^{\mathrm{a}}$ Yoshiko Wakabayashi, uma professora excelente pela qual tenho muito respeito particularmente devido à sua notável atenção e esforço em dar impulso à aprendizagem de seus alunos; sou grato pelo seu interesse em minha formação, pela sua participação em ambas as minhas bancas e pelos valiosos conselhos e sugestões dados quanto a este trabalho;

- à prof. ${ }^{a}$ Cristina Gomes Fernandes, que sempre mostrou interesse e teve uma grande parte no desenvolvimento deste trabalho particularmente perto de seu início, oferecendo interessantes comentários e sugestões sempre com o entusiasmo de explorar possíveis caminhos;

- ao prof. Paulo Feofiloff, pelo qual tenho grande respeito por suas notáveis qualidades como professor; particularmente por, no curso de graduação, ter me feito enxergar a elegância em algoritmos, graças à sua habilidade em elaborar e dar aulas que têm precisão e "encaixam";

- ao prof. José Coelho de Pina, que participou em minha banca de qualificação e trouxe comentários detalhados e ótimas sugestões para este trabalho;

- ao prof. Roberto Hirata Jr., por sempre demonstrar interesse mesmo sendo de uma área diferente; e

- à prof. ${ }^{a}$ Marie-France Sagot, pela participação em minha banca e seus interessantes comentários sobre este trabalho.

Enfim, fico feliz por ter conhecido e aprendido com todos estes professores, que certamente foram importantes para minha formação. 



\title{
Resumo
}

Exploramos o seguinte problema: dadas duas sequências $X$ e $Y$ sobre um alfabeto finito, encontre uma subsequência comum máxima de $X$ e $Y$ sem símbolos repetidos. Estudamos a estrutura deste problema, particularmente do ponto de vista de grafos e de combinatória poliédrica. Desenvolvemos algoritmos de aproximação e heurísticas para este problema. O enfoque deste trabalho está na construção de um algoritmo baseado na técnica branch-and-cut, aproveitando-nos de um algoritmo de separação eficiente e de heurísticas e técnicas para encontrarmos uma solução ótima mais cedo.

Também estudamos um problema mais fácil no qual este problema é baseado: dadas duas sequências $X$ e $Y$ sobre um alfabeto finito, encontre uma subsequência comum máxima de $X$ e $Y$. Exploramos este problema do ponto de vista de combinatória poliédrica e descrevemos vários algoritmos conhecidos para resolvê-lo.

Palavras-chave: Subsequência comum máxima sem repetições, subsequência comum máxima, programação inteira, combinatória poliédrica, branch-and-cut, algoritmos de aproximação, heurísticas.

\begin{abstract}
We explore the following problem: given two sequences $X$ and $Y$ over a finite alphabet, find a longest common subsequence of $X$ and $Y$ without repeated symbols. We study the structure of this problem, particularly from the point of view of graphs and polyhedral combinatorics. We develop approximation algorithms and heuristics for this problem. The focus of this work is in the construction of an algorithm based on the branch-and-cut technique, taking advantage of an efficient separation algorithm and of heuristics and techniques to find an optimal solution earlier.

We also study an easier problem on which this problem is based: given two sequences $X$ and $Y$ over a finite alphabet, find a longest common subsequence of $X$ and $Y$. We explore this problem from the point of view of polyhedral combinatorics and describe several known algorithms to solve it.
\end{abstract}

Keywords: Repetition-free longest common subsequence, longest common subsequence, integer programming, polyhedral combinatorics, branch-and-cut, approximation algorithms, heuristics. 



\section{Sumário}

1 Introdução 13

1.1 Aplicações . . . . . . . . . . . . . . . . . . . . . . . 13

1.1 .1 Problema do LCS . . . . . . . . . . . . . . . . . . . 13

1.1 .2 Problema do RFLCS . . . . . . . . . . . . . . . . . . . . . 14

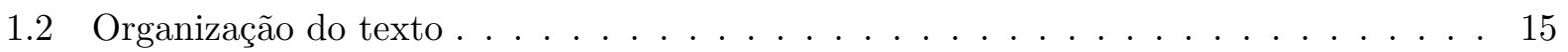

1.3 Informações sobre os resultados computacionais . . . . . . . . . . . . . 16

2 Os problemas e suas estruturas $\quad 17$

2.1 Descrição dos problemas . . . . . . . . . . . . . . . . . . . 17

2.2 Conceitos estruturais . . . . . . . . . . . . . . . . . . . 18

2.3 Grafos de cruzamento e de conflito . . . . . . . . . . . . . . . . . 19

3 Formulações e poliedros $\quad 21$

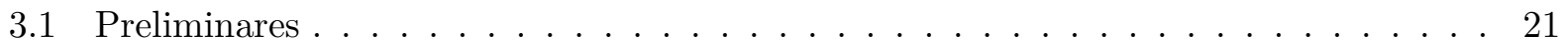

3.2 Formulações para LCS . . . . . . . . . . . . . . . . . . . . . . . 24

3.3 Formulações para RFLCS . . . . . . . . . . . . . . . . . . . 31

3.3.1 Formulação por estrelas estendidas . . . . . . . . . . . . . . . . 31

3.3.2 Formulação por símbolos distintos . . . . . . . . . . . . . . . . . . . . . . . . . . . . .

3.4 Limitantes e gap de integralidade para RFLCS . . . . . . . . . . . . . . . 39

4 Aproximabilidade e heurísticas para RFLCS 41

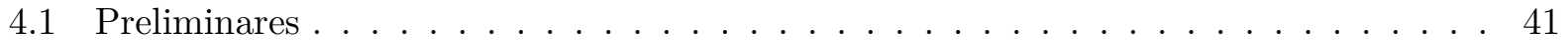

4.2 Algoritmos de aproximação baseados em remoção de repetições . . . . . . . . . . . . 42

4.2 .1 LCS e remove repetições . . . . . . . . . . . . . . . . . . . . 42

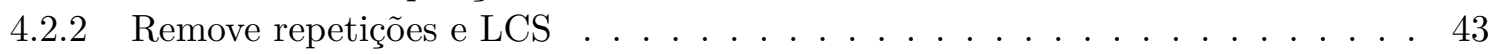

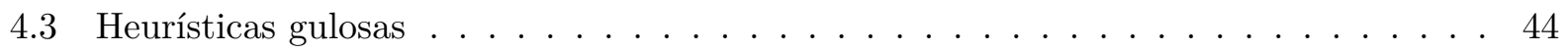

4.3 .1 Escolha simples . . . . . . . . . . . . . . . . . . 44

4.3 .2 Menor número de conflitos . . . . . . . . . . . . . . . . 44

4.3 .3 Maior limitante de casamento . . . . . . . . . . . . . . . . . . 45

4.4 Resultados computacionais . . . . . . . . . . . . . . . . 46

4.5 Inaproximabilidade do RFLCS . . . . . . . . . . . . . . . . . . . . . . . . . . . . . . . . .

4.5 .1 Preliminares . . . . . . . . . . . . . . . . . . . 49

4.5.2 Uma L-redução de MAX 2,3-SAT para uma versão restrita do RFLCS . . . . 49 
5 Algoritmo branch-and-cut para RFLCS $\mathbf{5 5}$

5.1 A técnica branch-and-cut . . . . . . . . . . . . . . . . 55

5.2 Algoritmo de separação para estrelas estendidas maximais . . . . . . . . . . . . 56

5.2 .1 Algoritmo de separação baseado em programação dinâmica . . . . . . . . . . . 57

5.2 .2 Algoritmo de separação baseado em limiares . . . . . . . . . . . . . . . . . . 62

5.2.3 Comparação entre os dois algoritmos de separação . . . . . . . . . . . . . . 69

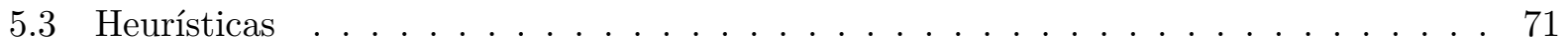

5.4 Limitante de casamento . . . . . . . . . . . . . . . . . . . . 73

5.5 Pré-processamento . . . . . . . . . . . . . . . . . . . . 75

5.6 Resultados computacionais gerais . . . . . . . . . . . 76

6 Algoritmos de enumeração para RFLCS 81

6.1 Decomposição em subproblemas fáceis . . . . . . . . . . . . . . . . . 81

6.2 Decomposição em subproblemas fáceis com branch-and-bound . . . . . . . . . . . 82

6.3 Programação dinâmica . . . . . . . . . . . . . . . . . . . 83

6.4 Conjunto independente no grafo de conflito . . . . . . . . . . . . . . 88

7 Algoritmos para LCS $\quad \mathbf{8 9}$

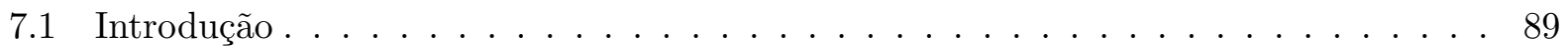

7.2 Algoritmo de programação dinâmica . . . . . . . . . . . . . . . . 90

7.3 Visualização da estrutura do LCS . . . . . . . . . . . . . . . . . . . . . 93

7.4 Algoritmo por limiares de Hunt e Szymanski . . . . . . . . . . . . . . . . . 95

7.4.1 Modificação por Kuo e Cross . . . . . . . . . . . . . . . . . . . . 100

7.5 Algoritmo por contornos de Hirschberg . . . . . . . . . . . . . . . . . . 101

7.6 Modificações dos algoritmos de Hirschberg e de Hunt-Szymanski por Apostolico e

Guerra . . . . . . . . . . . . . . . . . . 106

7.6.1 Modificação do algoritmo de Hirschberg . . . . . . . . . . . . . . . . . . 107

7.6.2 Modificação do algoritmo de Hunt-Szymanski . . . . . . . . . . . . . . . . 110

7.7 Algoritmo por preenchimento de diagonais de Nakatsu, Kambayashi e Yajima . . . . 111

7.8 Algoritmo de divisão e conquista de Hirschberg em espaço linear . . . . . . . . . . 115

7.9 Algoritmo de subdivisão de matriz de Masek e Paterson . . . . . . . . . . . . . . 118

7.10 Algoritmo por limiares e saltos para casamentos . . . . . . . . . . . . . . . 120

7.11 Resultados computacionais . . . . . . . . . . . . . . . . . . . . . . . . . . . . . . . .

7.12 Resumo . . . . . . . . . . . . . . . . . . . . . . 124

$\begin{array}{llr}8 \text { Conclusão } & 127\end{array}$

A Técnicas não usadas no algoritmo branch-and-cut 129

A.1 Algoritmo de separação para circuito ímpar . . . . . . . . . . . . . . . . . 129

A.2 Pool de inequações . . . . . . . . . . . . . . . . . . . . . . 131

A.3 Atualização da matriz de programação dinâmica no algoritmo de separação . . . . 131

B Comparação entre resultados computacionais usando CPLEX e GLPK 133 
C Dados numéricos dos resultados computacionais $\quad 135$

C.1 Algoritmos de aproximação e heurísticas . . . . . . . . . . . . . . . . . . 135

C.2 Algoritmos de separação de estrela estendida . . . . . . . . . . . . . . . . 138

C.3 Heurísticas no branch-and-cut . . . . . . . . . . . . . . . . . . . 139

C.4 Variáveis fixadas através de limitantes de casamento . . . . . . . . . . . . . . 140

C.5 Resultados gerais do algoritmo branch-and-cut . . . . . . . . . . . . 140

C.6 Formulação por símbolos distintos . . . . . . . . . . . . . . . . . . . . 142

C.7 Formulação por cruzamentos . . . . . . . . . . . . . . . . . . . . . . 142

C.8 Algoritmos de decomposição em subproblemas . . . . . . . . . . . . . . . . . . 142

C.9 Algoritmo de programação dinâmica . . . . . . . . . . . . . . . . . . . 143

C.10 Algoritmos de conjunto independente . . . . . . . . . . . . . . . . . 144

C.11 Algoritmos para o LCS . . . . . . . . . . . . . . . . . . . . . 144

$\begin{array}{lr}\text { Créditos } & 147\end{array}$

$\begin{array}{lr}\text { Referências Bibliográficas } & 149\end{array}$ 


\section{Capítulo 1}

\section{Introdução}

O objetivo deste trabalho é explorar a fundo um problema de otimização combinatória denominado problema da subsequência comum máxima sem repetições e desenvolver um algoritmo exato eficiente para o problema. No decorrer deste trabalho estudamos também o problema do qual ele é derivado, o problema da subsequência comum máxima.

O problema de comparar duas sequências surge em diversas aplicações. Um critério comum para comparar duas sequências consiste em olhar para a mais longa sequência da qual podemos obter cada uma das duas apenas adicionando símbolos a ela (nesse sentido, é uma espécie de ancestral). Se for possível obter uma sequência desse tipo que é longa, então as duas sequências são similares. O problema de encontrar a sequência mais longa desse tipo é o problema da subsequência comum máxima, ou LCS (longest common subsequence).

O problema estudado neste trabalho é uma variante do problema do LCS: o problema da subsequência comum máxima sem repetições, ou RFLCS (repetition-free longest common subsequence). Ele é um problema pouco estudado, mas, assim como o problema do LCS, pode ser usado para determinar a similaridade entre duas sequências. No entanto, o critério usado tem uma condição adicional: a sequência usada como critério pode ter no máximo uma ocorrência de cada símbolo do alfabeto. Este critério é útil para comparar genomas em que hajam famílias de genes, como veremos na seção seguinte.

Os problemas serão definidos formalmente e exemplos serão dados no capítulo seguinte.

\subsection{Aplicações}

\subsubsection{Problema do LCS}

O problema do LCS é um problema bem conhecido e estudado em computação. Uma aplicação relativamente recente do problema do LCS e de bastante interesse é a comparação de segmentos de DNA e de proteínas. Podemos estar interessados em saber o grau de similaridade de dois segmentos, que pode ser um indicativo de que têm um ancestral comum parecido com os dois. Com a evolução, nucleotídeos ou aminoácidos podem ter sido inseridos, removidos ou alterados, e o comprimento de um LCS dos segmentos é uma medida que considera bem isso. Atualmente existem outras variantes do LCS para compará-los mais precisamente, pois existem outras transformações que podem ocorrer com esses segmentos conforme a evolução, mas o problema do LCS não deixa de ter um papel muito importante nas comparações. 
Uma outra aplicação é comparar arquivos, como no programa Unix diff. Queremos comparar dois arquivos e saber quais linhas foram inseridas ou removidas. Se considerarmos um arquivo como uma sequência de linhas, um LCS nos dá o "núcleo" que pertence a ambos os arquivos, e para saber quais linhas foram inseridas ou removidas, basta observar a diferença entre esse "núcleo" e algum dos arquivos. A comparação de arquivos também é útil para sistemas de controle de versão.

Mais uma aplicação é corrigir erros ortográficos - podemos procurar palavras dentro de um dicionário que tenha um LCS de comprimento alto entre ela e a palavra incorreta. Também existem aplicações em compressão de dados, reconhecimento de voz, atualização de tela em monitores CRT, entre outras. Algumas dessas aplicações e outras são descritas em [42].

\subsubsection{Problema do RFLCS}

Devido a características de sequências, diversas variantes do problema do LCS surgiram. O problema do RFLCS é uma delas, e sua aplicação vem da comparação entre genomas, levando em conta a teoria de rearranjo de genomas. Nessa abordagem, representamos cada gene como um símbolo, sem se preocupar com sua estrutura interna, e consideramos a evolução de genomas baseada em processos de rearranjo.

Durante esses processos, duplicatas de genes podem surgir de diversas maneiras. Uma suposição comum feita para comparar rearranjos de genomas é que cada gene é homólogo a no máximo um gene de outro genoma. Em outras palavras, dadas duas sequências $X$ e $Y$ de genomas, essa suposição diz que, dado um símbolo em $X$, só pode ter no máximo uma ocorrência desse símbolo em $Y$. Essa suposição tem fundamento para alguns genomas pequenos, como os de vírus ou de mitocôndrias, e torna o problema mais fácil, já que o comprimento de um LCS é uma medida boa para esse caso. No entanto, para genomas maiores, ela é problemática devido ao número de duplicatas de genes. No genoma humano, aproximadamente $15 \%$ dos genes de proteína são duplicatas [31]. Ainda mais, a situação é complicada pelo processo de divergência de sequência, no qual as duplicatas podem se tornar estruturalmente e funcionalmente diferentes até o ponto de deixarem de ser duplicatas, mas continuam sendo da mesma família de genes, que são homólogas e funcionalmente similares.

Com esse conceito de família de genes, em vez de considerar cada gene separadamente, podemos considerar um representante de cada família, chamado de exemplar. Usando essa ideia, Sankoff [39] propõe uma medida de comparação de genes, denominado de distância exemplar. Ademais, com base nessa medida, Bonizzoni et al. [6] estuda variantes do LCS chamados de subsequência comum máxima exemplar (exemplar longest common subsequence, ELCS), que consideram um conjunto de símbolos obrigatórios na subsequência. Uma dessas variantes limita em 1 o número de ocorrências de cada símbolo opcional e, assim, é uma generalização do RFLCS. Outra generalização do problema do RFLCS também é considerada em [7], em que os autores juntam o problema do RFLCS com o problema do CLCS (constrained longest common subsequence).

O comprimento de um RFLCS é uma outra medida que leva em consideração a noção de exemplar. Ele pode ser visto como uma medida de similaridade entre dois genomas na qual, para cada família de genes, desconsideramos todos os genes exceto um representante da família, o exemplar.

Uma noção melhor sobre rearranjo de genomas e duplicação de genes pode ser obtida em [41, 40].

Em particular, a variante do problema do RFLCS que permite reversões de sequências é uma medida boa para evidenciar uma conjectura que afirma que o cromossomo Y é derivado do cromossomo X a partir de cinco grandes reversões [30,44]. Nessas referências, observa-se que o cromossomo $\mathrm{X}$ é dividido em quatro ou cinco trechos (estratos) que são comparáveis com partes do cromossomo Y em termos da distância entre eles. 


\subsection{Organização do texto}

Os capítulos seguintes são organizados como abaixo.

Capítulo 2: Os problemas e suas estruturas. Iniciamos descrevendo alguns conceitos importantes para resolver os problemas do LCS e do RFLCS e apresentamos uma visão dos problemas sob o ponto de vista de grafos.

Capítulo 3: Formulações e poliedros. Prosseguimos com formulações de programação inteira para os problemas do LCS e do RFLCS e provamos que as inequações das formulações são "fortes" do ponto de vista de poliedros. Além disso, mostramos que o poliedro da formulação para o problema do LCS descreve por completo o poliedro associado ao problema. Na última seção desse capítulo, descrevemos limitantes para o comprimento de um RFLCS. Esse capítulo contém a maior parte dos resultados teóricos desta dissertação.

Capítulo 4: Aproximabilidade e heurísticas para RFLCS. Nesse capítulo, descrevemos algoritmos de aproximação e heurísticas para o problema do RFLCS e mostramos o resultado de dificuldade sobre a aproximabilidade do problema desenvolvido por Adi et al. [1]. Apresentamos alguns resultados computacionais dos algoritmos.

Capítulo 5: Algoritmo branch-and-cut para RFLCS. Os dois capítulos anteriores formam a base para esse capítulo, que descreve a implementação de um algoritmo baseado na técnica branch-and-cut para o problema do RFLCS. Ele é baseado em uma formulação do Capítulo 3 e usa heurísticas inspiradas nos algoritmos de aproximação e heurísticas do Capítulo 4, além de usar técnicas para permitir que uma solução ótima seja encontrada mais cedo. Mostramos resultados computacionais do algoritmo.

Capítulo 6: Algoritmos de enumeração para RFLCS. Esse curto capítulo descreve mais alguns algoritmos exatos para o problema do RFLCS que se aproveitam da estrutura do problema para enumerar soluções e encontrar uma solução ótima no processo. Apresentamos dois algoritmos que enumeram subproblemas computacionalmente mais fáceis de se resolver e um algoritmo de programação dinâmica eficiente para alfabetos muito pequenos. Também mostramos resultados computacionais desses algoritmos. Além disso, comparamos o consumo de tempo do algoritmo branch-and-cut com os de dois algoritmos de conjunto independente no grafo relacionado ao problema.

Capítulo 7: Algoritmos para LCS. Estudamos e implementamos alguns algoritmos para o problema do LCS. Em particular, a Seção 7.10 apresenta um algoritmo para o problema do LCS que não encontramos na literatura.

Para o leitor que não conhece nenhum algoritmo para resolver o problema do LCS, pode valer a pena pelo menos conhecer o algoritmo de programação dinâmica lendo a Seção 7.2. Mais adiante, descreveremos um algoritmo que faz parte do algoritmo branch-and-cut (algoritmo de separação) que usa como base os algoritmos de programação dinâmica e de Hunt e Szymanski, da Seção 7.4. O restante dos algoritmos descritos no Capítulo 7 não são usados em nenhum outro capítulo desta dissertação, com exceção de uma técnica por Apostolico e Guerra (Seção 7.6.1) usada no algoritmo de programação dinâmica (Seção 6.3). Apresentamos resultados computacionais das implementações. 
O Capítulo 7 é uma resenha auto-contida e o leitor que deseja apenas estudar algoritmos para o problema do LCS pode pular diretamente para esse capítulo.

Finalmente, o Capítulo 8 resume os principais resultados obtidos nesta dissertação de mestrado e sugere alguns trabalhos futuros que podem ser realizados.

Além dos capítulos, esta dissertação contém três apêndices. O primeiro apêndice comenta algumas técnicas que foram implementadas mas não usadas no algoritmo branch-and-cut por não contruibuírem ao algoritmo. O segundo compara a implementação do algoritmo, que usa a biblioteca GLPK, com uma mesma implementação que usa a biblioteca comercial CPLEX. O terceiro documenta os valores numéricos dos resultados computacionais dos gráficos apresentados nesta dissertação (recomendamos ao leitor interessado que observe os valores numéricos junto com os gráficos).

Este trabalho foi desenvolvido com contribuições técnicas diretas de algumas pessoas. A seção de Créditos no final desta dissertação menciona as contribuições, especificando que partes o autor e essas pessoas tiveram neste trabalho.

\subsection{Informações sobre os resultados computacionais}

Todas as instâncias usadas para os testes foram sequências geradas de forma aleatória e uniforme de acordo com o alfabeto. Isto é, para cada posição na sequência, escolhemos um símbolo aleatório do alfabeto. Ambas as sequências geradas para cada teste são do mesmo comprimento.

Em todos os testes que envolveram programação linear, foi usada a biblioteca de código aberto GLPK 4.41 [14], que cuida da resolução de programas lineares e organiza a estrutura do algoritmo branch-and-cut (com exceção da formulação por cruzamentos, para o qual foi usada a versão 4.31 pela razão explicada no Apêndice C.7).

Todos os resultados computacionais neste texto foram obtidos a partir da média de 10 execuções. A máquina utilizada para realizar os testes roda Linux, é 64 -bit e tem dois processadores Intel ${ }^{\circledR}$ Xeon ${ }^{\circledR}$ E5440 (quad-core), com velocidade de clock 2.83GHz, e 32GB de RAM. Cada execução foi sequencial (usou apenas uma thread).

Para facilitar a identificação das curvas nos gráficos, as legendas dos gráficos estão ordenadas na mesma ordem em que os valores estão na margem direita do gráfico (ou, se a curva não atingir a margem direita, o valor que a atingiria se a curva crescesse na mesma taxa). 


\section{CAPÍtUlo 2}

\section{Os problemas e suas estruturas}

Neste capítulo, descrevemos os problemas do LCS e do RFLCS e exploramos suas características estruturais. Tal investigação é especialmente importante para o desenvolvimento do algoritmo exato para o problema do RFLCS do Capítulo 5.

\subsection{Descrição dos problemas}

Defina um alfabeto como um conjunto finito cujos elementos são chamados de símbolos. Por exemplo, o conjunto de letras $\Sigma=\{\mathrm{a}, \mathrm{b}, \mathrm{c}, \ldots, \mathrm{z}\}$ é um alfabeto. Uma sequência é uma lista ordenada de símbolos de algum alfabeto. Por exemplo, uma palavra como projeto é uma sequência sobre o alfabeto $\Sigma$ do exemplo anterior.

Dada uma sequência qualquer $Z$, denote por $z_{i}$ o seu $i$-ésimo símbolo, por $|Z|$ o seu comprimento, e por $Z[r . . s]$ a subsequência $z_{r} z_{r+1} \ldots z_{s}$.

Dada uma sequência $X$ sobre algum alfabeto (por exemplo, $X=$ mestrado), $Z$ é uma subsequência de $X$ se podemos obter $Z$ removendo zero ou mais símbolos de $X$ (por exemplo, $Z$ pode ser etrdo). Vale ressaltar que os símbolos de $Z$ não precisam estar em ordem contígua em $X$ e, além disso, $Z$ pode ser vazio ou ser igual a $X$. Formalmente, $Z$ é uma subsequência de $X$ se existe uma sequência estritamente crescente $i_{1} i_{2} \ldots i_{k}$ de índices de $X$ tal que $z_{j}=x_{i_{j}}$ para todo $j=1, \ldots,|Z|$.

Uma subsequência comum de duas sequências $X$ e $Y$ é uma sequência que é tanto subsequência de $X$ como de $Y$ (por exemplo, se $X=$ mestrado e $Y=$ matrizes, ela pode ser $m a$ ). Uma subsequência comum máxima ou LCS (longest common subsequence) de $X$ e $Y$ é uma subsequência comum de comprimento máximo entre todas as subsequências comuns de $X$ e $Y$ (no exemplo anterior, ela pode ser $m t r$ ou mes). O problema do LCS é encontrar um LCS de duas sequências.

Dizemos que uma sequência é sem repetições se não contém dois símbolos que são iguais no alfabeto (por exemplo, a sequência abcd é sem repetições enquanto abca tem repetições). Assim, uma subsequência comum máxima sem repetições ou RFLCS (repetition-free longest common subsequence) de $X$ e $Y$ é uma subsequência comum sem repetições de comprimento máximo entre todas as subsequências comuns sem repetições de $X$ e $Y$. O problema do RFLCS é encontrar um RFLCS de duas sequências.

Nesta dissertação, as sequências $X$ e $Y$ estão implícitas (a menos que definidas explicitamente). Assim, quando nos referirmos a uma subsequência comum, LCS, ou RFLCS, estamos nos referindo a uma subsequência comum, LCS, ou RFLCS das duas sequências $X$ e $Y$ para as quais queremos 
resolver o problema do LCS ou do RFLCS, dependendo do contexto. O alfabeto $\Sigma$ também está implícito nesta dissertação como o alfabeto que contém os símbolos de $X$ e $Y$.

Observe que nem sempre podemos obter um RFLCS removendo os símbolos repetidos de um LCS. Por exemplo, se $X=a a a b c$ e $Y=b c a a a$, então o único LCS de $X$ e $Y$ é $a a a$, mas o único RFLCS de $X$ e $Y$ é $b c$.

LCS

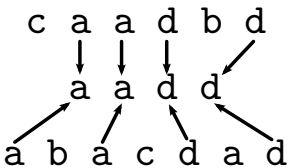

RFLCS

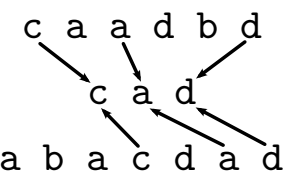

O problema do LCS pode ser resolvido usando programação dinâmica em tempo $O(m n)$, onde $m$ e $n$ são os comprimentos das duas sequências para as quais se quer encontrar um LCS (Seção 7.2). Já o problema do RFLCS é APX-difícil [1]. Em outras palavras, adicionar essa restrição aparentemente simples não só torna o problema NP-difícil como também faz com que seja impossível encontrar, a menos que $\mathrm{P}=\mathrm{NP}$, um esquema de aproximação polinomial para o problema (descrito na Seção 4.1).

\subsection{Conceitos estruturais}

Defina um casamento como um par ordenado de índices $(i, j)$ para o qual $x_{i}=y_{j}$, isto é, o $i$-ésimo símbolo de $X$ é igual ao $j$-ésimo símbolo de $Y$. Cada casamento $(i, j)$ está associado a um símbolo $x_{i}\left(=y_{j}\right)$. Seja $\mathcal{C}$ o conjunto de casamentos associados a $X$ e $Y$. Dizemos que dois casamentos $(i, j) \in \mathcal{C}$ e $(k, l) \in \mathcal{C}$ se cruzam se $i \geq k$ e $j \leq l$, ou $i \leq k$ e $j \geq l$ (representando os casamentos graficamente como abaixo, eles se cruzam se e só se eles se intersectam graficamente). Dizemos também que um casamento conflita com outro se eles se cruzam ou seus símbolos são iguais.

casamentos que conflitam um com o outro

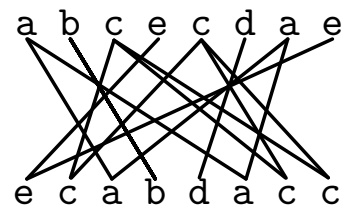

casamentos

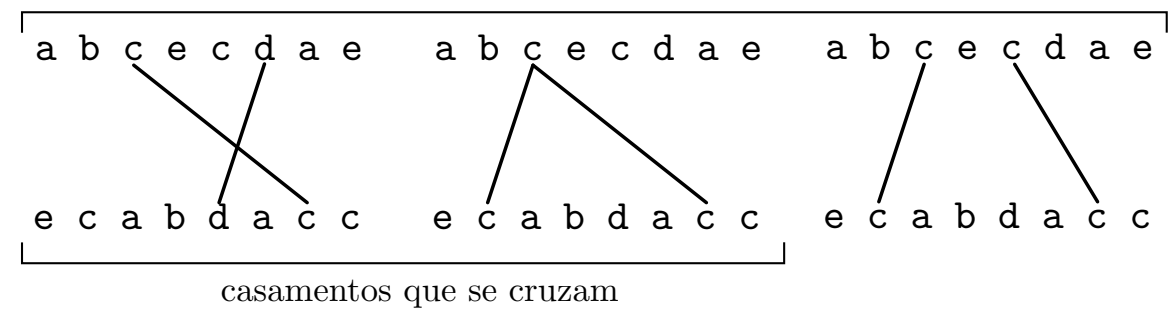

Dizemos que $(i, j)$ precede $(k, l)$ (ou $(k, l)$ sucede $(i, j)$ ) se $i<k$ e $j<l$, e denotamos isso por $(i, j) \prec(k, l)$. Isto é, $(i, j)$ não cruza com $(k, l)$ e está à esquerda de $(k, l)$ na representação gráfica.

É fácil ver que, dado um conjunto de casamentos $C=\left\{\left(i_{1}, j_{1}\right),\left(i_{2}, j_{2}\right), \ldots,\left(i_{k}, j_{k}\right)\right\}$, seus elementos não se cruzam dois a dois se e só se eles podem ser ordenados de forma que $\left(i_{l_{1}}, j_{l_{1}}\right) \prec$ $\left(i_{l_{2}}, j_{l_{2}}\right) \prec \ldots \prec\left(i_{l_{k}}, j_{l_{k}}\right)$, onde $\left(l_{1}, l_{2}, \ldots, l_{k}\right)$ é uma permutação de $\{1,2, \ldots, k\}$. Assim, dizemos que um conjunto de casamentos $C=\left\{\left(i_{1}, j_{1}\right),\left(i_{2}, j_{2}\right), \ldots,\left(i_{k}, j_{k}\right)\right\}$ com seus elementos ordenados de tal maneira é uma representação da subsequência comum $S=x_{i_{1}} x_{i_{2}} \ldots x_{i_{k}}=y_{j_{1}} y_{j_{2}} \ldots y_{j_{k}}$. Note que, embora toda representação esteja associada a uma subsequência comum, uma mesma subsequência comum pode ter mais de uma representação, como ilustrado na figura seguinte. 

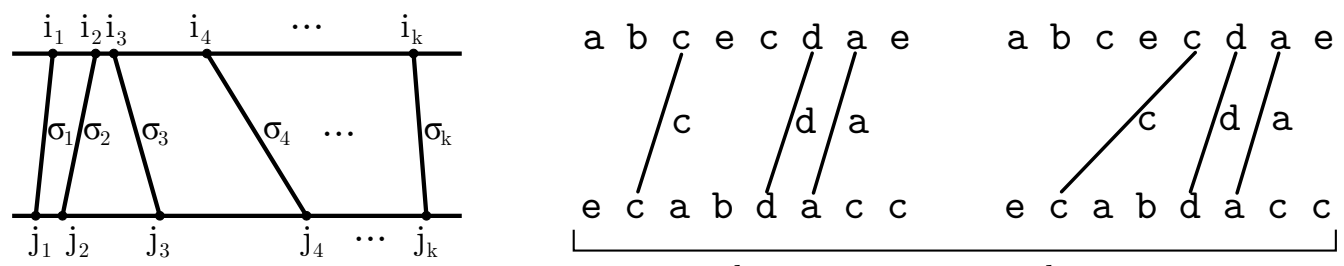

duas representações distintas

da subsequência comum cda

A relação entre esses conceitos e os problemas estudados é clara: é de interesse buscar uma representação de cardinalidade máxima, livre ou não de repetições dependendo do problema, pois dela obtemos um RFLCS ou um LCS. É importante observar que, se o conjunto de casamentos não conflitam entre si dois a dois, então ele representa uma subsequência comum sem repetições. Todos os algoritmos exatos para o problema do LCS e do RFLCS comentados neste texto primeiro encontram uma representação, implicitamente ou explicitamente, e dela se constrói um LCS ou um RFLCS.

\subsection{Grafos de cruzamento e de conflito}

É interessante observar os conceitos anteriores sob o ponto de vista de grafos. Um grafo é um par $(V, E)$, onde $V$ é um conjunto finito cujos elementos são chamados de vértices, e $E$ é uma família de pares não-ordenados de $V$ chamados de arestas.

Defina $G_{c r}=\left(V_{c r}, E_{c r}\right)$ como o grafo de cruzamento de $X$ e $Y$, onde $V_{c r}$ é o conjunto de casamentos de $X$ e $Y$ e uma aresta $(u, v) \in E_{c r}$ se e só se os casamentos $u$ e $v$ se cruzam. Analogamente, defina o grafo de conflito $G_{c}$ da mesma forma, mas a aresta $(u, v)$ pertence ao grafo se e só se $u$ conflita com $v$.

Sejam $\operatorname{occ}_{X}(\sigma)$ e $o c c_{Y}(\sigma)$ o número de ocorrências do símbolo $\sigma \in \Sigma$ em $X$ e $Y$ respectivamente e seja $\Sigma^{\prime} \subseteq \Sigma$ o conjunto de símbolos $\sigma$ tal que $\operatorname{occ}_{X}(\sigma)>1$ e $o c c_{Y}(\sigma)>1$. Então o grafo de conflito tem exatamente $\sum_{\sigma \in \Sigma^{\prime}}\left(\begin{array}{c}o c c_{X}(\sigma) \\ 2\end{array}\right)\left(\begin{array}{c}o c c_{Y}(\sigma) \\ 2\end{array}\right)$ arestas a mais que o grafo de cruzamento. No exemplo abaixo, as quatro arestas destacadas no grafo de conflito são a única diferença entre os dois grafos.

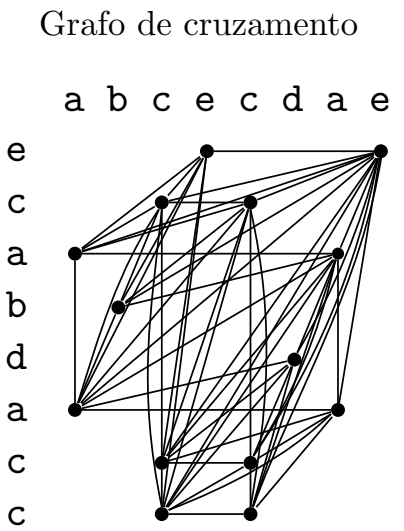

Grafo de conflito

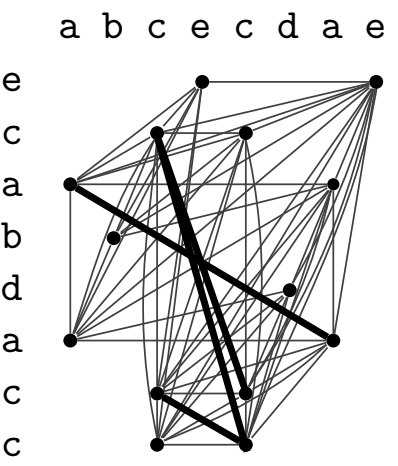


Para resolver o problema do LCS ou do RFLCS, buscamos um conjunto de casamentos que, dois a dois, não se cruzam ou não conflitam um com o outro respectivamente. Portanto, é o mesmo que procurar um conjunto independente máximo para o grafo de cruzamento ou de conflito respectivamente (um conjunto independente máximo é um conjunto de vértices dois a dois não adjacentes de cardinalidade máxima).

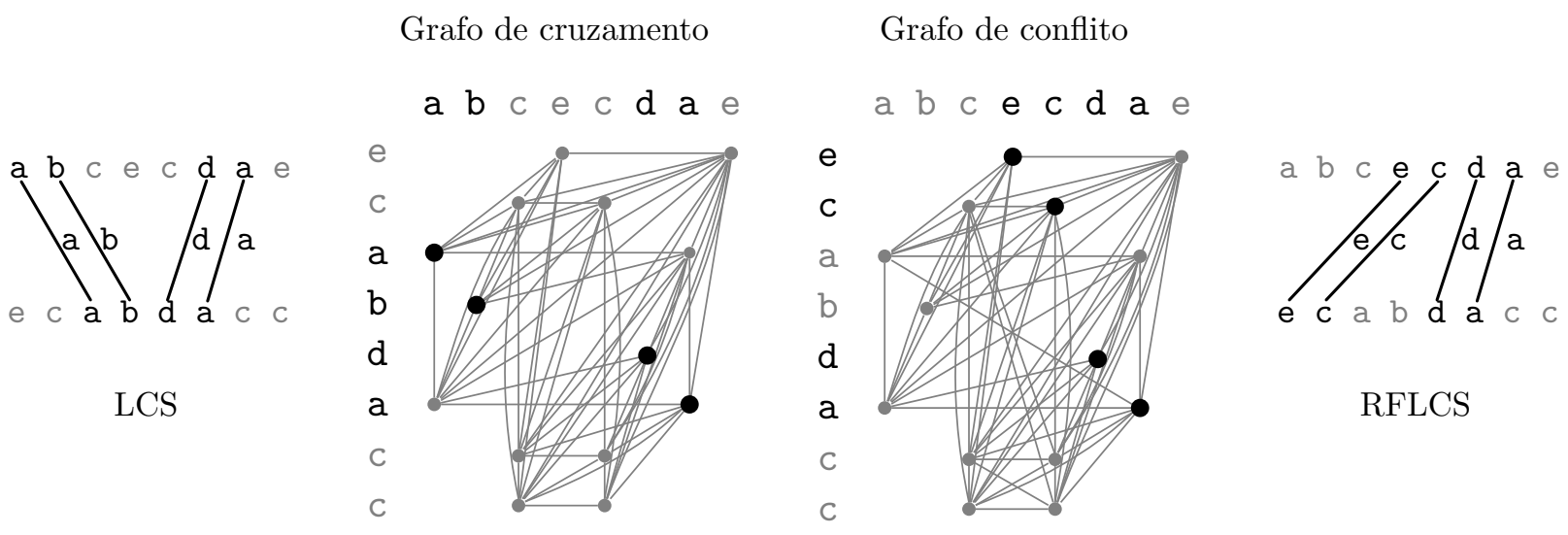

Seja $\prec_{c}$ uma ordem parcial tal que $(i, j) \prec_{c}(k, l)$ se $i \leq k$ e $j \geq l$ (ela é uma ordem parcial pois é reflexiva, antissimétrica e transitiva). Com isso, podemos reescrever a definição de cruzamento da seguinte forma: $(i, j)$ e $(k, l)$ se cruzam se $(i, j) \prec_{c}(k, l)$ e $(k, l) \prec_{c}(i, j)$. Portanto, por definição, o grafo de cruzamento pertence à classe dos grafos de comparabilidade. Sabe-se que o problema do conjunto independente para grafos de comparabilidade é computacionalmente fácil, o que é consistente com o fato que o problema do LCS é também um problema fácil.

Tome o complemento de $G_{c}, \bar{G}_{c}$. Dois casamentos são adjacentes em $\bar{G}_{c}$ se e só se eles não se cruzam. Como $\prec$ é uma ordem parcial estrita (ela é irreflexiva, antissimétrica e transitiva), $\bar{G}_{c}$ também é um grafo de comparabilidade. Nesse caso, o problema do LCS é equivalente ao problema do clique máximo em $\bar{G}_{c}$, que é equivalente ao problema do caminho mínimo na orientação transitiva em $\bar{G}_{c}$, por ser um grafo de comparabilidade.

Já o grafo de conflito não tem essa propriedade. Em particular, o grafo de conflito não pertence à classe dos grafos perfeitos (que contém a classe dos grafos de comparabilidade), pois se pertencesse, o problema do RFLCS seria polinomialmente tratável, já que o problema do conjunto independente máximo também o é em grafos perfeitos. (As relações entre grafos de comparabilidade, grafos perfeitos, e o problema do conjunto independente máximo podem ser encontradas em [15]. Voltaremos a falar sobre grafos de comparabilidade e grafos perfeitos na segunda prova do Teorema 3.2.3.) 


\section{CAPÍtUlo 3}

\section{Formulações e poliedros}

Neste capítulo, investigamos possíveis formulações para os problemas do LCS e do RFLCS, e exploramos características dos poliedros associados a essas formulações.

\subsection{Preliminares}

Descrevemos brevemente alguns conceitos básicos de programação linear, programação inteira e combinatória poliédrica necessários para o entendimento deste capítulo. Esta seção é baseada no livro de Wolsey [46].

Um programa linear é, de uma forma geral, um problema de maximizar ou minimizar uma função linear sobre um poliedro, dado por um sistema de inequações lineares. Trataremos apenas de problemas de maximização nesta seção; o de minimização é análogo.

Mais formalmente, um programa linear é um problema do tipo

$$
\begin{aligned}
& \text { maximize } c x \quad \text { (função objetivo) } \\
& \text { sujeito a } A x \leq b \quad \text { (sistema de inequações lineares) } \\
& x \geq 0
\end{aligned}
$$

onde $x$ é um vetor coluna de variáveis de dimensão $n$, e o restante são dados: $A$ é uma matriz $m$ por $n, c$ é um vetor linha de dimensão $n$, e $b$ é um vetor coluna de dimensão $m$ (0 denota o vetor zero neste caso). Em outras palavras, queremos encontrar um vetor $x$ que maximiza $c x$ e satisfaz as restrições $A x \leq b$ e $x \geq 0$.

Exemplo 3.1.1. Se o problema é de maximização, e $n=2, m=3, x=\left(x_{1}, x_{2}\right) \in \mathbb{R}^{2}, c=(1,2)$,

$$
\begin{aligned}
& A=\left(\begin{array}{cc}
1 & 1 \\
2 & -1 \\
-1 & 1
\end{array}\right) \text { e } b=\left(\begin{array}{l}
5 \\
6 \\
2
\end{array}\right) \text {, então temos o programa linear: } \quad \text { maximize } \quad x_{1}+2 x_{2} \\
& \text { sujeito a } \quad x_{1}+x_{2} \leq 5 \\
& 2 x_{1}-x_{2} \leq 6 \\
& -x_{1}+x_{2} \leq 2 \\
& x_{1} \geq 0 \\
& x_{2} \geq 0
\end{aligned}
$$


Uma solução viável é um vetor $x$ que satisfaz as restrições do programa linear. Uma solução ótima é uma solução viável que maximiza a função objetivo, isto é, é uma solução propriamente dita do problema.

Um poliedro é um conjunto $\left\{x \in \mathbb{R}^{n} \mid A x \leq b\right\}$ para alguma matriz $A \in \mathbb{R}^{m \times n}$ e vetor $b \in \mathbb{R}^{m}$. O poliedro associado à formulação linear anterior ao exemplo é

$$
P:=\left\{x \in \mathbb{R}^{n} \mid A x \leq b, x \geq 0\right\} .
$$

Exemplo 3.1.2. O poliedro do exemplo anterior é o conjunto $P:=\left\{\left(x_{1}, x_{2}\right) \in \mathbb{R}^{2} \mid x_{1}+x_{2} \leq 5\right.$, $\left.2 x_{1}-x_{2} \leq 6,-x_{1}+x_{2} \leq 2, x_{1} \geq 0, x_{2} \geq 0\right\}$, ilustrado pela região sombreada delimitada pelas retas abaixo.

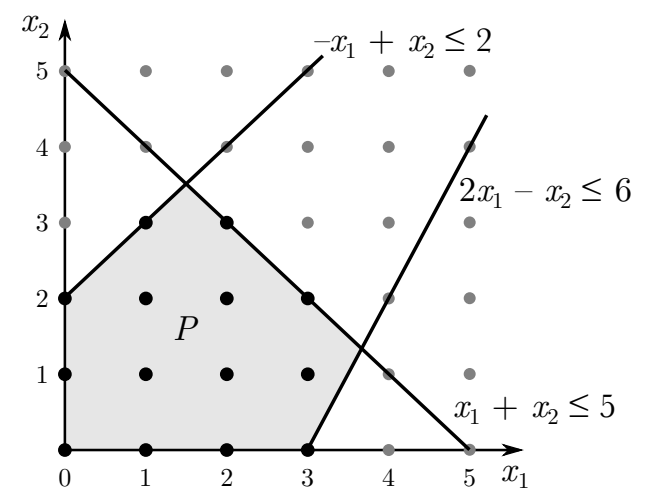

Programas lineares podem ser resolvidos usando o método simplex, desenvolvido por Dantzig em 1947 [10]. A ideia do método, em termos gerais, é encontrar um vértice do poliedro e andar de vértice em vértice adjacente sempre aumentando o valor da função objetivo até não ser mais possível. O método simplex funciona bem na prática e é bastante usado, embora não se saiba até agora um limitante superior polinomial para seu consumo de tempo. A figura seguinte ilustra, em linhas gerais, a ideia do método simplex.

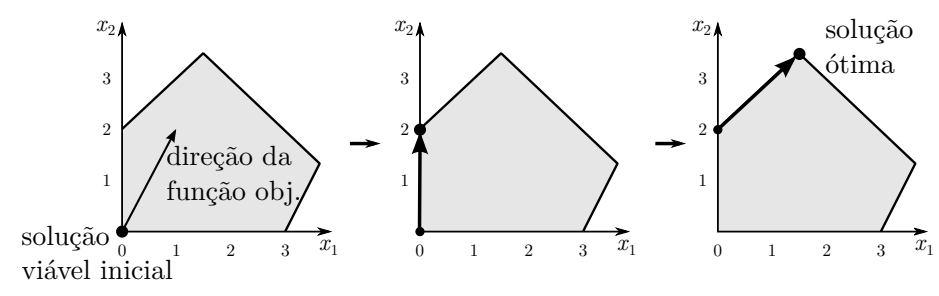

Em 1979 e 1984, Khachiyan [26] e Karmarkar [24] desenvolveram dois outros métodos para resolver programas lineares: o método do elipsoide e o método dos pontos interiores, respectivamente. Ambos os métodos consomem tempo polinomial, apesar do primeiro não ser rápido o suficiente para aplicações práticas. Já o segundo é comparável com o método simplex na prática. 
Um programa linear inteiro (ou apenas programa inteiro) é um programa linear no qual adicionamos a restrição de que as variáveis são inteiras, como a seguir.

$$
\begin{aligned}
\max & c x \\
\text { s. a } & A x \leq b \\
& x \in \mathbb{Z}_{+}^{n}
\end{aligned}
$$

Os métodos mencionados para resolver um programa linear não resolvem um programa inteiro, especialmente pelo fato de que as soluções viáveis do problema não formam um conjunto convexo. Ainda mais, o problema geral de resolver um programa inteiro é NP-difícil. Veremos como resolver um programa inteiro (particularmente, um relacionado ao problema do RFLCS) no Capítulo 5.

O casco convexo de um conjunto de pontos $P$, denotado por conv $(P)$, é o conjunto convexo minimal que contém $P$. Mais formalmente, se $P=\left\{x_{1}, \ldots, x_{k}\right\}$, então conv $(P)=\left\{\lambda_{1} x_{1}+\ldots+\lambda_{k} x_{k} \mid\right.$ $\left.\lambda_{1}+\ldots+\lambda_{k}=1, \lambda_{1}, \ldots, \lambda_{k} \geq 0\right\}$. O casco convexo de um conjunto finito de pontos é um poliedro limitado.

O poliedro associado à formulação inteira anterior é

$$
P_{I}:=\operatorname{conv}\left\{x \in \mathbb{Z}_{+}^{n} \mid A x \leq b\right\} .
$$

Se $A$ e $b$ têm valores racionais, então $\operatorname{conv}\left(P_{I}\right)$ é um poliedro racional [33].

Exemplo 3.1.3. Os pontos em preto da figura ao lado são as soluções da formulação inteira dada pelo exemplo anterior adicionando a restrição de integralidade. A região sombreada, definida pelos traços cheios, definem o casco convexo dessas soluções, e, portanto, definem $P_{I}$ (as linhas pontilhadas são do poliedro original $P$ ).

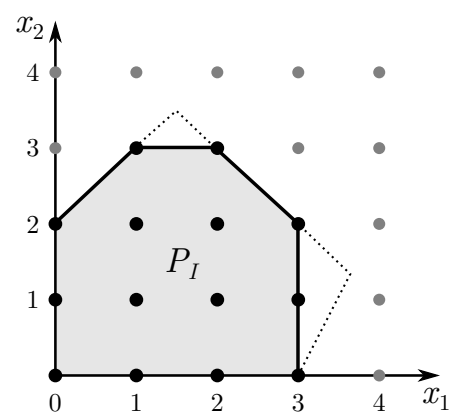

A relaxação linear de um programa inteiro é o programa linear obtido ao remover a restrição de integralidade do programa inteiro. Por exemplo, a relaxação linear do programa inteiro anterior é $\max \{c x \mid A x \leq b, x \geq 0\}$, e o poliedro associado a ele é $\left\{x \in \mathbb{R}^{n} \mid A x \leq b, x \geq 0\right\}$. Idealmente, gostaríamos de ter o poliedro associado à formulação inteira, mas, se o problema for NP-difícil e $\mathrm{NP} \neq$ co-NP, não é possível obter uma descrição completa dele de forma que exista uma "prova curta" para toda inequação linear que o define de que ela é necessária para o poliedro [25]. Então, trabalhamos, em geral, com o poliedro associado à relaxação linear, que podemos obter diretamente da formulação.

Uma inequação é válida para um poliedro $P$ se ela é satisfeita por todos os pontos de $P$. Uma inequação válida $\pi x \leq \pi_{0}$ domina uma outra inequação válida $\mu x \leq \mu_{0}$ se existe $u>0$ tal que $\pi \geq u \mu$ e $\pi_{0} \leq u \mu_{0} \cdot{ }^{1}$ Note que se $\pi x \leq \pi_{0}$ domina $\mu x \leq \mu_{0}$, então toda solução $x$ não-negativa que satisfaz a primeira inequação também satisfaz a segunda.

Os pontos $x_{1}, x_{2}, \ldots, x_{k}$ são linearmente independentes se, quando $\sum_{i=1}^{k} \alpha_{i} x_{i}=0$, onde $\alpha_{i} \in \mathbb{R}$, temos que $\alpha_{1}=\alpha_{2}=\ldots=\alpha_{k}=0$. Os pontos $x_{1}, x_{2}, \ldots, x_{k}$ são afim-independentes se os

\footnotetext{
${ }^{1} \mathrm{~A}$ definição usual inclui a condição de que $\left(\pi, \pi_{0}\right) \neq\left(u \mu, u \mu_{0}\right)$. Neste texto, desconsideraremos essa condição por conveniência.
} 
$k-1$ pontos $x_{2}-x_{1}, \ldots, x_{k}-x_{1}$ são linearmente independentes, ou os $k$ pontos $\left(x_{1}, 1\right), \ldots,\left(x_{k}, 1\right)$ são linearmente independentes. Afim-independência é análogo a independência linear desconsiderando a origem (todo conjunto de pontos linearmente independentes são também afim-independentes).

A dimensão de um poliedro $P$ é o número máximo de pontos afim-independentes em $P$ menos um. Um poliedro $P \subseteq \mathbb{R}^{n}$ tem dimensão plena se sua dimensão é $n$. Isso implica que não existe equação $a x=b$ satisfeita por todos os pontos de $P$, onde $a \in \mathbb{R}^{n}$ e $b \in \mathbb{R}$. Pode-se provar que se um poliedro tem dimensão plena, então ele tem uma descrição minimal única (cujas inequações são únicas a menos de um múltiplo positivo).

Uma face de um poliedro $P$ é um conjunto $F=\left\{x \in P \mid \pi x=\pi_{0}\right\}$ para alguma inequação válida $\pi x \leq \pi_{0}$. Dizemos que essa inequação define a face. Uma face é uma faceta se sua dimensão é a dimensão do poliedro menos um.

Exemplo 3.1.4. Ainda considerando as inequações e os poliedros dos exemplos anteriores, as inequações $x_{1}+x_{2} \leq 5$, $-x_{1}+x_{2} \leq 2, x_{1} \geq 0$ e $x_{2} \geq 0$ definem facetas de $P_{I}$. A única inequação das anteriores que não define uma faceta é $2 x_{1}-x_{2} \leq 6$, pois existe apenas um ponto $x$ do poliedro tal que $2 x_{1}-x_{2}=6$. Note que as inequações $x_{1} \leq 3 \mathrm{e}$ $x_{2} \leq 3$, não presentes nas inequações anteriores, definem facetas de $P_{I}$. Com essas inequações, temos uma descrição completa de $P_{I}$.

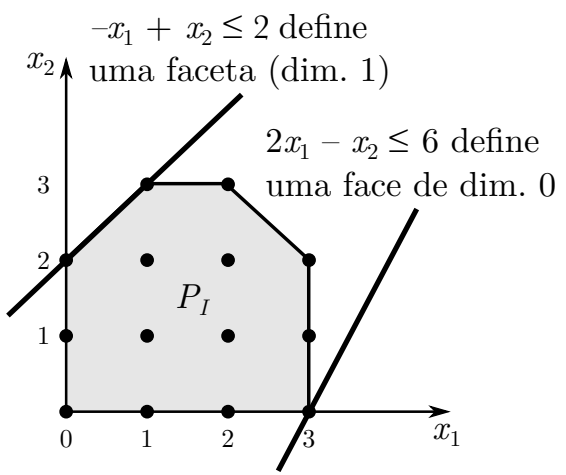

O foco deste capítulo é descrever formulações e provar que algumas inequações definem facetas de poliedros associados aos problemas do LCS e do RFLCS. A importância disso é que, se um poliedro $P$ tem dimensão plena, então uma inequação válida de $P$ define faceta se e só se ela é necessária na descrição de $P$ (isto é, não existe outra inequação válida além de um múltiplo dela que a domina).

\subsection{Formulações para LCS}

Como vimos no capítulo anterior, resolver o problema do LCS é equivalente a escolher um conjunto de casamentos de cardinalidade máxima em que não haja dois casamentos que se cruzam. Em outras palavras, para cada dois casamentos que se cruzam, podemos apenas escolher um deles. Usando isso, construiremos, a seguir, uma formulação de programação inteira que é válida para o problema do LCS.

Para todo casamento $(i, j)$ em $\mathcal{C}$, seja $z_{i j}$ uma variável que é 1 se o casamento $(i, j)$ está na representação da subsequência comum associada a $z$, ou é 0 em caso contrário.

$$
\begin{aligned}
& \max \sum_{(i, j) \in \mathcal{C}} z_{i j} \\
& \text { (formulação por cruzamentos) } \\
& \text { s. a } z_{i j}+z_{k l} \leq 1 \quad \text { para todo }(i, j) \text { e }(k, l) \text { em } \mathcal{C} \text { que se cruzam, } \\
& z_{i j} \in\{0,1\} \text { para todo }(i, j) \text { em } \mathcal{C} \text {. }
\end{aligned}
$$


O poliedro associado à relaxação linear da formulação é

$$
\begin{gathered}
P_{C}:=\left\{z \in \mathbb{R}^{\mathcal{C}} \mid z_{i j}+z_{k l} \leq 1 \text { para todo }(i, j) \text { e }(k, l) \text { em } \mathcal{C}\right. \text { que se cruzam, e } \\
\left.0 \leq z_{i j} \leq 1 \text { para todo }(i, j) \text { em } \mathcal{C}\right\}
\end{gathered}
$$

Sobre $P_{C}$, apenas faremos a observação de que $P_{C}$ pode ter vértices fracionários (isto é, nãointeiros). De fato, tome o caso em que as sequências de entrada são $X=a b c$ e $Y=c b a$, ou seja, existem apenas três casamentos $(1,3),(2,2)$ e $(3,1)$ que se cruzam dois a dois. Então as inequações de cruzamento são $z_{13}+z_{22} \leq 1, z_{13}+z_{31} \leq 1$ e $z_{22}+z_{31} \leq 1$. O ponto fracionário $\left(\frac{1}{2}, \frac{1}{2}, \frac{1}{2}\right)$ é um vértice do poliedro, pois pertence ao poliedro e satisfaz $d=3$ inequações com igualdade, onde $d$ é a dimensão do poliedro.

O ideal seria o poliedro não ter vértices fracionários, pois otimizar sobre tal poliedro nos daria sempre um ponto inteiro, que é o que queremos. Observe que, se substituirmos essas 3 inequações pela inequação $z_{13}+z_{22}+z_{31} \leq 1$, o ponto fracionário $\left(\frac{1}{2}, \frac{1}{2}, \frac{1}{2}\right)$ deixa de ser um vértice do poliedro pois ele viola a inequação, e a formulação inteira original continua sendo válida sob este poliedro pois a nova inequação não elimina nenhum ponto inteiro do poliedro.
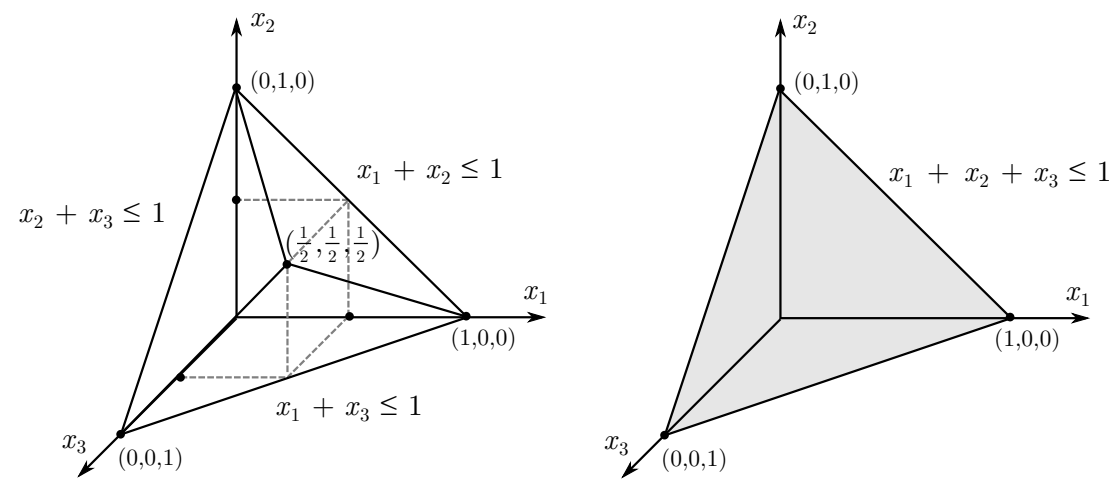

A seguir, construiremos uma outra formulação mais forte com inequações como a última do exemplo acima e, mais adiante, mostraremos que o poliedro dado por esse tipo de inequações tem apenas vértices inteiros.

Uma estrela é um conjunto de casamentos que se cruzam dois a dois (ilustrada na página seguinte), ou seja, é um clique no grafo de cruzamento definido na Seção 2.3 (um clique de um grafo é um conjunto de vértices dois a dois adjacentes). Dizemos que uma estrela $S$ é maximal se não existe nenhum casamento que pode ser acrescentado a $S$ de forma a se obter uma estrela maior. Note que, para qualquer estrela maximal $S$, podemos escolher no máximo um casamento de $S$ para estar em uma representação de uma subsequência comum. Construiremos, a seguir, uma formulação baseada nesse fato.

Seja $z \in\{0,1\}^{\mathcal{C}}$ uma variável como na formulação anterior, isto é, $z_{i j}=1$ se e só se $(i, j)$ pertence à representação dada por $z$.

$$
\begin{array}{lll}
\max & \sum_{(i, j) \in \mathcal{C}} z_{i j} & \text { (formulação por estrelas) } \\
\text { s. a } & \sum_{(i, j) \in S} z_{i j} \leq 1 & \text { para toda estrela maximal } S \subseteq \mathcal{C}, \\
z_{i j} \in\{0,1\} & \text { para todo }(i, j) \text { em } \mathcal{C} .
\end{array}
$$



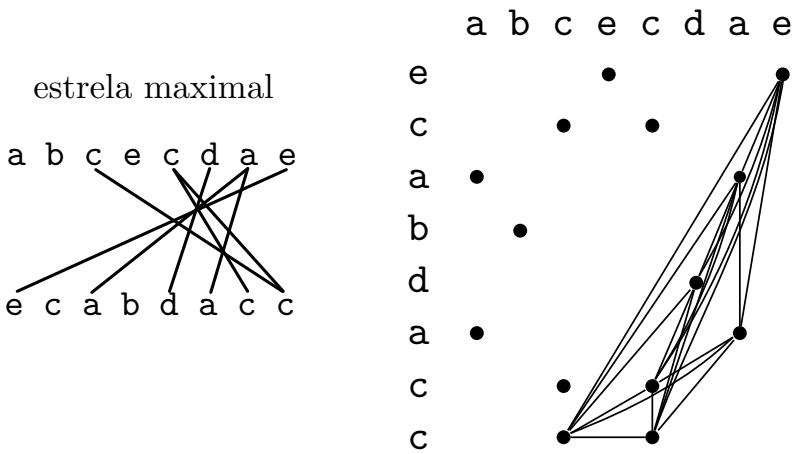

Uma relaxação linear da formulação pode ser obtida trocando $z_{i j} \in\{0,1\}$ por $z_{i j} \geq 0$ (não são necessárias as inequações $z_{i j} \leq 1$ pois as inequações de estrela as dominam).

Vale comentar que a formulação é a formulação por cliques para o problema do conjunto independente máximo, mas restrito a grafos de cruzamento (ela aparece no contexto de conjunto independente máximo, por exemplo, na referência [16]). As inequações $\sum_{v \in K} z_{v} \leq 1$ para todo clique maximal $K$ são chamadas de inequações de clique e são válidas para o problema do conjunto independente máximo. As inequações baseadas em estrelas maximais são uma adaptação das inequações de clique, uma vez que uma estrela é um clique no grafo de cruzamento.

Como todo par de casamentos que se cruzam está contido em alguma estrela maximal, as restrições baseadas em cruzamento são dominadas pelas restrições baseadas em estrelas maximais. Logo, o poliedro associado à formulação por cruzamentos está contido no poliedro associado à formulação por estrelas. Ainda mais, podemos provar um resultado mais forte: o poliedro associado à formulação por estrelas é o melhor poliedro possível (o mais justo) em termos de representações de subsequências comuns.

Defina o poliedro do problema do LCS como

$$
P_{\mathrm{LCS}}:=\operatorname{conv}\left\{z \in\{0,1\}^{\mathcal{C}} \mid z \text { representa uma subsequência comum de } X \text { e } Y\right\} \text {. }
$$

Observe primeiro que o poliedro $P_{\mathrm{LCS}}$ tem dimensão $|\mathcal{C}|$, isto é, tem dimensão plena. De fato, o vetor zero e os $|\mathcal{C}|$ vetores unitários $e^{i j}$ para todo $(i, j) \in \mathcal{C}$ estão em $P_{\mathrm{LCS}}$ e são afim-independentes (um vetor unitário $e^{k}$ tem valor 1 na posição $k$ e 0 nas restantes).

Provaremos a seguir que as inequações da relaxação linear da formulação por estrelas,

$$
\begin{aligned}
\sum_{(i, j) \in S} z_{i j} \leq 1 & \text { para toda estrela maximal } S \subseteq \mathcal{C}, \text { e } & \text { (inequação de estrela) } \\
z_{i j} \geq 0 & \text { para todo }(i, j) \text { em } \mathcal{C}, & \text { (inequação de não-negatividade) }
\end{aligned}
$$

definem facetas de $P_{\mathrm{LCS}}$.

Proposição 3.2.1. Para todo $(i, j)$ em $\mathcal{C}$, a inequação de não-negatividade $z_{i j} \geq 0$ define uma faceta de $P_{\mathrm{LCS}}$.

Prova. Considere um casamento $(i, j) \in \mathcal{C}$. O vetor zero e os vetores unitários $e^{k l}$ para todo $(k, l) \neq(i, j)$ estão contidos na face $\left\{z \in P_{\mathrm{LCS}} \mid z_{i j}=0\right\}$ e são afim-independentes. Portanto, $z_{i j} \geq 0$ define uma faceta. 
Lema 3.2.2. Considere uma estrela $S \subseteq \mathcal{C}$. Então a inequação de estrela $\sum_{(i, j) \in S} z_{i j} \leq 1$ define uma faceta de $P_{\mathrm{LCS}}$ se e só se $S$ é maximal.

Prova. Mostraremos primeiro que a inequação de estrela define uma faceta quando $S$ é maximal.

Seja $F$ a face definida em $P_{\mathrm{LCS}}$ pela inequação de estrela, isto é, $F:=\left\{z \in P_{\mathrm{LCS}} \mid \sum_{(i, j) \in S} z_{i j}=1\right\}$.

Suponha que $S$ é maximal. Então, para cada casamento $(k, l)$ em $\mathcal{C} \backslash S$, existe um casamento $(i, j)$ em $S$ que não cruza com $(k, l)$. Tome os $|\mathcal{C}|-|S|$ vetores $e^{k l}+e^{i j}$ para todo par de casamentos $(k, l)$ e $(i, j)$ dessa forma. Como eles representam uma subsequência comum e satisfazem a igualdade $\sum_{(i, j) \in S} z_{i j}=1$, eles pertencem à face $F$. Além disso, os $|S|$ vetores $e^{i j}$ para todo $(i, j)$ em $S$ também pertencem a $F$. Esses $|\mathcal{C}|$ vetores são afim-independentes e, assim, $F$ é uma faceta de $P_{\text {LCS }}$.

Agora, suponha que $F$ é uma faceta de $P_{\mathrm{LCS}}$. Se $S$ não é maximal, então existe uma estrela maximal $S^{\prime}$ que contém $S$, e $\sum_{(i, j) \in S} z_{i j} \leq 1$ pode ser escrito como uma soma da inequação $\sum_{\left(i^{\prime}, j^{\prime}\right) \in S^{\prime}} z_{i^{\prime} j^{\prime}} \leq 1$ com as inequações $-z_{k l} \leq 0$ para todo $(k, l)$ em $S^{\prime} \backslash S$, o que é uma contradição.

Considere o poliedro associado à relaxação linear da formulação por estrelas, isto é, dado pelas inequações de estrela e de não-negatividade:

$$
\begin{aligned}
P_{S}:=\left\{z \in \mathbb{R}^{\mathcal{C}} \mid\right. & \sum_{(i, j) \in S} z_{i j} \leq 1 \text { para toda estrela maximal } S \subseteq \mathcal{C}, \text { e } \\
& \left.z_{i j} \geq 0 \text { para todo }(i, j) \in \mathcal{C}\right\} .
\end{aligned}
$$

Provaremos que as inequações de estrela e de não-negatividade definem o poliedro do problema do LCS por completo, isto é:

Teorema 3.2.3. $P_{\mathrm{LCS}}=P_{S}$.

Apresentaremos duas provas do teorema acima, ambas por Fernandes et al. [12]. A primeira prova mostra diretamente que toda inequação que define faceta de $P_{\mathrm{LCS}}$ é uma inequação de estrela ou de não-negatividade. A segunda prova usa um teorema de Chvátal relacionando grafos perfeitos e poliedros de clique.

Antes de apresentarmos as demonstrações, uma primeira tentativa para provar o teorema seria verificar se a matriz de restrições $A$ da relaxação linear da formulação por estrelas é totalmente unimodular. Uma matriz é totalmente unimodular se o determinante de toda submatriz quadrada dela é 1, 0 ou -1. Pode-se provar que se a matriz de restrições de um programa linear for totalmente unimodular e o lado direito das inequações tiver apenas valores inteiros, então os vértices do poliedro associado a esse programa são inteiros [46], o que provaria o teorema. No entanto, no caso do LCS, nem sempre a matriz de restrições de estrela é totalmente unimodular, como no exemplo em que $X=a b c d e f$ e $Y=e f c d a b$, cuja matriz de restrições possui um subdeterminante -2 .

Prova 1. (Teorema 3.2.3) Seja $a z \leq \alpha$ uma inequação que define uma faceta $F$ de $P_{\mathrm{LCS}}$. Isto é,

$$
F:=\left\{z \in P_{\mathrm{LCS}} \mid a z=\alpha\right\}
$$


Sejam $F_{1}(i, j)$ e $F_{2}(S)$ as facetas definidas pelas inequações de não-negatividade para $(i, j)$ e de estrela para $S$ respectivamente. Isto é,

$$
\begin{aligned}
F_{1}(i, j) & :=\left\{z \in \mathbb{R}^{\mathcal{C}} \mid z_{i j}=0\right\}, \mathrm{e} \\
F_{2}(S) & :=\left\{z \in \mathbb{R}^{\mathcal{C}} \mid \sum_{(i, j) \in S} z_{i j}=1\right\} .
\end{aligned}
$$

Como $F$ é faceta, é suficiente provarmos que $F \subseteq F_{1}(i, j)$ para algum $(i, j)$ em $\mathcal{C}$, ou $F \subseteq F_{2}(S)$ para alguma estrela maximal $S \subseteq \mathcal{C}$.

Denote por $F$-representação um conjunto de casamentos que representa uma subsequência comum cujo vetor de incidência $z$ pertence a $F$ (um vetor de incidência $z$ de um conjunto $S$ é aquele em que $z_{s}=1$ se $s \in S$, ou $z_{s}=0$ caso contrário). Como os vértices de $P_{\mathrm{LCS}}$ são inteiros, é suficiente considerar apenas vetores $z$ em $P_{\text {LCS }}$ que são vetores de incidência de alguma $F$-representação.

Primeiro, suponha que existe $(i, j)$ em $\mathcal{C}$ tal que $a_{i j}<0$. Qualquer $F$-representação $R$ satisfaz $z_{i j}=0$, pois, caso contrário (se $z_{i j}=1$ ), $R \backslash\{(i, j)\}$ também representa uma subsequência comum, mas $a\left(z-e^{i j}\right)=a z-a_{i j}>\alpha$, isto é, $z-e^{i j}$ não pertence a $P_{\mathrm{LCS}}$, o que é um absurdo. Portanto, $F \subseteq F_{1}(i, j)$.

Podemos supor então que $a_{i j} \geq 0$ para todo $(i, j)$ em $\mathcal{C}$.

Seja $T$ o vetor suporte para $a z \leq \alpha$, isto é, $T:=\left\{(i, j) \in \mathcal{C} \mid a_{i j}>0\right\}$. Como a inequação define faceta, podemos supor que $T \neq \varnothing$.

Seja $R$ uma $F$-representação e $z$ seu vetor de incidência. Se $z_{i j}=0$ para qualquer $(i, j)$ em $T$, então $\sum_{(i, j) \in T} a_{i j} z_{i j}=0$, e, logo, $\alpha=0$. Então, como $a_{i j} \geq 0$ para todo $(i, j)$ em $\mathcal{C}$ e $a \neq 0$, existe um $\left(i^{\prime}, j^{\prime}\right)$ em $\mathcal{C}$ tal que $z_{i^{\prime} j^{\prime}}=0$ para qualquer vetor de incidência $z$ de uma $F$-representação e, portanto, $F \subseteq F_{1}\left(i^{\prime}, j^{\prime}\right)$.

Assim, podemos supor que, para qualquer $F$-representação, existe $(i, j)$ em $T$ tal que $z_{i j}=1$.

Definiremos agora uma ordem lexicográfica entre conjuntos de casamentos. Considere dois subconjuntos $S_{1}$ e $S_{2}$ de $\mathcal{C}$ ordenados de forma que $(i, j)$ vem antes de $(k, l)$ se $i<k$ ou $(i=k$ e $j<l$ ). Dizemos que $S_{1}$ é lexicograficamente menor ou igual a $S_{2}$ se, sob a ordem acima, ou $S_{1}$ é prefixo de $S_{2}$, ou, para o primeiro índice $p$ tal que o $p$-ésimo casamento $\left(i_{1}, j_{1}\right)$ de $S_{1}$ é diferente do $p$-ésimo casamento $\left(i_{2}, j_{2}\right)$ de $S_{2},\left(i_{1}, j_{1}\right)$ vem antes de $\left(i_{2}, j_{2}\right)$ na ordem acima (se existir tal $p$ ). Esta ordem lexicográfica é uma ordem total.

Seja $S_{1}$ a primeira estrela maximal em $T$ em ordem lexicográfica. Provaremos que $F \subseteq F_{2}\left(S_{1}\right)$. Para isso, temos que mostrar que sempre vale $\sum_{(i, j) \in S_{1}} z_{i j}=1$ para qualquer vetor de incidência $z$ de uma $F$-representação.

Suponha, por contradição, que existe uma $F$-representação $R$ com vetor de incidência $z$ tal que $z_{i j}=0$ para todo casamento em $S_{1}$. Como existe $(i, j)$ em $T$ tal que $z_{i j}=1, R \cap\left(T \backslash S_{1}\right) \neq \varnothing$. Então cada casamento $(i, j)$ em $S_{1}$ cruza com algum casamento em $R \cap\left(T \backslash S_{1}\right)$, pois, caso contrário, $R \cup\{(i, j)\}$ representaria uma subsequência comum e $a\left(z+e^{i j}\right)=a z+a_{i j}>\alpha$, isto é, $z+e^{i j}$ não pertenceria a $P_{\mathrm{LCS}}$, o que é um absurdo.

Mostraremos agora que existe um par de casamentos distintos $(i, j)$ e $(k, l)$ em $R \cap\left(T \backslash S_{1}\right)$ tal que todo casamento em $S_{1}$ cruza com $(i, j)$ ou com $(k, l)$. De fato, suponha que tal par não existe. Então, para qualquer par de casamentos distintos em $R \cap\left(T \backslash S_{1}\right)$, existe um casamento em $S_{1}$ que não cruza com nenhum dos dois. Lembremos da definição de precedência entre casamentos: $(i, j)$ precede $(k, l)$, ou $(i, j) \prec(k, l)$, se $i<k$ e $j<l$. Considere dois casamentos $\left(i_{1}, j_{1}\right)$ e $\left(i_{2}, j_{2}\right)$ em $R \cap\left(T \backslash S_{1}\right)$ tal que $\left(i_{1}, j_{1}\right)$ precede imediatamente $\left(i_{2}, j_{2}\right)$, e seja $(k, l)$ um casamento em $S_{1}$ que não cruza 
com nenhum dos dois. Se $\left(i_{1}, j_{1}\right) \prec(k, l) \prec\left(i_{2}, j_{2}\right)$, então $(k, l)$ não cruza com nenhum casamento em $R \cap\left(T \backslash S_{1}\right)$, uma contradição. Caso contrário, para todo par desse tipo, $(k, l) \prec\left(i_{1}, j_{1}\right)$ ou $\left(i_{2}, j_{2}\right) \prec(k, l)$. Em ordem de precedência, tome o primeiro par de casamentos $\left(i_{1}, j_{1}\right)$ e $\left(i_{2}, j_{2}\right)$ de $R \cap\left(T \backslash S_{1}\right)$, com $\left(i_{1}, j_{1}\right)$ precedendo imediatamente $\left(i_{2}, j_{2}\right)$, tal que $(k, l) \prec\left(i_{1}, j_{1}\right)$, onde $(k, l)$ é um casamento em $S_{1}$ que não cruza com $\left(i_{1}, j_{1}\right)$ ou $\left(i_{2}, j_{2}\right)$. Se $\left(i_{1}, j_{1}\right)$ for o primeiro casamento ou se tal par não existir (ou seja, $\left(i_{2}, j_{2}\right) \prec(k, l)$ para o último casamento $\left(i_{2}, j_{2}\right)$ em $R \cap\left(T \backslash S_{1}\right)$ ), então, em ambos os casos, $(k, l)$ não cruza com nenhum casamento de $R \cap\left(T \backslash S_{1}\right)$, o que é uma contradição. Assim, existe um casamento $\left(i_{0}, j_{0}\right)$ em $R \cap\left(T \backslash S_{1}\right)$ que precede imediatamente $\left(i_{1}, j_{1}\right)$, e vale que $\left(i_{1}, j_{1}\right) \prec\left(k^{\prime}, l^{\prime}\right)$ para algum $\left(k^{\prime}, l^{\prime}\right)$ em $S_{1}$ que não cruza com $\left(i_{0}, j_{0}\right)$ ou $\left(i_{1}, j_{1}\right)$, já que $\left(i_{1}, j_{1}\right)$ e $\left(i_{2}, j_{2}\right)$ são o primeiro par tal que $(k, l) \prec\left(i_{1}, j_{1}\right)$. Mas então $(k, l) \prec\left(k^{\prime}, l^{\prime}\right)$, ou seja, existem dois casamentos de $S_{1}$ que não se cruzam, o que é uma contradição.

Considere tal par $(i, j)$ e $(k, l)$ e suponha, sem perda de generalidade, que $(i, j) \prec(k, l)$. Como $S_{1}$ é a primeira estrela maximal em ordem lexicográfica, existe um casamento $\left(i_{1}, j_{1}\right)$ em $S_{1}$ que não cruza com $(i, j)$ e é tal que $i_{1}<i$ ou $\left(i_{1}=i\right.$ e $\left.j_{1}<j\right)$. De fato, caso contrário, ou $S_{1}$ não seria maximal, ou todo casamento que não cruza com $(i, j)$ vem depois de $(i, j)$ (na ordem definida anteriormente), o que implicaria que o conjunto $S_{1} \cup\{(i, j)\} \backslash\left\{(k, l) \in S_{1} \mid(k, l)\right.$ não cruza com $(i, j)\}$ seria uma estrela que vem antes de $S_{1}$ em ordem lexicográfica, o que é um absurdo. Logo, vale que $\left(i_{1}, j_{1}\right) \prec(i, j) \prec(k, l)$. Assim, $\left(i_{1}, j_{1}\right)$ não cruza nem com $(i, j)$, nem com $(k, l)$, o que é uma contradição.

Logo, $F \subseteq F_{2}\left(S_{1}\right)$.

Finalmente, note que $F_{2}\left(S^{\prime}\right) \subseteq F_{2}(S)$ para qualquer estrela $S^{\prime}$ e qualquer estrela maximal $S$ que contém $S^{\prime}$. De fato, para todo $z \in \mathbb{R}^{\mathcal{C}}$ tal que $\sum_{(i, j) \in S^{\prime}} z_{i j}=1$, vale que $\sum_{(i, j) \in S} z_{i j} \geq 1$. Como $S$ é uma estrela, $\sum_{(i, j) \in S} z_{i j}=1$.

Assim, $F \subseteq F_{2}(S)$ para alguma estrela maximal $S$ que contém $S_{1}$.

A segunda prova requer que olhemos para o problema sob o ponto de vista de grafos novamente.

A prova se baseia essencialmente no teorema de Chvátal a seguir. Lembremos que um clique é um conjunto de vértices dois a dois adjacentes e um conjunto independente é um conjunto de vértices dois a dois não-adjacentes. Dizemos que $G$ é um grafo perfeito se, para cada subgrafo induzido $G^{\prime}$ de $G$, o tamanho de um clique máximo de $G^{\prime}$ é igual ao número mínimo de cores necessárias para colorir os vértices de $G^{\prime}$ de forma que dois vértices adjacentes não tenham a mesma cor.

Teorema 3.2.4 (Chvátal $[9])$. Seja $G=(V, E)$ um grafo. Considere o poliedro

$$
\begin{gathered}
P:=\left\{z \in \mathbb{R}^{V} \mid \sum_{v \in S} z_{v} \leq 1 \text { para todo conjunto independente maximal } S \subseteq V, e\right. \\
\left.z_{v} \geq 0 \text { para todo } v \in V\right\} .
\end{gathered}
$$

Então $P$ é o casco convexo dos cliques de $G$ se e somente se $G$ é perfeito.

Uma prova do teorema acima pode ser encontrada nas referências [15, 43].

Prova 2. (Teorema 3.2.3) Usando-se o teorema de Chvátal acima, a prova é simples. Considere o complemento do grafo de cruzamento $G_{c}$ definido na Seção 2.3: $\bar{G}_{c}=(\mathcal{C}, E)$ é o grafo onde os vértices são os casamentos e dois casamentos são adjacentes se e só se eles não se cruzam. Lembremos também da relação da precedência entre casamentos: $(i, j) \prec(k, l)$ se $i<k$ e $j<l$. A relação $\prec$ é 
uma ordem parcial estrita, pois ela é irreflexiva $((i, j) \nprec(i, j))$, antissimétrica (se $\left(i_{1}, j_{1}\right) \prec\left(i_{2}, j_{2}\right)$ e $\left(i_{2}, j_{2}\right) \prec\left(i_{1}, j_{1}\right)$, então $\left.\left(i_{1}, j_{1}\right)=\left(i_{2}, j_{2}\right)\right)$ e transitiva (se $\left(i_{1}, j_{1}\right) \prec\left(i_{2}, j_{2}\right)$ e $\left(i_{2}, j_{2}\right) \prec\left(i_{3}, j_{3}\right)$, então $\left.\left(i_{1}, j_{1}\right) \prec\left(i_{3}, j_{3}\right)\right)$. Como dois casamentos $(i, j)$ e $(k, l)$ são adjacentes em $\bar{G}_{c}$ se e só se $(i, j) \prec(k, l)$ ou $(k, l) \prec(i, j), \bar{G}_{c}$ pertence à classe dos grafos de comparabilidade, por definição.

Veremos agora que todo grafo de comparabilidade é perfeito [11, 15]. De fato, sejam $G$ um grafo de comparabilidade e $F$ sua orientação transitiva. Tome uma coloração $c$ tal que $c(v)=0$ se $v$ não tem arcos de saída em $F$, e $c(v)=1+\max \{c(w) \mid v w \in F\}$ caso contrário. É fácil ver que a coloração $c$ é própria em $G$ (isto é, dois vértices adjacentes não têm a mesma cor) e o número de cores usadas é o comprimento de um caminho máximo em $F$. Além disso, como $F$ é transitiva, os vértices de um caminho em $F$ correspondem a um clique em $G$. Portanto, temos uma coloração própria do tamanho de um clique máximo. Além disso, como todo subgrafo induzido de um grafo de comparabilidade também é de comparabilidade, a mesma propriedade vale para os subgrafos induzidos de $G$. Logo, $G$ é um grafo perfeito.

Seja $P$ o poliedro enunciado no teorema de Chvátal para $\bar{G}_{c}$. Um conjunto independente, no contexto de $\bar{G}_{c}$, é um conjunto de casamentos que se cruzam dois a dois, que é exatamente a definição de estrela. Portanto, podemos enunciar $P$ da seguinte forma:

$$
\begin{gathered}
P=\left\{z \in \mathbb{R}^{\mathcal{C}} \mid \sum_{(i, j) \in \mathcal{C}} z_{i j} \leq 1 \text { para toda estrela maximal } S \subseteq \mathcal{C}, \mathrm{e}\right. \\
\left.z_{i j} \geq 0 \text { para todo }(i, j) \in \mathcal{C}\right\} .
\end{gathered}
$$

Vemos que $P=P_{S}$. Pelo teorema de Chvátal, $P=P_{S}$ é o casco convexo dos cliques de $\bar{G}_{c}$. Um clique em $\bar{G}_{c}$ é um conjunto de casamentos que não se cruzam dois a dois, ou seja, uma representação. Portanto, $P_{S}$ é o casco convexo dos conjuntos de casamentos que representam uma subsequência comum, isto é, $P_{S}=P_{\mathrm{LCS}}$.

Nesta seção, descrevemos de forma completa e minimal o poliedro do problema do LCS através de inequações lineares. Assim, qualquer solução básica ótima $z^{*}$ da relaxação linear da formulação por estrelas (isto é, uma solução ótima que corresponde a um vértice do poliedro) é inteira e, logo, representa um LCS. Portanto, podemos resolver o problema do LCS apenas resolvendo um programa linear. Isso é apenas interessante em teoria, pois, na prática, já temos algoritmos que resolvem o problema do LCS de forma muito mais eficiente que um algoritmo que usa a formulação por estrelas. Como o problema de otimização sobre um poliedro e o problema de separação de suas inequações são computacionalmente equivalentes [16], e conhecemos um algoritmo polinomial para separar as inequações (uma versão mais simples do algoritmo de separação para o problema do RFLCS descrito na Seção 5.2), então sabemos que é possível otimizar sobre o poliedro do problema do LCS em tempo polinomial. Isso é consistente com o fato do problema do LCS ser resolvível em tempo polinomial usando programação dinâmica.

Esta seção, porém, se reflete indiretamente na prática ao servir de apoio para a seção seguinte, na qual desenvolvemos a base teórica para um algoritmo que resolve a variante sem repetições do problema do LCS. 


\subsection{Formulações para RFLCS}

Veremos nesta seção algumas características dos poliedros do problema do RFLCS e de um outro problema equivalente. O algoritmo baseado em branch-and-cut implementado, que descreveremos no Capítulo 5, é relacionado à formulação principal da subseção seguinte.

\subsubsection{Formulação por estrelas estendidas}

Uma primeira formulação para o problema do RFLCS é simplesmente adicionar à formulação do problema do LCS a restrição de que queremos no máximo uma ocorrência de cada símbolo do alfabeto na subsequência comum obtida. A seguir, estendemos tanto a formulação baseada em cruzamento como a baseada em estrelas, e ambas as formulações são válidas para o problema do RFLCS.

Para todo casamento $(i, j)$ em $\mathcal{C}$, seja $z_{i j}$ uma variável que é 1 se o casamento $(i, j)$ está na representação da subsequência comum associada a $z$, ou é 0 caso contrário. Seja $\mathcal{C}(\sigma)$ o conjunto dos casamentos em $\mathcal{C}$ que são do símbolo $\sigma$.

$$
\begin{aligned}
& \max \sum_{(i, j) \in \mathcal{C}} z_{i j} \\
& \text { s. a } \sum_{(i, j) \in \mathcal{C}(\sigma)} z_{i j} \leq 1 \quad \text { para todo } \sigma \text { em } \Sigma \text {, } \\
& z_{i j}+z_{k l} \leq 1 \quad \text { para todo }(i, j) \text { e }(k, l) \text { em } \mathcal{C} \text { que se cruzam, } \\
& z_{i j} \in\{0,1\} \text { para todo }(i, j) \text { em } \mathcal{C} \text {. }
\end{aligned}
$$

A formulação seguinte é baseada na formulação por estrelas do problema do LCS.

$$
\begin{aligned}
& \max \sum_{(i, j) \in \mathcal{C}} z_{i j} \\
& \text { s. a } \sum_{(i, j) \in \mathcal{C}(\sigma)} z_{i j} \leq 1 \quad \text { para todo } \sigma \text { em } \Sigma \text {, } \\
& \sum_{(i, j) \in S} z_{i j} \leq 1 \quad \text { para toda estrela maximal } S \subseteq \mathcal{C}, \\
& z_{i j} \in\{0,1\} \text { para todo }(i, j) \text { em } \mathcal{C} .
\end{aligned}
$$

Do ponto de vista de poliedros, a segunda formulação é mais forte que a primeira pelo mesmo motivo que no problema do LCS (as inequações de estrela dominam as de cruzamento). Porém, ainda vale tentar obter uma formulação mais forte ainda.

Lembremos que um casamento conflita com outro se eles se cruzam ou são do mesmo símbolo, e que encontrar um RFLCS de duas sequências é equivalente a encontrar um conjunto de casamentos que dois a dois não conflitam entre si. É natural então a formulação seguinte.

$$
\begin{aligned}
& \max \sum_{(i, j) \in \mathcal{C}} z_{i j} \\
& \text { (formulação por conflitos) } \\
& \text { s. a } \quad z_{i j}+z_{k l} \leq 1 \quad \text { para todo }(i, j) \text { e }(k, l) \text { em } \mathcal{C} \text { que conflitam entre si, } \\
& z_{i j} \in\{0,1\} \text { para todo }(i, j) \text { em } \mathcal{C} \text {. }
\end{aligned}
$$

A formulação acima nos lembra da formulação por cruzamentos para o problema do LCS. De 
forma análoga à que fizemos com estrelas na seção anterior, estenderemos o conceito de conflito para considerar conjuntos de casamentos em vez de pares. Defina uma estrela estendida como um conjunto de casamentos que dois a dois conflitam entre si (ou seja, é um clique no grafo de conflito). É verdade que, para toda estrela estendida maximal, podemos escolher apenas um casamento dela para estar em uma representação de uma subsequência comum sem repetições.

estrela estendida maximal

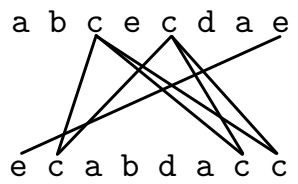

$\mathrm{a} b \mathrm{c} e \mathrm{c} d \mathrm{a} e$

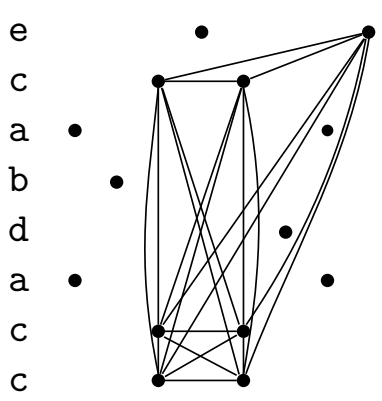

Seja $z_{i j}$ uma variável como na formulação anterior: é 1 se o casamento $(i, j)$ está na representação da subsequência comum sem repetições associada a $z$, ou é 0 em caso contrário. A seguinte formulação é válida para o problema do RFLCS.

$$
\begin{aligned}
& \max \sum_{(i, j) \in \mathcal{C}} z_{i j} \\
& \text { (formulação por estrelas estendidas) } \\
& \text { s. a } \sum_{(i, j) \in S} z_{i j} \leq 1 \quad \text { para toda estrela estendida maximal } S \subseteq \mathcal{C} \text {, } \\
& z_{i j} \in\{0,1\} \text { para todo }(i, j) \text { em } \mathcal{C} .
\end{aligned}
$$

A formulação acima é a base do algoritmo exato do Capítulo 5. Não é difícil ver que as inequações da formulação acima dominam as inequações de todas as formulações anteriores. De fato, qualquer par de casamentos que se cruzam ou que conflitam entre si, qualquer conjunto de todos os casamentos de um mesmo símbolo, ou qualquer estrela maximal está contido em alguma estrela estendida maximal.

\section{Defina o poliedro do problema do RFLCS como}

$$
P_{\mathrm{RFLCS}}:=\operatorname{conv}\left\{z \in\{0,1\}^{\mathcal{C}} \mid z \text { representa uma subsequência comum sem repetições de } X \text { e } Y\right\} \text {. }
$$

O poliedro $P_{\text {RFLCS }}$ tem dimensão plena pois o vetor zero e os $|\mathcal{C}|$ vetores unitários $e^{i j}$ para todo $(i, j) \in \mathcal{C}$ estão em $P_{\text {RFLCS }}$ e são afim-independentes.

As inequações da relaxação linear da formulação por estrelas estendidas,

$$
\begin{array}{ll}
\sum_{(i, j) \in S} z_{i j} \leq 1 \text { para toda estrela estendida maximal } S \subseteq \mathcal{C}, \text { e } & \text { (inequação de estrela estendida) } \\
z_{i j} \geq 0 \text { para todo }(i, j) \text { em } \mathcal{C}, & \text { (inequação de não-negatividade) } \\
\text { definem facetas de } P_{\mathrm{RFLS}} . &
\end{array}
$$


Proposição 3.3.1. Para todo $(i, j)$ em $\mathcal{C}$, a inequação de não-negatividade $z_{i j} \geq 0$ define uma faceta de $P_{\mathrm{RFLCS}}$.

Prova. Análoga à prova da Proposição 3.2.1, onde isso foi provado para $P_{\mathrm{LCS}}$.

Lema 3.3.2. Considere uma estrela estendida $S \subseteq \mathcal{C}$. Então a inequação de estrela estendida $\sum_{(i, j) \in S} z_{i j} \leq 1$ define uma faceta de $P_{\mathrm{RFLCS}}$ se e só se $S$ é maximal.

Prova. Análoga à prova da Proposição 3.2.2, onde foi provado que a inequação de estrela define faceta para $P_{\mathrm{LCS}}$.

O poliedro associado à formulação não tem todos os vértices inteiros, pois o problema do RFLCS é NP-difícil e, como já mencionado na primeira seção deste capítulo, não se espera ter uma descrição explícita e completa do poliedro inteiro associado a um problema NP-difícil [25] (além disso, o poliedro contém pontos fracionários que violam as inequações de buraco ímpar mais adiante).

Usaremos, no Capítulo 5, um método para adicionar as inequações de estrela estendida conforme elas são necessárias. Essencialmente, otimizamos sobre um poliedro relaxado, procuramos uma inequação de estrela estendida que é violada pela solução ótima do poliedro relaxado se existir, adicionamos a inequação violada ao programa linear relaxado, e repetimos o processo até nenhuma inequação de estrela estendida ser violada pela solução ótima de um poliedro relaxado. O problema de encontrar tal inequação é chamado de problema da separação.

De acordo com as formulações que discutimos, o poliedro associado ao problema do RFLCS é equivalente ao poliedro associado ao problema do conjunto independente máximo no correspondente grafo de conflito. Assim, as inequações válidas para o poliedro do conjunto independente também são válidas para o poliedro do RFLCS. Por exemplo, as seguintes inequações são válidas para o problema do RFLCS, considerando o grafo de conflito:

$$
\begin{array}{ll}
\sum_{(i, j) \in B} z_{i j} \leq \frac{|B|-1}{2} & \text { para todo buraco ímpar (odd hole) } B \subseteq \mathcal{C}, \text { e } \\
\sum_{(i, j) \in A} z_{i j} \leq 2 & \text { para todo anti-buraco ímpar (odd antihole) } A \subseteq \mathcal{C} .
\end{array}
$$

buraco ímpar de comprimento 5

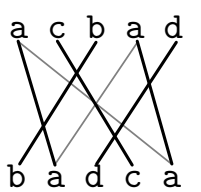

a c b a d

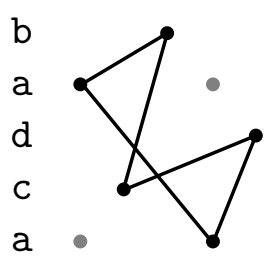

$\mathrm{a} b \mathrm{~b}$ a d c e

anti-buraco ímpar de comprimento 7

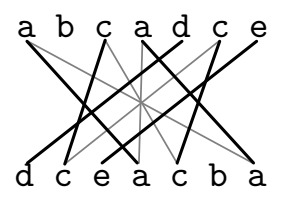

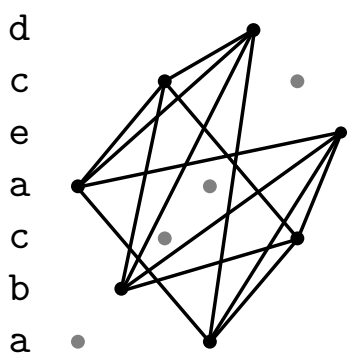


Um buraco ímpar é um circuito induzido de comprimento ímpar maior ou igual a 5, e um anti-buraco ímpar é o complemento de um buraco ímpar. As duas inequações anteriores definem facetas se o buraco ou anti-buraco ímpar for todo o conjunto de vértices do grafo de conflito [37]. Observe que essas inequações podem deixar o poliedro mais justo: no exemplo do buraco ímpar dado, uma solução em que todos os casamentos destacados têm valor $\frac{1}{2}$ (e os outros dois zero) é uma solução fracionária válida para as inequações de estrela estendida que viola inequações de buraco ímpar. O mesmo pode ser dito para o exemplo do anti-buraco ímpar dado, com uma solução em que os casamentos destacados têm valor $\frac{1}{3}$ e os outros zero.

Existem outras restrições que podem ser herdadas do problema do conjunto independente máximo, mas elas costumam ser difíceis de se lidar. Discutiremos mais sobre a restrição de buraco ímpar na Seção A.1 (apêndice).

\subsubsection{Formulação por símbolos distintos}

Descreveremos nesta seção uma formulação de programação inteira para um problema equivalente ao problema do RFLCS.

Denotaremos uma subsequência comum com número máximo de símbolos (do alfabeto) distintos por MSCS (maximum-symbol common subsequence). Dadas duas sequências $X$ e $Y$, o problema do MSCS é encontrar um MSCS de $X$ e $Y$.

O problema do RFLCS e o problema do MSCS são equivalentes a menos de uma transformação simples. Mais especificamente,

- Todo RFLCS de $X$ e $Y$ é um MSCS de $X$ e $Y$.

- Para todo MSCS de $X$ e $Y$, existe pelo menos um RFLCS de $X$ e $Y$ que é subsequência desse MSCS (podendo ser ele próprio). Tal RFLCS pode ser obtido removendo símbolos repetidos desse MSCS de forma a manter apenas uma ocorrência de cada símbolo.

Como consequência, o comprimento de um RFLCS é igual ao número de símbolos distintos de um MSCS. Isto é, o valor ótimo de ambos os problemas são iguais. Note também que as soluções viáveis do problema do MSCS contém as soluções viáveis do problema do RFLCS.

Exemplo 3.3.3. A figura ao lado mostra duas sequências e todos os seus RFLCSs e MSCSs. Note que todo RFLCS é um MSCS.
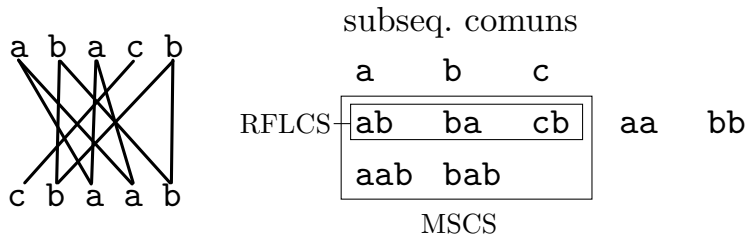

Dado que conhecemos a formulação por estrelas para o problema do LCS, a seguinte formulação é natural para o problema do MSCS.

Para todo $(i, j)$ em $\mathcal{C}$, seja $z_{i j}$ uma variável binária como nas formulações anteriores: é 1 se o casamento $(i, j)$ está na representação da subsequência comum associada a $z$, ou é 0 em caso contrário. Para todo $\sigma$ em $\Sigma$, seja $x_{\sigma}$ uma variável binária igual a 1 se o símbolo $\sigma$ ocorre na solução, ou 0 caso contrário (na formulação seguinte, isso vale para uma solução ótima, mas não necessariamente para qualquer solução viável; explicaremos isso melhor mais adiante). Seja $\mathcal{C}(\sigma)$ o conjunto de casamentos em $\mathcal{C}$ que são do símbolo $\sigma$. 


$$
\begin{array}{rlrl}
\max \sum_{\sigma \in \Sigma} x_{\sigma} & & \\
\text { s. a } \sum_{(i, j) \in S} z_{i j} & \leq 1 & & \text { para toda estrela maximal } S \subseteq \mathcal{C}, \\
x_{\sigma} & \leq \sum_{(i, j) \in \mathcal{C}(\sigma)} z_{i j} & & \text { para todo } \sigma \text { em } \Sigma, \\
z_{i j} & \in\{0,1\} & & \text { para todo }(i, j) \text { em } \mathcal{C}, \\
x_{\sigma} & \in\{0,1\} & & \text { para todo } \sigma \text { em } \Sigma .
\end{array}
$$

Obtemos, ao otimizar esse programa inteiro, um conjunto de casamentos que representa um MSCS, e, se removermos casamentos de símbolos repetidos, o conjunto resultante representa um RFLCS. De fato, na formulação, a primeira classe de inequações garante que $z$ esteja associada a uma representação de uma subsequência comum, e a segunda classe de inequações garante que $x_{\sigma}$ seja 0 se não houver casamentos de símbolo $\sigma$ na solução dada por $z$. Não é necessário forçar que a variável $x_{\sigma}$ seja 1 se $\sigma$ ocorre na solução, pois, ao maximizarmos a soma de todas essas variáveis, isso sempre valerá já que $x_{\sigma}$ é limitado superiormente por 1 . O poliedro mais adiante leva isso em consideração.

Além disso, para todo $\sigma$ em $\Sigma$, como $z_{i j}$ é binária para todo $(i, j)$ em $\mathcal{C}$, e com a restrição $x_{\sigma} \leq 1$ implícita, $x_{\sigma}$ é limitado superiormente por um valor inteiro (0 ou 1). Logo, dado que o problema é de maximização, $x_{\sigma}$ é binária na solução ótima mesmo sem forçar explicitamente que ela seja binária. Portanto, para todo $\sigma$ em $\Sigma$, a restrição $x_{\sigma} \in\{0,1\}$ pode ser relaxada para as restrições $x_{\sigma} \in \mathbb{R}$ e $x_{\sigma} \leq 1$.

Considere o poliedro associado à formulação acima,

$$
\begin{array}{r}
P_{\mathrm{MSCS}}:=\operatorname{conv}\left\{(z, x) \in\{0,1\}^{\mathcal{C}} \times\{0,1\}^{\Sigma} \mid\right. \\
z \text { representa uma subsequência comum de } X \text { e } Y, \text { e } \\
x_{\sigma}=0 \text { se } \sigma \text { não ocorre em } z \\
\text { (podendo ser } 0 \text { ou } 1 \text { caso contrário) }\} .
\end{array}
$$

O resultado seguinte nos dá uma noção da força das inequações usadas na formulação anterior.

Lema 3.3.4. As seguintes restrições definem facetas de $P_{\mathrm{MSCS}}$ :

(a) $z_{i j} \geq 0$ para todo $(i, j)$ em $\mathcal{C}$ tal que $(i, j)$ não é o único casamento em $\mathcal{C}$ de seu símbolo;

(b) $\sum_{(i, j) \in S} z_{i j} \leq 1$ para toda estrela maximal $S \subseteq \mathcal{C}$;

(c) $x_{\sigma} \geq 0$ para todo $\sigma$ em $\Sigma$;

(d) $x_{\sigma} \leq \sum_{(i, j) \in \mathcal{C}(\sigma)} z_{i j}$ para todo $\sigma$ em $\Sigma$.

Prova. Para provar que as restrições acima definem facetas, para cada caso, enumeraremos $|\mathcal{C}|+|\Sigma|$ vetores afim-independentes em $P_{\text {MSCS }}$ que satisfazem as inequações com igualdade. Supomos que existe pelo menos um casamento em $\mathcal{C}$ de cada símbolo em $\Sigma$.

Denotamos por $e^{i j}$ o vetor unitário para o casamento $(i, j)$ e $e^{\sigma}$ o vetor unitário para o símbolo $\sigma$. 
(a) $z_{i j} \geq 0$ para todo $(i, j)$ em $\mathcal{C}$ tal que $(i, j)$ não é o único casamento em $\mathcal{C}$ de seu símbolo.

- vetor zero (1 vetor);

- vetores $e^{k l}$ para todo $(k, l)$ em $\mathcal{C}, \operatorname{com}(k, l) \neq(i, j)(|\mathcal{C}|-1$ vetores);

- vetores $e^{\sigma}+e^{k l}$ para todo $\sigma$ em $\Sigma$, onde $(k, l)$ é um casamento de símbolo $\sigma$ diferente de $(i, j)(|\Sigma|$ vetores $)$.

Um dos vetores deste último item não existe sem a suposição sobre $(i, j)$ acima. Entretanto, observe que se $(i, j)$ é o único casamento de seu símbolo $\sigma$, a inequação $z_{i j} \geq x_{\sigma}$ domina $z_{i j} \geq 0$ (dado que $x_{\sigma} \geq 0$ ) e também define faceta por ser uma inequação do tipo (d) (provado mais adiante).

(b) $\sum_{(i, j) \in S} z_{i j} \leq 1$ para toda estrela maximal $S \subseteq \mathcal{C}$.

- vetores $e^{i j}$ para todo $(i, j)$ em $S(|S|$ vetores);

- vetores $e^{i j}+e^{k l}$ para todo $(i, j)$ fora de $S$, onde $(k, l)$ é um casamento de $S$ que não cruza $\operatorname{com}(i, j)((k, l)$ existe pois $S$ é maximal $)(|\mathcal{C}|-|S|$ vetores $)$;

- vetores $e^{\sigma}+e^{i j}$ para todo $\sigma$ em $\Sigma$ tal que existe um casamento $(i, j)$ de símbolo $\sigma$ em $S$ $\left(\left|\Sigma^{\prime}\right|\right.$ vetores para algum $\left.\Sigma^{\prime} \subseteq \Sigma\right)$;

- vetores $e^{\sigma}+e^{i j}+e^{k l}$ para todo $\sigma$ em $\Sigma$ tal que não existe casamento de símbolo $\sigma$ em $S$, onde $(i, j)$ é um casamento de símbolo $\sigma$ fora de $S$ e $(k, l)$ é um casamento em $S$ que não cruza com $(i, j)\left((k, l)\right.$ existe pois $S$ é maximal) $\left(|\Sigma|-\left|\Sigma^{\prime}\right|\right.$ vetores $)$.

(c) $x_{\sigma} \geq 0$ para todo $\sigma$ em $\Sigma$.

- vetor zero (1 vetor);

- vetores $e^{i j}$ para todo $(i, j)$ em $\mathcal{C}(|\mathcal{C}|$ vetores $)$

- vetores $e^{\sigma^{\prime}}+e^{i j}$ para todo $\sigma^{\prime} \neq \sigma$ em $\Sigma$, onde $(i, j)$ é um casamento de símbolo $\sigma^{\prime}(|\Sigma|-1$ vetores).

(d) $x_{\sigma} \leq \sum_{(i, j) \in \mathcal{C}(\sigma)} z_{i j}$ para todo $\sigma$ em $\Sigma$.

- vetor zero (1 vetor);

- vetores $e^{i j}+e^{\sigma}$ para todo $(i, j)$ em $\mathcal{C}$ de símbolo $\sigma(|\mathcal{C}(\sigma)|$ vetores $)$;

- vetores $e^{i j}$ para todo $(i, j)$ em $\mathcal{C}$ de símbolo diferente de $\sigma(|\mathcal{C}|-|\mathcal{C}(\sigma)|$ vetores $) ;$

- vetores $e^{\sigma^{\prime}}+e^{i j}$ para todo $\sigma^{\prime} \neq \sigma$ em $\Sigma$, onde $(i, j)$ é um casamento de símbolo $\sigma^{\prime}(|\Sigma|-1$ vetores).

Para todos os casos acima, não é difícil ver que os vetores listados são afim-independentes. Nos casos (a), (c) e (d), subtraímos o vetor zero dos outros vetores, e a matriz formada pelos vetores como linhas na ordem dada, desconsiderando as colunas de $z_{i j}, x_{\sigma}$ e $x_{\sigma}$ respectivamente, é uma matriz triangular com diagonal formada por 1s, o que significa que os vetores são linearmente independentes. Já no caso (b), isso já vale sem precisar subtrair nenhum vetor de outros. Portanto, em todos os casos, os vetores são afim-independentes. 
A seguinte classe de inequações também é válida para $P_{\mathrm{MSCS}}$ e define facetas.

Denote por estrela estendida especial (ou simplesmente estrela especial) um conjunto de casamentos $\hat{S}$ de $\mathcal{C}$ tal que, para cada $(i, j)$ e $(k, l)$ em $\hat{S}$, ou $(i, j)$ e $(k, l)$ se cruzam, ou $(i, j)$ e $(k, l)$ não se cruzam mas são do mesmo símbolo $\sigma$ e todo casamento de símbolo $\sigma$ pertence a $\hat{S}$ (isto é, $\mathcal{C}(\sigma) \subseteq \hat{S}$ ). Uma estrela especial maximal é um conjunto maximal desse tipo. Note que uma estrela especial é uma estrela estendida.

Seja $\operatorname{sim} b(\hat{S})$ o conjunto de símbolos $\sigma$ tal que todo casamento de símbolo $\sigma$ está em $\hat{S}$ e existem pelo menos dois casamentos desse símbolo que não se cruzam. Seja rest $(\hat{S})$ os casamentos restantes, isto é, $\operatorname{rest}(\hat{S})=\hat{S} \backslash \cup_{\sigma \in \operatorname{simb}(\hat{S})} \mathcal{C}(\sigma)$. Note que uma estrela é um caso particular de uma estrela especial em que $\operatorname{simb}(\hat{S})=\varnothing$ e $\operatorname{rest}(\hat{S})=\hat{S}$, e a classe de inequações abaixo inclui todas as inequações de estrela.

A seguinte inequação é válida para $P_{\mathrm{MSCS}}$ :

$$
\sum_{\sigma \in \operatorname{simb}(\hat{S})} x_{\sigma}+\sum_{(i, j) \in \operatorname{rest}(\hat{S})} z_{i j} \leq 1 \text { para toda estrela especial maximal } \hat{S} \subseteq \mathcal{C} .
$$

Denominamos a inequação acima de inequação de estrela especial.

É fácil ver que a inequação acima é válida. De fato, se escolhermos um casamento de $\hat{S}$ de símbolo $\sigma$, não podemos escolher nenhum casamento em $\operatorname{rest}(\hat{S})$ ou de símbolo $\sigma^{\prime} \neq \sigma$ em $\operatorname{simb}(\hat{S})$ pois eles se cruzam (posso escolher outro casamento de símbolo $\sigma$ que não cruza com ele se $\sigma \in \operatorname{simb}(\hat{S})$, mas $x_{\sigma}$ ainda é limitado por 1$)$.

Lema 3.3.5. Para qualquer estrela especial maximal $\hat{S}$, a inequação de estrela especial $\hat{S}$ define faceta de $P_{\mathrm{MSCS}}$.

Prova. Mostraremos $|\mathcal{C}|+|\Sigma|$ vetores afim-independentes em $P_{\text {MSCS }}$ que satisfazem a inequação com igualdade.

Para todo $(i, j)$ em $\hat{S}$, seja

$$
y_{1}(i, j)= \begin{cases}e^{i j} & \text { se }(i, j) \text { está em } \operatorname{rest}(\hat{S}), \text { ou } \\ e^{i j}+e^{\sigma} & \text { caso contrário, onde } \sigma \text { é o símbolo de }(i, j) .\end{cases}
$$

Para todo $(i, j)$ em $\mathcal{C} \backslash \hat{S}$, seja

$$
\begin{gathered}
y_{2}(i, j)=e^{i j}+y_{1}(k, l) \text { tal que }(k, l) \text { é um casamento de } \hat{S} \text { que não cruza com }(i, j) \\
((k, l) \text { existe pois } \hat{S} \text { é maximal }) \text {. }
\end{gathered}
$$

Para todo $\sigma$ em $\Sigma \backslash \operatorname{simb}(\hat{S})$, seja

$$
y_{3}(\sigma)= \begin{cases}e^{i j} & \text { se existe casamento }(i, j) \text { de símbolo } \sigma \text { em } \hat{S}, \text { ou } \\ y_{2}(i, j) & \text { caso contrário, onde }(i, j) \text { é um casamento de símbolo } \sigma \text { (fora de } \hat{S}) .\end{cases}
$$

Os vetores são os seguintes:

- vetores $y_{1}(i, j)$ para todo $(i, j)$ em $\hat{S}(|\hat{S}|$ vetores $)$;

- vetores $y_{2}(i, j)$ para todo $(i, j)$ em $\mathcal{C} \backslash \hat{S}(|\mathcal{C}|-|\hat{S}|$ vetores $) ;$ 
- vetores $e^{\sigma}+y_{3}(\sigma)$ para todo $\sigma$ em $\Sigma \backslash \operatorname{simb}(\hat{S})(|\Sigma|-|\operatorname{simb}(\hat{S})|$ vetores $)$;

- vetores $e^{\sigma}+e^{i j}+e^{k l}$ para todo $\sigma$ em $\operatorname{simb}(\hat{S})$, onde $(i, j)$ e $(k, l)$ são dois casamentos de símbolo $\sigma$ de $\hat{S}$ que não se cruzam $((i, j)$ e $(k, l)$ existem pela definição de $\operatorname{simb}(\hat{S}))(|\operatorname{simb}(\hat{S})|$ vetores).

Provaremos indiretamente que os vetores listados são afim-independentes. Considere um hiperplano genérico $\sum_{(i, j) \in \mathcal{C}} \mu_{i j} z_{i j}+\sum_{\sigma \in \Sigma} \mu_{\sigma} x_{\sigma}=\mu_{0}$. Se, colocando os vetores listados nesse hiperplano, obtivermos uma única solução $\mu$ tal que $\mu_{i j}=\mu_{0}$ para todo casamento $(i, j)$ em $\operatorname{rest}(\hat{S}), \mu_{\sigma}=\mu_{0}$ para todo $\sigma$ em $\operatorname{simb}(\hat{S})$ e $\mu_{i j}=\mu_{\sigma}=0$ para o restante dos casamentos $(i, j)$ e símbolos $\sigma$, então o único vetor de coeficientes $\left(\mu, \mu_{0}\right)$ possível é um múltiplo do vetor de coeficientes da inequação de estrela especial, o que significa que os vetores são afim-independentes. Mostraremos que isso vale.

Pelo primeiro grupo de vetores, para todo $(i, j)$ em $\operatorname{rest}(\hat{S}), \mu_{i j}=\mu_{0}$, e, para todo $(i, j)$ em $\hat{S} \backslash \operatorname{rest}(\hat{S}), \mu_{i j}+\mu_{\sigma}=\mu_{0}$, onde $\sigma$ é o símbolo de $(i, j)$.

Pelo quarto grupo de vetores, para todo $\sigma$ em $\operatorname{simb}(\hat{S}), \mu_{\sigma}+\mu_{i j}+\mu_{k l}=\mu_{0}$, onde $(i, j)$ e $(k, l)$ são dois casamentos de símbolo $\sigma$ que não se cruzam. Observe que $(i, j)$ e $(k, l)$ pertencem então a $\hat{S} \backslash \operatorname{rest}(\hat{S})$. Logo, reescrevendo a segunda equação do primeiro grupo, $\mu_{i j}=\mu_{k l}=\mu_{0}-\mu_{\sigma}$. Aplicando isso na equação, temos que $\mu_{\sigma}+2 \mu_{0}-2 \mu_{\sigma}=\mu_{0}$, isto é, $\mu_{\sigma}=\mu_{0}$.

Voltando ao primeiro grupo de vetores, para todo $(i, j)$ em $\hat{S} \backslash \operatorname{rest}(\hat{S}), \mu_{i j}+\mu_{0}=\mu_{0}$, isto é, $\mu_{i j}=0$, pelo fato do símbolo de $(i, j)$ estar em $\operatorname{simb}(\hat{S})$, junto com o fato anterior. Então, $\mu y_{1}(i, j)=\mu_{0}$ para todo $(i, j)$ em $\hat{S}$.

Pelo segundo grupo de vetores, para todo $(i, j)$ em $\mathcal{C} \backslash \hat{S}, \mu_{i j}+\mu y_{1}(k, l)=\mu_{0}$, onde $(k, l)$ é um casamento em $\hat{S}$ que não cruza $\operatorname{com}(i, j)$. Logo, $\mu_{i j}+\mu_{0}=\mu_{0}$, ou seja, $\mu_{i j}=0$ para todo $(i, j)$ em $\mathcal{C} \backslash \hat{S}$. Além disso, também obtemos que $\mu_{2}(i, j)=\mu_{0}$ para todo $(i, j)$ em $\mathcal{C} \backslash \hat{S}$.

Pelo terceiro grupo de vetores, para todo $\sigma$ em $\Sigma \backslash \operatorname{simb}(\hat{S}), \mu_{\sigma}+\mu_{i j}=\mu_{0}$ se existe casamento $(i, j)$ de símbolo $\sigma$ em $\hat{S}$, ou $\mu_{\sigma}+\mu y_{2}(i, j)=\mu_{0}$ caso contrário, para algum $(i, j)$ em $\mathcal{C} \backslash \hat{S}$ de símbolo $\sigma$. No primeiro caso, como $\sigma \notin \operatorname{simb}(\hat{S})$, qualquer casamento de símbolo $\sigma$ em $\hat{S}$ deve estar em $\operatorname{rest}(\hat{S})$. Logo, nesse caso, $\mu_{i j}=\mu_{0}$, e, portanto, $\mu_{\sigma}=0$. No segundo caso, temos que $\mu_{\sigma}+\mu_{0}=\mu_{0}$, isto é, $\mu_{\sigma}=0$.

Em resumo, temos que, para todo $(i, j)$ em $\operatorname{rest}(\hat{S}), \mu_{i j}=\mu_{0}$, e, para todo $\sigma$ em $\operatorname{simb}(\hat{S}), \mu_{\sigma}=\mu_{0}$. Para qualquer casamento $(i, j)$ e símbolo $\sigma$ no restante dos casos, $\mu_{i j}=\mu_{\sigma}=0$. Logo, os vetores são afim-independentes.

Vale observar que, para qualquer $\sigma$ em $\Sigma$, a inequação $x_{\sigma} \leq 1$ é dominada diretamente por uma inequação de estrela especial se existir uma estrela especial maximal $\hat{S}$ tal que $\sigma$ está em $\operatorname{simb}(\hat{S})$. Se não existir, todos os casamentos de símbolo $\sigma$ se cruzam dois a dois e, portanto, pertencem a alguma estrela maximal $S$ (isto é, $\mathcal{C}(\sigma) \subseteq S$ ). Se somarmos a inequação dessa estrela $\sum_{(i, j) \in S} z_{i j} \leq 1$ com a inequação $x_{\sigma}-\sum_{(i, j) \in \mathcal{C}(\sigma)} z_{i j} \leq 0$, obtemos uma inequação que domina $x_{\sigma} \leq 1$.

Outro detalhe relevante é o motivo da condição na definição da estrela especial $\hat{S}$ de que, para todo símbolo de $\operatorname{sim} b(\hat{S})$, existe um par de casamentos desse símbolo que não se cruzam. Considere uma versão da inequação de estrela especial $\hat{S}$ que ignora essa condição, isto é, com um $\sigma \mathrm{em}$ $\operatorname{simb}(\hat{S})$ tal que todos os casamentos de símbolo $\sigma$ se cruzam dois a dois. Então podemos obtê-la somando a inequação de estrela especial $\hat{S}$ (em que os casamentos de $\sigma$ entram em rest $(\hat{S})$ ) com a inequação $x_{\sigma}-\sum_{(i, j) \in \mathcal{C}(\sigma)} z_{i j} \leq 0$. Isto é, uma inequação de estrela especial sem a condição é dominada pela soma de duas inequações que definem facetas. 
Dadas todas essas observações, podemos então reformular o problema MSCS da seguinte maneira.

$$
\begin{array}{rlrl}
\sum_{\sigma \in \Sigma} x_{\sigma} & & \\
\text { s. a } \sum_{\sigma \in \operatorname{simb}(\hat{S})} x_{\sigma}+\sum_{(i, j) \in \operatorname{rest}(\hat{S})} z_{i j} & \leq 1 & & \text { para toda estrela especial maximal } \hat{S} \subseteq \mathcal{C}, \\
x_{\sigma} & \leq \sum_{(i, j) \in \mathcal{C}(\sigma)} z_{i j} & & \text { para todo } \sigma \text { em } \Sigma \\
z_{i j} & \in\{0,1\} & & \text { para todo }(i, j) \text { em } \mathcal{C} \\
x_{\sigma} & \in \mathbb{R}_{+} & \text {para todo } \sigma \text { em } \Sigma .
\end{array}
$$

Todas as inequações da formulação acima e a maioria das de não-negatividade para todas as variáveis definem facetas.

\subsection{Limitantes e gap de integralidade para RFLCS}

Podemos expressar limitantes inferiores e superiores para o comprimento de um RFLCS de $X$ e $Y$ em termos do comprimento de um LCS de $X$ e $Y$ e do tamanho do alfabeto $\Sigma$ sobre o qual estão $X$ e $Y$. Denote por $\operatorname{opt}(\operatorname{LCS}(X, Y))$ o comprimento de um LCS de $X$ e $Y$ e por $\operatorname{opt}(\operatorname{RFLCS}(X, Y))$ o de um RFLCS de $X$ e $Y$.

Lema 3.4.1. Sejam $X$ e $Y$ duas sequências sobre o alfabeto $\Sigma$, onde $\Sigma$ contém apenas os símbolos presentes em ambas as sequências.

Seja occ $(\sigma)$ o número de ocorrências do símbolo $\sigma \in \Sigma$ em $X$ ou em $Y$, o que for menor. Seja occ $_{\max }$ o maior desses valores entre todo $\sigma \in \Sigma$ (isso é também o número máximo de casamentos de mesmo símbolo que não se cruzam dois a dois). Seja também $S_{\max }$ uma estrela de cardinalidade máxima.

Então,

1. $\frac{1}{\operatorname{occ}_{\max }} \operatorname{opt}(\operatorname{LCS}(X, Y)) \leq \operatorname{opt}(\operatorname{RFLCS}(X, Y)) \leq \operatorname{opt}(\operatorname{LCS}(X, Y))$

2. $\frac{1}{\left|S_{\max }\right|}|\Sigma| \leq \operatorname{opt}(\operatorname{RFLCS}(X, Y)) \leq|\Sigma|$

Prova. 1. O limitante superior é fácil ver: todo RFLCS é também uma subsequência comum.

Para provar o limitante inferior, considere uma sequência $Z$ construída removendo símbolos repetidos de um LCS (isto é, escolhendo uma ocorrência de cada símbolo e removendo as ocorrências restantes). Em particular, $Z$ é uma subsequência comum sem repetições e, portanto, tem comprimento menor ou igual ao de um RFLCS. Ainda mais, observe que, para construir $Z$, removemos no máximo occ $\max -1$ ocorrências de cada símbolo de um LCS. Portanto, se multiplicarmos o comprimento de $Z$ por occ $\max$, temos pelo menos o comprimento de um LCS.

Isto é, $\operatorname{occ}_{\max } \operatorname{opt}(\operatorname{RFLCS}(X, Y)) \geq \operatorname{occ}_{\max }|Z| \geq \operatorname{opt}(\operatorname{LCS}(X, Y))$.

Como uma observação adicional, note que diretamente da prova podemos obter um outro limitante inferior mais justo mas mais complicado de se calcular. Seja occ ${ }_{\max }^{\prime}(Z)$ o número máximo de ocorrências de um mesmo símbolo em um LCS $Z$ e tome occ $c_{\max }^{\prime}$ o menor occ ${ }_{\max }^{\prime}(Z)$ entre todo LCS $Z$. Então $\frac{1}{\text { occ }_{\max }^{\prime}} \operatorname{opt}(\operatorname{LCS}(X, Y)) \leq \operatorname{opt}(\operatorname{RFLCS}(X, Y))$. 
2. O limitante superior é dado pela própria restrição do RFLCS de não haver mais de uma ocorrência de um mesmo símbolo.

Quanto ao limitante inferior, considere uma representação $R$ de um RFLCS. Escolha um casamento qualquer para cada símbolo que não está no RFLCS e considere o conjunto de casamentos formado por $R$ e tais casamentos. Esses $|\Sigma|$ casamentos definem duas sequências $X^{\prime}$ e $Y^{\prime}$ ambas de comprimento $|\Sigma|$.

O problema dual do LCS (no sentido de programação linear e baseado na formulação por estrelas) é encontrar uma cobertura de cardinalidade mínima de casamentos por estrelas, isto é, encontrar um conjunto mínimo de estrelas cuja união contém todos os casamentos. Pelo teorema forte da dualidade para o problema do LCS e pelo fato de que o poliedro do LCS é inteiro, a cardinalidade de tal cobertura mínima é igual ao comprimento de um LCS. É claro que $R$ também representa um LCS em $X^{\prime}$ e $Y^{\prime}$, pois, caso contrário, existiria um RFLCS de comprimento maior em $X$ e $Y$. Portanto, existe um conjunto de $|R|$ estrelas que cobre todos os $|\Sigma|$ casamentos dados por $X^{\prime}$ e $Y^{\prime}$. Logo, se $S_{\max }^{\prime}$ for a cardinalidade máxima de uma estrela em $X^{\prime}$ e $Y^{\prime}$, então vale que opt $(\operatorname{RFLCS}(X, Y))\left|S_{\text {max }}\right|=|R|\left|S_{\text {max }}\right| \geq|R|\left|S_{\text {max }}^{\prime}\right| \geq|\Sigma|$.

Vale observar também que o limitante ainda vale se trocarmos $S_{\max }$ por uma estrela máxima "sem repetições" (uma estrela com casamentos de símbolos distintos e de cardinalidade máxima), embora este seja mais difícil de se computar.

Como corolário do lema anterior, podemos obter um limitante superior para o gap de integralidade da relaxação da formulação por estrelas estendidas do RFLCS da Seção 3.3.1. O gap de integralidade de uma relaxação é o maior valor possível da razão entre os valores de uma solução ótima inteira e de uma solução ótima da relaxação.

Corolário 3.4.2. O gap de integralidade da relaxação linear da formulação por estrelas estendidas do problema do RFLCS é limitado superiormente por $\min \left\{\mathrm{occ}_{\max },\left|S_{\max }\right|\right\}$.

Prova. Sejam $z_{S}^{*}$ e $z_{E S}^{*}$ as soluções ótimas para as relaxações de estrela (para o problema do LCS) e de estrela estendida (para o problema do RFLCS) respectivamente. Como toda estrela está contida em uma estrela estendida, as inequações de estrela estendida restringem mais que os de estrela e, assim, o poliedro da relaxação de estrela estendida está contido no de estrela. Logo, $z_{E S}^{*} \leq z_{S}^{*}=\operatorname{opt}(\operatorname{LCS}(X, Y)) \leq \operatorname{occ}_{\max } \operatorname{opt}(\operatorname{RFLCS}(X, Y))$, sendo que a igualdade vem do fato que o poliedro da relaxação de estrela é inteiro e a última inequação vem do Lema 3.4.1.

Além disso, $z_{E S}^{*} \leq|\Sigma|$, pois o conjunto de todos casamentos de um mesmo símbolo é uma estrela estendida. Logo, pelo Lema 3.4.1, $z_{E S}^{*} \leq\left|S_{\text {max }}\right| \operatorname{opt}(\operatorname{RFLCS}(X, Y))$.

Portanto, $\frac{z_{E S}^{*}}{\operatorname{opt}(\operatorname{RFLCS}(X, Y))} \leq \min \left\{\operatorname{occ}_{\max },\left|S_{\max }\right|\right\}$.

Essencialmente, o corolário indica que se $o c c_{\max }$ ou $\left|S_{\max }\right|$ for pequeno (perto de 1), então uma solução ótima da relaxação linear da formulação por estrelas estendidas está perto da solução inteira ótima. 


\section{Capítulo 4}

\section{Aproximabilidade e heurísticas para RFLCS}

Neste capítulo, descreveremos alguns algoritmos de aproximação e heurísticas para o problema do RFLCS, junto com resultados computacionais. Na última seção deste capítulo, mostraremos que o problema do RFLCS é APX-difícil.

Iniciamos com um breve resumo de alguns conceitos básicos de algoritmos de aproximação a seguir, baseado no livro de Carvalho et al. [8]. Definiremos apenas o necessário para este capítulo.

\subsection{Preliminares}

Um problema de otimização é formado por um conjunto de instâncias, um conjunto de soluções viáveis para cada instância, e uma função que atribui um valor val $(S)$ a cada solução viável $S$ (função objetivo). Por exemplo, no problema do RFLCS, as instâncias são as possíveis sequências de entrada $X$ e $Y$, as soluções viáveis são as subsequências comuns sem repetições, e o valor de uma solução viável é seu comprimento. Um problema de maximização, como o problema do RFLCS, está interessado em soluções viáveis de valor máximo (soluções ótimas), e denotamos por opt $(I$ ) o valor de uma solução ótima para a instância $I$.

Considere um problema de otimização em que val $(S) \geq 0$ para toda solução viável $S$ de qualquer instância do problema. Seja $A$ um algoritmo que, para toda instância $I$ do problema, devolve uma solução viável $A(I)$ de $I$. Se o problema é de maximização, e

$$
\operatorname{val}(A(I)) \geq \frac{1}{\alpha} \operatorname{opt}(I)
$$

para toda instância $I$, dizemos que $A$ é uma $\alpha$-aproximação para o problema e $\alpha$ é uma razão de aproximação do algoritmo. Vale notar que $\alpha \geq 1 .{ }^{1}$ Por exemplo, um algoritmo que devolve sempre uma subsequência comum sem repetições de comprimento pelo menos metade do de um RFLCS é uma 2-aproximação para o problema do RFLCS. Um algoritmo de aproximação é uma $\alpha$-aproximação para algum $\alpha$.

Um algoritmo probabilístico é aquele que utiliza um gerador de bits aleatório (na prática, pseudoaleatório). Dada uma variável aleatória $X$, denotamos por $E[X]$ a esperança de $X$. Considere

\footnotetext{
${ }^{1}$ Nosso $\alpha$ é o inverso do $\alpha$ da referência [8]. Em [8], $\operatorname{val}(A(I)) \geq \alpha \operatorname{opt}(I)$ e $0<\alpha \leq 1$.
} 
um problema de maximização. Uma $\alpha$-aproximação probabilística é um algoritmo tal que

$$
E\left[X_{I}\right] \geq \frac{1}{\alpha} \operatorname{opt}(I)
$$

para toda instância $I$, onde $X_{I}$ é a variável aleatória cujo valor é o valor da solução viável produzida pelo algoritmo para a instância $I$. Desaleatorizar uma $\alpha$-aproximação probabilística significa convertê-lo para um algoritmo determinístico que mantém a mesma razão de aproximação $\alpha$.

Uma heurística é um algoritmo desenvolvido com o propósito de obter soluções viáveis boas para o problema (de valor próximo do ótimo), mas que não precisa ter uma razão de aproximação.

Voltaremos a introduzir mais alguns conceitos preliminares na última seção deste capítulo, onde eles serão necessários (especificamente, sobre complexidade de aproximação).

\subsection{Algoritmos de aproximação baseados em remoção de repeti- ções}

Nesta seção, apresentamos algoritmos de aproximação para o problema do RFLCS propostos por Adi et al. [1]. Os algoritmos LCS e remove repetições, Remove repetições e LCS e a variante deste último são, respectivamente, os algoritmos A1, A2 e A3 no artigo de Adi et al.

\subsubsection{LCS e remove repetições}

Um algoritmo de aproximação natural para o problema do RFLCS é computar um LCS e remover ocorrências de símbolos repetidos, mantendo apenas uma ocorrência de cada símbolo. Chamamos esse algoritmo de LCS e remove repetições, ou LCS-RR.

Lembremos, da Seção 3.4, que occmax é o maior occ $(\sigma)$ entre todo $\sigma$ em $\Sigma$, onde occ $(\sigma)$ é o número de vezes que $\sigma$ ocorre em $X$ ou em $Y$, o que for menor.

Proposição 4.2.1. O algoritmo LCS e remove repetições é uma occ $_{\max }$-aproximação para o problema do RFLCS para $X$ e $Y$.

Prova. Esta prova é análoga à prova do limitante inferior do item 1 do Lema 3.4.1.

Seja $Z$ a sequência devolvida pelo algoritmo LCS-RR. Isto é, $Z$ é uma sequência obtida removendo símbolos repetidos de um LCS de $X$ e $Y$ de comprimento $l$, de forma a manter apenas uma ocorrência de cada símbolo. Observe que removemos no máximo occ ${ }_{\max }-1$ ocorrências de cada símbolo. Logo, occ $\max |Z| \geq l$. Além disso, $l \geq \operatorname{opt}(\operatorname{RFLCS}(X, Y))$. Portanto, opt $(\operatorname{RFLCS}(X, Y)) /|Z| \leq$ occ $_{\max }$.

Observe que, se $\operatorname{occ}_{\max }^{\prime}(Z)$ for o número máximo de ocorrências de um mesmo símbolo em um LCS $Z$, o algoritmo LCS-RR é uma occ $c_{\max }^{\prime}(Z)$-aproximação, onde $Z$ é o LCS computado no algoritmo. Ainda mais, se o algoritmo escolher, entre todos os possíveis LCSs, o LCS $Z$ com menor $\operatorname{occ}_{\max }^{\prime}(Z)$, então o algoritmo se torna uma occ $\max ^{\prime}$-aproximação, onde occ max $_{\text {max }}^{\prime}$ o menor occ ${ }_{\max }^{\prime}(Z)$ entre todo LCS $Z$.

O consumo de tempo deste algoritmo é $O(f(X, Y)+(m+n))$, onde $f(X, Y)$ é o consumo de tempo de um algoritmo para computar um LCS de $X$ e $Y$ (lembrando que $m=|X|$ e $n=|Y|$ ). Se, por exemplo, usarmos o algoritmo de programação dinâmica para computar um LCS, o consumo de tempo é $O(m n)$. 


\subsubsection{Remove repetições e LCS}

Um segundo algoritmo de aproximação é realizar o processo do algoritmo anterior em ordem inversa: primeiro, removemos ocorrências de símbolos repetidos de $X$ e $Y$, construindo duas novas sequências $X^{\prime}$ e $Y^{\prime}$ de forma que cada símbolo do alfabeto ocorra no máximo uma vez em alguma das duas sequências, e, depois, encontramos um LCS para $X^{\prime}$ e $Y^{\prime}$. Chamamos este algoritmo de Remove repetições e LCS, ou RR-LCS.

A remoção de repetições ocorre de forma probabilística: o algoritmo escolhe aleatoriamente uma ocorrência de cada símbolo $\sigma \in \Sigma$ para permanecer na sequência. Como só é necessário fazer a remoção em uma das sequências, para cada $\sigma \in \Sigma$, ela é feita na que menos ocorre o símbolo $\sigma$, pois mantemos mais casamentos dessa maneira (se os números de ocorrências forem iguais em $X$ e em $Y$, escolhemos uma qualquer). É claro que a sequência resultante é sem repetições pois $X^{\prime}$ e $Y^{\prime}$ não tem nenhum par de casamentos de mesmo símbolo que não se cruzam.

O consumo de tempo deste algoritmo é $O(f(X, Y)+(m+n))$, onde $f(X, Y)$ é o consumo de tempo de um algoritmo para computar um LCS de $X$ e $Y$.

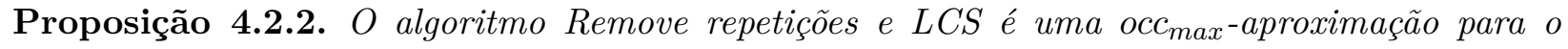
problema do RFLCS para $X$ e $Y$.

Prova. Sejam $W$ um RFLCS de $X$ e $Y$ e $R$ uma representação qualquer de $W$. Seja $\Sigma(W)$ o alfabeto dado pelos símbolos de $W$. Note que, como $W$ é sem repetições, cada símbolo de $\Sigma(W)$ está associado a um casamento de $R$. Sejam $X^{\prime}$ e $Y^{\prime}$ as sequências construídas no processo do algoritmo RR-LCS. Para cada símbolo $\sigma$ em $\Sigma(W)$, seja $L_{\sigma}$ uma variável aleatória binária que é igual a 1 se e só se o casamento $(i, j)$ em $R$ associado a $\sigma$ "existe" em $X^{\prime}$ e $Y^{\prime}$, no sentido que as ocorrências $i$ e $j$ não foram removidas de $X$ para $X^{\prime}$ e de $Y$ para $Y^{\prime}$ respectivamente.

Seja $W^{\prime}$ a sequência que o algoritmo RR-LCS devolve. Seja $L=\sum_{\sigma \in \Sigma(W)} L_{\sigma}$ e observe que existe uma subsequência comum de $X^{\prime}$ e $Y^{\prime}$ dada pelos símbolos $\sigma$ tais que $L_{\sigma}=1$. Como $W^{\prime}$ é um LCS de $X^{\prime}$ e $Y^{\prime}, L \leq\left|W^{\prime}\right|$. Logo, $E\left[\left|W^{\prime}\right|\right] \geq E[L]$. Pela linearidade da esperança, $E[L]=\sum_{\sigma \in \Sigma(W)} E\left[L_{\sigma}\right]$. Como $L_{\sigma}$ é uma variável aleatória binária para qualquer $\sigma$ em $\Sigma(W), E\left[L_{\sigma}\right]=P\left[L_{\sigma}=1\right]$, que é maior ou igual a $1 /$ occ $_{\max }$, já que a escolha entre as no máximo occ $\mathrm{c}_{\max }$ ocorrências é feita de forma uniforme e a remoção é feita em apenas uma das sequências para cada $\sigma$.

Juntando tudo,

$$
E\left[\left|W^{\prime}\right|\right] \geq E[L]=\sum_{\sigma \in \Sigma(W)} E\left[L_{\sigma}\right] \geq \frac{|W|}{\operatorname{occ}_{\max }}=\frac{\operatorname{opt}(\operatorname{RFLCS}(x, y))}{\operatorname{occ}_{\max }} .
$$

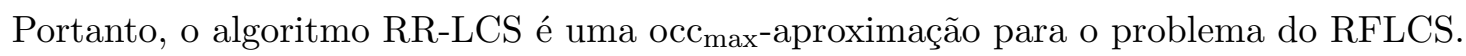

Uma variante do RR-LCS usa apenas um valor aleatório $r \in[0,1)$ para determinar todas as ocorrências mantidas. Se um símbolo $\sigma$ ocorre $k$ vezes, então a ocorrência escolhida é a $i$-ésima tal que $\frac{i-1}{k} \leq r<\frac{i}{k}$, para algum $i$ inteiro com $1 \leq i \leq k$. Isso facilita a desaleatorização do algoritmo, pois, dessa maneira, existe um número polinomial de comportamentos que o algoritmo pode ter de acordo com o valor $r$. Assim, basta gerar todos os valores de $r$ para cada comportamento, executar o algoritmo usando cada $r$, e escolher o melhor resultado. No entanto, na prática, a desaleatorização consome bastante tempo e contribui pouco para o algoritmo. 
Como a prova anterior apenas depende de cada escolha entre ocorrências ser uniformemente aleatória (e não da independência entre escolhas), a variante do algoritmo também tem a mesma razão de aproximação occ $\max$.

\subsection{Heurísticas gulosas}

Os algoritmos seguintes usam critérios gulosos para construir subsequências comuns sem repetições de comprimentos razoáveis. Embora para alguns dos algoritmos seguintes seja possível provar uma razão de aproximação, o propósito principal deles é servir como heurísticas boas.

\subsubsection{Escolha simples}

Uma heurística simples é escolher gulosamente os casamentos $(i, j)$ que minimizam a soma $i+j$ e, como segundo critério, minimizam a diferença $|i-j|$, de forma que eles não conflitem entre si [27]. Se considerarmos uma matriz em que as linhas são os índices de $X$ e as colunas os índices de $Y$, a ordem em que procuramos casamentos é percorrendo a diagonal $i=j$ e nos afastando ortogonalmente a cada ponto da diagonal, como na figura ao lado.

Para garantir a escolha de casamentos que não se cruzam dois a dois, a cada vez que a heurística encontra um casamento $(i, j)$, ela considera

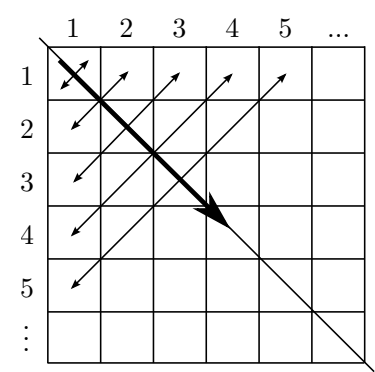
a partir desse ponto as sequências $X[i+1 . . m]$ e $Y[j+1 . . n]$. Já para garantir que a sequência devolvida pelo algoritmo seja sem repetições, os símbolos dos casamentos são marcados conforme são escolhidos e casamentos desses símbolos não são escolhidos novamente. Uma versão alternativa é remover as repetições apenas no final do algoritmo, como no algoritmo LCS-RR.

Uma variante desta heurística é escolher os casamentos que minimizam a diferença $|i-j|$ e, como segundo critério, minimizam a soma $i+j$. Ou seja, é o mesmo algoritmo mas com os critérios invertidos, tornando-o em um algoritmo de divisão e conquista: o algoritmo escolhe um casamento $(i, j)$ de acordo com esse critério e aplica o algoritmo novamente para $X[1 . . i-1]$ e $Y[1 . . j-1]$, e para $X[i+1 . . m]$ e $Y[j+1 . . n]$, para que um casamento que cruza com $(i, j)$ não seja escolhido, juntando os dois resultados no final.

Esta heurística pode não resultar em boas aproximações: no exemplo $X=z x x x x x x a b c d e f$ e $Y=$ abcdef $z$, o algoritmo escolhe a subsequência comum $z$ quando existe o RFLCS abcdef. A vantagem desta heurística é sua simplicidade e sua eficiência de tempo e espaço (ela consome tempo $O(|X||Y|)$ e espaço constante).

\subsubsection{Menor número de conflitos}

Um outro critério para uma heurística gulosa é o número de conflitos (número de casamentos que conflita com ele). A cada iteração, a heurística escolhe o casamento que tem menos conflitos. Para determinar o número de cruzamentos de cada casamento, usamos duas matrizes de programação dinâmica: $C_{1}[i, j]$ é o número de casamentos $(k, l) \neq(i, j)$ com $k \leq i$ e $l \geq j$, e $C_{2}[i, j]$ é o mesmo mas com $k \geq i$ e $l \leq j$. Para obter o número de conflitos de um casamento $(i, j)$ de símbolo $\sigma$, somamos a $C_{1}[i, j]+C_{2}[i, j]$ o número de casamentos de símbolo $\sigma$ que não cruzam com $(i, j)$, contados através de força bruta. 
A cada iteração do algoritmo, obtemos de uma fila de prioridades (um heap, por exemplo) o casamento com o menor número de conflitos, e, ao adicioná-lo à solução, removemos da fila todos os casamentos que conflitam com ele e, para cada um desses, decrementamos em 1 o número de conflitos de todos os casamentos que conflitam com ele.

Esta heurística é herdada do problema do conjunto independente máximo (apesar de não construirmos o grafo explicitamente), e pode-se provar que ela tem uma razão de aproximação $(\bar{d}+2) / 2$, onde $\bar{d}$ é o grau médio do grafo de conflito (isto é, o número total de conflitos dividido pelo número de casamentos) [18].

\subsubsection{Maior limitante de casamento}

Considere algum limitante superior para o problema do RFLCS. Seja $(i, j)$ um casamento de símbolo $\sigma$ e $u_{\text {pref }}(i, j)$ e $u_{\text {suf }}(i, j)$ limitantes superiores para $X[1 . . i-1]$ e $Y[1 . . j-1]$, e $X[i+1 . . m]$ e $Y[j+1 . . n]$ respectivamente, ignorando as ocorrências de $\sigma$ nessas sequências.

Denote por limitante de casamento uma função

$$
u_{c}(i, j)=u_{\text {pref }}(i, j)+u_{\text {suf }}(i, j)+1 .
$$

Observe que $u_{c}(i, j)$ é um limitante superior para o problema do RFLCS em que fixamos o casamento $(i, j)$ na solução, pois uma solução que contém $(i, j)$ pode conter, além dele, apenas casamentos dos prefixos ou sufixos de $X$ e $Y$ separados por $(i, j)$.

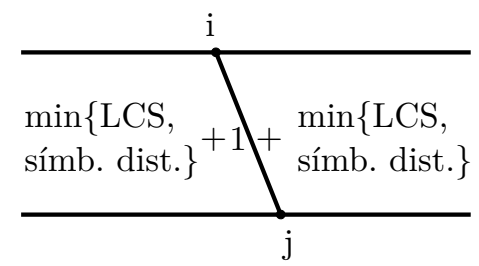

Os limitantes superiores $u_{\text {pref }}(i, j)$ e $u_{\text {suf }}(i, j)$ calculados para cada casamento $(i, j)$ são o mínimo entre o comprimento de um LCS das sequências em questão e o número de símbolos distintos do alfabeto que ocorrem nas duas sequências, que podem ser computados como a seguir.

- Para calcular o comprimento de um LCS para todo casamento nos prefixos, podemos executar um algoritmo para o problema do LCS. Boa parte dos algoritmos para o problema do LCS podem ser facilmente modificados para devolverem o LCS de todos os prefixos que terminam em algum casamento, sem aumentar muito o consumo de tempo do algoritmo. O mesmo pode ser feito para os sufixos considerando os reversos das sequências $X$ e $Y$, e assim temos todos os limitantes desejados. O algoritmo adaptado na implementação é o de Hunt e Szymanski, descrito na Seção 7.4. Usando esse método, no entanto, não desconsideramos as ocorrências do símbolo do casamento $(i, j)$, mas isso pode aumentar o valor do limitante em no máximo 1 , o que deve fazer pouca diferença para instâncias grandes.

- Para calcular o número de casamentos com símbolos distintos, armazenamos, para cada símbolo $\sigma$, o primeiro e último casamento de $\sigma$ (isto é, os dois casamentos $(i, j)$ de símbolo $\sigma$ com $i$ e $j$ mínimos e máximos respectivamente). Assim, para cada casamento $(i, j)$, contamos o número de símbolos tais que o primeiro casamento vem antes de $(i, j)$ para o caso do limitante do prefixo, e o número de símbolos tais que o último casamento que vem depois de $(i, j)$ para o caso do sufixo. Nesse caso, podemos levar em conta o símbolo do casamento $(i, j)$, ignorando esse símbolo na contagem.

Dados todos os limitantes de casamento, a heurística consiste em, a cada passo, encontrar o casamento $(i, j)$ com limitante de casamento máximo e resolver o mesmo problema recursivamente para $X[1 . . i-1]$ e $Y[1 . . j-1]$, e para $X[i+1 . . m]$ e $Y[j+1 . . n]$. Os símbolos já usados são removidos 
das sequências inclusive para o cálculo de limitantes, de forma que o mesmo símbolo nunca é escolhido mais de uma vez. Os casamentos escolhidos não se cruzam devido à forma que o problema é subdividido.

Intuitivamente, o motivo pelo qual esta heurística pode resultar em boas soluções é que, ao escolher tal casamento, há mais "espaço" para uma subsequência comum sem repetições longa.

Esta versão consome mais tempo comparado com os outros algoritmos desta seção, já que é necessário calcular limitantes de casamento várias vezes. Implementamos também uma versão mais simples que consome menos tempo, que calcula todos os limitantes de casamento e escolhe casamentos em ordem decrescente de limitante, tomando cuidado para evitar conflitos.

O conceito de limitante de casamento será mais útil mais adiante na Seção 5.4 para descartar variáveis de um programa inteiro.

\subsection{Resultados computacionais}

Nesta seção, observamos alguns gráficos resultantes da implementação dos algoritmos de aproximação e heurísticas.

Antes de observar a eficácia dos algoritmos em relação à aproximabilidade, veremos primeiro o tempo gasto por eles. O gráfico seguinte deixa claro que o algoritmo guloso de limitante de casamento e o de número de conflitos consomem muito mais tempo do que os outros. Vemos também a eficiência dos algoritmos gulosos simples.

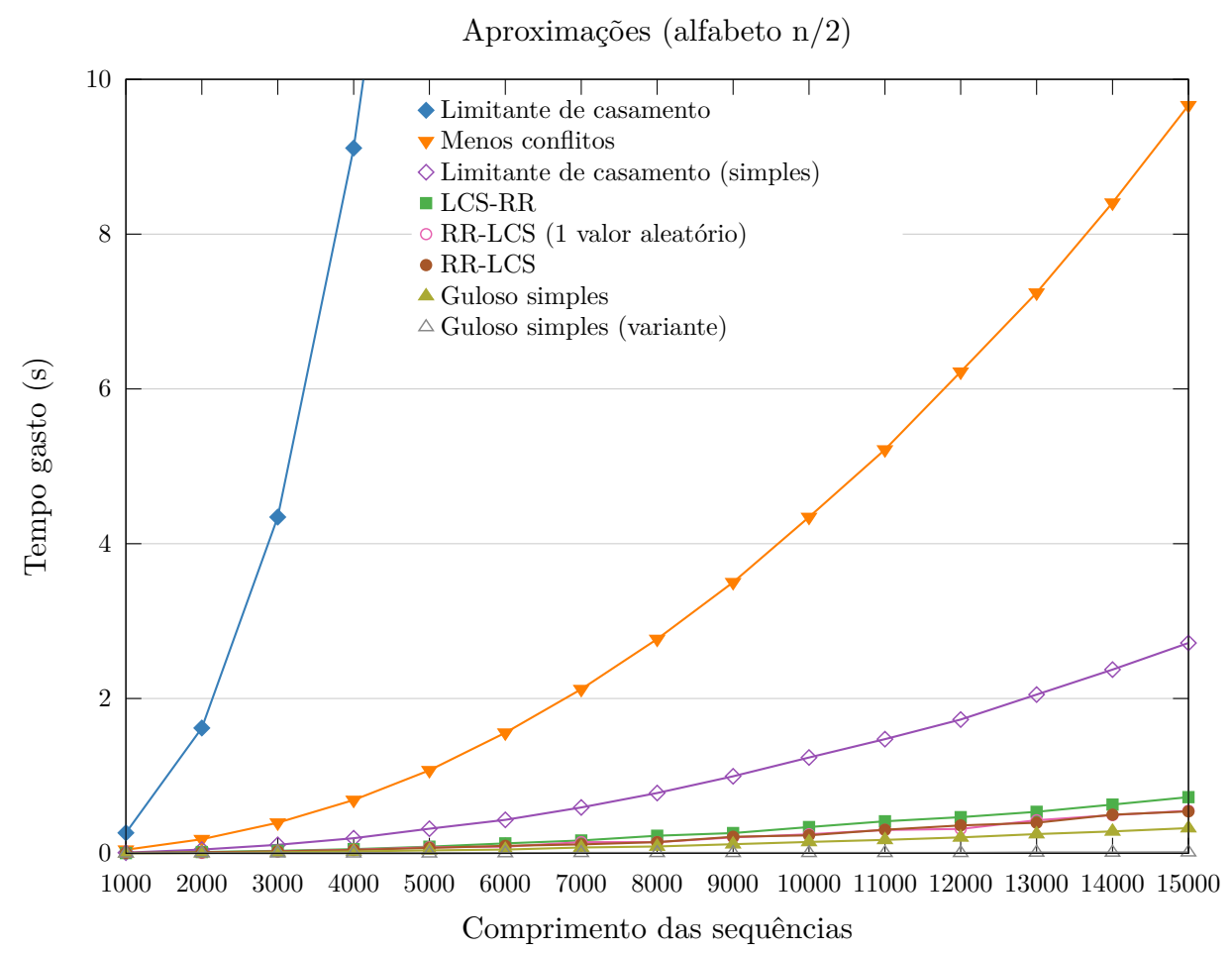

Os dois gráficos seguintes mostram as soluções devolvidas pelos algoritmos nos casos em que o alfabeto é $1 / 2$ e $1 / 8$ do comprimento das sequências respectivamente. 
Como não temos um algoritmo eficiente o suficiente para calcular o comprimento de um RFLCS para valores altos, colocamos os comprimentos de um LCS nos gráficos como base de comparação, já que ele é um limitante superior para o comprimento de um RFLCS.

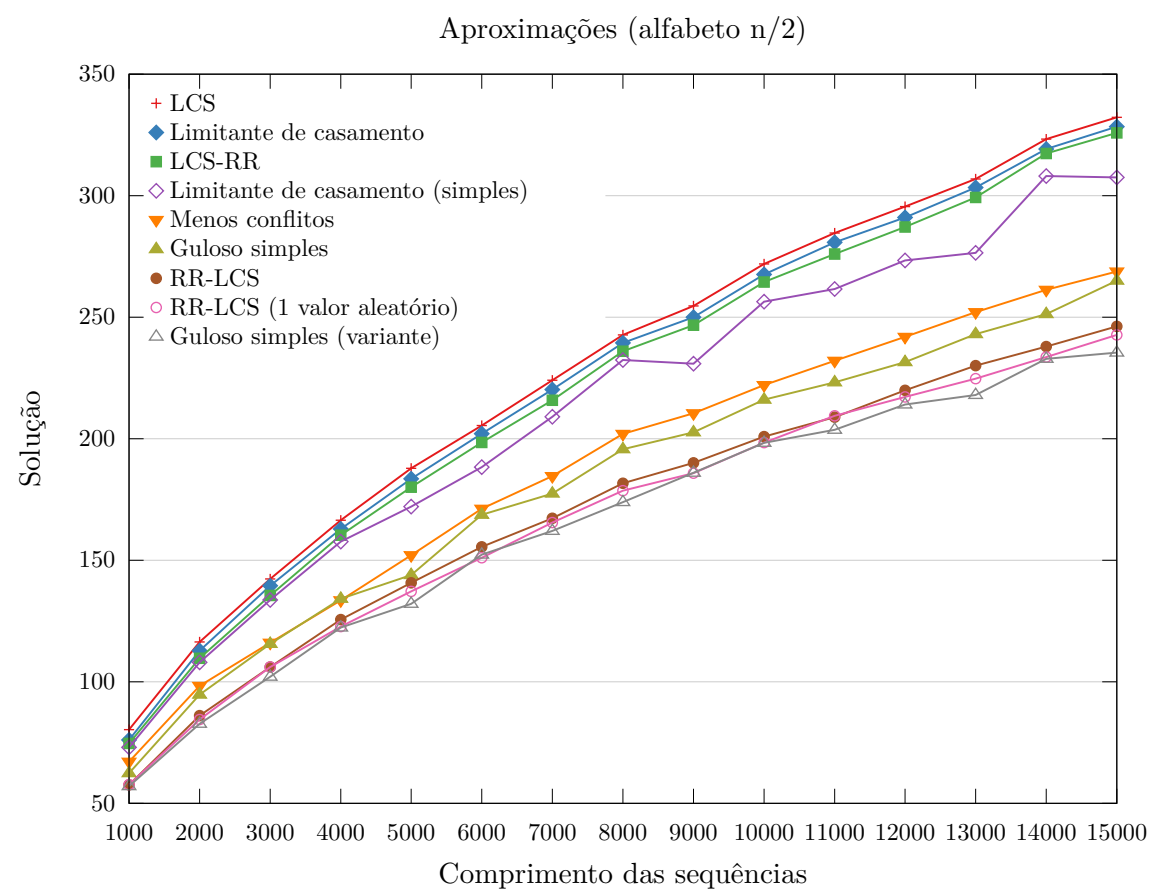

Aproximações (alfabeto $\mathrm{n} / 8$ )

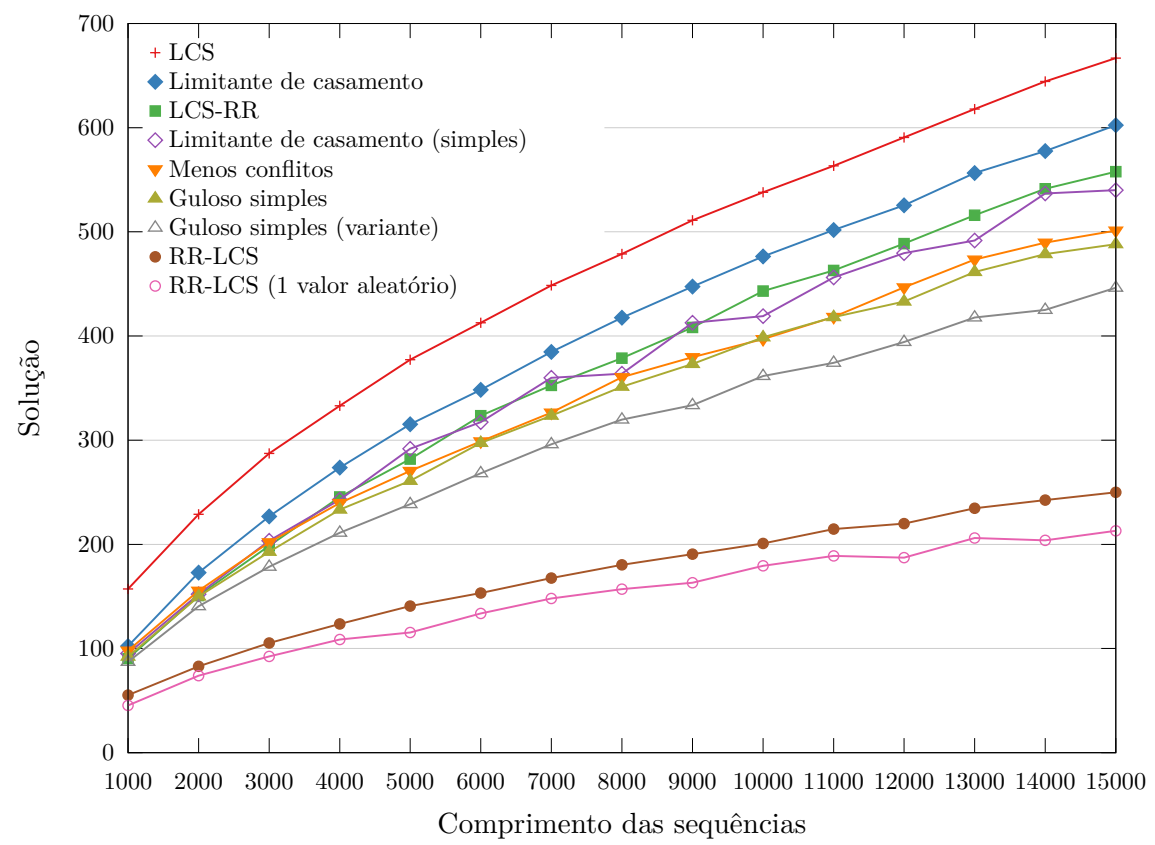

Comparando os algoritmos, tanto no caso do alfabeto de tamanho $n / 8$ como no de $n / 2$, o algoritmo de limitante de casamento tem resultados melhores, seguido pelo algoritmo LCS-RR. O 
algoritmo RR-LCS e sua variante, no entanto, são os piores de todos em ambos os casos. A relação com o tamanho do alfabeto pode ser melhor evidenciada pelos gráficos seguintes. Alguns valores ótimos do problema do RFLCS estão indicados no primeiro gráfico.

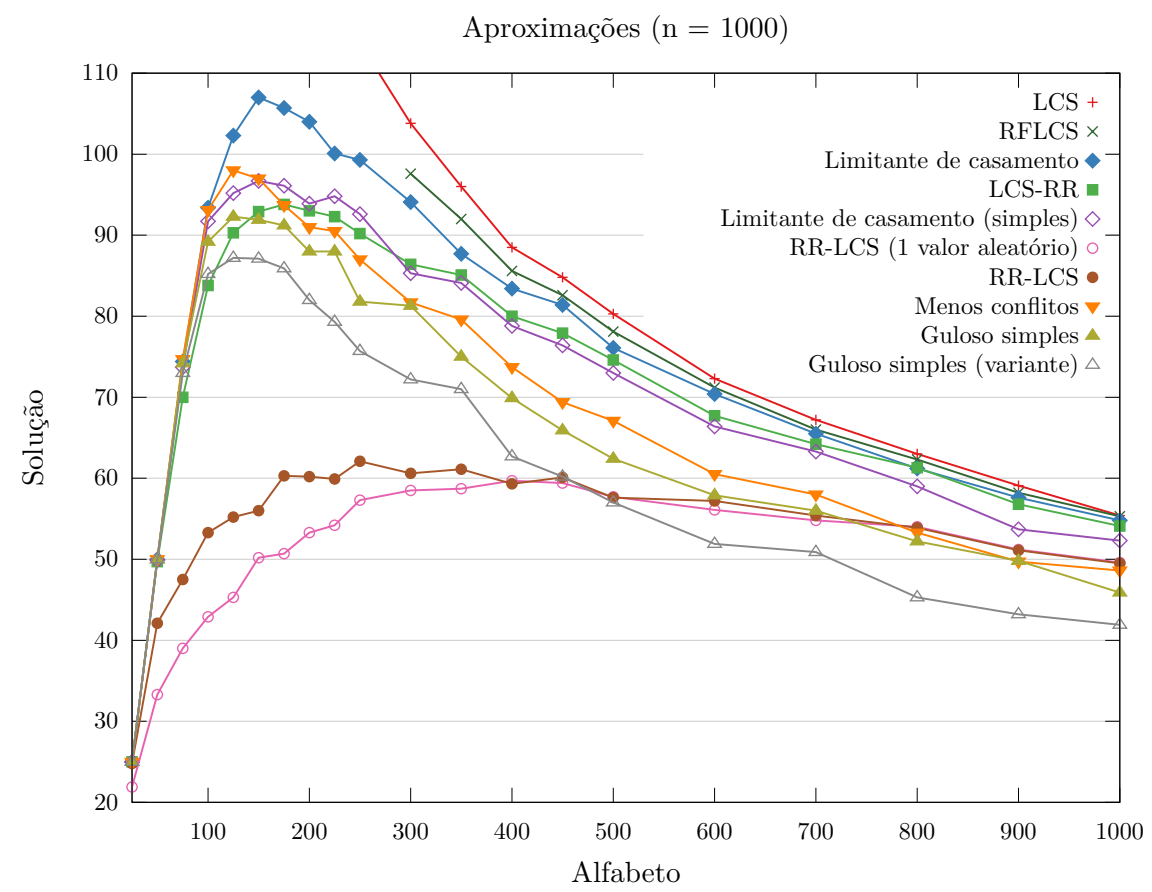

Aproximações $(\mathrm{n}=10000)$

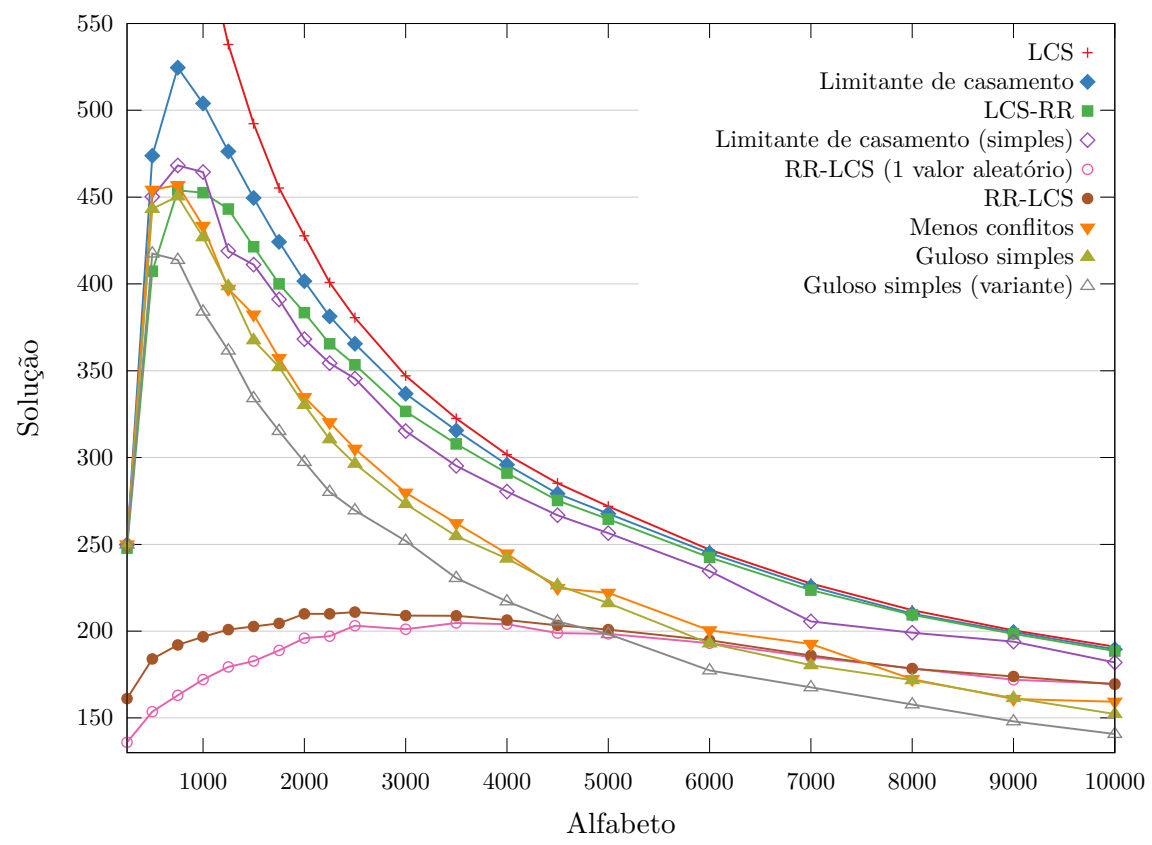

É interessante observar a forma das curvas nos gráficos acima: no início, com alfabeto pequeno, os valores são baixos pois são limitados pelo tamanho do alfabeto, e, conforme o tamanho do alfabeto aumenta, eles começam a ser limitados pelo comprimento de um LCS. 


\subsection{Inaproximabilidade do RFLCS}

O problema do RFLCS é APX-difícil. Para provar isso, descreveremos nesta seção uma L-redução do problema MAX 2,3-SAT, que é um problema APX-completo, para uma versão mais restrita do problema do RFLCS. Esta demonstração é de em um artigo por Adi et al. [1].

\subsubsection{Preliminares}

A classe de problemas NPO é uma extensão da classe NP para problemas de otimização. Um problema de otimização está em NPO se existem algoritmos polinomiais para reconhecer instâncias do problema, reconhecer soluções viáveis do problema e computar a função objetivo para qualquer solução viável, e, além disso, o tamanho de qualquer solução viável é limitado polinomialmente no tamanho de sua instância. A classe de problemas APX é formada pelos problemas em NPO para os quais existe uma $\alpha$-aproximação polinomial para alguma constante $\alpha$. Um problema em NPO é APX-difícil se qualquer problema em APX pode ser AP-reduzido a ele (uma AP-redução é um tipo de redução que preserva propriedades de aproximabilidade). Ele é APX-completo se, além de ser APX-difícil, está em APX.

Dizer que um problema é APX-difícil é um resultado de inaproximabilidade no seguinte sentido. Um esquema de aproximação polinomial é um algoritmo que recebe um número racional positivo $\epsilon$ e uma instância $I$, e devolve uma solução viável com valor no mínimo $(1-\epsilon) \operatorname{opt}(I)$ (para problemas de maximização), e é polinomial para todo $\epsilon$ fixo. Um problema é APX-difícil se e só se não existe um esquema de aproximação polinomial para ele a menos que $\mathrm{P}=\mathrm{NP}$. Isto é, dado que o problema do RFLCS é APX-difícil, se $\mathrm{P} \neq \mathrm{NP}$, não existe um esquema de aproximação polinomial para o problema do RFLCS.

\subsubsection{Uma L-redução de MAX 2,3-SAT para uma versão restrita do RFLCS}

Primeiro, definiremos o problema MAX 2,3-SAT e o conceito de L-redução, e, depois, mostraremos uma L-redução dele para a versão do problema do RFLCS em que o número de ocorrências de cada símbolo em cada sequência de entrada é limitado por dois.

Seja $V$ um conjunto de variáveis Booleanas e denote por $\bar{v}$ a negação de uma variável $v$. Um literal (sobre $V$ ) é uma variável de $V$ ou uma negação de uma variável de $V$, ou seja, é um elemento de $V \cup\{\bar{v} \mid v \in V\}$. Uma cláusula é um conjunto de literais, e é uma $k$-cláusula se tem $k$ literais. Uma valoração para $V$ é uma função $h: V \rightarrow\{\mathbf{T}, \mathbf{F}\}$ (true ou false, isto é, verdadeiro ou falso). Uma cláusula $c$ é satisfeita por uma valoração $h$ se existe um literal $l$ em $c$ tal que $l=v$ e $h(v)=\mathbf{T}$, ou $l=\bar{v}$ e $h(v)=\mathbf{F}$.

O problema MAX 2,3-SAT(V,C) consiste em, dados um conjunto $C$ de 2-cláusulas sobre $V$ tal que cada literal ocorre em no máximo 3 cláusulas de $C$, encontrar uma valoração de $V$ que maximiza o número de cláusulas satisfeitas em $C$. Este problema é APX-completo [4, 38].

Supomos que nenhuma cláusula de $C$ é da forma $\{v, \bar{v}\}$ para qualquer $v$ em $V$, pois tal cláusula é satisfeita por qualquer valoração. Para uma valoração $h$, denote por val(MAX 2,3-SAT(V,C), h) o número de cláusulas em $C$ que são satisfeitas por $h$, e por $\operatorname{opt}(\mathbf{M A X} \mathbf{2 , 3 - S A T}(\mathbf{V}, \mathbf{C})$ ) o maior possível desses valores entre todas as valorações $h$.

Exemplo 4.5.1. Seja $V=\left\{v_{1}, v_{2}, v_{3}\right\}$ um conjunto de variáveis. O conjunto de literais sobre $V$ é $L=\left\{v_{1}, v_{2}, v_{3}, \bar{v}_{1}, \bar{v}_{2}, \bar{v}_{3}\right\}$. Um exemplo de uma cláusula (2-cláusula) é $c=\left\{v_{1}, \bar{v}_{2}\right\}$. Uma possível 
valoração é $h$ tal que $h\left(v_{1}\right)=\mathbf{T}, h\left(v_{2}\right)=\mathbf{T}, h\left(v_{3}\right)=\mathbf{F}$. A valoração $h$ satisfaz $c_{1}$ pois existe um literal igual a $v_{1}$ em $c_{1}$ e $h\left(v_{1}\right)=\mathbf{T}$.

Tome o conjunto de cláusulas $C=\left\{c_{1}, c_{2}, c_{3}\right\}$, onde $c_{1}=\left\{v_{1}, \bar{v}_{2}\right\}, c_{2}=\left\{v_{1}, \bar{v}_{3}\right\}$ e $c_{3}=\left\{v_{2}, v_{3}\right\}$.

Uma valoração $h_{1}$ tal que $h_{1}\left(v_{1}\right)=\mathbf{T}, h_{1}\left(v_{2}\right)=\mathbf{F}, h_{1}\left(v_{3}\right)=\mathbf{F}$ satisfaz $c_{1}$ e $c_{2}$. Isto é, $\operatorname{val}(\operatorname{MAX} 2,3-\operatorname{SAT}(V, C), h)=2$.

Já a valoração $h_{2}$ tal que $h_{2}\left(v_{1}\right)=\mathbf{T}, h_{2}\left(v_{2}\right)=\mathbf{T}, h_{2}\left(v_{3}\right)=\mathbf{F}$ satisfaz todas as três cláusulas. Assim, $h_{2}$ é uma solução ótima para MAX 2,3-SAT $(V, C)$, isto é, opt(MAX 2,3-SAT $\left.(V, C)\right)$ é igual a val(MAX 2,3-SAT $\left.(V, C), h_{2}\right)=3$.

Definiremos um tipo de redução menos poderoso que AP-redução, mas ainda útil. Denote por $\operatorname{opt}(\operatorname{RFLCS}(X, Y))$ o comprimento de um RFLCS de $X$ e $Y$.

Uma L-redução de MAX 2,3-SAT para o problema do RFLCS consiste em um par de funções computáveis em tempo polinomial $(f, g)$ tal que, para duas constantes positivas fixas $\alpha$ e $\beta$, as seguintes condições valham:

1. para cada instância $(V, C)$ de MAX 2,3-SAT, $f(V, C)=(X, Y)$ é uma instância do problema do $\operatorname{RFLCS}$, e opt(RFLCS $(X, Y)) \leq \alpha \operatorname{opt}(\operatorname{MAX} 2,3-\operatorname{SAT}(V, C))$;

2. para cada instância $(V, C)$ de MAX 2,3-SAT, e para cada subsequência comum sem repetições $W$ de $X$ e $Y$, onde $(X, Y)=f(V, C)$, temos que $h=g(V, C, W)$ é uma valoração para $V$, e $\operatorname{opt}(\operatorname{MAX} 2,3-\operatorname{SAT}(V, C))-\operatorname{val}(\operatorname{MAX} 2,3-\operatorname{SAT}(V, C), h) \leq \beta(\operatorname{opt}(\operatorname{RFLCS}(X, Y))-|W|)$.

A existência de uma L-redução de um problema APX-completo para um outro problema em APX implica que este último é também APX-completo [38].

O teorema a seguir é um resultado de inaproximabilidade para o problema do RFLCS.

Teorema 4.5.2. O problema do RFLCS é APX-completo quando restrito a instâncias $(X, Y)$ em que o número de ocorrências de cada símbolo em cada sequência $X$ e $Y$ é limitado por dois.

Prova. Primeiro, observe que o problema do RFLCS está em APX quando o número de ocorrências de cada símbolo em $X$ e $Y$ é limitado por dois. De fato, o algoritmo de aproximação LCS e remove repetições da Seção 4.2 é uma 2-aproximação determinística neste caso.

Mostraremos uma L-redução de MAX 2,3-SAT para a versão do problema do RFLCS com essa restrição. Esta prova tem 4 passos: primeiro, (1a) definiremos uma função $f$ computável em tempo polinomial que traduz uma instância do problema MAX 2,3-SAT para uma do problema do RFLCS com a restrição. Depois, (2a) definiremos uma função $g$ computável em tempo polinomial que traduz uma subsequência comum sem repetições da instância $f(V, C)$ para uma valoração para $V$. Finalmente, para as funções $f$ e $g$, mostraremos (1b) a condição 1 e $\mathbf{( 2 b )}$ a condição 2 da definição de L-redução, necessárias para preservar aproximabilidade.

(1a) Construção de uma função $f$ computável em tempo polinomial tal que, para cada instância $(V, C)$ de MAX 2,3-SAT, $f(V, C)=(X, Y)$ é uma instância do problema do RFLCS, tal que o número de ocorrências de cada símbolo em cada sequência $X$ e $Y$ é limitado por dois.

Seja $(V, C)$ uma instância de MAX 2,3-SAT, onde $V=\left\{v_{1}, v_{2}, \ldots, v_{n}\right\}$ é o conjunto de variáveis e $C=\left\{c_{1}, c_{2}, \ldots, c_{m}\right\}$ é o conjunto de 2-cláusulas sobre $V$. Construiremos uma instância $(X, Y)=$ 
$f(V, C)$ do problema do RFLCS. Por conveniência, o símbolo que representa a cláusula $c_{i}$ também é rotulado por $c_{i}$, e denotamos também por $C$ o conjunto desses símbolos.

Para cada literal $l$, denotamos por $S(l)$ uma sequência composta por símbolos que representam as cláusulas que contêm $l$, em uma ordem qualquer (usaremos no exemplo mais adiante a ordem crescente de índices em $C$ ). Isto é, para cada $v$ em $V$ e uma valoração $h$ para $V$, a sequência $S(v)$ contém as cláusulas de $C$ que seriam satisfeitas se $h(v)=\mathbf{T}$, e $S(\bar{v})$ as cláusulas de $C$ que seriam satisfeitas se $h(v)=\mathbf{F}$. Note que $S(v)$ e $S(\bar{v})$ não têm símbolo em comum pois não temos uma cláusula da forma $\{v, \bar{v}\}$. Além disso, para qualquer literal $l$, como $l$ pode aparecer em no máximo 3 cláusulas de $C$, temos que $|S(l)| \leq 3$.

Ainda mais, utilizaremos um conjunto de novos símbolos $D=\left\{d_{1}, d_{2}, \ldots, d_{k}\right\}$ com $k=6(n-1)$ (e $C \cap D=\varnothing$ ). Seja $D_{k}$ a sequência $d_{j+1} d_{j+2} d_{j+3} d_{j+4} d_{j+5} d_{j+6} \operatorname{com} j=6(k-1)$ (isto é, $D_{1}$ é $d_{1} d_{2} d_{3} d_{4} d_{5} d_{6}, D_{2}$ é $d_{7} d_{8} d_{9} d_{10} d_{11} d_{12}$, e assim em diante). A instância $(X, Y)$ é a que segue, com alfabeto $\Sigma=C \cup D$.

$$
\begin{aligned}
& X=S\left(v_{1}\right) S\left(\bar{v}_{1}\right) D_{1} S\left(v_{2}\right) S\left(\bar{v}_{2}\right) D_{2} \ldots D_{n-1} S\left(v_{n}\right) S\left(\bar{v}_{n}\right), \mathrm{e} \\
& Y=S\left(\bar{v}_{1}\right) S\left(v_{1}\right) D_{1} S\left(\bar{v}_{2}\right) S\left(v_{2}\right) D_{2} \ldots D_{n-1} S\left(\bar{v}_{n}\right) S\left(v_{n}\right) .
\end{aligned}
$$

Cada símbolo em $D$ ocorre uma vez tanto em $X$ como em $Y$. Além disso, como cada cláusula $c$ em $C$ tem dois literais, e, para cada literal $l$, a sequência $S(l)$ aparece uma vez tanto em $X$ como em $Y$, segue que cada símbolo $c$ ocorre duas vezes em cada sequência, obedecendo a restrição.

Além disso, é fácil ver que a construção dessas sequências pode ser feita em tempo polinomial.

Exemplo 4.5.3. Sejam $V=\left\{v_{1}, v_{2}, v_{3}\right\}$ e $C=\left\{c_{1}, \ldots, c_{9}\right\}$, com $c_{1}=\left\{v_{1}, v_{2}\right\}, c_{2}=\left\{\bar{v}_{1}, v_{2}\right\}$, $c_{3}=\left\{\bar{v}_{1}, \bar{v}_{2}\right\}, c_{4}=\left\{v_{1}, v_{3}\right\}, c_{5}=\left\{v_{1}, \bar{v}_{3}\right\}, c_{6}=\left\{\bar{v}_{1}, \bar{v}_{3}\right\}, c_{7}=\left\{v_{2}, v_{3}\right\}, c_{8}=\left\{\bar{v}_{2}, v_{3}\right\}$ e $c_{9}=\left\{\bar{v}_{2}, \bar{v}_{3}\right\}$. Sejam $D=\left\{d_{1}, \ldots, d_{12}\right\}, D_{1}=d_{1} d_{2} d_{3} d_{4} d_{5} d_{6}$ e $D_{2}=d_{7} d_{8} d_{9} d_{10} d_{11} d_{12}$. Aplicando a transformação descrita, obtemos as sequências

$$
\begin{aligned}
& X=\overbrace{c_{1} c_{4} c_{5}}^{S\left(v_{1}\right)} \overbrace{c_{2} c_{3} c_{6}}^{S\left(\bar{v}_{1}\right)} D_{1} \overbrace{c_{1} c_{2} c_{7}}^{S\left(v_{2}\right)} \overbrace{c_{3} c_{8} c_{9}}^{S\left(\bar{v}_{2}\right)} D_{2} \overbrace{c_{4} c_{7} c_{8} c_{8}}^{S\left(v_{3}\right)} \overbrace{S\left(v_{5} c_{6} c_{9}\right.}^{S\left(\bar{v}_{3}\right)}, \mathrm{e} \\
& Y=\underbrace{c_{1} c_{4} c_{5}}_{c_{2} c_{3} c_{6}} D_{1} \underbrace{c_{3} c_{8} c_{9}}_{\underbrace{}_{3} \bar{v}_{2})} \underbrace{c_{1} c_{2} c_{7}}_{S\left(v_{2}\right)} D_{2} \underbrace{c_{5} c_{6} c_{9}}_{S\left(\bar{v}_{3}\right)} \underbrace{c_{4} c_{7} c_{8}}_{S\left(v_{3}\right)} .
\end{aligned}
$$

Um RFLCS de $X$ e $Y$ é $c_{1} c_{4} c_{5} D_{1} c_{3} c_{8} c_{9} D_{2} c_{7}$. Como veremos no item (2a) a seguir, ele corresponde a uma solução viável do problema $\operatorname{MAX} 2,3-\operatorname{SAT}(V, C)$ em que escolhemos a valoração $h$ tal que $h\left(v_{1}\right)=\mathbf{T}, h\left(v_{2}\right)=\mathbf{F}$, e $h\left(v_{3}\right)=\mathbf{T}$, pois os símbolos em $C$ escolhidos foram os de $S\left(v_{1}\right)$, $S\left(\bar{v}_{2}\right)$ e $S\left(v_{3}\right)$.

(2a) Construção de uma função g computável em tempo polinomial tal que, para cada instância $(V, C)$ de MAX 2,3-SAT, e para cada subsequência comum sem repetições $W$ de $X$ e $Y$, onde $(X, Y)=f(V, C), h=g(V, C, W)$ é uma valoração para $V$.

Sejam $(V, C)$ uma instância de MAX 2,3-SAT e $W$ uma subsequência comum sem repetições de $X$ e $Y$, onde $(X, Y)=f(V, C)$. Construiremos uma valoração $h=g(V, C, W)$ para $W$.

Primeiro, descreveremos uma subsequência comum sem repetições $Z$ de $X$ e $Y$ de comprimento pelo menos $|W|$ que contém todos os símbolos de $D$. Seja $R$ uma representação de $W$. Observe que, para todo $i=1, \ldots, n-1$, temos no máximo 6 casamentos que têm uma ponta em $S\left(v_{i}\right)$ ou $S\left(\bar{v}_{i}\right)$ e 
a outra ponta em $S\left(v_{j}\right)$ ou $S\left(\bar{v}_{j}\right)$ para algum $j>i$, pois $S\left(v_{i}\right)$ e $S\left(\bar{v}_{i}\right)$ têm no máximo 6 símbolos juntos. Tais casamentos cruzam com todos os casamentos associados a $D_{i}$. Então, sequencialmente, para $i=1, \ldots, n-1$, podemos remover de $R$ tais casamentos e adicionar todos os casamentos associados a $D_{i}$ se eles não estiverem em $R$. A sequência $Z$ obtida ao realizar essa transformação contém todos os símbolos de $D$ e tem comprimento maior ou igual a $|W|$.

Como $Z$ contém todos os símbolos de $D$, as outras partes de $Z$ são subsequências de $S\left(v_{i}\right) S\left(\bar{v}_{i}\right)$ em $X$ e $S\left(\bar{v}_{i}\right) S\left(v_{i}\right)$ em $Y$, para todo $i=1, \ldots, n$, separados por $D_{i}$ s. Denote por $D_{0}$ o início da sequência $Z$. Observe que, para todo $i=1, \ldots, n$, não existem simultaneamente símbolos de ambas as sequências $S\left(v_{i}\right)$ e $S\left(\bar{v}_{i}\right)$ em $Z$ entre $D_{i-1}$ e $D_{i}$, pois os casamentos associados a $S\left(v_{i}\right)$ cruzam com os associados a $S\left(\bar{v}_{i}\right)$. Assim, podemos construir uma valoração $h$ tal que $h\left(v_{i}\right)=\mathbf{T}$ se $Z$ contém um símbolo de $S\left(v_{i}\right)$ entre $D_{i-1}$ e $D_{i}$, ou $h\left(v_{i}\right)=\mathbf{F}$ caso contrário (se não houver símbolo entre $D_{i-1}$ e $D_{i}$, a escolha de $h\left(v_{i}\right)$ não faz diferença). As cláusulas satisfeitas por essa valoração são os símbolos de $Z$ em $C$.

Um exemplo foi dado no item anterior. A transformação de $W$ para $Z$ e a construção de $h$ podem ser feitas em tempo polinomial.

(1b) Para cada instância $(V, C)$ de MAX 2,3-SAT, existe uma constante positiva $\alpha$ tal que

$$
\operatorname{opt}(\operatorname{RFLCS}(X, Y)) \leq \alpha \operatorname{opt}(\operatorname{MAX} 2,3-\operatorname{SAT}(V, C)),
$$

onde $(X, Y)=f(V, C)$.

Seja $(V, C)$ uma instância de MAX 2,3-SAT e tome $(X, Y)=f(V, C)$. Como cada cláusula tem dois literais, vale que $n \leq 2 m$, onde $n=|V|$ e $m=|C|$. Além disso, como cada símbolo pode aparecer no máximo uma vez em uma subsequência comum sem repetições de $X$ e $Y$, $\operatorname{opt}(\operatorname{RFLCS}(X, Y)) \leq|\Sigma|=|C \cup D| \leq m+6(n-1) \leq 13 m$.

Podemos também construir uma valoração $h$ para $V$ tal que val(MAX 2,3-SAT $(V, C), h) \geq m / 2$. De fato, seja $C_{i}$ o conjunto de cláusulas que contém $v_{i}$ ou $\bar{v}_{i}$, e construa todos os $C_{i}^{\prime}$ s iterativamente tomando $C_{1}^{\prime}=C_{1}$ e $C_{i}^{\prime}=C_{i} \backslash \cup_{j<i} C_{j}^{\prime}$ para todo $i=1, \ldots, n$ (isto é, iterando em $i=1, \ldots, n$ e removendo os elementos já escolhidos de $C_{i}$ ). Tome $h\left(v_{i}\right)=\mathbf{T}$ se $v_{i}$ ocorre mais vezes que $\bar{v}_{i}$ nas cláusulas de $C_{i}^{\prime}$, e $h\left(v_{i}\right)=\mathbf{F}$ caso contrário. Como $h$ satisfaz pelo menos $\left|C_{i}^{\prime}\right| / 2$ cláusulas para cada $i$ e $\cup C_{i}^{\prime}=C$, a valoração $h$ satisfaz pelo menos $m / 2$ cláusulas de $C$. Assim, opt $(\operatorname{MAX} 2,3-\operatorname{SAT}(V, C)) \geq m / 2$.

Portanto, opt $(\operatorname{RFLCS}(X, Y)) \leq 26 \operatorname{opt}(\operatorname{MAX} 2,3-\operatorname{SAT}(V, C))$, e a afirmação vale com $\alpha=26$.

(2b) Para cada instância $(V, C)$ de MAX 2,3-SAT, e para cada subsequência comum sem repetições $W$ de $X$ e $Y$, onde $(X, Y)=f(V, C)$, existe uma constante positiva $\beta$ tal que

$$
\operatorname{opt}(\operatorname{MAX} 2,3-\operatorname{SAT}(V, C))-\operatorname{val}(\operatorname{MAX} 2,3-\operatorname{SAT}(V, C), h) \leq \beta(\operatorname{opt}(\operatorname{RFLCS}(X, Y))-|W|) \text {, }
$$

onde $h=g(V, C, W)$.

Sejam $(V, C)$ uma instância de MAX 2,3-SAT e $W$ uma subsequência comum sem repetições de $X$ e $Y$, onde $(X, Y)=f(V, C)$. Tome $h=g(V, C, W)$. Provaremos que opt(MAX 2,3-SAT $(V, C))-$ $\operatorname{val}(\operatorname{MAX} 2,3-\operatorname{SAT}(V, C), h) \leq \operatorname{opt}(\operatorname{RFLCS}(X, Y))-|W|$, isto é, a afirmação vale com $\beta=1$.

Seja $Z$ a sequência dada pela transformação de $W$ do item (2a). Como já visto, $|Z| \geq|W|$. As cláusulas satisfeitas pela valoração $h$ são os símbolos em $C$ de $Z$. Como $Z$ é sem repetições, o número de cláusulas é $|Z|-|D|$. Logo, val(MAX 2,3-SAT $(V, C), h) \geq|W|-|D|$. 
Além disso, seja $h$ uma valoração para $V$ que satisfaz $q$ cláusulas de $C$. Tome a subsequência comum $W^{\prime}=S_{1} D_{1} S_{2} D_{2} \ldots D_{n-1} S_{n}$, onde $S_{i}$ é igual a $S\left(v_{i}\right)$ se $h\left(v_{i}\right)=\mathbf{T}$, ou $S\left(\bar{v}_{i}\right)$ se $h\left(v_{i}\right)=\mathbf{F}$. Dessa forma, $W^{\prime}$ contém, além dos símbolos de $D$, apenas e todas as cláusulas satisfeitas por $h$. Assim, removendo símbolos repetidos de $W^{\prime}$, obtemos uma subsequência comum sem repetições $W$ de comprimento $q+|D|$. Em particular, se $h$ for ótima, isso implica que opt $(\operatorname{RFLCS}(X, Y)) \geq$ $\operatorname{opt}(\operatorname{MAX} 2,3-\operatorname{SAT}(V, C))+|D|$.

Juntando as duas inequações, vale que opt(MAX 2,3-SAT $(V, C))-\operatorname{val}(\operatorname{MAX} 2,3-\operatorname{SAT}(V, C), h) \leq$ $(\operatorname{opt}(\operatorname{RFLCS}(X, Y))-|D|)-(|W|-|D|)=\operatorname{opt}(\operatorname{RFLCS}(X, Y))-|W|$.

Provamos que existe uma L-redução de MAX 2,3-SAT, um problema APX-completo, para a versão do problema do RFLCS em que o número de ocorrências de cada símbolo em cada sequência de entrada é limitado por dois. Logo, tal problema também é APX-completo.

Corolário 4.5.4. O problema do RFLCS é APX-difícil.

Prova. Resultado direto do teorema anterior. 
Capítulo 4. Aproximabilidade e heurísticas para RFLCS 


\section{CAPÍtulo 5}

\section{Algoritmo branch-and-cut para RFLCS}

Apresentamos neste capítulo detalhes de implementação de um algoritmo exato para o problema do RFLCS baseado na técnica branch-and-cut. Descrevemos dois algoritmos de separação para as inequações de estrela estendida, e também técnicas e heurísticas para obtermos uma solução ótima mais rapidamente. Mais uma classe de inequações e duas técnicas não usadas na implementação do algoritmo estão no Apêndice A.

\subsection{A técnica branch-and-cut}

Dado $\mathcal{C}$ o conjunto de casamentos de $X$ e $Y$, lembremos da formulação de programação inteira por estrelas estendidas para o problema do RFLCS, descrita na Seção 3.3.1:

$$
\begin{array}{rlrl}
\max & \sum_{(i, j) \in \mathcal{C}} z_{i j} & & \\
\text { s. a } & \sum_{(i, j) \in S} z_{i j} & \leq 1 & \text { para toda estrela estendida maximal } S \subseteq \mathcal{C}, \\
z_{i j} & \in\{0,1\} & \text { para todo }(i, j) \text { em } \mathcal{C} .
\end{array}
$$

Existem dois obstáculos à implementação de um algoritmo que resolve a formulação acima: o número de restrições de estrela estendida maximal é exponencial no tamanho da entrada, e existe uma classe de restrições de integralidade.

Para lidar com o primeiro caso, podemos iniciar o algoritmo sem restrições ou com algumas restrições lineares válidas simples, otimizar, acrescentar alguma restrição de estrela estendida violada pela solução ao programa linear e otimizar novamente (pelo dual, para aproveitar a solução anterior), repetindo esse processo até que não haja mais restrição de estrela estendida que esteja violada pela solução. Tais restrições, usadas dessa maneira, se chamam planos de corte (faciais).

Já para tratar o segundo caso, podemos resolver primeiro a relaxação linear do problema, trocando a restrição $z_{i j} \in\{0,1\}$ por $0 \leq z_{i j} \leq 1$ para todo $(i, j)$ em $\mathcal{C}$, e depois escolher uma variável fracionária, fixá-la em 0 ou 1, e resolver os dois subproblemas recursivamente, levando em conta limitantes para eliminar alguns subproblemas desnecessários. Embora isso não pareça eficiente, restrições inteiras costumam ser inerentemente difíceis e, na prática, esse método funciona bem.

Essa técnica para resolver esses dois obstáculos é chamada de branch-and-cut, justamente por ramificarmos o problema em subproblemas para lidar com a restrição inteira (branch) e 
aplicarmos planos de corte para cuidar do número grande de restrições (cut). Usando esse método, implementamos um algoritmo exato para o problema com o auxílio do pacote open source de programação linear GLPK [14]. Usamos o método simplex para resolver as relaxações lineares.

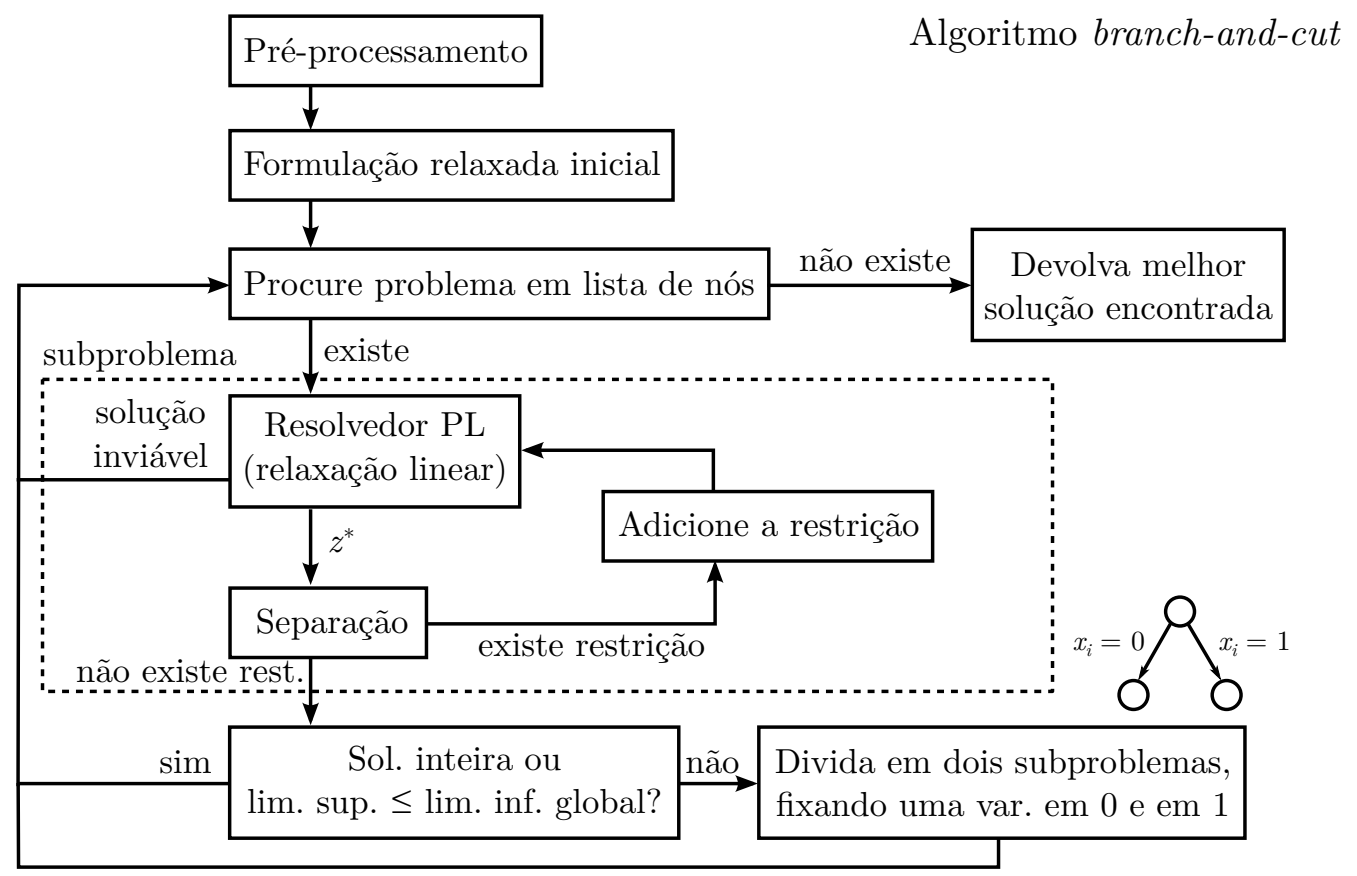

Nosso algoritmo branch-and-cut requer um algoritmo que recebe uma solução do programa linear e devolve uma estrela estendida maximal que viola a solução se houver. Um algoritmo desse tipo é chamado de algoritmo de separação.

Na seção seguinte, descreveremos um algoritmo de separação eficiente baseado no algoritmo de programação dinâmica para o problema do LCS (Seção 7.2), e também um outro baseado no algoritmo de Hunt e Szymanski para o problema do LCS (Seção 7.4). Compararemos ambos os algoritmos na prática. Nas seções subsequentes, apresentaremos heurísticas que podem ser usadas como limitantes inferiores e técnicas para tornar o algoritmo branch-and-cut mais eficiente.

\subsection{Algoritmo de separação para estrelas estendidas maximais}

Estamos interessados em um algoritmo que, dada uma solução ótima $z^{*}$ da relaxação linear do programa inteiro (descrito anteriormente) com apenas algumas das restrições de estrela estendida, encontra uma estrela estendida maximal $S$ cuja inequação de estrela estendida é violada por $z^{*}$ (isto é, $\sum_{(i, j) \in S} z_{i j}^{*}>1$ ), ou informa se não existe tal estrela estendida maximal. Reescreveremos este problema de uma forma mais conveniente.

Dizemos que $Y^{r}=y_{n} y_{n-1} \ldots y_{1}$ é o reverso da sequência $Y=y_{1} y_{2} \ldots y_{n}$. Se revertermos uma das sequências (digamos, $Y$ ) e tomarmos $\mathcal{C}^{\prime}$ como o conjunto de casamentos após esta transformação, cada casamento $(i, j)$ em $\mathcal{C}$ se torna o casamento $(i, n-j+1)$ em $\mathcal{C}^{\prime}$. Resulta direto da definição de cruzamento que, com essa transformação,

- os casamentos com pontas distintas que se cruzavam em $\mathcal{C}$ deixam de se cruzar em $\mathcal{C}^{\prime}$, 
- os casamentos com alguma ponta em comum em $\mathcal{C}$ continuam com a mesma ponta em comum em $\mathcal{C}^{\prime}$ e portanto se cruzam em $\mathcal{C}^{\prime}$, e

- os casamentos que não cruzavam em $\mathcal{C}$ passam a se cruzar em $\mathcal{C}^{\prime}$.

Assim, ao reverter uma das sequências, as estrelas estendidas se tornam conjuntos de casamentos que, dois a dois, ou não se cruzam, ou estão associados ao mesmo símbolo. Denominamos tal conjunto de emparelhamento planar estendido. Para obter uma estrela estendida maximal, é suficiente reverter uma das sequências e encontrar um emparelhamento planar estendido maximal.

estrela estendida

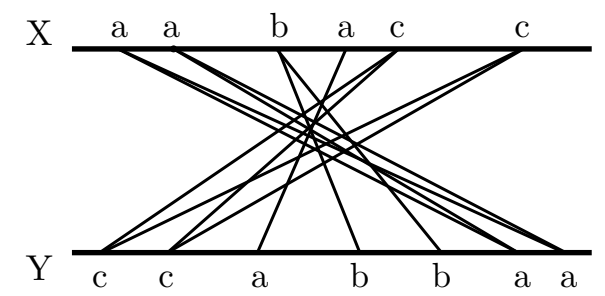

emparelhamento planar estendido

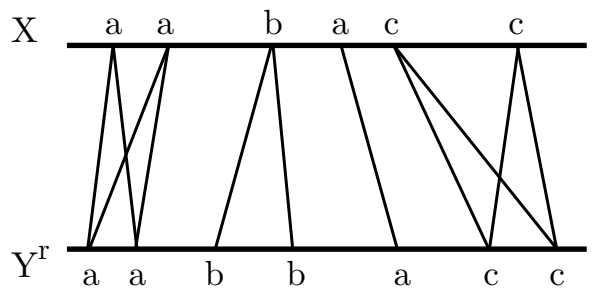

Podemos então reescrever o problema como a seguir: dado um conjunto de pesos nos casamentos $w: \mathcal{C} \rightarrow \mathbb{R}_{+}$, encontre um emparelhamento planar estendido máximo sob $w$, isto é, um emparelhamento planar estendido $E$ tal que a soma dos pesos dos casamentos de $E$ seja máxima e, como segundo critério, $|E|$ seja máximo (este critério é uma forma de garantir maximalidade dado que podem existir pesos de valor zero). Se tomarmos $w$ como uma solução do programa linear anterior, e se o peso máximo for maior que 1, então encontramos uma restrição de estrela estendida maximal que é violada por essa solução. Caso contrário, sabemos que não existe restrição violada pela solução.

Essa reversão é feita por conveniência: um emparelhamento planar estendido é, de uma certa forma, similar a um conjunto de casamentos que representa um LCS, e podemos adaptar algoritmos para o problema do LCS para resolver este problema.

Desenvolvemos dois algoritmos de separação com essa mesma base: um baseado no algoritmo de programação dinâmica para o problema do LCS (Seção 7.2), e outro baseado no algoritmo de Hunt e Szymanski para o problema do LCS, que usa o conceito de limiares (Seção 7.4). Não é necessário conhecê-los para entender os algoritmos seguintes; escreveremos as partes relevantes deles aqui conforme necessário.

\subsubsection{Algoritmo de separação baseado em programação dinâmica}

Este algoritmo de separação é baseado no algoritmo de programação dinâmica para o problema do LCS, descrito na Seção 7.2.

Considere primeiro o problema de, dado um peso $w(i, j)$ para cada casamento, encontrar um conjunto de casamentos de peso máximo que não se cruzam dois a dois, que chamamos de emparelhamento planar máximo. Usando mesma ideia do algoritmo de programação dinâmica para o problema do LCS, considere uma função $L$ tal que $L(i, j)$ é o peso de um emparelhamento planar máximo de $X[1 . . i]$ e $Y[1 . . j]$. Considerando $X[1 . .0]$ e $Y[1 . .0]$ como sequências vazias, é claro que vale que $L(0, j)=0$ e $L(i, 0)=0$ para todo $i=0, \ldots, m$ e $j=0, \ldots, n$.

Além disso, vale a seguinte recorrência para $i \geq 1$ e $j \geq 1$ : 


$$
L(i, j)= \begin{cases}\max \{L(i, j-1), L(i-1, j), L(i-1, j-1)+w(i, j)\} & \text { se } x_{i}=y_{j}, \\ \max \{L(i, j-1), L(i-1, j)\} & \text { se } x_{i} \neq y_{j} .\end{cases}
$$

De fato, se $(i, j)$ é um casamento $\left(x_{i}=y_{j}\right)$, então uma solução ótima de $X[1 . . i]$ e $Y[1 . . j]$ pode ou não conter $(i, j)$. Observe que, neste caso, uma solução sem $(i, j)$ pode ser melhor do que uma com $(i, j)$, pois os pesos dos casamentos não necessariamente são iguais. Se ela contém $(i, j)$, então podemos obter uma solução ótima adicionando $(i, j)$ a uma solução ótima de $X[1 . . i-1]$ e $Y[1 . . j-1]$. Caso contrário, uma solução ótima seria a melhor entre soluções ótimas de $X[1 . . i-1]$ e $Y[1 . . j]$, e $X[1 . . i]$ e $Y[1 . . j-1]$. Se $(i, j)$ não é um casamento, caímos apenas no segundo caso.

O algoritmo seguinte calcula o valor de $L(m, n)$ preenchendo uma matriz de programação $L$ através da recorrência acima, em ordem crescente de linha e de coluna. Denotamos de $L[i, j]$ o valor na linha $i$ e coluna $j$ da matriz $L$. Recuperar um emparelhamento planar máximo pode ser feito de maneira análoga à maneira do algoritmo para o problema do LCS: armazenamos em uma matriz $B$ as escolhas dos subproblemas para cada posição $(i, j)$ de $L$ (as possibilidades são $(i, j-1)$, $(i-1, j)$ e $(i-1, j-1))$ e, após construir $L$, percorremos os subproblemas a partir de $B[m, n]$ para obter os casamentos do emparelhamento planar em ordem inversa de precedência, dado que escolhemos um casamento $(i, j)$ para a solução se e só se o subproblema escolhido na posição $(i, j)$ é o de $(i-1, j-1)$ (veja Seção 7.2 para mais detalhes; omitimos esta parte no pseudocódigo seguinte).

Exemplo 5.2.1. A figura à direita abaixo é um exemplo de uma matriz de programação dinâmica com os valores de $L$, usando os pesos dados pela figura à esquerda (os círculos sombreados indicam casamentos).

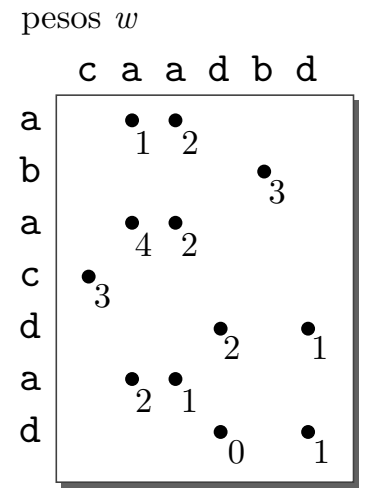

\begin{tabular}{|c|c|c|c|c|c|}
\hline & & $\mathrm{a}$ & & & \\
\hline & 0 & 00 & 0 & 0 & 0 \\
\hline & \multirow{7}{*}{0} & 01 & 2 & 2 & \\
\hline & & $\begin{array}{ll}0 & 1\end{array}$ & 2 & 2 & 5 \\
\hline & & 04 & 4 & 4 & \\
\hline & & 34 & $=4$ & 4 & 5 \\
\hline & & 34 & 4 & & \\
\hline & & 35 & & 6 & \\
\hline & & 35 & 6 & 6 & \\
\hline
\end{tabular}




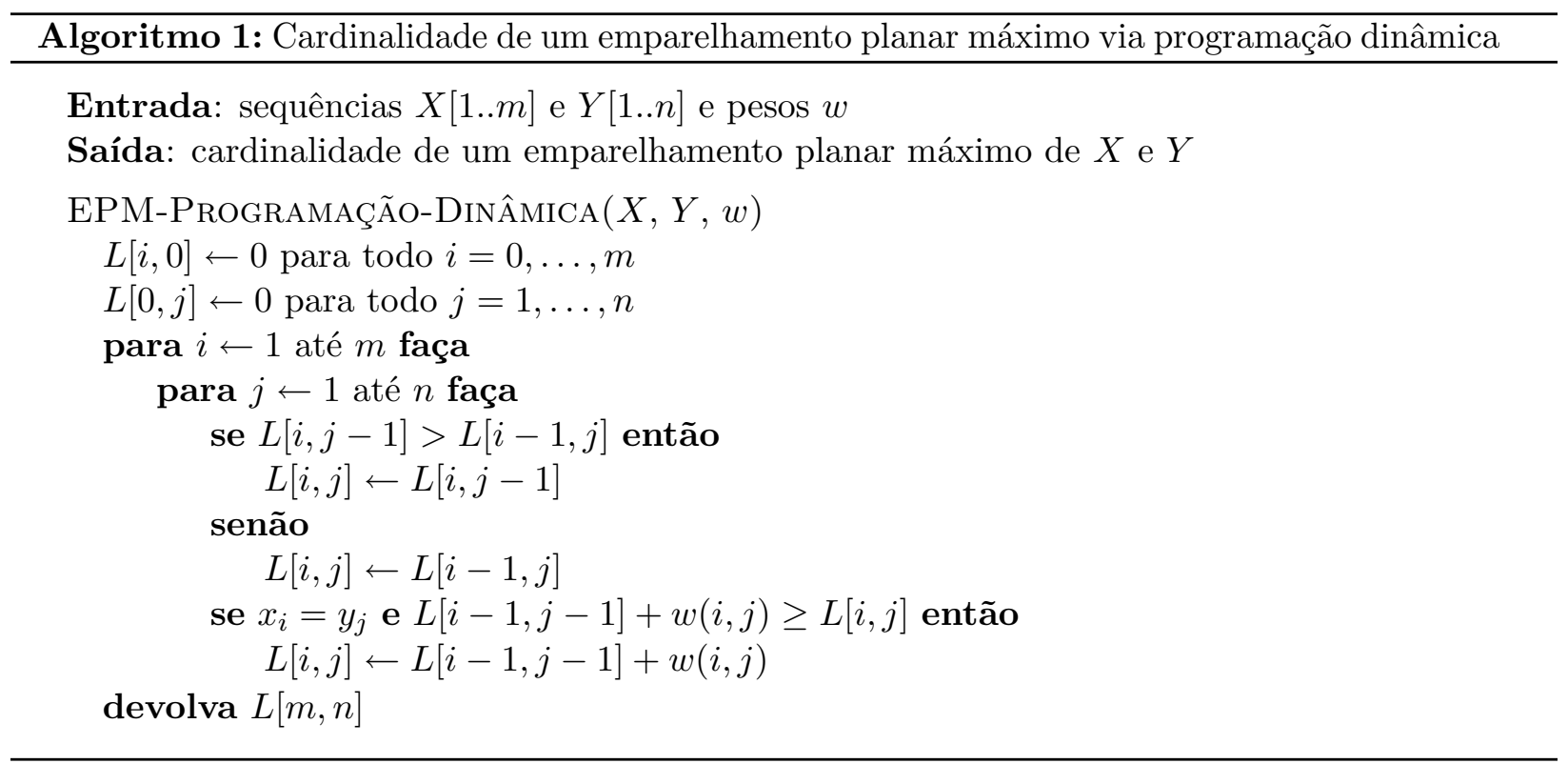

As complexidades de tempo e espaço do algoritmo são $\Theta(m n)$.

Agora, voltamos nosso interesse a encontrar um emparelhamento planar estendido máximo: um conjunto de casamentos maximal de peso máximo que, dois a dois, ou não se cruzam, ou estão associados ao mesmo símbolo. Para isso, estenderemos o algoritmo anterior.

Sejam $\left(i^{\prime}, j^{\prime}\right)$ e $(i, j)$ casamentos de símbolo $\sigma$ tais que $i^{\prime} \leq i$ e $j^{\prime} \leq j$. Considere o conjunto $B$ de todos os casamentos do mesmo símbolo $\sigma$ entre $\left(i^{\prime}, j^{\prime}\right)$ e $(i, j)$, inclusive ambos. Isto é, $B:=\left\{(k, l) \in \mathcal{C}(\sigma) \mid i^{\prime} \leq k \leq i, j^{\prime} \leq l \leq j, \sigma\right.$ é o símbolo de $\left.(i, j)\right\}$, onde $\mathcal{C}(\sigma)$ é o conjunto de casamentos de símbolo $\sigma$. Denominamos tal conjunto de bloco que inicia em $\left(i^{\prime}, j^{\prime}\right)$ e termina em $(i, j)$. Dizemos que dois blocos se cruzam se, dentre os casamentos desses blocos, existem dois casamentos de blocos diferentes que se cruzam.
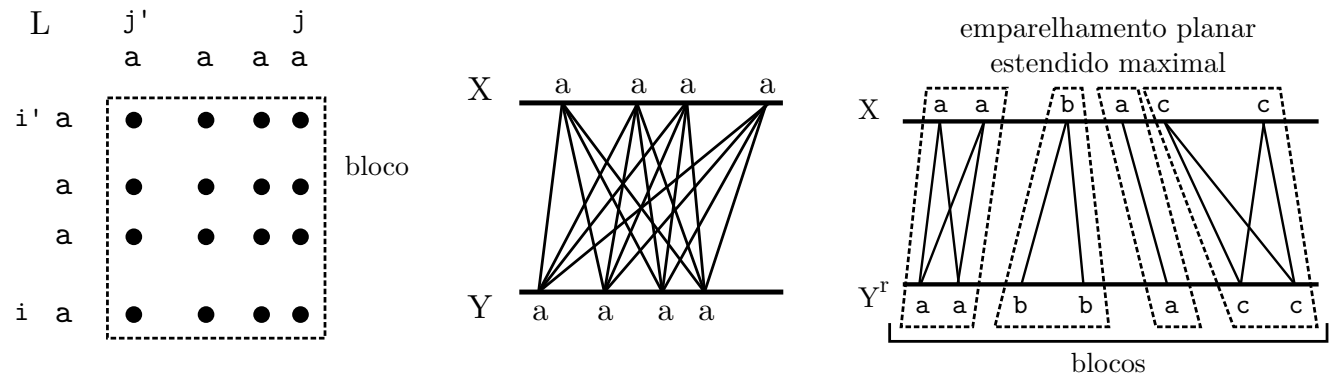

Basta aplicar as definições para perceber que os casamentos de um conjunto de blocos que não se cruzam dois a dois formam um emparelhamento planar estendido. Observe que a recíproca não necessariamente vale, pois podemos ter casamentos de um emparelhamento planar estendido que formam apenas uma parte incompleta de um bloco. No entanto, ela vale ao considerarmos maximalidade como na proposição seguinte, cuja prova é menos direta apesar de ser intuitivamente clara.

Proposição 5.2.2. Seja $C$ um conjunto de casamentos. Então $C$ é um emparelhamento planar estendido maximal se e só se $C$ é um conjunto maximal de casamentos que formam blocos que 
não se cruzam dois a dois (isto é, não existe um conjunto de casamentos com essas condições que propriamente contém $C$ ).

Prova. $(\Leftarrow)$ Seja $C$ um emparelhamento planar estendido maximal. Provaremos que os casamentos de $C$ formam blocos que não se cruzam dois a dois. Ordene os índices dos casamentos de $C$ em $X$ tais que $i_{1}<i_{2}<\ldots<i_{k}$ e os índices dos casamentos de $C$ em $Y$ tal que $j_{1}<j_{2}<\ldots<j_{l}$. Como todo par de casamento que se cruza são do mesmo símbolo, $x_{i_{1}}$ é igual a $y_{j_{1}}$. Sejam $s$ e $t$ os maiores $\hat{s}$ e $\hat{t}$ respectivamente tal que todo $x_{i}$ para $i=i_{1}, i_{2}, \ldots, i_{\hat{s}}$ e todo $y_{j}$ para $j=j_{1}, j_{2}, \ldots, j_{\hat{t}}$ são todos do mesmo símbolo. Como $C$ é maximal, todos os casamentos do bloco $B$ que inicia em $\left(i_{1}, j_{1}\right)$ e termina em $\left(i_{s}, j_{t}\right)$ estão em $C$. Além disso, não existe nenhum casamento $\left(i_{k}, j_{l}\right)$ com $k \leq s$ e $l>t$, ou $k>s$ e $l \leq t$, pois tal casamento cruzaria com um casamento de outro símbolo. Logo, $C \backslash B$ é um emparelhamento planar estendido maximal para $X[s+1 . . m]$ e $Y[t+1 . . n]$ (que pode ser vazio). Portanto, $C$ pode ser particionado em blocos que não se cruzam dois a dois. Ele é maximal entre blocos que não se cruzam dois a dois pois é maximal entre emparelhamentos planares estendidos.

$(\Rightarrow)$ Seja $C$ um conjunto maximal de casamentos que formam blocos que não se cruzam dois a dois. Então, para cada par de casamentos de $C$, ou eles não se cruzam, ou eles estão no mesmo bloco, ou seja, eles são do mesmo símbolo. Logo, $C$ é um emparelhamento planar estendido. Além disso, provamos que todo emparelhamento planar estendido maximal formam blocos que não se cruzam dois a dois. Então a maximalidade entre blocos que não se cruzam dois a dois implica que ele também é maximal entre emparelhamentos planares estendidos.

A proposição implica que é suficiente considerar apenas tais conjuntos para encontrar um emparelhamento planar estendido máximo. Assim, adaptaremos a recorrência anterior para considerar blocos.

Considere uma função $L_{e}$ tal que $L_{e}(i, j)$ é o peso de um emparelhamento planar estendido máximo de $X[1 . . i]$ e $Y[1 . . j]$. Seja $w_{b}\left(\left(i^{\prime}, j^{\prime}\right),(i, j)\right)$ o peso do bloco que inicia em $\left(i^{\prime}, j^{\prime}\right)$ e termina em $(i, j)$. Seja $\mathcal{C}_{b}(i, j)$ o conjunto dos possíveis casamentos que iniciam um bloco que termina em $(i, j)$, isto é, os casamentos $\left(i^{\prime}, j^{\prime}\right)$ com símbolo igual ao de $(i, j)$ e tais que $i^{\prime} \leq i$ e $j^{\prime} \leq j$. Seja $B_{\text {max }}(i, j)$ o peso de um emparelhamento planar estendido máximo de $X[1 . . i]$ e $Y[1 . . j]$ que contém o casamento $(i, j)$. Então vale a seguinte recorrência para $i \geq 1$ e $j \geq 1$ :

$$
\begin{gathered}
B_{\text {max }}(i, j)=\max _{\left(i^{\prime}, j^{\prime}\right) \in \mathcal{C}_{b}(i, j)}\left\{L_{e}\left(i^{\prime}-1, j^{\prime}-1\right)+w_{b}\left(\left(i^{\prime}, j^{\prime}\right),(i, j)\right)\right\}, \mathrm{e} \\
L_{e}(i, j)= \begin{cases}\max \left\{L_{e}(i, j-1), L_{e}(i-1, j), B_{\max }(i, j)\right\} & \text { se } x_{i}=y_{j}, \\
\max \left\{L_{e}(i, j-1), L_{e}(i-1, j)\right\} & \text { se } x_{i} \neq y_{j} .\end{cases}
\end{gathered}
$$

A recorrência acima descreve essencialmente um conjunto de blocos que não se cruzam dois a dois, por motivo análogo ao da recorrência $L$. O valor $B_{\max }(i, j)$ pode ser calculado através de força bruta, percorrendo todos os casamentos de $\mathcal{C}_{b}(i, j)$. O algoritmo da página seguinte computa uma matriz de programação dinâmica $L_{e}$ que calcula os valores de $L_{e}(i, j)$ para todo $i=1, \ldots, m$ e $j=1, \ldots, n$, armazenando os casamentos usados pela solução ótima de forma análoga à anterior.

Uma forma de garantir a maximalidade, lembrando que podem existir casamentos de peso zero, é escolher sempre a solução com maior número de casamentos. Para isso, basta manter uma matriz $m \times n$ que armazena na posição $(i, j)$ o número de casamentos da melhor solução para $X[1 . . i] \mathrm{e}$ $Y[1 . . j]$, e escolher as soluções com maior número de casamentos como critério secundário (após peso). Omitimos esta parte no pseudocódigo seguinte. 


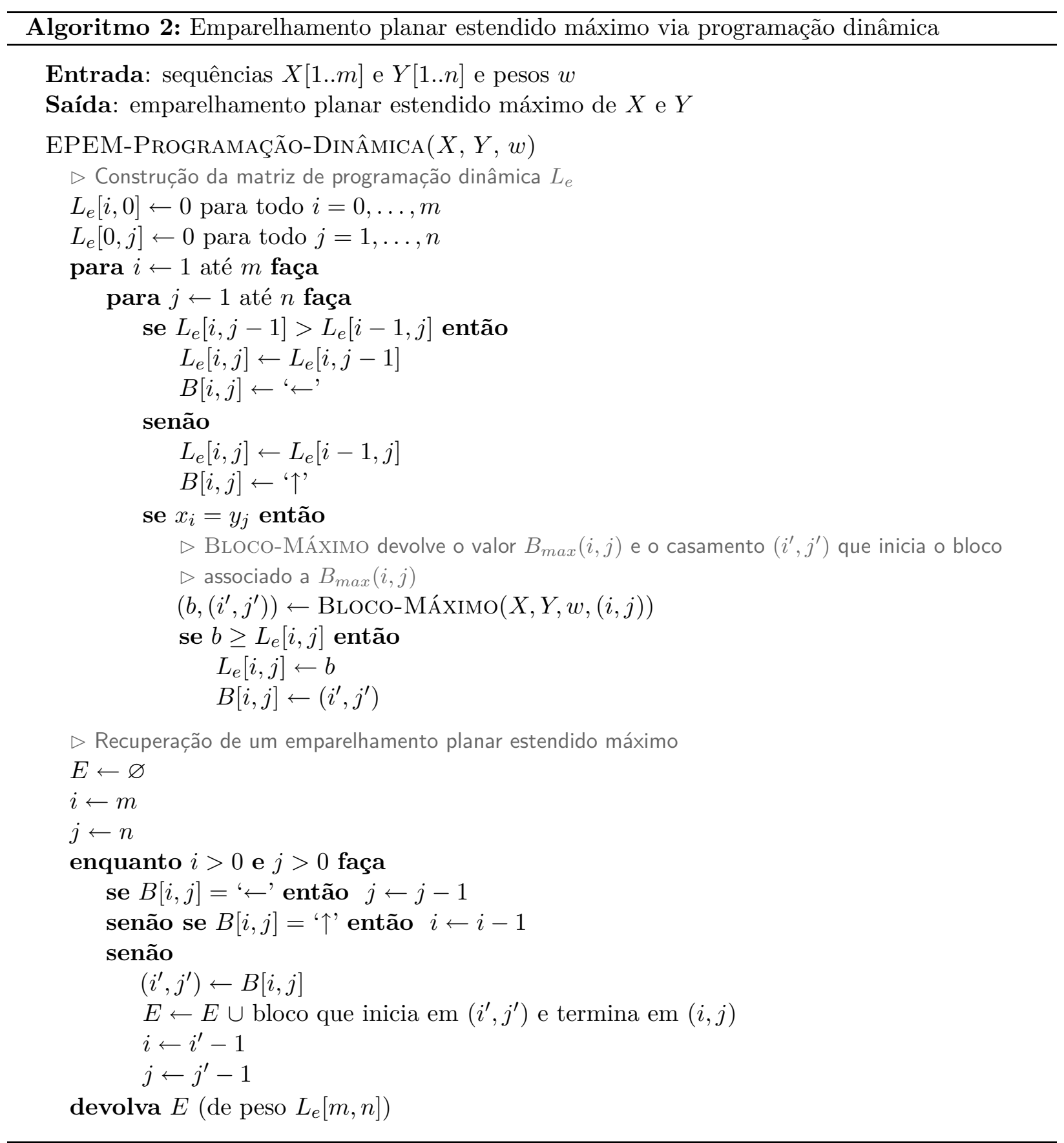

O algoritmo acima tem complexidade de tempo $O\left(m n|\mathcal{C}|^{2}\right)$ se os casamentos percorridos em Bloco-MÁximo forem apenas os necessários. A complexidade de espaço é $\Theta(m n)$. Detalharemos uma maneira um pouco mais esperta de computar Bloco-MÁximo (mas ainda através de força bruta) na próxima subseção. 


\subsubsection{Algoritmo de separação baseado em limiares}

O algoritmo de Hunt e Szymanski, no qual este algoritmo de separação é baseado, está descrito na Seção 7.4 .

Como na subseção anterior, considere primeiro o problema de, dado um peso $w(i, j)$ para cada casamento, encontrar um emparelhamento planar máximo, isto é, um conjunto de casamentos de peso máximo que não se cruzam dois a dois. Seja $L(i, j)$ o peso de um emparelhamento planar máximo de $X[1 . . i]$ e $Y[1 . . j]$. Da mesma forma que na subseção anterior, $L(0, j)=0$ e $L(i, 0)=0$ para todo $i=0, \ldots, m$ e $j=0, \ldots, n$, e, para $i \geq 1$ e $j \geq 1$,

$$
L(i, j)= \begin{cases}\max \{L(i, j-1), L(i-1, j), L(i-1, j-1)+w(i, j)\} & \text { se } x_{i}=y_{j}, \\ \max \{L(i, j-1), L(i-1, j)\} & \text { se } x_{i} \neq y_{j}\end{cases}
$$

Usando a mesma ideia do algoritmo de Hunt e Szymanski, defina um limiar (threshold) como uma tripla $(i, j, w)$ (linha $i$, coluna $j$ e peso $w$ ) tal que $j$ é o menor $\hat{\jmath}$ para o qual vale $L(i, \hat{\jmath})=w$. Equivalentemente, um limiar é uma tripla $(i, j, w)$ tal que $L(i, j)=w$ e $L(i, j-1)<w$ se $j>0$. Considere limiares artificiais $(i, 0,0)$ para todo $i=0, \ldots, m$. O algoritmo consiste em calcular os limiares linha por linha e em ordem crescente de coluna.

O lema seguinte é análogo ao Lema 7.4.2 da Seção 7.4, do algoritmo de Hunt e Szymanski, mas levando pesos em consideração.

Lema 5.2.3. Defina um candidato a limiar como uma tripla $(i, j, w)$ tal que

1. $(i, j)$ é um casamento e o limiar $\left(i-1, j^{\prime}, w^{\prime}\right)$ existe, com $j^{\prime}<j, j^{\prime}$ máximo, e $w=w^{\prime}+w(i, j)$; ou

2. o limiar $(i-1, j, w)$ existe.

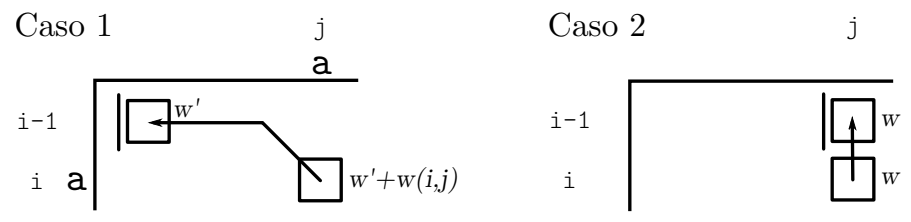

Para $j>0$, a tripla $(i, j, w)$ é um limiar se e só se $(i, j, w)$ é um candidato a limiar e $w>w^{\prime}$ para todo candidato a limiar $\left(i, j^{\prime}, w^{\prime}\right)$ diferente de $(i, j, w)$ com $j^{\prime} \leq j$.

Prova. Esta prova tem como base a recorrência da função $L$ acima.

$(\Leftarrow)$ Provaremos primeiro que se $(i, j, w)$ é um limiar, então $(i, j, w)$ é um candidato a limiar. Seja $(i, j, w)$ um limiar com $j>0$. Queremos provar que vale pelo menos um dos dois itens da definição de candidato a limiar. Pela definição de limiar, $L(i, j)=w$ e $L(i, j-1)<w$, supondo $j>0$. Ou seja, $L(i, j)>L(i, j-1)$. Então podemos eliminar o termo $L(i, j-1)$ da recorrência de $L$, isto é, $L(i, j)=\max \{L(i-1, j), L(i-1, j-1)+w(i, j)$ se $(i, j)$ é casamento $\}$. Dividiremos esta parte da prova em dois casos.

Suponha que $(i, j)$ não é um casamento ou $L(i-1, j) \geq L(i-1, j-1)+w(i, j)$. Então, pela recorrência, $L(i, j)=L(i-1, j)=w$ e, para $j>0, L(i-1, j-1) \leq L(i, j-1)<w$. Portanto, o limiar $(i-1, j, w)$ existe e o item 2 é satisfeito. 
Agora, suponha que $(i, j)$ é um casamento e $L(i-1, j-1)+w(i, j)>L(i-1, j)$, que é o caso restante. Seja $w^{\prime}=L(i-1, j-1)$ e escolha o menor $j^{\prime}$ tal que $L\left(i-1, j^{\prime}\right)=L(i-1, j-1)=w^{\prime}$. Isto é, existe um $j^{\prime}<j$ tal que $L\left(i-1, j^{\prime}\right)=w^{\prime}$ e $L\left(i-1, j^{\prime}-1\right)<w^{\prime}$ se $j^{\prime}>0$. Então $\left(i-1, j^{\prime}, w^{\prime}\right)$ é um limiar. Pela suposição e pela recorrência, $L(i, j)=L(i-1, j-1)+w(i, j)$, isto é, $w=w^{\prime}+w(i, j)$. Observe também que $j^{\prime}$ é máximo entre as colunas dos limiares da linha $i-1$ menores que $j$, pois, para todo $j^{\prime \prime}$ tal que $j^{\prime}<j^{\prime \prime}<j, L\left(i-1, j^{\prime \prime}-1\right)=w^{\prime}=L\left(i-1, j^{\prime \prime}\right)$ e, portanto, não existe limiar com coluna $j^{\prime \prime}$. Logo, o item 1 é satisfeito.

Assim, se $(i, j, w)$ é um limiar, pelo menos um dos itens da definição é satisfeito e, portanto, $(i, j, w)$ é um candidato a limiar.

$(\Rightarrow)$ Provaremos agora que se $(i, j, w)$ é um candidato a limiar e $w>w^{\prime}$ para todo candidato a limiar $\left(i, j^{\prime}, w^{\prime}\right)$ diferente de $(i, j, w)$ com $j^{\prime} \leq j$, então $(i, j, w)$ é um limiar. O fato que $L(i, j-1)<w$ se $j>0$ vem direto da segunda suposição. Resta provar que $L(i, j)=w$.

Se $(i, j, w)$ surge do item 1 , então $w=L\left(i-1, j^{\prime}\right)+w(i, j)$, com $j^{\prime}<j$ e $j^{\prime}$ máximo. Como não existe limiar entre $j^{\prime}$ e $j$, vale que $L\left(i-1, j^{\prime}\right)=L(i-1, j-1)$ e, portanto, $w=L(i-1, j-1)+w(i, j)$. Agora, se $(i, j, w)$ surge do item 2 , então $w=L(i-1, j)$. Essas duas afirmações e o fato que $w$ é máximo resultam na igualdade $w=\max \{L(i-1, j), L(i-1, j-1)+w(i, j)$ se $(i, j)$ é casamento $\}$. Como $w>L(i, j-1)$, podemos dizer que $w=\max \{L(i-1, j), L(i, j-1), L(i-1, j-1)+w(i, j)$ se $(i, j)$ é casamento\}, que é equivalente a $L(i, j)$.

Portanto, $(i, j, w)$ é um limiar.

O algoritmo encontra todos os limiares em ordem crescente de linha e de coluna, usando os limiares da linha $i-1$ para construir os limiares da linha $i$. Para isso, ele usa as regras a seguir, que podem ser extraídas diretamente do lema anterior.

Suponha que já foram computados todos os limiares da linha $i-1$ e os limiares da linha $i$ de coluna menor que $j$, e queremos verificar se existe um limiar de linha $i$ e coluna $j$.

1. Se $(i, j)$ é um casamento, então ele procura, dentre os limiares da linha $i-1$, o limiar de maior coluna menor que $j$ (sua existência é garantida pelos limiares artificiais). Se o peso desse limiar é $w^{\prime}$, o peso do novo limiar deve ser $w=w^{\prime}+w(i, j)$. Se $w$ é maior que o peso do último limiar computado da linha $i$ (que é o maior peso dentre os limiares de coluna menor que $j$ ) e também se $w$ for maior que o peso do limiar de linha $i-1$ e coluna $j$ se existir, então o limiar $(i, j, w)$ deve ser adicionado à lista de limiares da linha $i$.

2. Se $(i-1, j, w)$ é um limiar e se $w$ é maior que o último peso encontrado na linha $i$, então o limiar $(i, j, w)$ deve ser adicionado à lista de limiares da linha $i$.

As regras acima podem ser aplicadas iterando na lista de casamentos de linha $i$ e na lista de limiares de linha $i-1$ simultaneamente e em ordem crescente de $j$, realizando o passo 1 e o passo 2 conforme encontramos casamentos $(i, j)$ e limiares $(i-1, j, w)$ respectivamente.

Em termos de estrutura de dados, para percorrer os casamentos, o algoritmo usa um vetor de listas $\operatorname{Pos} Y[1 . .|\Sigma|]$ tal que Pos $Y[\sigma]$ é uma lista ligada que armazena em ordem crescente os índices em que o símbolo $\sigma$ ocorre em $Y$ (similar ao do algoritmo de Hunt e Szymanski, mas em ordem crescente). Assim, dada uma linha $i$, podemos obter os casamentos $(i, j)$ percorrendo Pos $Y\left[x_{i}\right]$. Os limiares também são armazenados em listas ligadas, uma lista para cada linha. 


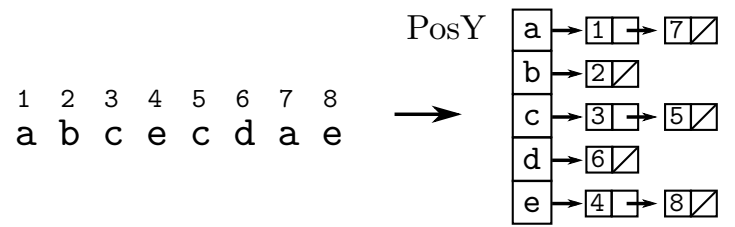

Para recuperar os casamentos da solução, cada limiar deve guardar uma referência para o limiar da linha anterior do qual ele é derivado conforme o Lema 5.2.3. Isso é uma versão análoga da matriz de backtracking do algoritmo de programação dinâmica da subseção anterior. Assim, para recuperar os casamentos, basta seguir as referências desde o último limiar até um limiar artificial, guardando os casamentos dos limiares que apontam para um limiar de coluna menor que a sua.

A estrutura $\operatorname{Pos} Y$ consome tempo para construção e espaço $\Theta(n)$. Seja $l$ o número de candidatos a limiar $(l=\Omega(|\mathcal{C}|)$ e $l=O(m n))$. Na busca de limiares, percorremos todos os candidatos a limiar e armazenamos todos os limiares, consumindo tempo e espaço $O(l)$, além de $\Omega(|\mathcal{C}|$ ) (o número de limiares também é $\Omega(|\mathcal{C}|)$ ). A recuperação de um emparelhamento planar máximo consome tempo $O(m)$. Assim, as complexidades de tempo e espaço do algoritmo são $O(l)$, isto é, $O(m n)$, mas, na prática, este algoritmo pode ser melhor que o baseado em programação dinâmica pois não precisamos percorrer todas as $m n$ posições da matriz de programação dinâmica. Além disso, o consumo de tempo e espaço do algoritmo também é $\Omega(|\mathcal{C}|)$.

Exemplo 5.2.4. A figura abaixo é o mesmo exemplo dado na subseção anterior (matriz de programação dinâmica com valores de $L$ usando os pesos $w$ da figura à esquerda), mas com os limiares à direita. As setas de um limiar para algum limiar de linha anterior são as referências para a recuperação de um emparelhamento planar máximo. Os círculos sombreados indicam casamentos.

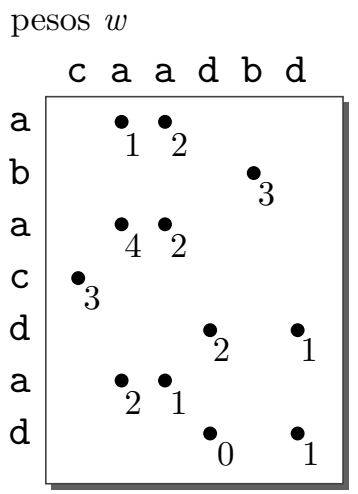

\begin{tabular}{|c|c|c|c|c|c|}
\hline & $c$ & $a$ & $\dot{c}$ & & \\
\hline & 00 & $\longdiv { 0 }$ & 0 & 0 & 0 \\
\hline & 00 & $\sqrt{1}$ & 12 & 2 & 2 \\
\hline & 00 & 1 & 12 & 21 & \\
\hline & 00 & 4 & 44 & 4 & \\
\hline & $0 \longdiv { 3 }$ & 3 & 44 & 4 & \\
\hline & 03 & 4 & 44 & 10 & 6 \\
\hline & 013 & 5 & 56 & 6 & \\
\hline & 0 & & $c$ & & $6 \Gamma$ \\
\hline
\end{tabular}

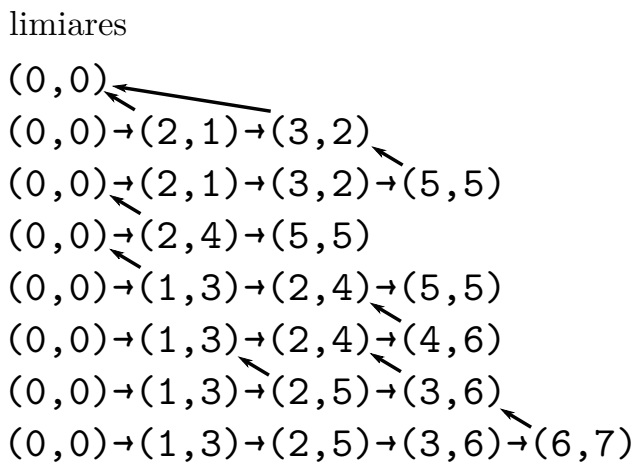




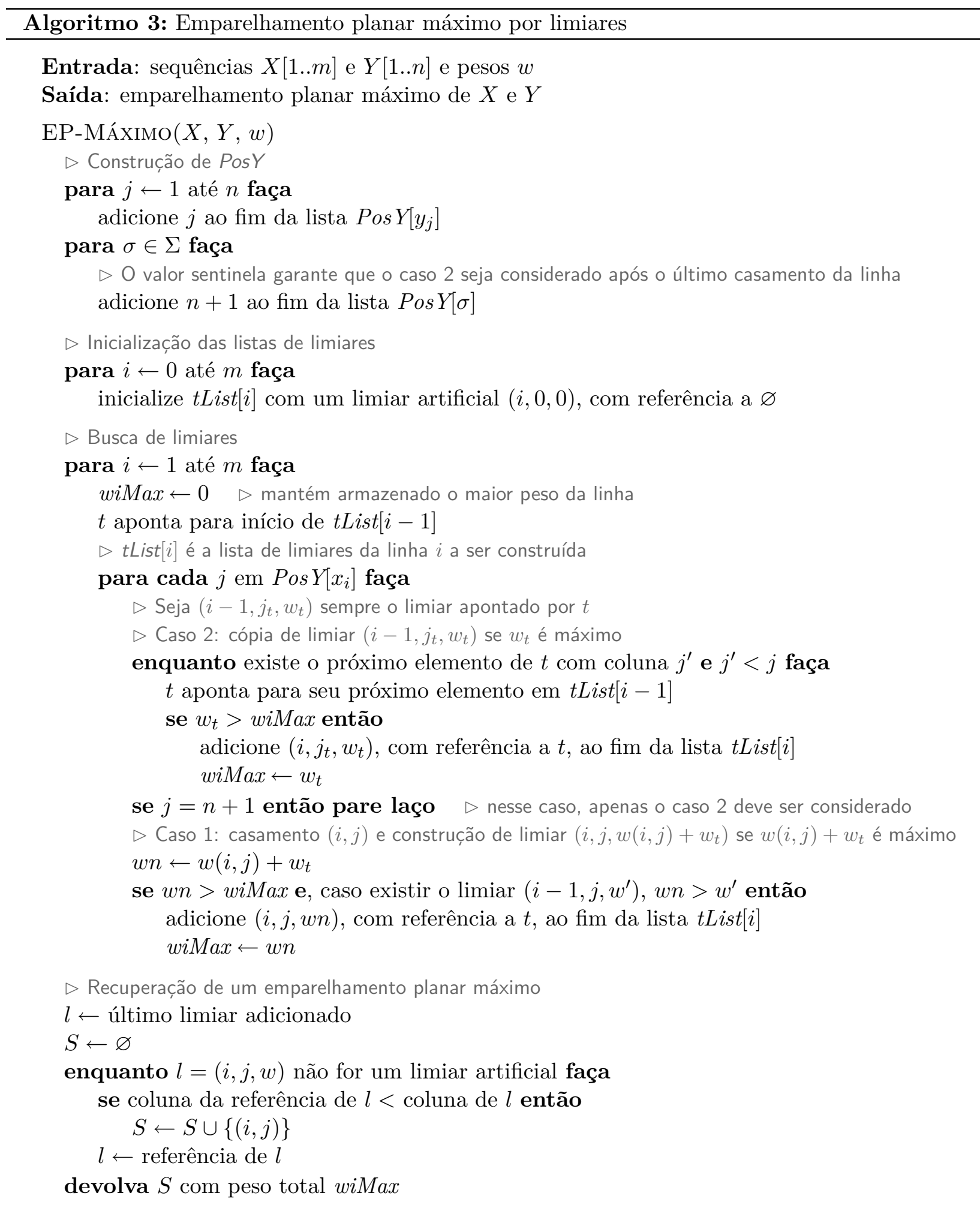


Agora, estendemos o algoritmo para encontrar um emparelhamento planar estendido máximo: um conjunto de casamentos maximal de peso máximo que, dois a dois, ou não se cruzam, ou estão associados ao mesmo símbolo. Lembremos, da subseção anterior, que se $L_{e}(i, j)$ é o peso de um emparelhamento planar estendido máximo de $X[1 . . i]$ e $Y[1 . . j], w_{b}\left(\left(i^{\prime}, j^{\prime}\right),(i, j)\right)$ é o peso do bloco que inicia em $\left(i^{\prime}, j^{\prime}\right)$ e termina em $(i, j)$, e $\mathcal{C}_{b}(i, j)$ é o conjunto dos possíveis casamentos que iniciam um bloco que termina em $(i, j)$, então vale a seguinte recursão:

$$
\begin{gathered}
B_{\max }(i, j)=\max _{\left(i^{\prime}, j^{\prime}\right) \in \mathcal{C}_{b}(i, j)}\left\{L_{e}\left(i^{\prime}-1, j^{\prime}-1\right)+w_{b}\left(\left(i^{\prime}, j^{\prime}\right),(i, j)\right)\right\} \\
L_{e}(i, j)= \begin{cases}\max \left\{L_{e}(i, j-1), L_{e}(i-1, j), B_{\max }(i, j)\right\} & \text { se } x_{i}=y_{j}, \\
\max \left\{L_{e}(i, j-1), L_{e}(i-1, j)\right\} & \text { se } x_{i} \neq y_{j} .\end{cases}
\end{gathered}
$$

Essencialmente, para computar os valores de $L_{e}$ usando limiares, basta alterar o caso 1 para considerar o melhor bloco possível. Porém, vale prestar atenção a alguns detalhes de implementação.

- A função que computa $B_{\max }(i, j)$ para algum casamento $(i, j)$ deve conhecer, para qualquer casamento $\left(i^{\prime}, j^{\prime}\right)$ que inicia um bloco que termina em $(i, j), L_{e}\left(i^{\prime}-1, j^{\prime}-1\right)$, que é o peso $w^{\prime}$ do limiar $\left(i^{\prime}-1, j^{\prime \prime}, w^{\prime}\right)$, onde $j^{\prime \prime}<j^{\prime}$ e $j^{\prime \prime}$ é máximo. Esse limiar é o limiar do caso 1 , que podemos obter no decorrer do algoritmo da mesma maneira que no algoritmo anterior. É conveniente armazenar as referências aos limiares na própria estrutura Pos $Y$, que, para isso, deve ser indexada por linha em vez de símbolo.

- De forma análoga ao caso anterior, a recuperação dos casamentos do emparelhamento planar estendido máximo pode ser permitida guardando uma referência em cada limiar ao limiar do qual ele é derivado, e também o primeiro casamento do bloco se for o caso, e, para recuperá-los, seguimos essas referências a partir do último limiar.

- Também gostaríamos que, como critério secundário, o número de casamentos seja máximo. Armazenamos, em cada limiar, o número de casamentos da solução associada a ele. No caso 2, apenas copiamos o número de casamentos do limiar da linha anterior, pois não envolve casamentos. No caso 1, contamos o número de casamentos usados e somamos esse número ao valor obtido do limiar da linha anterior.

- Precisamos tomar um cuidado adicional com casamentos com peso 0 , que podem ser comuns ao tomar soluções viáveis de um programa linear como pesos. Devemos permitir que os casamentos de peso 0 também definam limiares quando for o caso, pois estamos considerando número de casamentos como critério secundário e eles podem ser o último casamento de um bloco. Para isso, ao decidir se um candidato a limiar é um limiar ou não (comparação do peso do candidato com wiMax), basta fazer a comparação com o critério secundário de número de casamentos (no caso 1, é suficiente comparar os pesos com igualdade, pois sabemos que qualquer limiar anterior de mesmo peso ao candidato a limiar já teria um número menor ou igual de casamentos).

O algoritmo Bloco-MÁximo seguinte computa um bloco de peso máximo de símbolo $x_{i}$ que termina no casamento $(i, j)$, usando Pos $Y$ indexada por linha, e uma estrutura análoga Pos $X$ indexada por símbolo. Ele realiza uma espécie de programação dinâmica simples para calcular os pesos dos blocos. O algoritmo após o seguinte, EPE-MÁximo, computa um emparelhamento planar estendido máximo, levando em consideração todas as observações acima. 


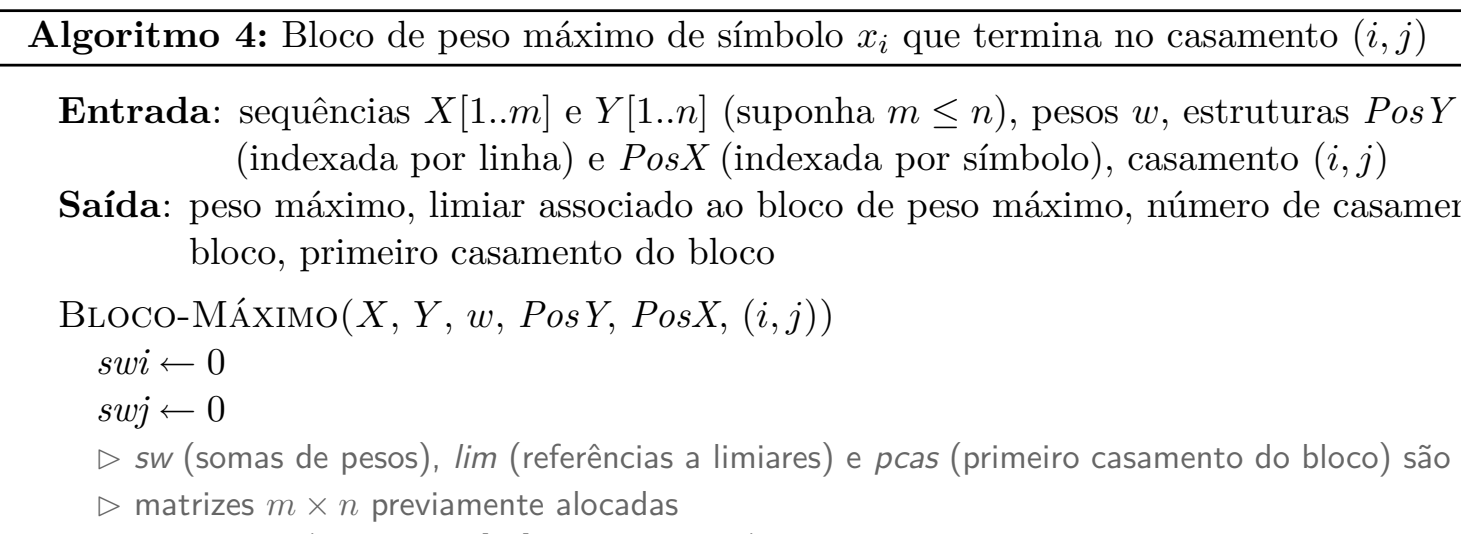

para cada $i^{\prime}$ em $\operatorname{Pos} X\left[x_{i}\right]$ enquanto $i^{\prime} \leq i$ faça

$s w i \leftarrow s w i+1$

para cada $j^{\prime}$ em $\operatorname{Pos} Y\left[i^{\prime}\right]$ enquanto $j^{\prime} \leq j$ faça

$\triangleright$ Seja $\operatorname{limiar}(i, j)$ a referência de limiar armazenada na célula de $\operatorname{Pos} Y[i]$ de valor $j$

$s w j \leftarrow s w j+1$

$s w[s w i, s w j] \leftarrow w\left(i^{\prime}, j^{\prime}\right)$

$\lim [\operatorname{swi}$, swj $] \leftarrow \operatorname{limiar}\left(i^{\prime}, j^{\prime}\right)$

$\operatorname{pcas}[s w i, s w j] \leftarrow\left(i^{\prime}, j^{\prime}\right)$

$\triangleright$ Calcula a soma de pesos

para $i^{\prime} \leftarrow s w i-1$ decrescente até 1 faça

$s w\left[i^{\prime}, s w j\right] \leftarrow s w\left[i^{\prime}, s w j\right]+s w\left[i^{\prime}+1, s w j\right]$

para $j^{\prime} \leftarrow s w j-1$ decrescente até 1 faça

$s w\left[s w i, j^{\prime}\right] \leftarrow s w\left[s w i, j^{\prime}\right]+s w\left[s w i, j^{\prime}+1\right]$

para $i^{\prime} \leftarrow s w i-1$ decrescente até 1 faça

para $j^{\prime} \leftarrow s w j-1$ decrescente até 1 faça

$$
s w\left[i^{\prime}, j^{\prime}\right] \leftarrow s w\left[i^{\prime}, j^{\prime}\right]+s w\left[i^{\prime}+1, j^{\prime}\right]+s w\left[i^{\prime}, j^{\prime}+1\right]-s w\left[i^{\prime}+1, j^{\prime}+1\right]
$$

$\triangleright$ Encontra a soma de pesos (com o peso do limiar) máxima

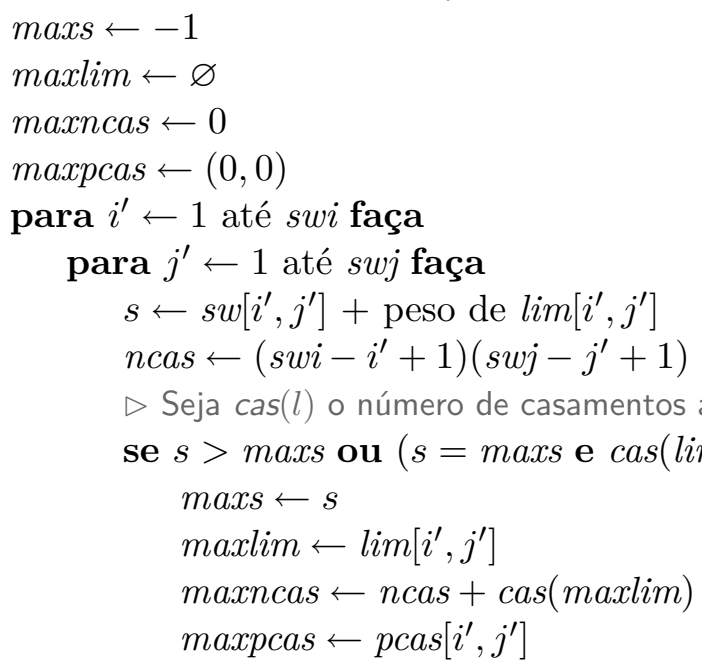

devolva maxs, maxlim, maxncas, maxpcas 


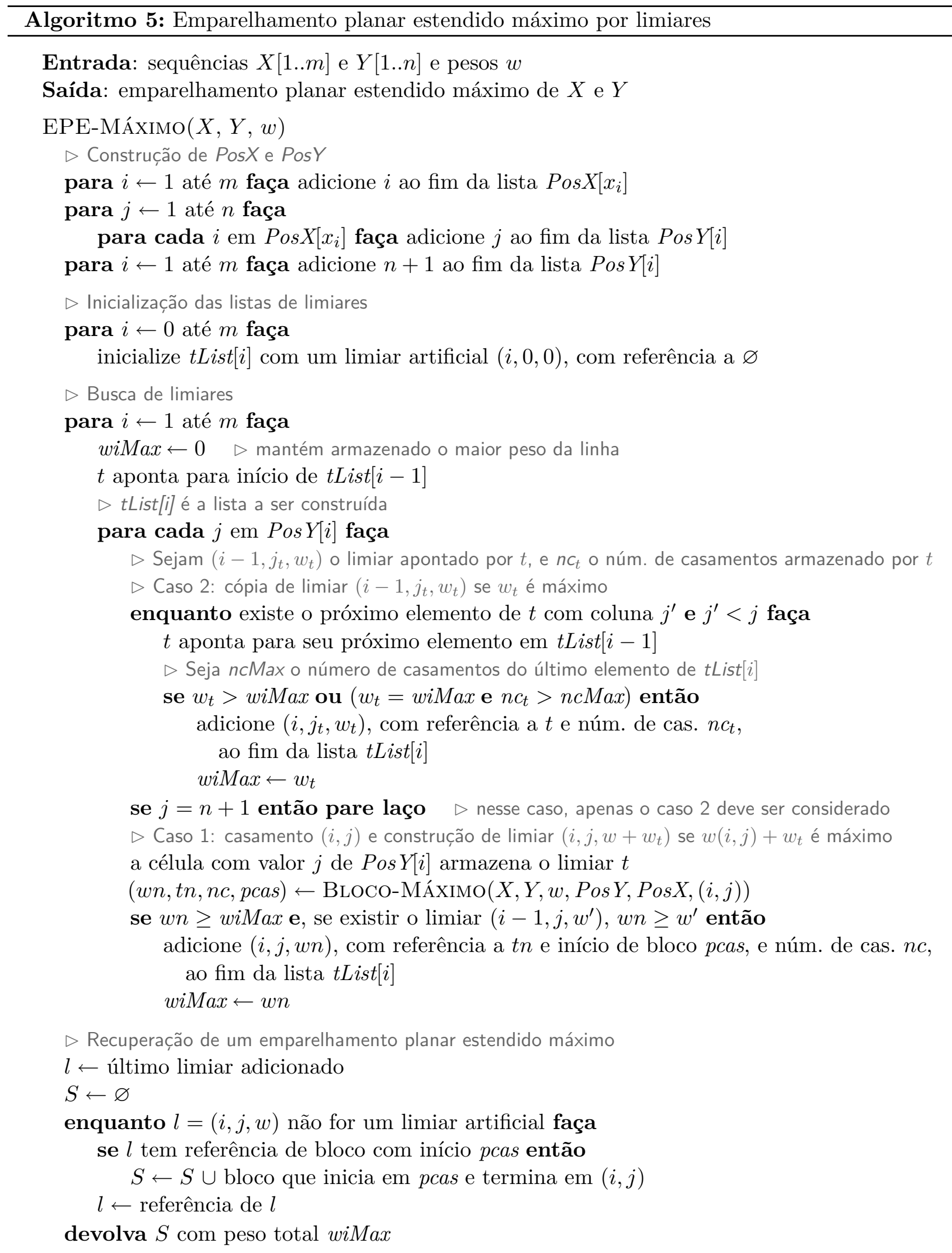


As complexidades de tempo e espaço de Bloco-Máximo são $\Theta(|\mathcal{C}(\sigma)|)$, onde $\sigma$ é o símbolo do casamento $(i, j)$ passado como parâmetro para a função e $\mathcal{C}(\sigma)$ é o conjunto de casamentos de símbolo $\sigma$.

Em EPE-MÁximo, consumimos tempo e espaço $\Theta(|\mathcal{C}|)$ para construir e armazenar Pos $X$ e Pos $Y$. Sejam $l$ o número de candidatos a limiar e $\sigma_{\max }$ um símbolo $\sigma$ que maximiza $|\mathcal{C}(\sigma)|$. A busca por limiares consome tempo $O\left(l\left|\mathcal{C}\left(\sigma_{\max }\right)\right|\right)$ e espaço $O(l)$. A recuperação de um emparelhamento planar estendido máximo consome tempo $O(|\mathcal{C}|)$. Como $l=O(m n)$, podemos dizer que o algoritmo consome tempo $O\left(m n\left|\mathcal{C}\left(\sigma_{\max }\right)\right|\right)$. Na prática, ele pode ser melhor que o algoritmo de programação dinâmica pois o número de candidatos a limiar pode ser significativamente menor que $m n$. O consumo de espaço é $O(l)=O(m n)$.

\subsubsection{Comparação entre os dois algoritmos de separação}

Nos dois gráficos seguintes, comparamos o consumo de tempo do algoritmo de separação de programação dinâmica com o do algoritmo baseado em Hunt e Szymanski, descritos nas duas subseções anteriores. No primeiro, consideramos os algoritmos isoladamente, gerando pesos para casamentos de forma aleatória. No segundo, consideramos o tempo gasto pela execução do algoritmo branch-and-cut para o problema do RFLCS utilizando os dois algoritmos de separação descritos. Em ambos os casos, o tamanho do alfabeto usado é metade do comprimento das sequências. Os gráficos seguintes deixam clara a maior eficiência do segundo algoritmo sobre o algoritmo de programação dinâmica.

Nota-se também nos gráficos seguintes que a diferença de tempo entre os algoritmos quando eles estão sob o contexto do algoritmo branch-and-cut não é tão pronunciada quanto no caso isolado. Uma possível explicação disso é que, em geral, o algoritmo gasta muito mais tempo resolvendo programas lineares do que encontrando cortes, como observamos em testes menos formais.

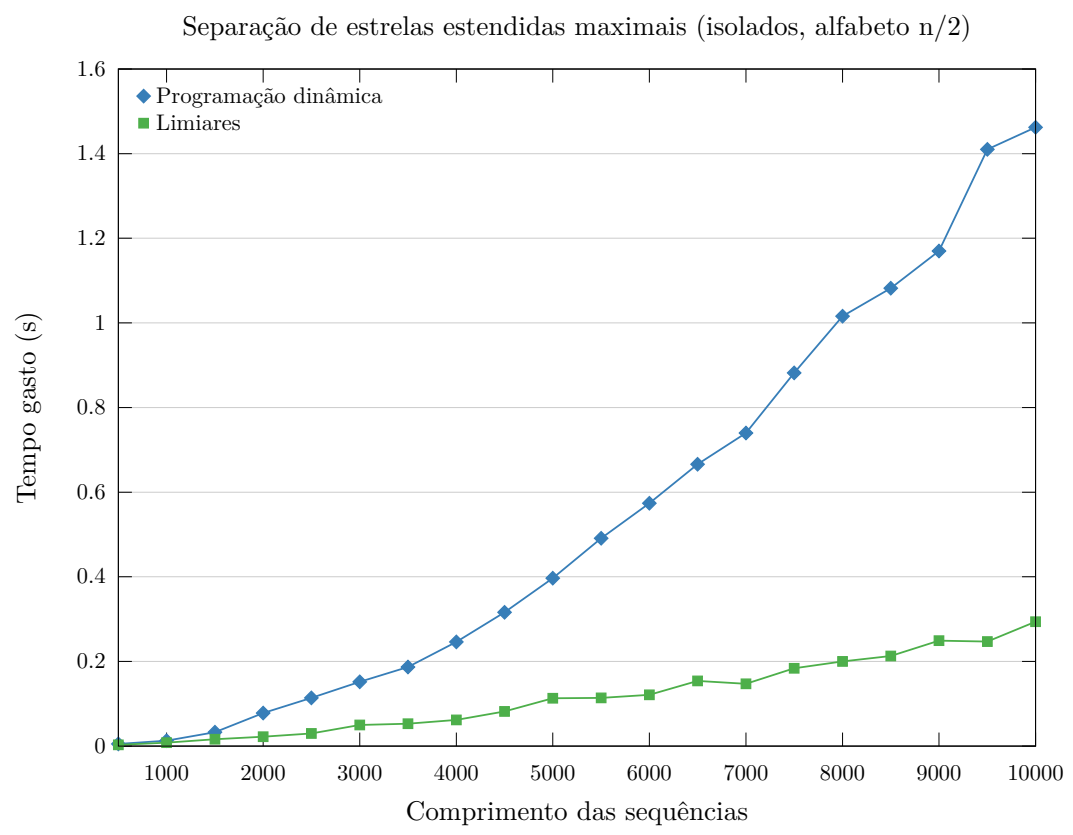


Separação de estrelas estendidas maximais (no branch-and-cut, alfabeto n/2)

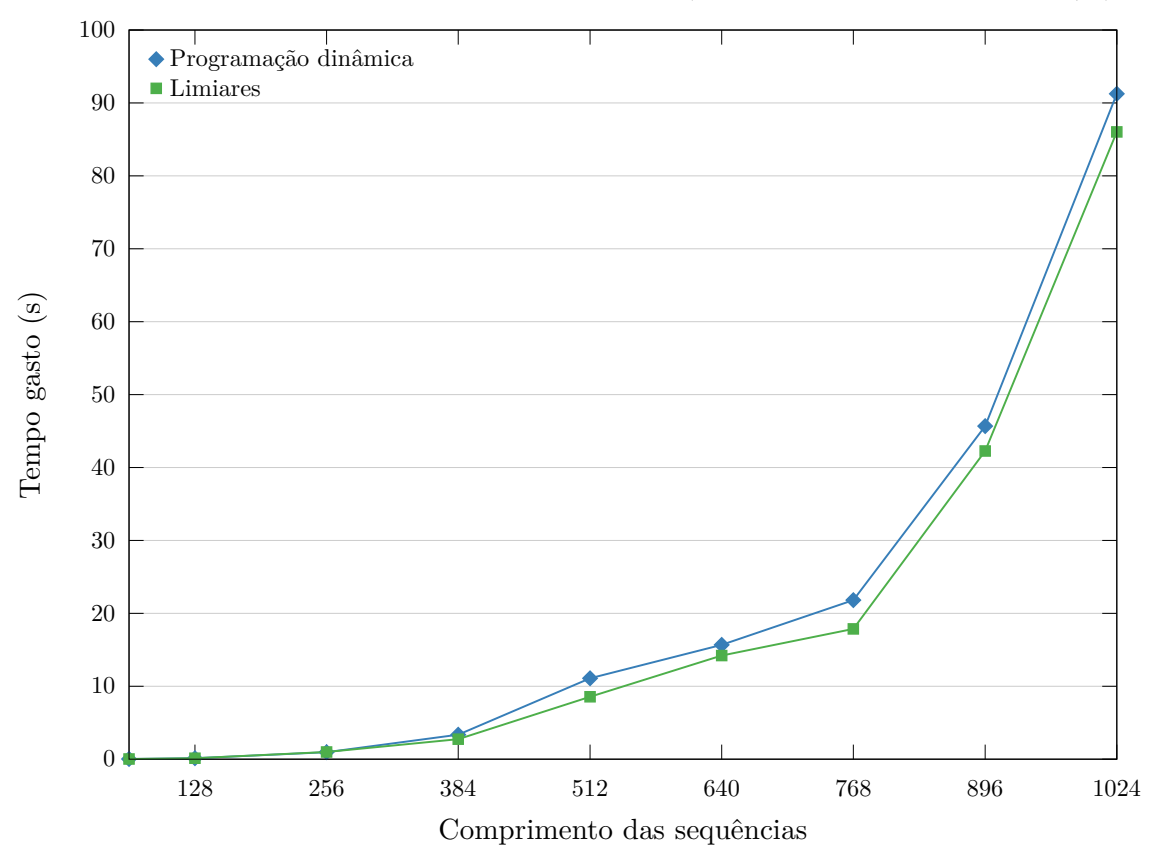

Vale observar também a relação dos algoritmos com o tamanho do alfabeto. O gráfico abaixo ilustra o tempo gasto pela execução dos algoritmos isoladamente, com o comprimento das sequências fixado em 2000.

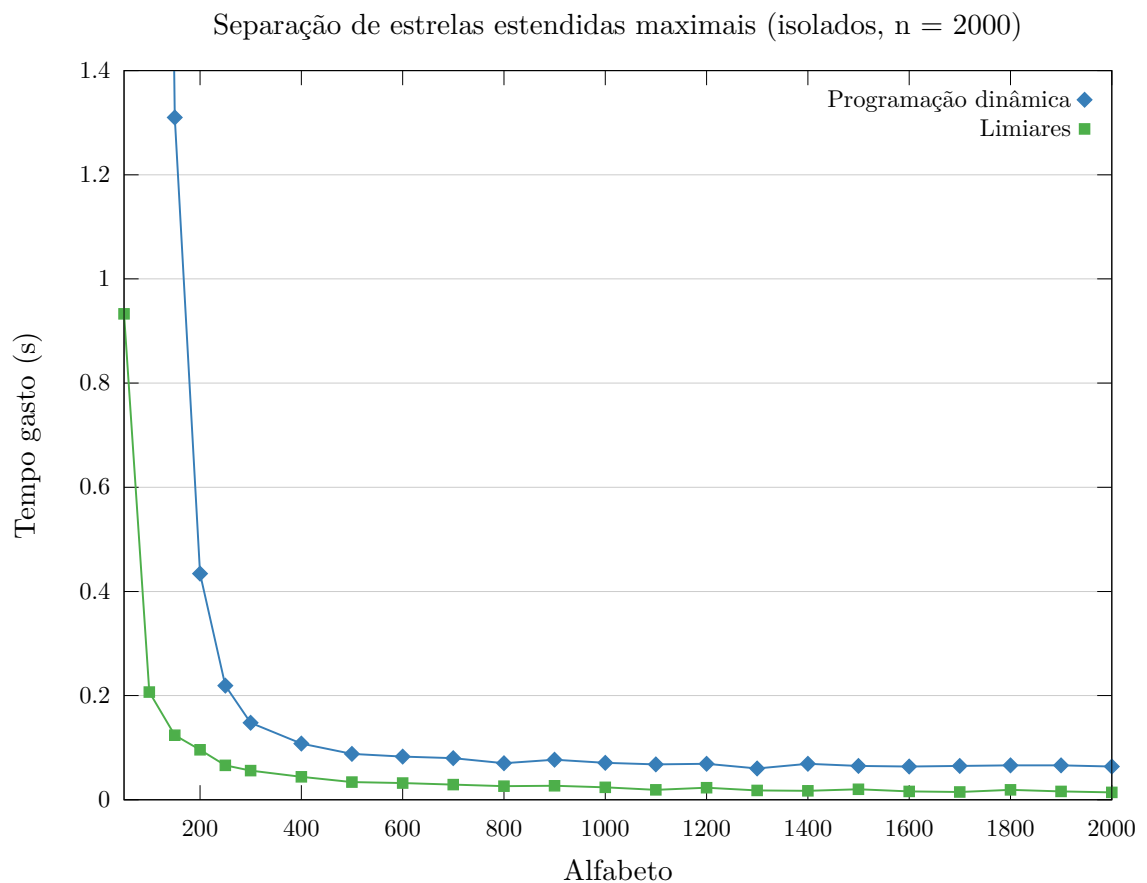


O consumo de tempo alto com alfabeto pequeno pode ser justificado pelo consumo de tempo necessário para encontrar os blocos máximos, que dependem do número de casamentos de cada símbolo, que aumenta conforme o alfabeto diminui. Uma consideração importante é que a busca por bloco máximo foi implementada usando força bruta pura para o algoritmo de programação dinâmica, e da forma descrita na Seção 5.2.2 para o algoritmo por limiares. Se o segundo método for usado para o algoritmo de programação dinâmica, a diferença entre os dois algoritmos no caso em que o alfabeto é pequeno deve ser reduzida.

\subsection{Heurísticas}

Em um algoritmo branch-and-cut, os resultados do algoritmo de resolução de programa linear executado a cada iteração (simplex, por exemplo) devolvem um limitante superior da solução ótima, pois estamos lidando com um problema mais relaxado (menos restrito) e o problema é de maximização. Uma maneira de obter a solução ótima mais cedo é obter soluções viáveis para o problema do RFLCS (isto é, subsequências comuns sem repetições) que servem como limitantes inferiores. Nesse caso, os limitantes inferiores são sempre inteiros e os superiores podem ser fracionários, e, portanto, se o chão do limitante superior for igual ao limitante inferior, então a solução viável encontrada é ótima. Para encontrar essas soluções, podemos usar heurísticas que se aproveitam da solução ótima do problema relaxado. De um modo geral, é natural esperar que quanto mais justo um poliedro relaxado está em relação ao original inteiro, mais próximo a solução ótima relaxada está da solução inteira ótima (embora isso possa não ocorrer dependendo do poliedro). As heurísticas desta seção propõem-se a encontrar soluções viáveis inteiras "perto" de uma solução fracionária, e espera-se que, de um modo vago, quanto mais próxima essa solução está da ótima, melhor serão as soluções das heurísticas.

Desenvolvemos e implementamos quatro heurísticas que recebem, além das sequências, uma solução viável $z$ na formulação relaxada e devolvem uma subsequência comum sem repetições.

RR-LCS A primeira heurística é baseada no algoritmo de aproximação RR-LCS descrito na Seção 4.2.2. Ela remove repetições das sequências de entrada com probabilidades baseadas na solução viável $z$, de modo que reste apenas uma ocorrência de cada símbolo em alguma das duas sequências. Para cada ocorrência de símbolo na sequência que tem menos ocorrências desse símbolo, a probabilidade dela ser mantida é a soma dos valores de $z$ dos casamentos que têm uma ponta nela (normalizada de modo que a soma das probabilidades entre todas as ocorrências desse símbolo seja 1). Ao sortear uma ocorrência para cada símbolo, o algoritmo remove as ocorrências restantes e um LCS é computado a partir dessas sequências novas. A sequência resultante é uma subsequência comum sem repetições.

LCS-RR A segunda heurística é análoga ao algoritmo de aproximação LCS-RR da Seção 4.2.1: ela calcula um emparelhamento planar máximo (um "LCS com pesos", visto na Seção 5.2) e depois remove as repetições da sequência associada a ele. A heurística usa o mesmo método descrito na Seção 5.2 para computar um emparelhamento planar máximo, tomando $z$ como pesos de casamentos.

Guloso A terceira heurística é um algoritmo guloso simples que prioriza casamentos com valores de $z$ próximos de 1 . Ela ordena os casamentos em ordem decrescente de valor em $z$ e escolhe casamentos nessa ordem, descartando aqueles que conflitam com algum casamento já escolhido. 
Para descartar os casamentos indesejados, basta marcar os símbolos de casamentos já escolhidos e manter a lista de casamentos em ordem de precedência para que seja fácil verificar se ele cruza com algum outro casamento. O conjunto resultante representa uma subsequência comum sem repetições.

Limitante de casamento A quarta heurística multiplica os valores em $z$ de cada casamento por seus limitantes de casamento (visto na Seção 4.3 .3 e revisto na próxima seção), e escolhe gulosamente aqueles que maximizam esses valores, com cuidado para não escolher dois casamentos conflitantes. Um algoritmo mais fiel seria considerar $z$ como peso para computar os limitantes superiores no cálculo dos limitantes de casamento, mas tal algoritmo seria pouco eficiente para ser executado múltiplas vezes e, portanto, apenas a versão simples descrita acima foi implementada. Vale ressaltar que este algoritmo precisa computar apenas uma vez os limitantes de casamento para várias execuções.

O gráfico seguinte ilustra o consumo de tempo do algoritmo branch-and-cut usando cada uma das heurísticas, no caso em que o alfabeto é metade do comprimento das sequências. As heurísticas são executadas toda vez que encontramos uma nova solução víavel da formulação relaxada.

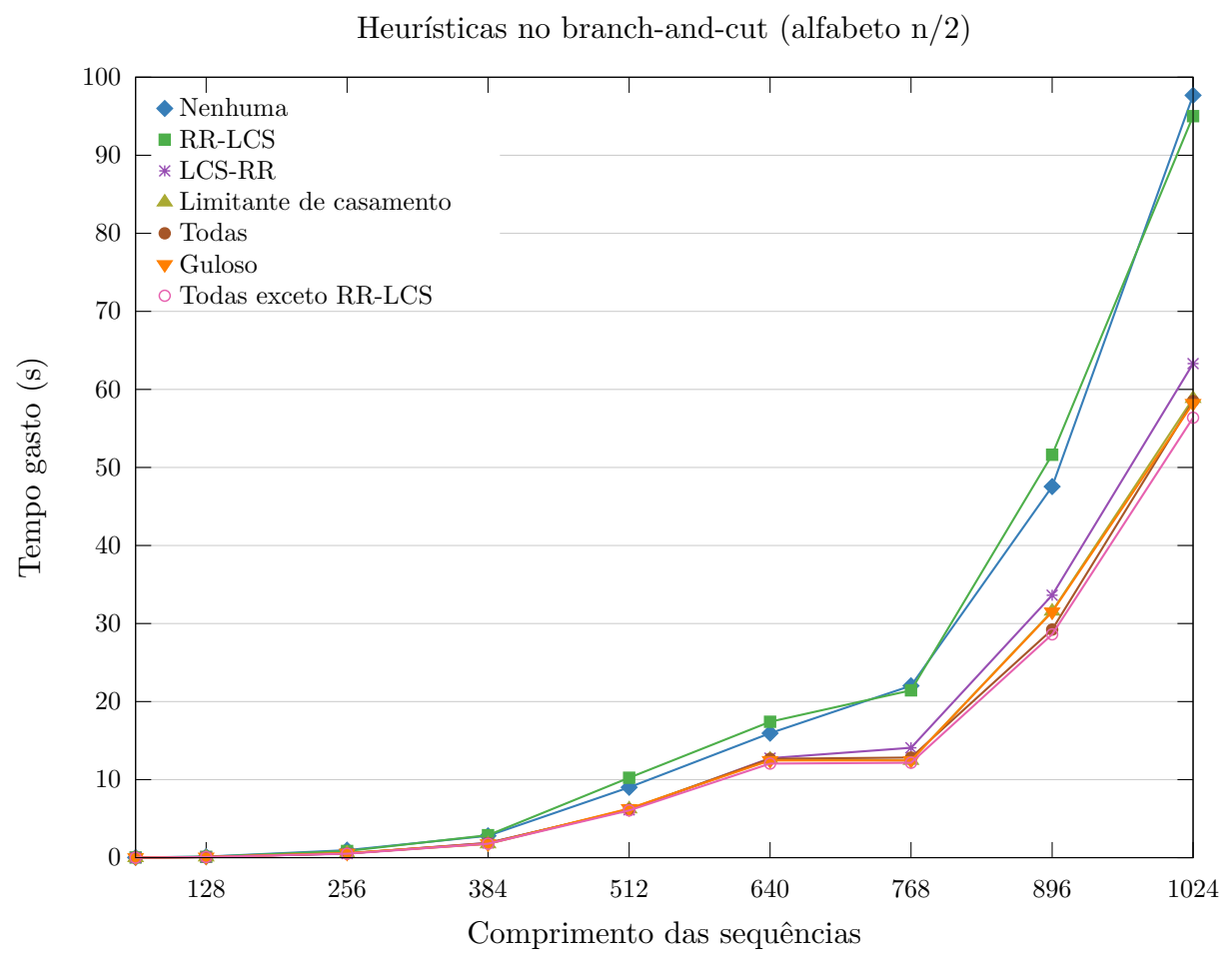

Como os valores estão bastante pertos uns dos outros, vale observar os dados numéricos no Apêndice C.3.

Uma primeira observação dos dados é que a heurística RR-LCS, embora diminua um pouco o número de cortes, piora o consumo de tempo do algoritmo. Ainda mais, se compararmos o número de cortes da versão com todas as heurísticas e o da versão com todas menos RR-LCS, ele é o mesmo, o que indica que o que a heurística RR-LCS contribui é superado pelas outras heurísticas. 
Quanto às outras heurísticas, elas reduzem o consumo de tempo do algoritmo e têm desempenhos similares umas às outras, com a heurística de limitante de casamento e gulosa mostrando melhores resultados. No entanto, comparando os números de cortes no Apêndice C.3, nem sempre o número de cortes com essas heurísticas é igual ao número de cortes com todas as heurísticas, o que significa que as outras heurísticas ainda podem ajudar a reduzir o número de cortes.

Realizamos também testes fixando o comprimento da sequência em 256 e variando o alfabeto. Eles apoiam as conclusões tiradas do teste anterior e mostram que o desempenho relativo entre si das heurísticas é similar independentemente do tamanho do alfabeto (novamente, recomendamos a observação dos valores numéricos no Apêndice C.3).

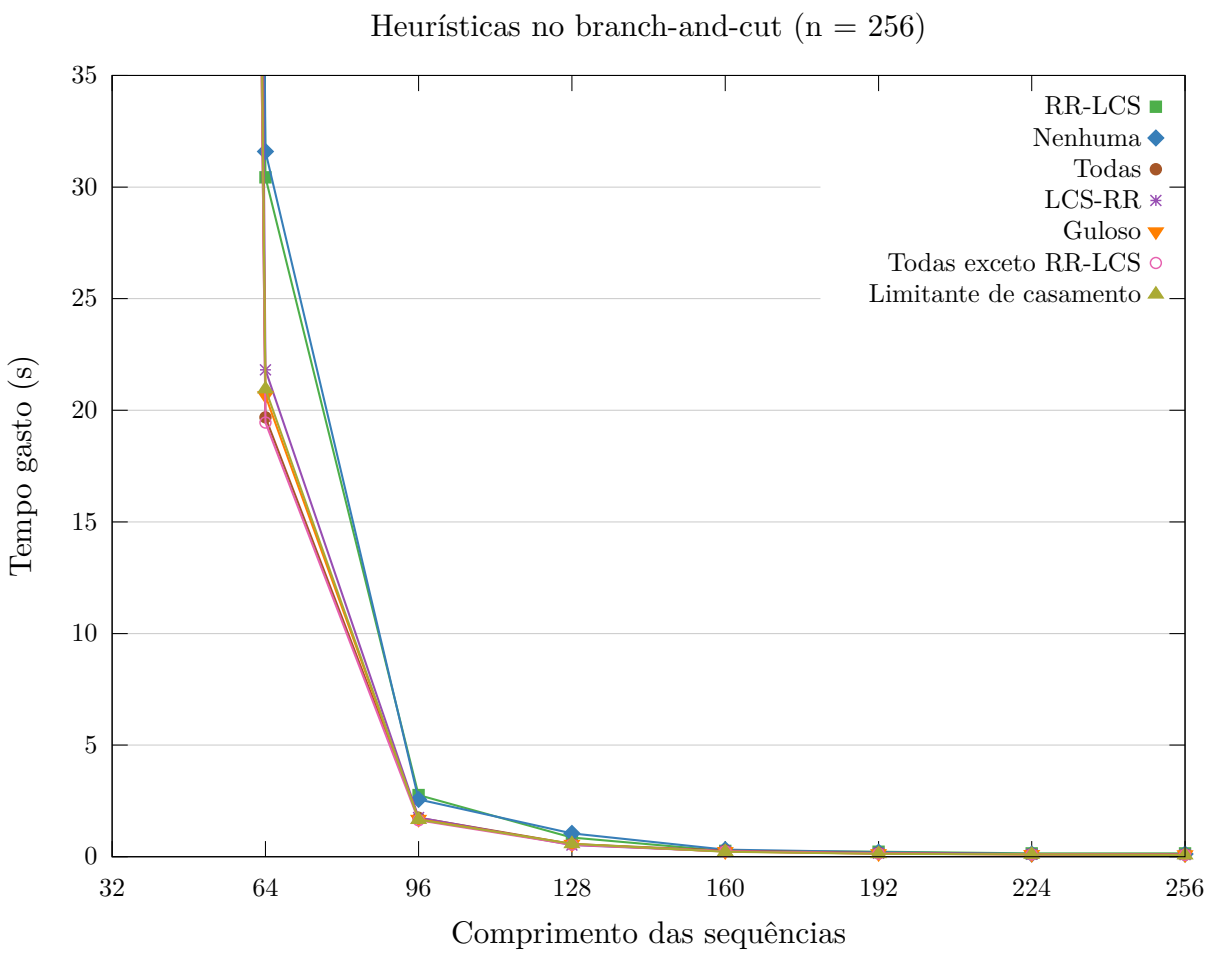

Usar o número de cortes como medida de comparação entre instâncias diferentes é pouco confiável pois ele varia bastante de instância para instância, mas os resultados computacionais indicam que, para o caso uniforme, as heurísticas devem reduzir o número de cortes para aproximadamente de $55 \%$ a $80 \%$ do número de cortes original.

\subsection{Limitante de casamento}

O simples lema a seguir nos dá uma condição para eliminar casamentos do programa linear. Lembremos da definição de limitante de casamento da Seção 4.3.3: $u_{c}(i, j)=u_{\text {pref }}(i, j)+u_{\text {suf }}(i, j)+1$ é chamado de limitante de casamento se $u_{\text {pref }}(i, j)$ e $u_{\text {suf }}(i, j)$ são limitantes superiores, respectivamente, de $X[1 . . i-1]$ e $Y[1 . . j-1]$, e de $X[i+1 . . m]$ e $Y[j+1 . . m]$.

Lema 5.4.1. Seja $u_{c}(i, j)$ um limitante de casamento de $(i, j)$. Se existe uma subsequência comum 
sem repetições de $X$ e $Y$ de comprimento $u_{c}(i, j)+1$, o casamento $(i, j)$ não pertence a nenhuma representação de um RFLCS.

Prova. Seja $R$ uma representação que contém $(i, j)$. Então, podem pertencer a $R$ apenas casamentos das sequências $X[1 . . i-1]$ e $Y[1 . . j-1]$ ou das sequências $X[i+1 . . m]$ e $Y[j+1 . . n]$, e de símbolo diferente de $\sigma$. Portanto, podem pertencer a $R$ mais outros $u_{\text {pref }}(i, j)+u_{\text {suf }}(i, j)$ casamentos, isto é, a cardinalidade máxima de $R$ é $u_{\text {pref }}(i, j)+u_{\text {suf }}(i, j)+1$. Como existe uma subsequência comum sem repetições de $X$ e $Y$ de comprimento maior que isso, $R$ não pode representar um RFLCS.

Para aplicar o lema acima, antes de iniciar o algoritmo branch-and-cut, calculamos todos os limitantes de casamento $u_{c}(i, j)$ como descrito na Seção 4.3.3. Dada uma solução viável de comprimento $k$, removemos as variáveis dos casamentos cujos limitantes são estritamente maiores que $k$. Além disso, durante a execução do algoritmo, conforme obtemos soluções viáveis de comprimentos cada vez maiores, eliminamos as variáveis que satisfazem essa condição para os novos comprimentos.

A melhoria no algoritmo resultante desta técnica é evidenciada no gráfico seguinte. Ele ilustra o tempo gasto do algoritmo branch-and-cut com e sem o uso dos limitantes de casamento da forma descrita nesta seção. O tamanho do alfabeto é metade do comprimento das sequências.

Limitante de casamento (alfabeto $\mathrm{n} / 2$ )

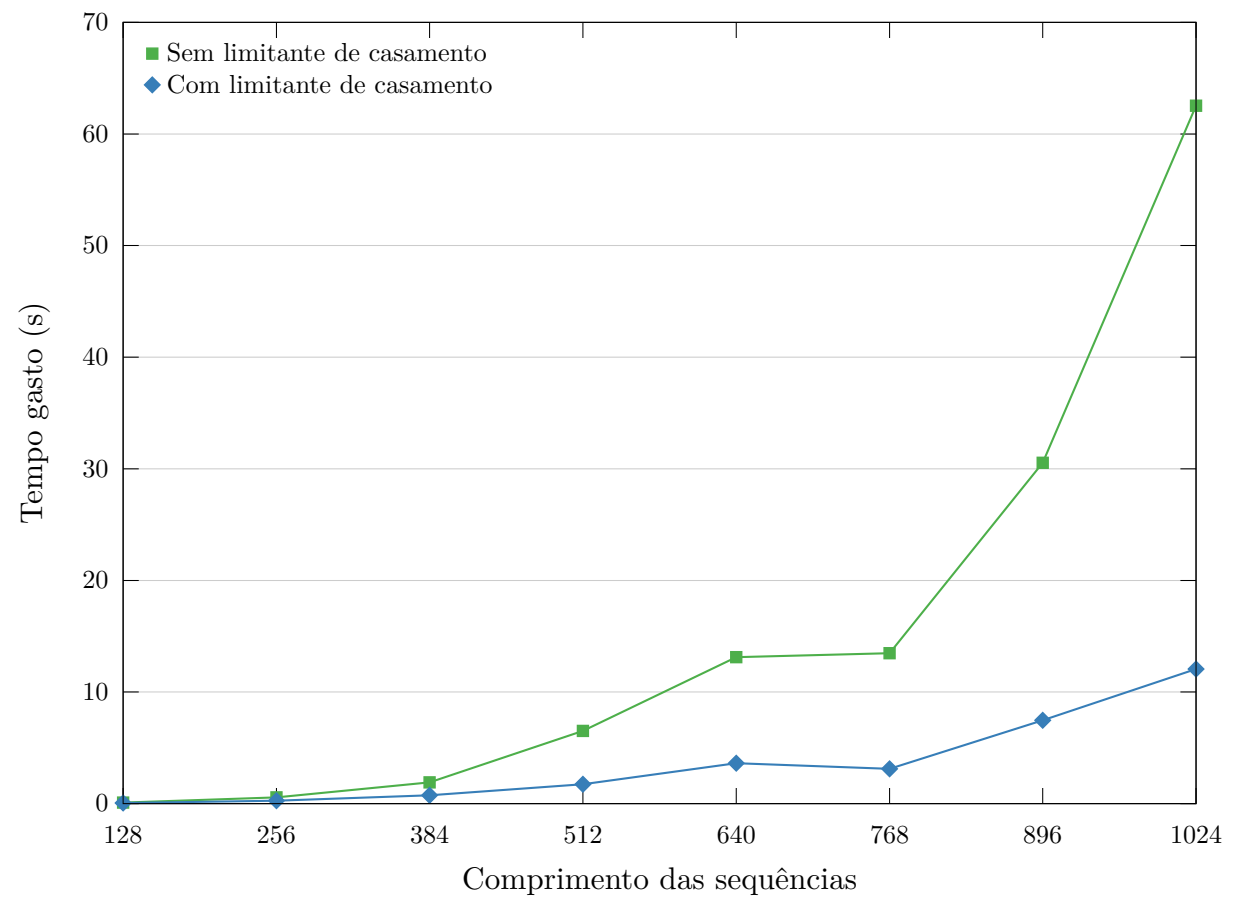

É curioso ver também qual a porcentagem de variáveis que foram removidas conforme a execução do algoritmo usando este método. O gráfico a seguir mostra que, para entradas grandes, mais da metade das variáveis são removidas no total. 
Limitante de casamento (alfabeto $\mathrm{n} / 2$ )

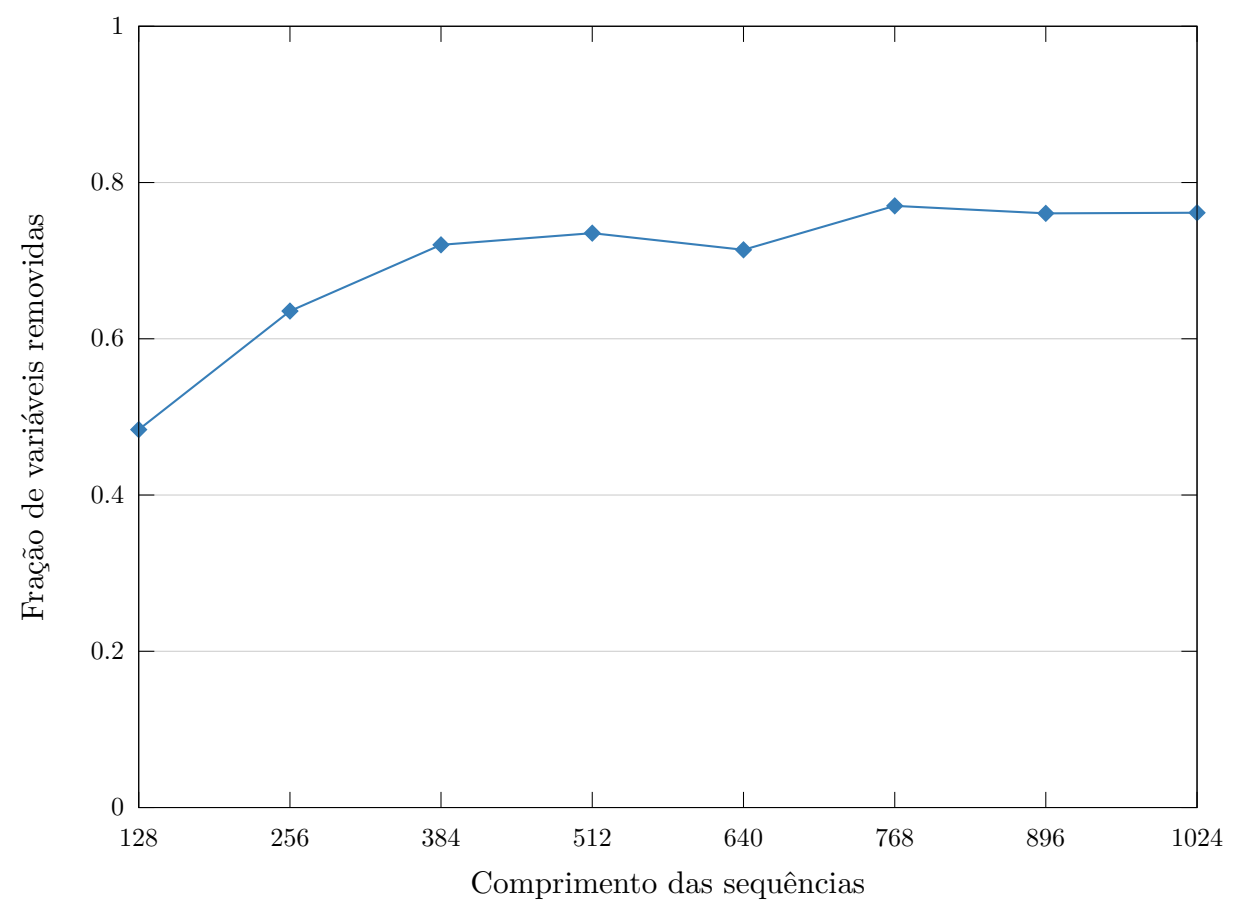

\subsection{Pré-processamento}

Antes de executar o algoritmo branch-and-cut, as sequências podem possivelmente ser transformadas de forma que elas se tornem mais curtas mas mantenham o mesmo RFLCS.

Proposição 5.5.1. Denote por $Z^{k}$ a sequência $Z$ repetida $k$ vezes de forma consecutiva. Seja $X$ uma sequência da forma $P Z^{k} Z_{p} S$, com $k \geq|Z|-1$, onde $P$ (prefixo), $S$ (sufixo) e $Z$ são outras três sequências, e $Z_{p}$ é um prefixo não-vazio de $Z$. Seja $X^{\prime}$ uma sequência da forma $P Z^{r} z_{1} S$, com $r=|Z|-1$. Então uma sequência $Y$ é uma subsequência sem repetições de $X$ se e só se ela é uma subsequência comum sem repetições de $X^{\prime}$.

Exemplo 5.5.2. • A sequência aaaa pode ser substituída por $a\left((a)^{0} a\right)$.

- A sequência abababa pode ser substituída por $a b a\left((a b)^{1} a\right)$.

- A sequência abcabcab pode ser substituída por abcabca $\left((a b c)^{2} a\right)$.

Os exemplos acima ainda valem se eles forem subsequência contígua de outra sequência. Por exemplo, a sequência bcbcbaaaad pode ser substituída por bcbad.

Prova. Como o prefixo $P$ e o sufixo $S$ de $X$ são os mesmos em $X^{\prime}$, basta provar que qualquer subsequência sem repetições de $Z^{k} Z_{p}$ é também subsequência sem repetições de $Z^{r} z_{1}$, e vice-versa.

Primeiro, observe que qualquer subsequência sem repetições de $Z^{r} z_{1}$ é uma subsequência de $Z^{k} Z_{p}$, pois $Z^{r} z_{1}$ é um prefixo de $Z^{k} Z_{p}$. 
Para provar a recíproca, provaremos primeiro que qualquer permutação de $Z$ é subsequência de $Z^{r} z_{1}$, com $r=|Z|-1$. Seja $S$ uma permutação de $Z$.

Suponha que $z_{i} z_{j}$ é uma subsequência contígua de $S$ para $i$ e $j$ índices de $Z$ com $i<j$. Como $z_{i} z_{j}$ é uma subsequência de $Z$ e cada um dos outros $r-1$ símbolos de $S$ também é uma subsequência de $Z, S$ é uma subsequência de $Z^{r}$ e, portanto, de $Z^{r} z_{1}$.

Agora, caso contrário, $S=z_{|Z|} z_{|Z|-1} \ldots z_{1}$. Como cada um dos primeiros $r(=|S|-1)$ símbolos de $S$ é uma subsequência de $Z, S$ é subsequência de $Z^{r} z_{1}$.

Portanto, qualquer permutação de $Z$ é subsequência de $Z^{r} z_{1}$. Em particular, dado $\Sigma(Z)$ o alfabeto composto pelos símbolos de $Z$, qualquer sequência sem repetições sobre $\Sigma(Z)$ é uma subsequência de $Z^{r} z_{1}$. Como qualquer subsequência sem repetições de $Z^{k} Z_{p}$ é sobre o alfabeto $\Sigma(Z)$, ela também é subsequência de $Z^{r} z_{1}$, o que prova o que queríamos.

Portanto, uma sequência é subsequência sem repetições de $Z^{k} Z_{p}$ se e só se ela também é subsequência sem repetições de $Z^{r} z_{1}$.

O fato acima implica que uma sequência de entrada como $X$ pode ser substituída por $X^{\prime}$ para resolver o problema do RFLCS. Na implementação, apenas aplicamos o pré-processamento acima para $|Z|$ igual a 1 e 2 , pois, em geral, há poucas ocorrências de casos em que $|Z|>2$. Um algoritmo que aplica este pré-processamento é simples: basta buscar as subsequências contíguas que se repetem pelo menos $k$ vezes e eliminar a parte desnecessária da sequência.

Como uma regra geral, se $C$ é o conjunto das subsequências sem repetições de $X$, podemos trocar $X$ por $X^{\prime}$ se as subsequências sem repetições de $X^{\prime}$ também é exatamente $C$, mas o único pré-processamento desse tipo que desenvolvemos é o descrito acima.

Um outro método para pré-processar o problema é fixar algumas variáveis.

Proposição 5.5.3. Se $(i, j)$ é um casamento que pertence a apenas uma estrela estendida maximal, então $(i, j)$ pertence à representação de algum RFLCS.

Prova. Seja $(i, j)$ como enunciado e seja $R$ a representação de um RFLCS que não contém $(i, j)$. O casamento $(i, j)$ conflita com exatamente um casamento $(k, l)$ em $R$, pois $(i, j)$ pertence a apenas uma estrela estendida maximal. Então $R \cup\{(i, j)\} \backslash\{(k, l)\}$ também representa um RFLCS e contém $(i, j)$.

A variável de um casamento $(i, j)$ que satisfaz a condição acima pode ser fixada em 1 no início do algoritmo, pois não alteramos o comprimento de um RFLCS no processo.

\subsection{Resultados computacionais gerais}

Para finalizar este capítulo, mostramos alguns gráficos de tempo médio de execução do algoritmo branch-and-cut, descritos numericamente no Apêndice C.5, com todas as técnicas descritas neste capítulo utilizadas. 

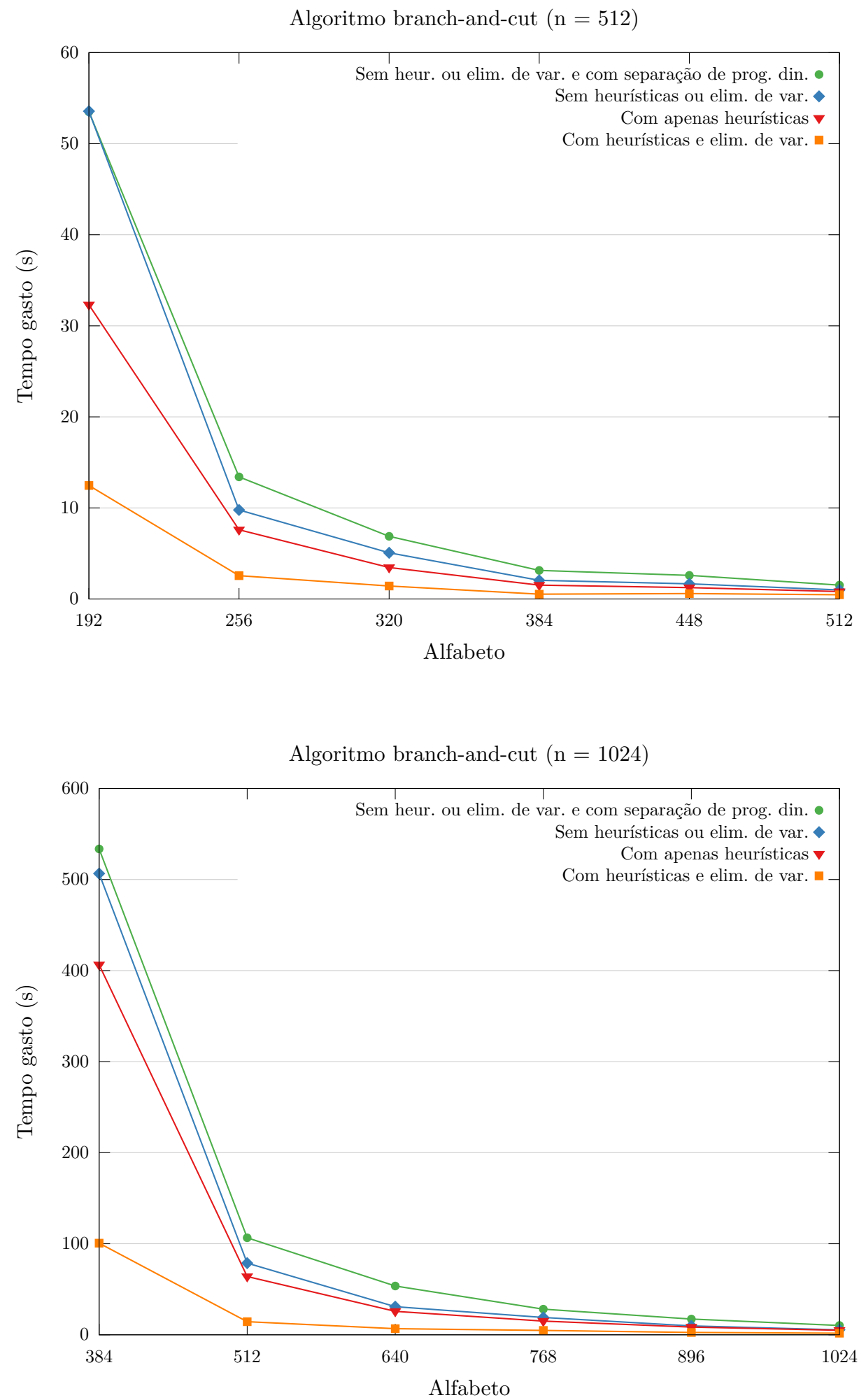

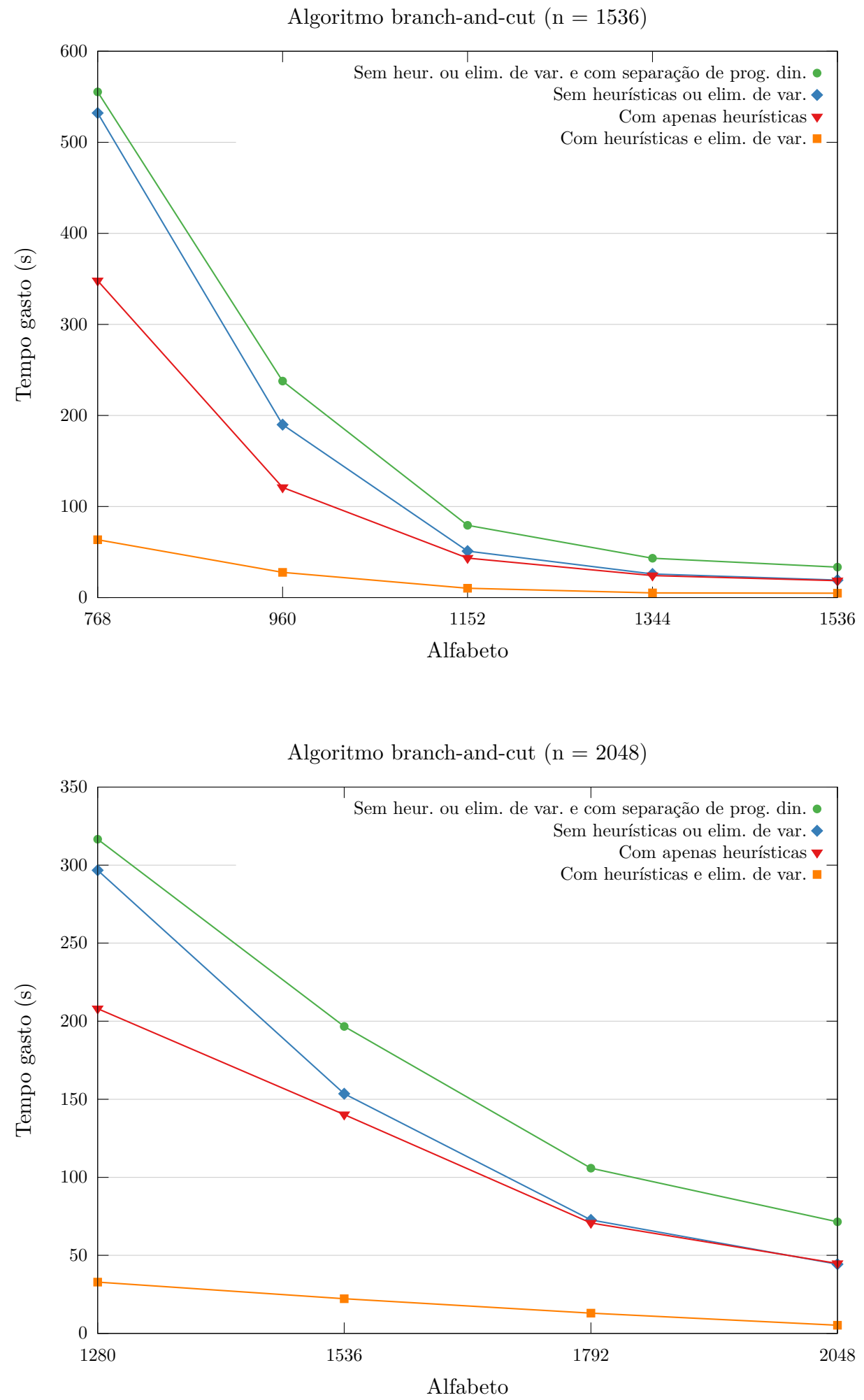


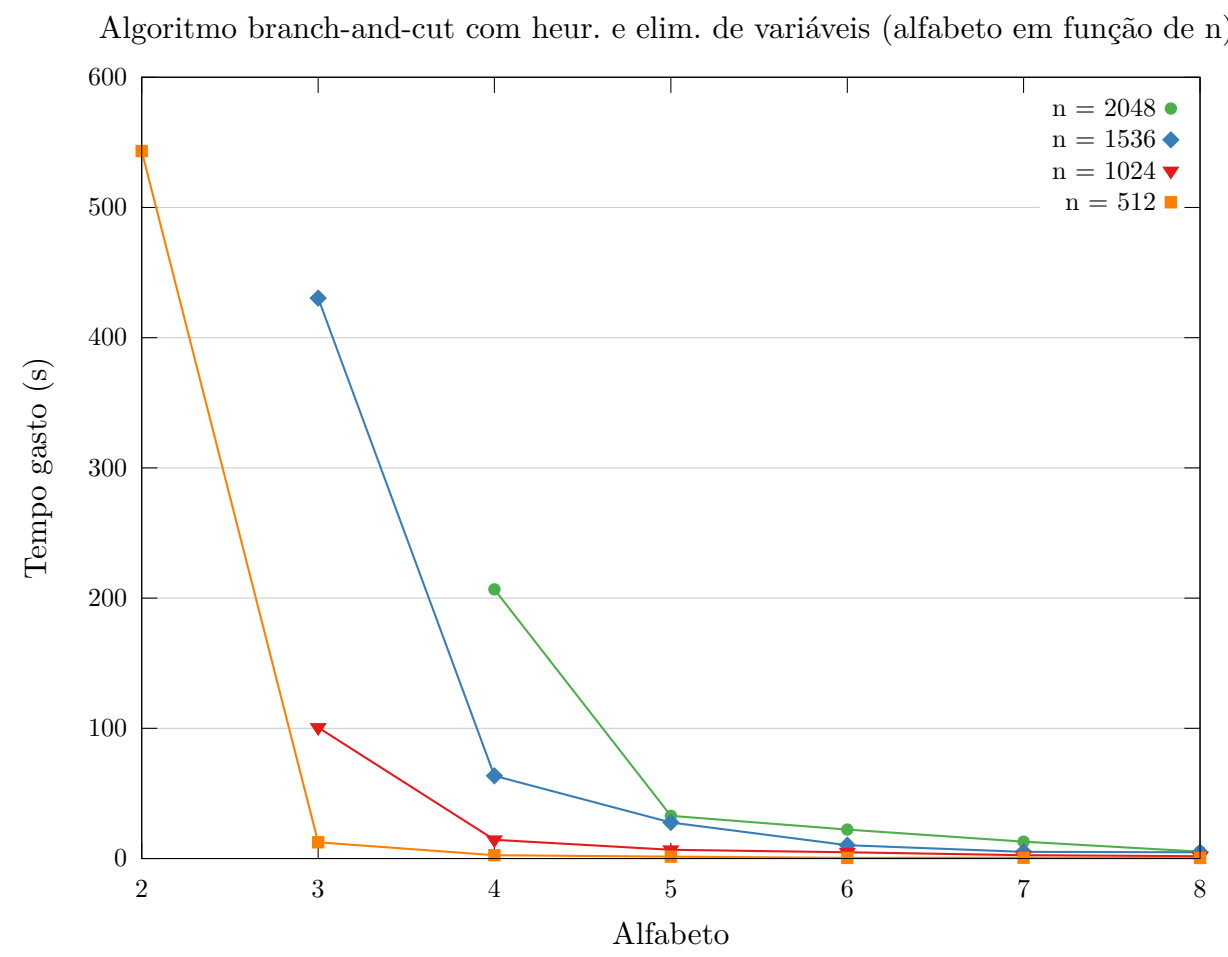

A característica mais facilmente perceptível desses gráficos é, como já vimos em resultados computacionais anteriores, a dificuldade do algoritmo com alfabetos de tamanho pequeno. O número de cortes adicionados também aumenta conforme o alfabeto diminui, como vemos nos dados numéricos do Apêndice C.5. É provável que isso se deva ao alto número de casamentos de sequências geradas com alfabeto pequeno, lembrando que as variáveis da formulação por estrelas estendidas são os casamentos.

Os dados numéricos mostram que o número de nós é, em geral, baixo, e o valor da solução ótima no nó raiz é perto da solução ótima inteira, o que é um indicador de que as restrições de estrela estendida são fortes no sentido de que o poliedro associado à relaxação linear da formulação é, informalmente, uma boa aproximação do poliedro do problema. Além disso, podemos ver pelos dados numéricos que o desempenho do algoritmo branch-and-cut com a formulação por estrelas estendidas é significativamente melhor que o desempenho do que usa a formulação por cruzamentos.

O Apêndice A descreve algumas técnicas que não foram adicionadas à implementação por não contribuirem ao algoritmo, mas elas ainda são interessantes mesmo assim.

Implementamos também um algoritmo branch-and-cut usando a formulação por símbolos distintos, mas sem o uso de nenhuma técnica ou heurística adicional além do pré-processamento. A separação das restrições de estrelas especiais é análoga à separação das restrições de estrelas estendidas, usando inclusive a ideia de limiares. O gráfico seguinte compara seu consumo de tempo com o do algoritmo descrito neste capítulo, sem o uso de heurísticas ou eliminação de variáveis através de limitantes de casamento. Podemos ver que este último tem um consumo de tempo menor. 
Capítulo 5. Algoritmo branch-and-cut para RFLCS

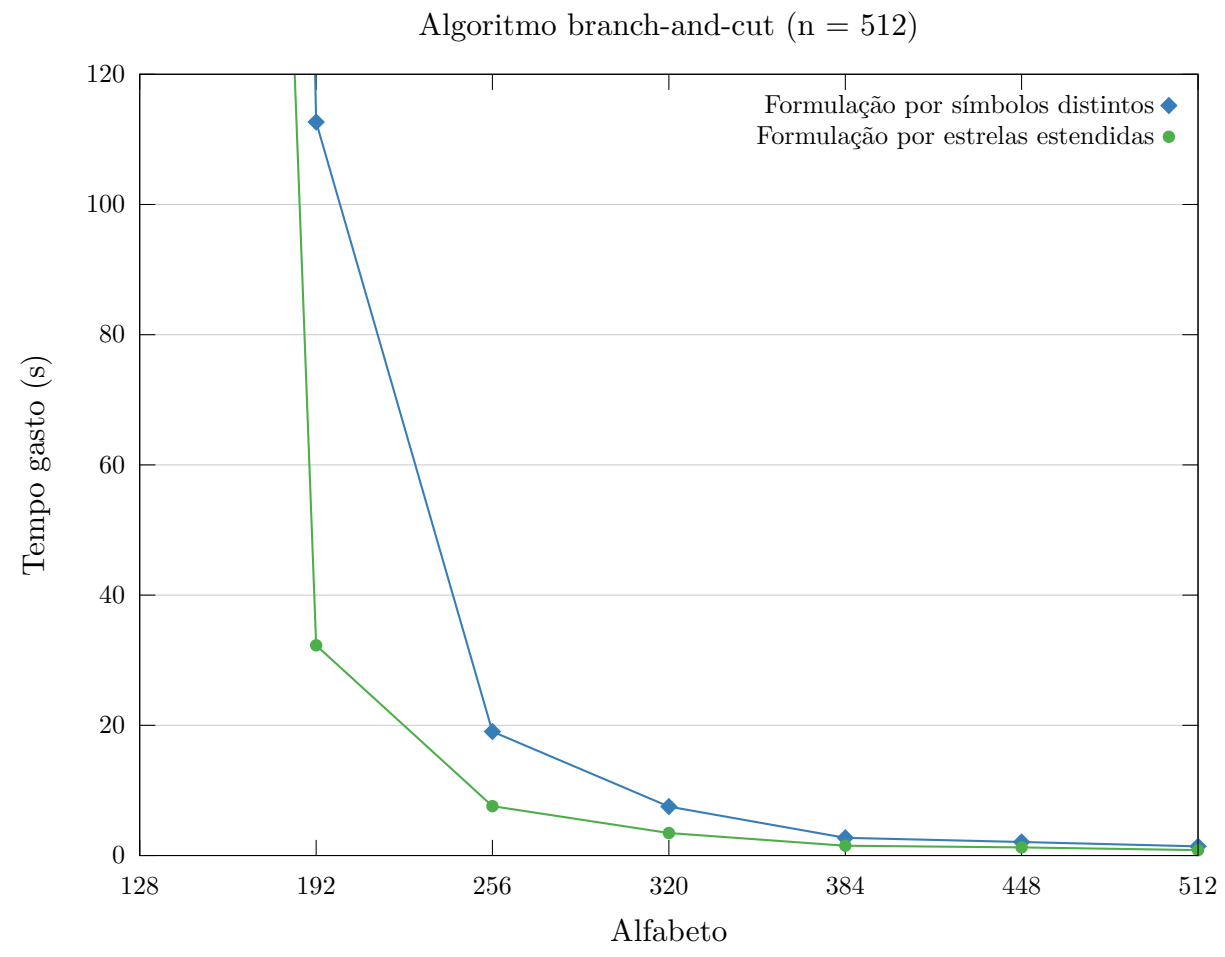




\section{CAPítulo 6}

\section{Algoritmos de enumeração para RFLCS}

Neste capítulo, descrevemos alguns algoritmos baseados em enumeração para o problema do RFLCS, sem o uso de programação linear. Vale observar que as sequências de entrada também podem ser pré-processadas como na Seção 5.5 antes de executar qualquer algoritmo deste capítulo.

\subsection{Decomposição em subproblemas fáceis}

Este algoritmo decompõe o problema em vários subproblemas mais fáceis e escolhe a melhor entre as soluções dos subproblemas. Mais especificamente, para cada subsequência $X^{\prime}$ de $X$ em que mantemos apenas uma ocorrência de cada símbolo, computamos um LCS de $X^{\prime}$ e $Y$, e escolhemos o melhor entre todos os LCSs computados. Por exemplo, se $X=a b a c b$, os possíveis $X^{\prime}$ são $a b c, a c b$ e bac. Para ver que esse algoritmo devolve um RFLCS de $X$ e $Y$, nos baseamos em dois fatos:

1. todo RFLCS de $X$ e $Y$ é um RFLCS de $X^{\prime}$ e $Y$ para algum $X^{\prime}$ como acima, pois ele "usa" apenas uma ocorrência de cada símbolo; e

2. se cada símbolo ocorrer no máximo uma vez ou em $X$, ou em $Y$, então qualquer subsequência comum de $X$ e $Y$ é sem repetições e, portanto, qualquer LCS também é um RFLCS.

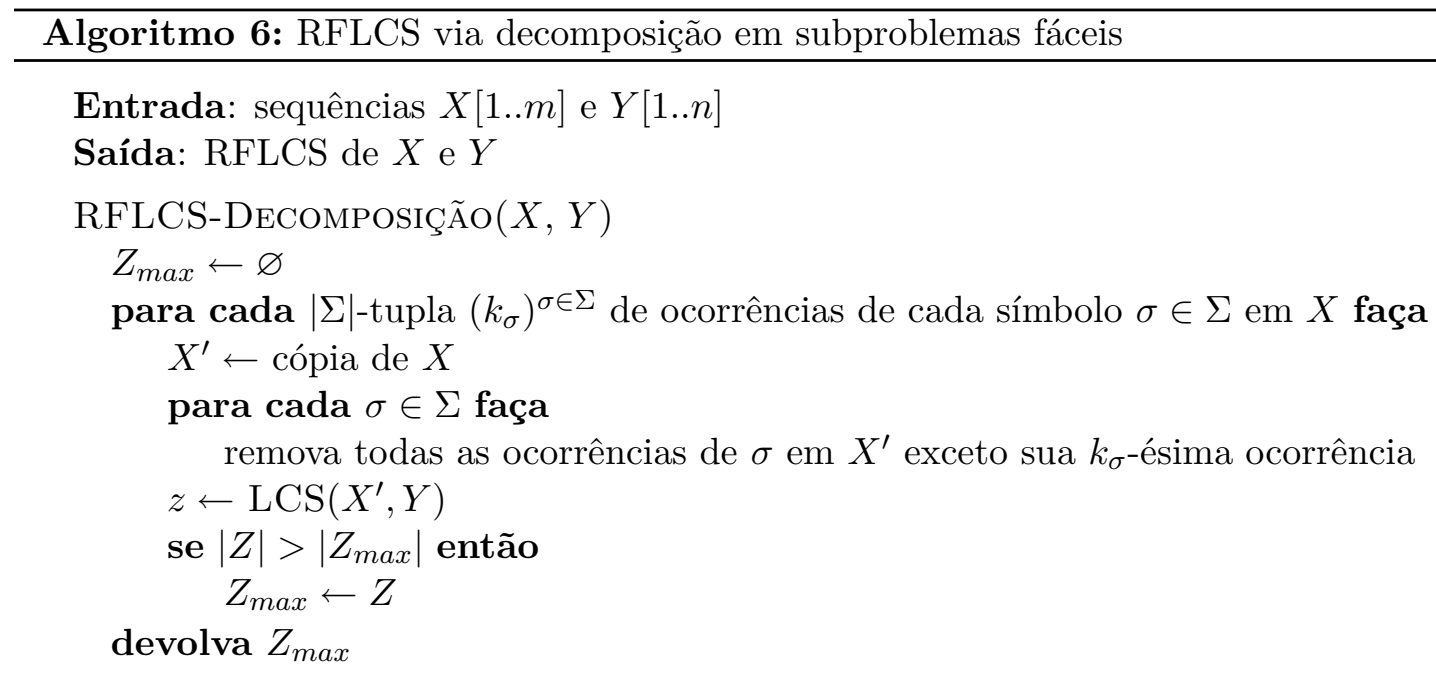


$\mathrm{O}$ algoritmo pode ser ajustado para remover ocorrências de símbolos em $Y$ se existem menos ocorrências de tal símbolo em $Y$ do que em $X$, o que resulta em menos computações de um LCS. Lembremos que occ $(\sigma)$ é o número de vezes que $\sigma$ ocorre em $X$ ou em $Y$, o que for menor. A iteração principal, com o ajuste, é feita $\prod_{\sigma \in \Sigma}$ occ $(\sigma)$ vezes e, logo, o consumo de tempo do algoritmo é $O\left((n+f(X, Y)) \prod_{\sigma \in \Sigma}\right.$ occ $\left.(\sigma)\right)$, onde $f(X, Y)$ é o consumo de tempo de um algoritmo que computa um LCS de $X$ e $Y$, e o fator $n$ refere-se à construção das sequências com ocorrências removidas (supondo $m \leq n$ ). Observe que a existência deste algoritmo implica que o problema do RFLCS é resolvível em tempo polinomial se o número de símbolos $\sigma$ tal que occ $(\sigma)>1$ é constante (digamos, $k)$, pois, nesse caso, $\prod_{\sigma \in \Sigma}$ occ $(\sigma)=O\left(n^{k}\right)$.

\subsection{Decomposição em subproblemas fáceis com branch-and-bound}

A desvantagem do algoritmo anterior é que, embora um subproblema só seja fácil de se resolver, existem muitos subproblemas para serem tratados. Para lidar com isso, aplicamos uma estratégia de poda (branch-and-bound) ao algoritmo anterior. O algoritmo mantém uma árvore de subproblemas (inicialmente, apenas o problema original), escolhe um subproblema que ainda não foi processado, calcula um limitante superior e um inferior para ele e descarta-o se seu limitante superior local não for maior que o limitante inferior global ou, caso contrário, subdivide-o em subproblemas mais específicos como no algoritmo anterior mas levando em consideração as ocorrências de apenas um símbolo.

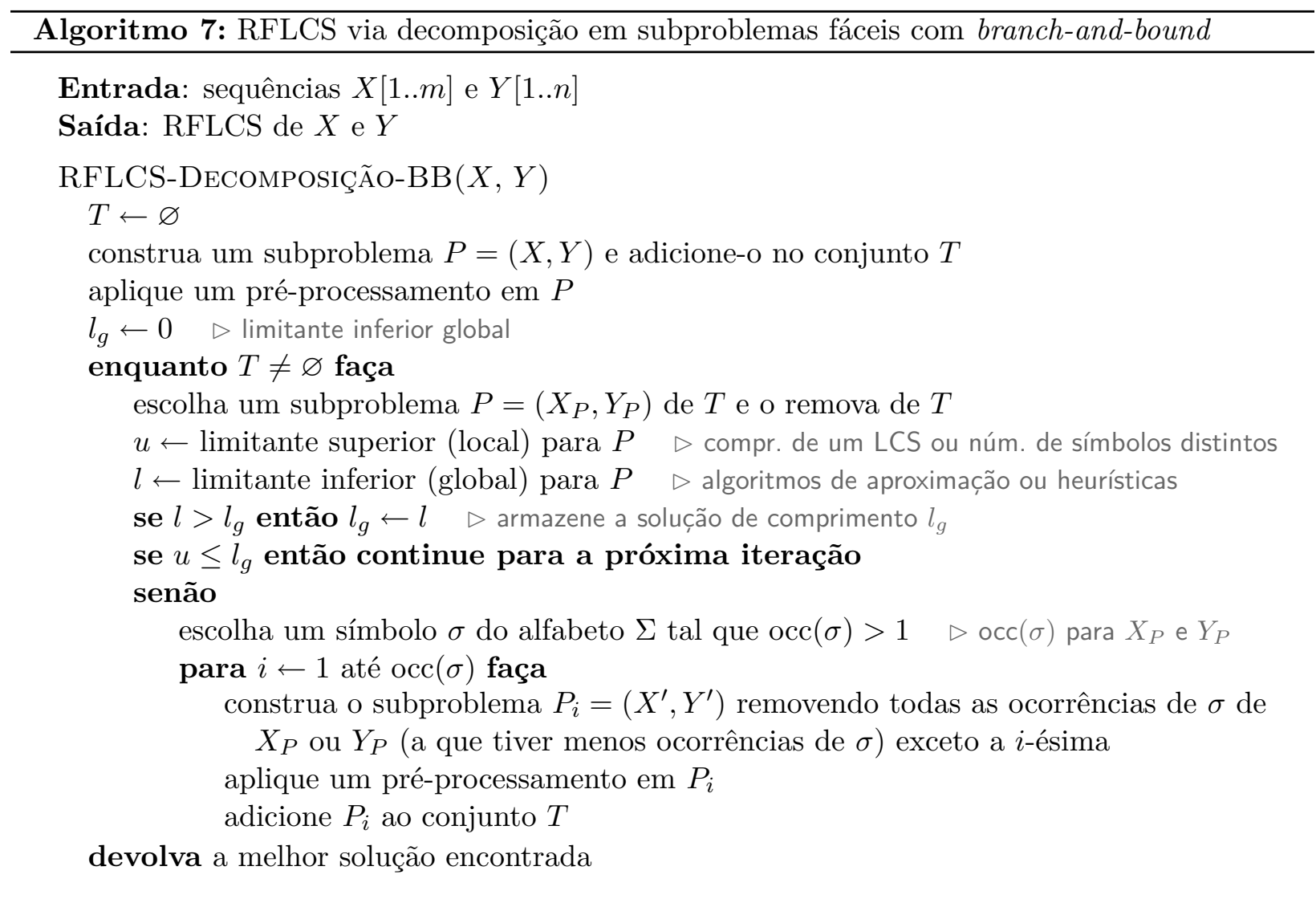


O exemplo abaixo ilustra uma árvore de subproblemas (sem limitantes, poda ou pré-processamento).

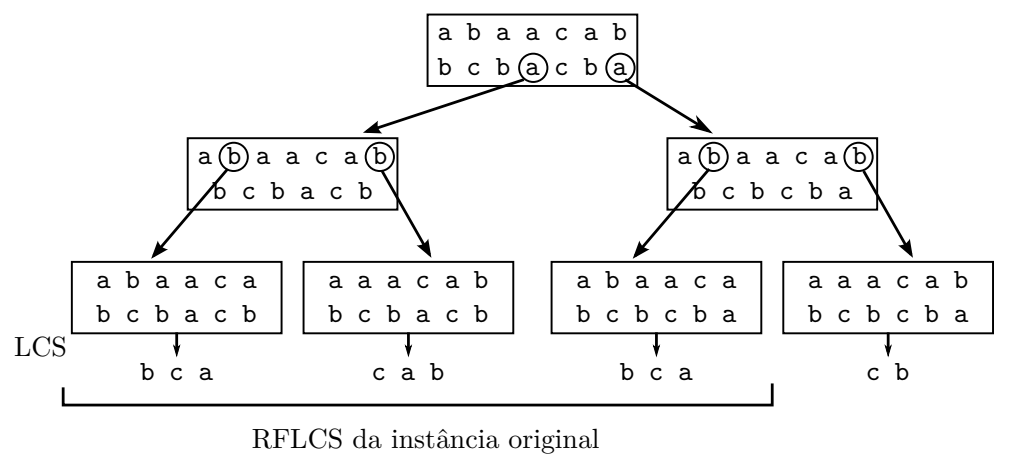

Os gráficos a seguir ilustram os desempenhos dos dois algoritmos anteriores. A escolha do subproblema no algoritmo branch-and-bound é feita por largura e o símbolo escolhido para ser feita a ramificação tem número mínimo de ocorrências. Vale ressaltar que, em geral, o algoritmo branch-and-cut do capítulo anterior tem um desempenho significativamente melhor que ambos os algoritmos.
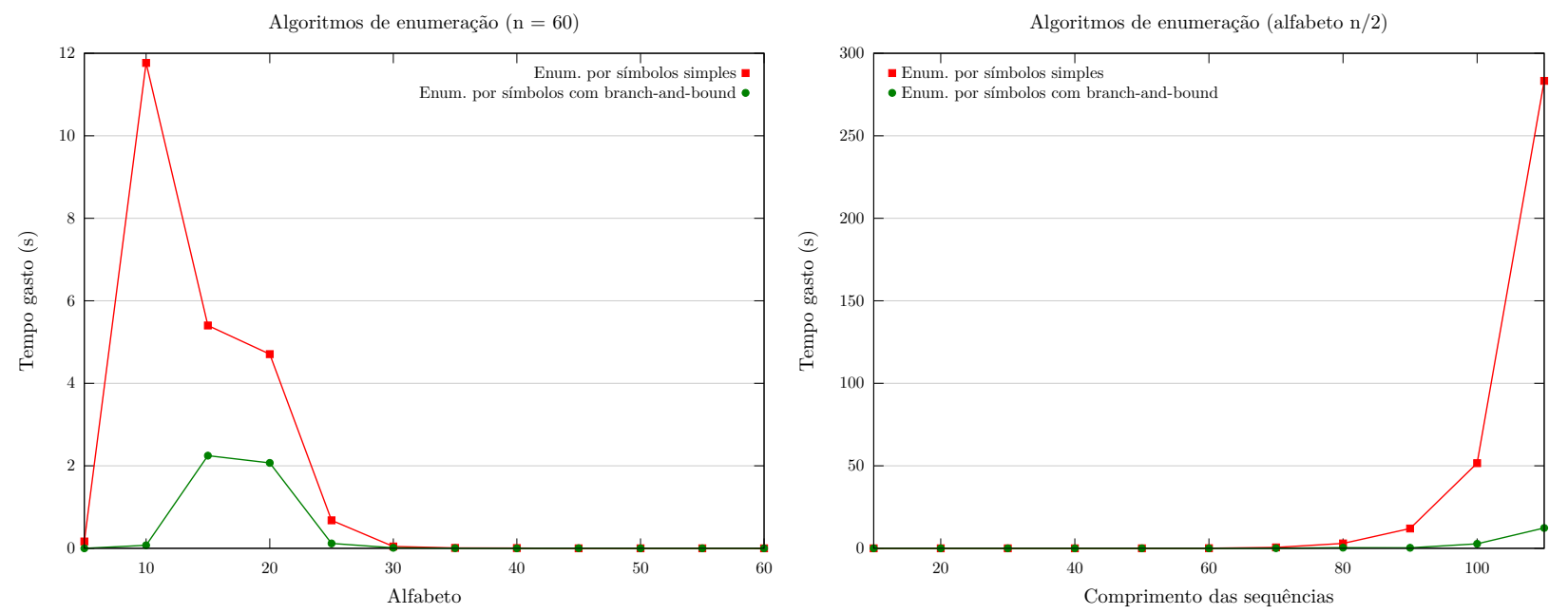

\subsection{Programação dinâmica}

O problema do RFLCS pode ser resolvido usando programação dinâmica de maneira similar ao algoritmo de programação dinâmica para o problema do LCS. No entanto, a matriz de programação dinâmica necessita de um número exponencial de posições e, na prática, este algoritmo é inviável exceto para problemas com alfabeto muito pequeno. Este algoritmo é uma versão bastante simplificada de um algoritmo de Bonizzoni et al. [7] para um problema mais geral.

Para todo $i=0, \ldots, m, j=0, \ldots, n$ e $S \subseteq \Sigma$, seja $R(i, j, S)$ uma função igual a 1 se existe uma subsequência comum sem repetições de $X[1 . . i]$ e $Y[1 . . j]$ formada pelos símbolos de $S$ (em alguma ordem), ou 0 caso contrário. A seguinte recorrência vale para $R$. 


$$
R(i, j, S)= \begin{cases}0 & \text { se } i=0 \text { ou } j=0(\text { e } S \neq \varnothing), \\ 1 & \text { se } S=\varnothing, \\ \max \{R(i, j-1, S), R(i-1, j, S)\} & \text { se } x_{i} \neq y_{j} \text { ou } x_{i}=y_{j} \notin S, \\ R\left(i-1, j-1, S \backslash\left\{x_{i}\right\}\right) & \text { se } x_{i}=y_{j} \in S\end{cases}
$$

De fato, a recorrência acima vale pois, para existir uma subsequência comum sem repetições de $X[1 . . i]$ e $Y[1 . . j]$ com símbolos $S$, deve ou existir uma de $X[1 . . i-1]$ e $Y[1 . . j]$ com símbolos $S$, ou existir uma de $X[1 . . i]$ e $Y[1 . . j-1]$ com símbolos $S$, ou, no caso em que $(i, j)$ é um casamento de símbolo em $S$, existir uma de $X[1 . . i-1]$ e $Y[1 . . j-1]$ de símbolos $S \backslash\left\{x_{i}\right\}$.

Ainda há um detalhe para mostrar: se $x_{i}=y_{j} \in S$, a afirmação acima implica que $R(i, j, S)=$ $\max \left\{R(i, j-1, S), R(i-1, j, S), R\left(i-1, j-1, S \backslash\left\{x_{i}\right\}\right)\right\}$, não a equação dada pela recorrência acima. Porém, se existe uma subsequência comum sem repetições de símbolos $S$ em $X[1 . . i]$ e $Y[1 . . j-1]$, então também existe uma de símbolos $S \backslash\left\{x_{i}\right\}$ nessas mesmas sequências. Se considerarmos $X[1 . . i-1]$ e $Y[1 . . j-1]$, ainda existe uma subsequência comum sem repetições de símbolos $S \backslash\left\{x_{i}\right\}$, pois o único símbolo removido foi $x_{i}$, que não pertence a $S \backslash\left\{x_{i}\right\}$. Logo, se $R(i, j-1, S)=1$, então $R\left(i-1, j-1, S \backslash\left\{x_{i}\right\}\right)=1$. O análogo vale para $R(i-1, j, S)=1$. Portanto, se $x_{i}=y_{j} \in S$, $R(i, j, S)=\max \left\{R(i, j-1, S), R(i-1, j, S), R\left(i-1, j-1, S \backslash\left\{x_{i}\right\}\right)\right\}=R\left(i-1, j-1, S \backslash\left\{x_{i}\right\}\right)$.

Calculados todos os valores da recorrência em uma matriz de programação dinâmica, procuramos o maior $S$ tal que $R[m, n, S]=1$. Para recuperar um RFLCS em si, podemos fazer algo análogo à matriz $B$ do algoritmo de programação dinâmica para o problema do LCS da Seção 7.2: armazenar em uma matriz de tamanho igual a $R$, para cada posição $(i, j, S)$, quais das três possibilidades $(i, j-1, S),(i-1, j, S)$ ou $\left(i-1, j-1, S \backslash\left\{x_{i}\right\}\right)$ escolhemos, e fazer o caminho inverso, guardando, na ordem inversa, os símbolos escolhidos ao trocar de $S$. Alternativamente, também é fácil refazer o caminho na própria matriz $R$ : basta, da posição $(i, j, S)$, "andar para cima" enquanto o valor for 1 até a linha $\hat{\imath}$, depois "andar para a esquerda" enquanto o valor for 1 até a coluna $\hat{\jmath}$, guardar o símbolo $\sigma$ do casamento $(\hat{\imath}, \hat{\jmath})$ dessa posição e repetir o mesmo processo a partir da posição $(\hat{\imath}-1, \hat{\jmath}-1, S \backslash\{\sigma\})$ até chegar na linha 0 , coluna 0 , ou $\mathrm{S}$ vazio, obtendo assim um RFLCS em ordem inversa.

A complexidade de tempo e espaço do algoritmo é $\Theta\left(m n 2^{|\Sigma|}\right)$, supondo que o cálculo de $S \backslash\{\sigma\}$ e o acesso a $R[i, j, S]$ possam ser feitos em tempo constante para quaisquer $\sigma \in \Sigma$ e $S \subseteq \Sigma$. Se o consumo de tempo para acessar $R[i, j, S]$ para qualquer $S$ for $|S|$ e for necessário armazenar cada conjunto $S \subseteq \Sigma$ em espaço $|S|$ (por exemplo, usando um vetor binário para representar $S$ e acessar $R[i, j, S]$ para todo $i$ e $j)$, então podemos dizer que a complexidade de tempo é $O\left(m n 2^{|\Sigma|}|\Sigma|\right)$, e a de espaço $O\left((m n+|\Sigma|) 2^{|\Sigma|}\right)$ (assintoticamente, são iguais ao caso anterior).

Vale notar que, se, para todo $R[i, j, S] \operatorname{com}|S|=p, R[i, j, S]=n+1$, então não existe solução de valor $p$, o que implica que podemos parar o algoritmo. Como as colunas da matriz (para cada conjunto $S \subseteq \Sigma$ ) podem ser construídas conforme necessárias, esse término também reduz o consumo de espaço.

Podemos aproveitar a estrutura da matriz para reduzir o consumo de tempo e espaço. Para qualquer $S \subseteq \Sigma$, observe que $R(i, j, S)=1$ implica que $R\left(i^{\prime}, j^{\prime}, S\right)=1$ para quaisquer $i^{\prime} \geq i, j^{\prime} \geq j$. Assim, em vez de armazenar uma matriz $\bar{R}[i, j]$ para representar os valores de $R(i, j, S)$ para um 
$S$ fixo, podemos representá-la em um vetor $R^{\prime}$ tal que $R^{\prime}[i]$ é o menor $j$ tal que $R(i, j, S)=1$, de forma parecida ao conceito de limiar do algoritmo de Hunt e Szymanski para LCS da Seção 7.4.

Assim, seja $R[i, S]$ o valor $R^{\prime}[i]$ para o conjunto $S$. Então, se $x_{i} \notin S$, pela recorrência, vale que $R[i, S]=R[i-1, S]$. Caso contrário, a recorrência implica que o primeiro valor de $j$ para o qual $R(i, j, S)=1$ é o menor $\hat{\jmath}$ tal que $(i, \hat{\jmath})$ é casamento e $R\left(i-1, \hat{\jmath}-1, S \backslash\left\{x_{i}\right\}\right)=1$. Isto é, $R[i, S]=j$, onde $j$ é o menor $\hat{\jmath}$ estritamente maior que $R\left[i-1, S \backslash\left\{x_{i}\right\}\right]$ tal que $(i, \hat{\jmath})$ é casamento.

$\mathrm{O}$ algoritmo fica como a seguir.

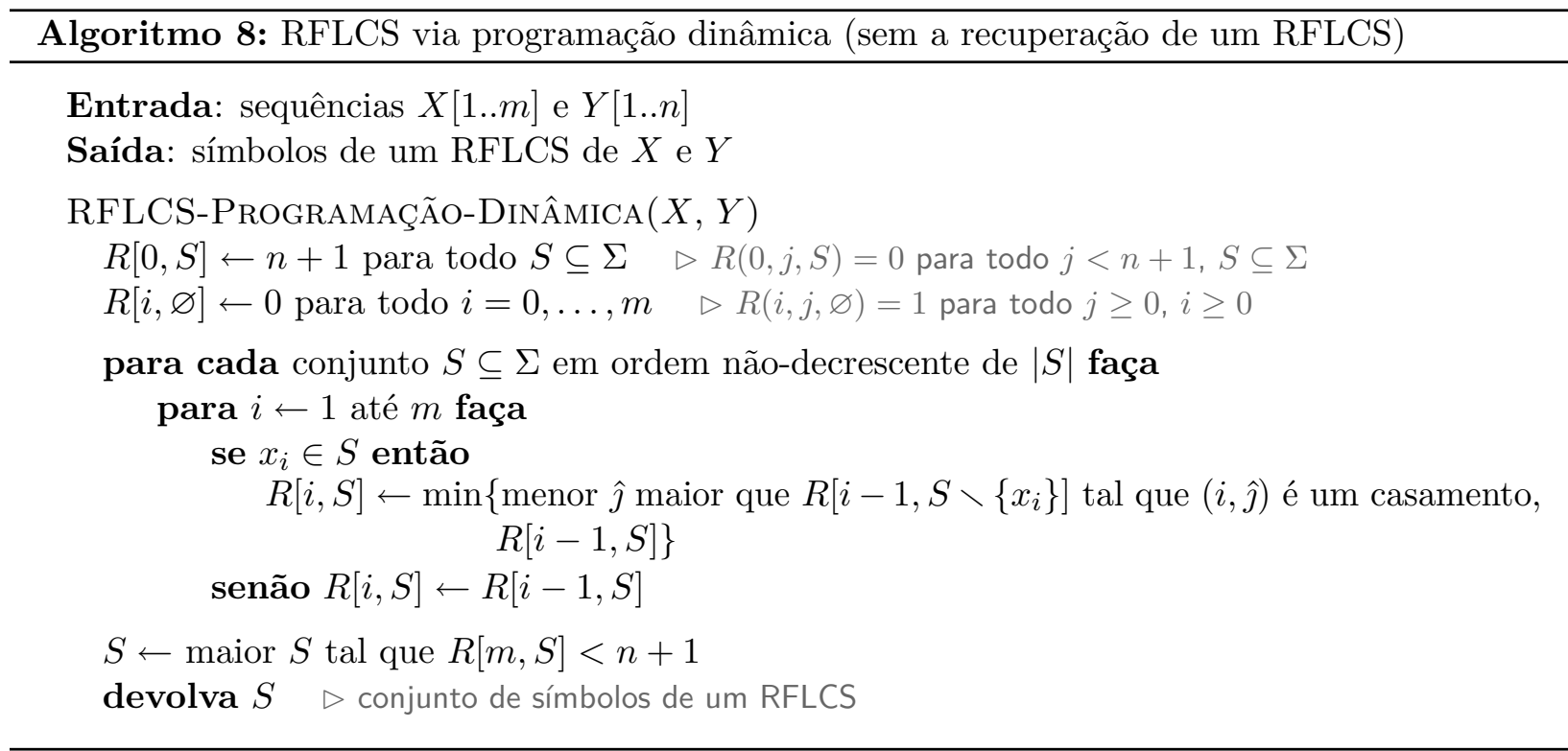

Neste caso, para recuperar um RFLCS, pode ser feito algo análogo à recuperação na versão anterior: construir uma matriz de tamanho igual a $R$ onde cada posição armazena quais das duas possibilidades $(i-1, j, S)$ ou $\left(i-1, j-1, S \backslash\left\{x_{i}\right\}\right)$ escolhemos, e fazer o caminho inverso, guardando, na ordem inversa, os símbolos escolhidos. Alternativamente, podemos refazer o caminho na própria matriz $R$ : basta, da posição $(i, S)$, encontrar o menor $\hat{\imath}$ tal que $\hat{\imath}=i^{\prime}$ para todo $i^{\prime} \geq \hat{\imath}$, guardar o símbolo $\sigma$ do casamento $(\hat{\imath}, R(i, S))$ dessa posição, e repetir o mesmo processo a partir da posição $(\hat{\imath}-1, S \backslash\{\sigma\})$ até chegar na linha 0 ou $\mathrm{S}$ vazio, obtendo assim um RFLCS em ordem inversa.

Supondo que $R[i, S]$ possa ser acessado em tempo constante, se percorrermos os casamentos explicitamente através de uma estrutura de dados (como na Seção 7.4), a complexidade de tempo deste algoritmo é $O\left(|\mathcal{C}| 2^{|\Sigma|}\right)$, e de espaço é $\Theta\left(m 2^{|\Sigma|}\right)$. Se usarmos uma tabela proxPos $Y$ como na Seção 7.6.1, onde proxPos $Y[\sigma, t]$ é o menor $j$ maior que $t$ tal que $y_{j}=\sigma$ (isto é, proxPos $Y\left[x_{i}, t\right]$ é o menor $j$ maior que $t$ tal que $(i, j)$ é um casamento), ou $n+1$ se não existir, as complexidades tanto de tempo como de espaço ficam $O\left(|\Sigma| n+m 2^{|\Sigma|}\right.$ ) (não é necessária uma estrutura de dados para percorrer casamentos nesse caso). Usando um vetor binário para representar todos os conjuntos $S \subseteq \Sigma$ e acessar o valor $R[i, S]$ para todo $i$, a complexidade de tempo fica $O\left(|\Sigma| n+m 2^{|\Sigma|}|\Sigma|\right)$, e a de espaço $O\left(|\Sigma| n+(m+|\Sigma|) 2^{|\Sigma|}\right)$ (assintoticamente, são as mesmas do caso anterior).

Isto é, se $|\Sigma|$ for constante, temos um algoritmo de tempo e espaço lineares para o problema do RFLCS. Se $|\Sigma|$ for limitado por $O(\log n)$, então o algoritmo tem tempo e espaço polinomiais.

Os gráficos seguintes mostram o consumo de tempo e de memória do algoritmo com um enfoque nos tamanhos de alfabeto 5, 15 e 20 respectivamente. A implementação codifica os subconjuntos 
do alfabeto nos bits de um número inteiro (assim, a implementação tem um limite no tamanho do alfabeto). Eles evidenciam o comportamento linear do algoritmo. A única aparente exceção é o caso em que o tamanho do alfabeto é 25. Porém, o gráfico tem essa aparência apenas porque o algoritmo termina ao encontrar um valor $k$ tal que $R[i, S]=n+1$ para todo $i>0$ e $|S|=k$, o que indica que não existe subsequência comum sem repetições de comprimento igual a $k$. Isso parece não ocorrer com os outros casos porque, para alfabetos menores, a solução é quase sempre o próprio tamanho do alfabeto (para instâncias uniformes). 

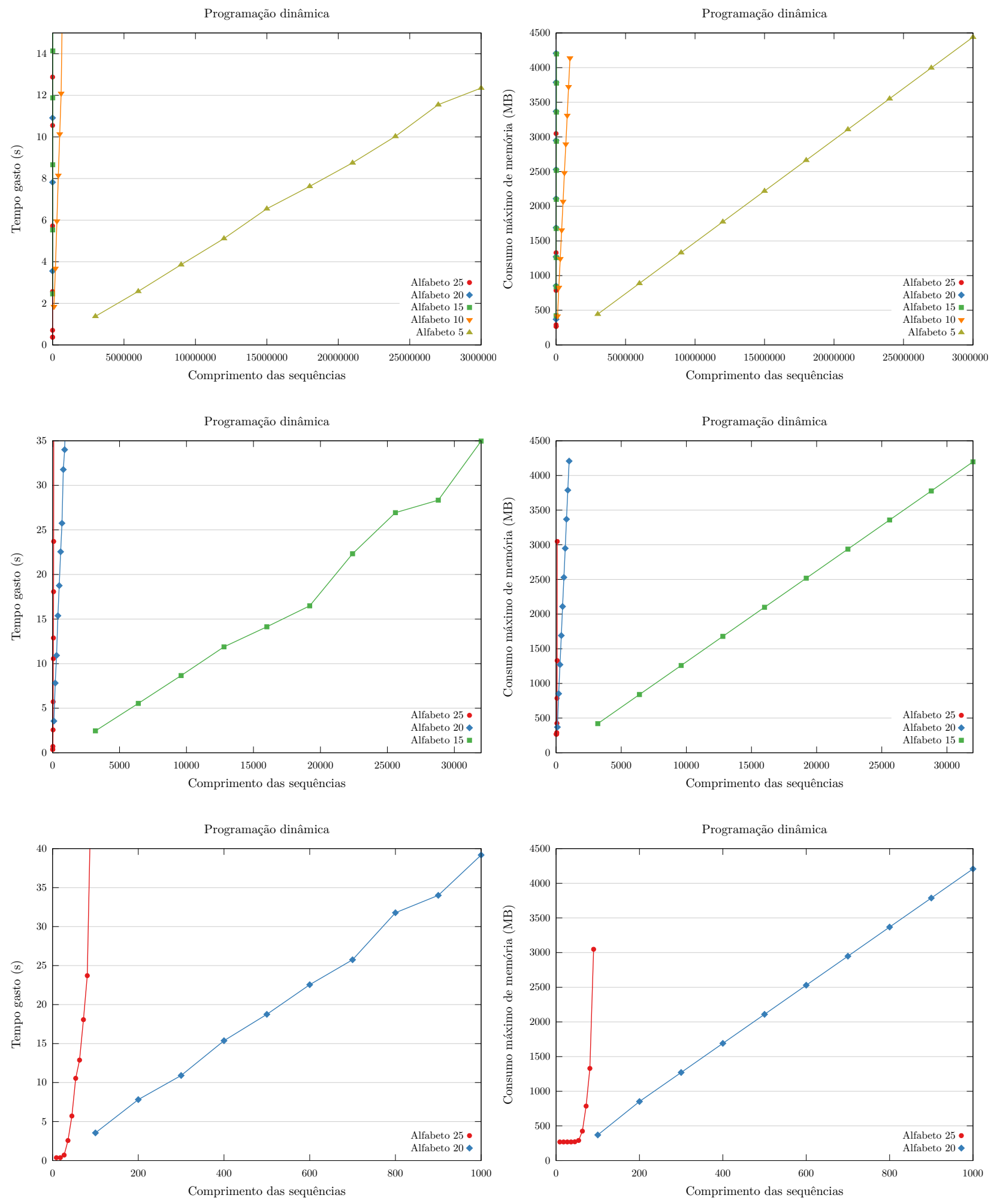


\subsection{Conjunto independente no grafo de conflito}

Lembremos que, como o problema do RFLCS para $X$ e $Y$ é, no fundo, o problema do conjunto independente máximo para o grafo de conflito de $X$ e $Y$ (como visto na Seção 2.3), podemos aplicar um algoritmo exato para o problema do conjunto independente máximo no grafo de conflito de $X$ e $Y$. Dois exemplos de algoritmos que podem ser aplicado são o de Östergård [36] e o de Konc e Janežič [28] (que são de clique máximo, mas basta usar o complemento do grafo de conflito como entrada).

Ambos os algoritmos funcionam muito bem para o problema do RFLCS e inclusive superam o algoritmo branch-and-cut em algumas instâncias. Porém, como podemos ver pelos gráficos abaixo, o algoritmo branch-and-cut funciona melhor em instâncias maiores. As implementações usadas nos gráficos abaixo são dos próprios autores.
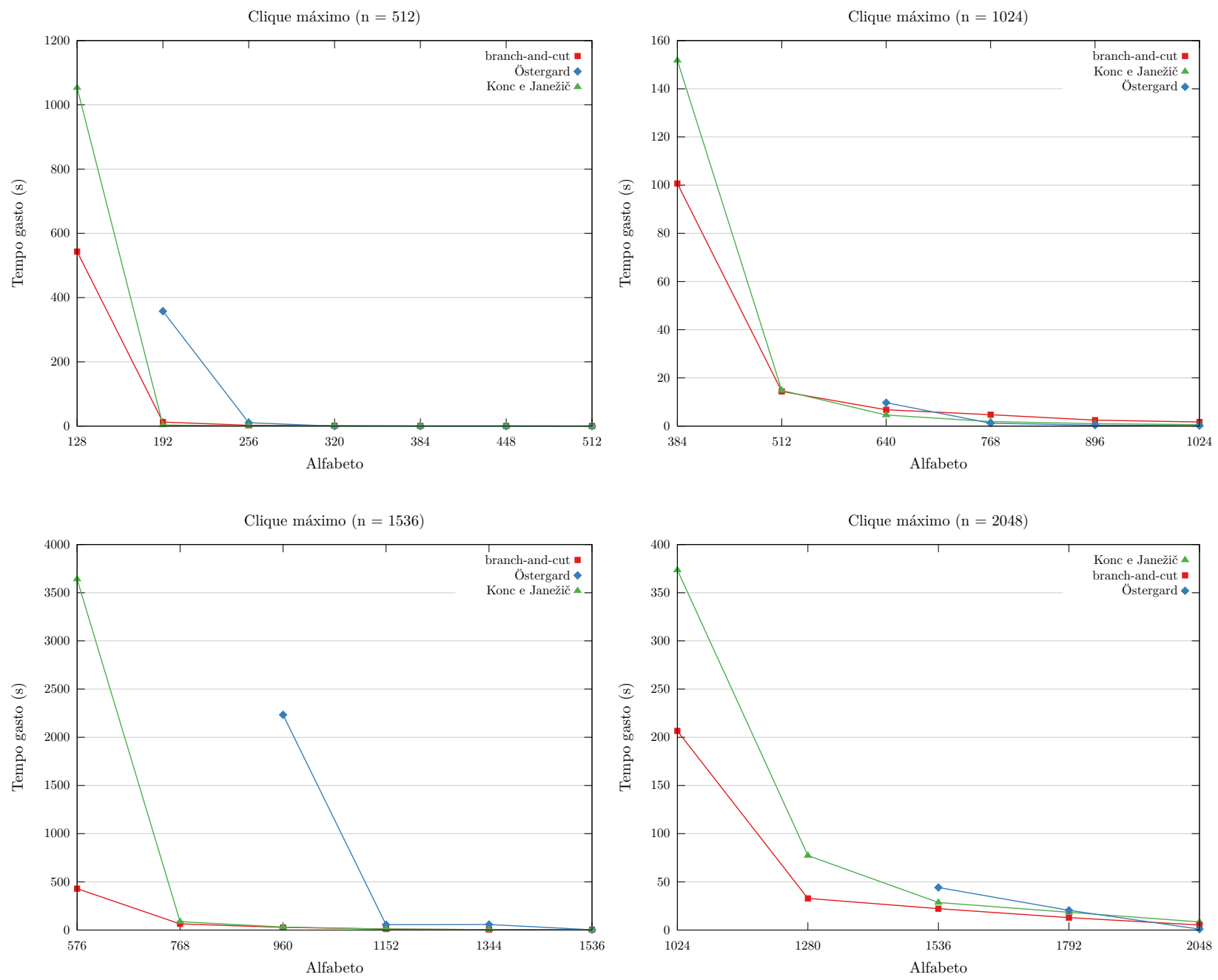


\section{CAPÍtulo 7}

\section{Algoritmos para LCS}

Este capítulo é uma resenha de algoritmos para o problema do LCS auto-contida e independente do resto da dissertação. Repetiremos algumas definições já dadas. O leitor que já leu o Capítulo 1 (Introdução) pode pular a seção de Introdução desta capítulo. O Capítulo 2 (Os problemas e suas estruturas) intersecta com a Seção 7.3. A Seção 7.10 apresenta um algoritmo não encontrado na literatura.

\subsection{Introdução}

Comparar sequências (como palavras, segmentos de DNA e linhas de arquivo) surge em diversos contextos. Um dos critérios mais comuns e simples para comparar duas sequências é encontrar uma outra sequência de maior comprimento possível cujos símbolos podem ser encontrados em ambas as sequências e na mesma ordem relativa (não necessariamente contígua). O comprimento dessa sequência nos diz quão similares são as duas sequências. É este critério que estudaremos neste texto: tal sequência se chama subsequência comum máxima, ou LCS, do inglês longest common subsequence.
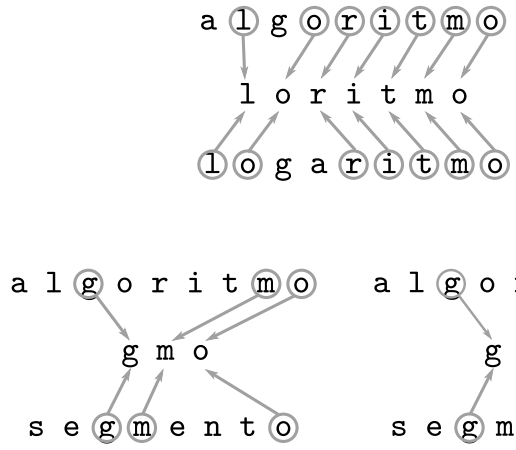
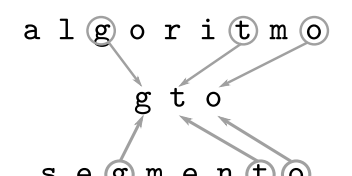

Comprimento dos LCSs $=3$

(palavras mais diferentes)

Formalmente, uma sequência é uma lista ordenada de símbolos que pertencem a um alfabeto finito $\Sigma$. Uma subsequência de uma sequência $X$ é uma sequência que pode ser construída removendo símbolos de $X$. Ela não precisa ser um pedaço contíguo de $X$, e ela pode inclusive ser o próprio $X$ ou vazia. Uma subsequência comum de $X$ e $Y$ é uma sequência que é tanto 
subsequência de $X$ como de $Y$. Uma subsequência comum máxima ou LCS é uma subsequência comum de $X$ e $Y$ que tem comprimento máximo entre todas as outras subsequências comuns de $X$ e $Y$. Note que pode existir mais de um LCS para as mesmas duas sequências. O problema do LCS é o problema de encontrar um LCS de duas sequências $X$ e $Y$ dadas.

O objetivo deste texto é descrever alguns algoritmos principais para o problema do LCS e compará-los. Um boa resenha sobre algoritmos para o problema do LCS foi publicada por Bergroth, Hakonen e Raita [5]. Neste texto, descrevemos os algoritmos de forma mais detalhada. Alguns aspectos superficiais dos algoritmos foram modificados neste texto para facilitar o entendimento.

Antes de prosseguir, estabeleceremos algumas convenções e suposições que facilitarão a leitura do texto. Escreveremos as sequências em letras maíusculas e seus elementos em minúsculas, como em $X=x_{1} x_{2} \ldots x_{m}$. A sequência $X[i . . j]$ denota o pedaço de $X$ que vai de $i$ até $j$; isto é, a sequência $x_{i} x_{i+1} \ldots x_{j}$. Algumas vezes essa notação é usada apenas para indicar o comprimento da sequência; isto é, dizer $X[1 . . m]$ sem ter mencionado $X$ antes significa que $X$ tem comprimento $m$. Denotamos $X$ concatenado com $Y$ por $X Y$, sejam $X$ e $Y$ sequências ou símbolos. Denotamos também o comprimento de $X$ por $|X|$. A entrada para o problema sempre será implicitamente $X$ e $Y$ de comprimentos $m$ e $n$ respectivamente, com a suposição de que $m \leq n$, sem perda de generalidade. Também suporemos neste texto que os símbolos do alfabeto vão de 1 a $|\Sigma|$ (caso contrário, podemos mapeá-los). Suporemos que $|\Sigma| \leq m$, pois nenhuma subsequência comum das sequências conterá algum símbolo que não está presente nas duas sequências.

O problema do LCS tem uma estrutura inerente bastante interessante, mas antes de examiná-la, vale a pena começar descrevendo o algoritmo tradicional para o problema do LCS, que já nos revela bastante sobre essa estrutura.

\subsection{Algoritmo de programação dinâmica}

Programação dinâmica é uma técnica que emprega uma tabela para resolver problemas com alguma recorrência inerente ("programação" tem o significado de "planejamento" neste contexto e não de programação de computadores ou máquinas). A ideia é armazenar soluções de subproblemas em uma tabela em alguma ordem esperta de forma que, quando um subproblema puder se aproveitar da solução de outro subproblema, este último já está na tabela. Para este método funcionar bem, o problema deve conter muitos subproblemas que se "sobrepõem", isto é, subproblemas cujas soluções ótimas possam ser utilizadas por outros subproblemas. Em outras palavras, o problema deve ter a propriedade da subestrutura ótima.

Um problema possui a propriedade da subestrutura ótima se podemos extrair soluções ótimas de subproblemas menores a partir de uma solução ótima desse problema. O lema seguinte enuncia essa propriedade para o problema do LCS: ele afirma que a partir de um LCS de duas sequências, podemos obter um LCS de duas sequências menores.

Lema 7.2.1 (Propriedade da subestrutura ótima). Seja $Z[1 . . k]$ um LCS de $X[1 . . i]$ e $Y[1 . . j]$.

$$
\begin{aligned}
& \text { Se } x_{i}=y_{j} \text {, então } z_{k}=x_{i}=y_{j} \text { e } Z[1 . . k-1] \text { é um LCS de } X[1 . . i-1] \text { e } Y[1 . . j-1] \text {. } \\
& \text { Se } x_{i} \neq y_{j} \text {, então } \\
& \quad \text { se } z_{k} \neq x_{i} \text {, então } Z[1 . . k] \text { é um } L C S \text { de } X[1 . . i-1] \text { e } Y[1 . . j] ; \text { e } \\
& \quad \text { se } z_{k} \neq y_{j} \text {, então } Z[1 . . k] \text { é um } L C S \text { de } X[1 . . i] \text { e } Y[1 . . j-1] \text {. }
\end{aligned}
$$


Prova. Se $x_{i}=y_{j}$, então $z_{k}=x_{i}\left(=y_{j}\right)$, pois, caso contrário, poderíamos adicionar $x_{i}$ a $Z$ para obter uma subsequência comum de comprimento maior, o que é uma contradição pois $Z$ é um LCS. Logo, $Z[1 . . k-1]$ é uma subsequência comum de $X[1 . . i-1]$ e $Y[1 . . j-1]$, e resta provar que seu comprimento $k-1$ é máximo. Suponha que existe alguma subsequência comum $Z^{\prime}$ de $X[1 . . i-1]$ e $Y[1 . . j-1]$ de comprimento maior que $k-1$. Se adicionarmos $z_{k}$ a $Z^{\prime}$, teríamos uma subsequência comum de $X[1 . . i]$ e $Y[1 . . j]$ de comprimento maior que $k$, o que é uma contradição. Portanto, $Z[1 . . k-1]$ é um LCS de $X[1 . . i-1]$ e $Y[1 . . j-1]$.

Se $x_{i} \neq y_{j}$ e $z_{k} \neq x_{i}$, então $Z[1 . . k]$ é uma subsequência comum de $X[1 . . i-1]$ e $Y[1 . . j]$. Seu comprimento $k$ é máximo pois toda subsequência comum de $X[1 . . i-1]$ e $Y[1 . . j]$ também é subsequência comum de $X[1 . . i]$ e $Y[1 . . j]$, cujo comprimento máximo é $k$. Portanto, $Z[1 . . k]$ é um LCS de $X[1 . . i-1]$ e $Y[1 . . j]$.

O caso $x_{i} \neq y_{i}$ e $z_{k} \neq y_{j}$ é análogo ao anterior.

Seja $L(i, j)$ o comprimento de um LCS de $X[1 . . i]$ e $Y[1 . . j]$. Se uma das sequências $X$ ou $Y$ é vazia (consideramos $X[1 . .0]$ como uma sequência vazia), a única subsequência comum de $X$ e $Y$ é vazia e portanto o comprimento de um LCS é 0. Logo,

$$
L(0, j)=0 \text { e } L(i, 0)=0 \text { para todo } i=0, \ldots, m \text { e } j=0, \ldots, n .
$$

Além disso, se $x_{i}=y_{j}$, podemos obter um LCS de $X[1 . . i]$ e $Y[1 . . j]$ adicionando $x_{i}$ ao final de um LCS de $X[1 . . i-1]$ e $Y[1 . . j-1]$. Se $x_{i} \neq y_{j}$, podemos obter um LCS de $X[1 . . i]$ e $Y[1 . . j]$ escolhendo o mais comprido entre um LCS de $X[1 . . i-1]$ e $Y[1 . . j]$ e um de $X[1 . . i]$ e $Y[1 . . j-1]$.

Assim, para $i \geq 1$ e $j \geq 1$, vale a seguinte recursão:

$$
L(i, j)= \begin{cases}L(i-1, j-1)+1 & \text { se } x_{i}=y_{j}, \\ \max \{L(i, j-1), L(i-1, j)\} & \text { se } x_{i} \neq y_{j}\end{cases}
$$

O algoritmo de programação dinâmica basicamente trata $L$ como uma matriz e constrói-a linha por linha usando a recursão acima. Denotaremos por $L[i, j]$ o valor na linha $i$ e coluna $j$ da matriz $L$.

O valor $L[m, n]$ nos dá apenas o comprimento de um LCS. Uma maneira de obter um LCS em si está implícita na recursão: símbolos são apenas adicionados quando $x_{i}=y_{j}$. Após construirmos $L$, podemos encontrar qual subproblema usamos para computar $L[m, n]$ (isto é, para qual posição de $L$ olhamos para computar $L[m, n]$ ), e repetir este processo recursivamente para cada subproblema encontrado. Se, neste processo, armazenarmos os símbolos $x_{i}$ quando $x_{i}=y_{j}$, obtemos um LCS em ordem inversa. Para isso, podemos manter uma matriz $B$ (de backtracking) tal que $B[i, j]$ guarda qual posição da matriz que escolhemos no cálculo de $L[i, j]$ (indicamos isso no algoritmo com setas

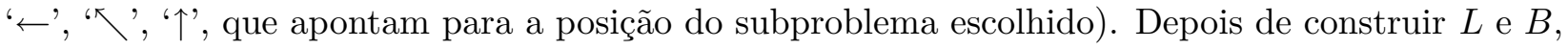
basta percorrer $B$ começando de $B[m, n]$, seguindo essas setas e guardando símbolos $x_{i}$ ao encontrar setas ‘ ' (ou seja, quando $x_{i}=y_{j}$ ). Essa sequência de símbolos é um LCS em ordem inversa.

Quando $L[i, j-1]=L[i-1, j]$, não importa se escolhemos ' $\leftarrow$ ' ou ' $\uparrow$ ' na matriz $B$. A diferença é que o LCS resultante pode ser diferente se escolhido um outro caminho. Seguir todos os possíveis caminhos resulta em todos os possíveis LCSs da sequência, embora provavelmente um mesmo LCS será encontrado várias vezes.

O exemplo nas figuras seguintes ilustra as matrizes $L$ e $B$ para duas sequências. Na matriz $L$ estão destacadas as posições $(i, j)$ para as quais $x_{i}=y_{j}$. Observe que, para essas posições, existe 
uma seta ' $\$ ' em $B$. Na matriz $B$, sobrepomos ' $\leftarrow$ ' e ' $\uparrow$ ' para indicar que ambos os caminhos são possíveis, e indicamos um caminho para cada LCS das sequências (podem existir outros caminhos para um mesmo LCS). Além disso, em $B$, traçamos em pontilhado contornos que delimitam os valores da matriz $L$.

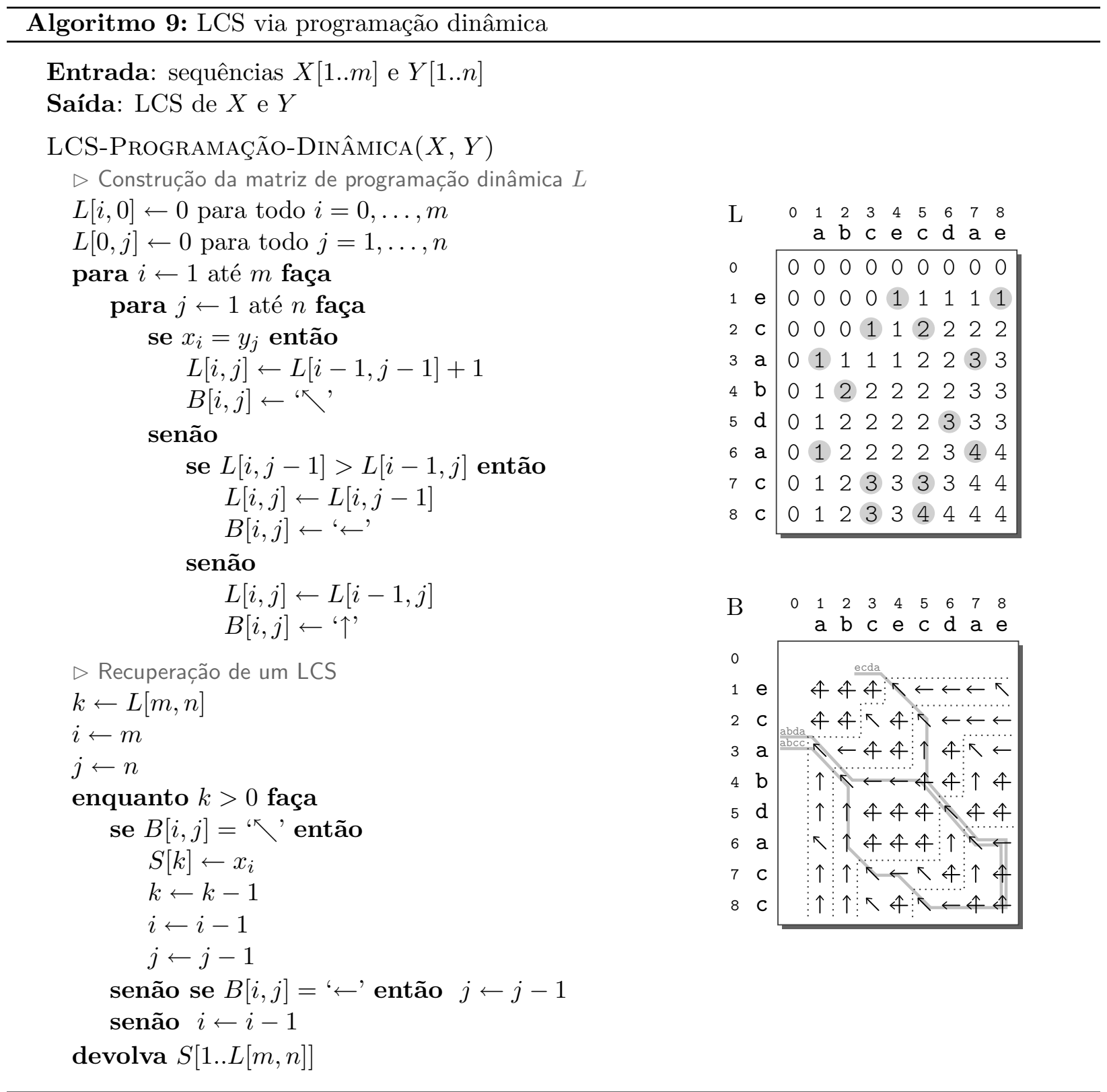

É fácil ver que o algoritmo consome tempo e espaço $\Theta(m n)$ : a computação de cada um dos $m n$ elementos das matrizes $L$ e $B$ é feita em tempo constante e a recuperação do LCS resultante é feita em tempo $O(m+n)$. Este algoritmo é geralmente atribuído a Wagner e Fischer [45], de 1974. Ocasionalmente, ele também é atribuído a Needleman e Wunsch [35], que construíram um algoritmo similar a este sob o contexto de Biologia Computacional. Nas seções seguintes, referiremo-nos bastante à matriz de programação dinâmica $L$ para explicar melhor as ideias dos algoritmos. 


\subsection{Visualização da estrutura do LCS}

O objetivo desta seção é definir alguns conceitos importantes e dar uma noção visual da estrutura de subsequências comuns, o que facilitará o entendimento dos algoritmos para o problema do LCS.

Na seção anterior, vimos que, na recursão, o comprimento de um LCS só aumenta ao encontrarmos pares $(i, j)$ tais que $x_{i}=y_{j}$. Como cada par $(i, j)$ está associado a um símbolo $\sigma=x_{i}=y_{j}$, podemos enxergar qualquer subsequência comum como um conjunto de pares $(i, j)$ tais que $x_{i}=y_{j}$. Denominamos esses pares ordenados de casamentos. Observe pelas duas primeiras figuras abaixo que uma subsequência comum pode estar relacionada a mais de um conjunto de casamentos. A terceira figura mostra todos os casamentos de duas sequências.
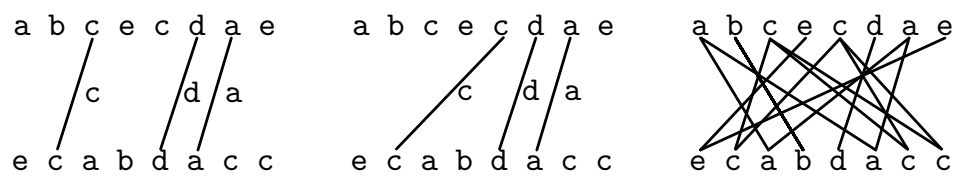

É claro que nem todo conjunto de casamentos está relacionado a uma subsequência comum. Se dois casamentos visualmente se cruzam ou têm uma ponta em comum, como no exemplo abaixo, não é possível construir uma subsequência comum baseada diretamente neles. Assim, definimos que dois casamentos $\left(c_{i}, c_{j}\right)$ e $\left(d_{i}, d_{j}\right)$ se cruzam se $c_{i} \leq d_{i}$ e $c_{j} \geq d_{j}$, ou $c_{i} \geq d_{i}$ e $c_{j} \leq d_{j}$ (essa definição inclui ter pontas em comum).
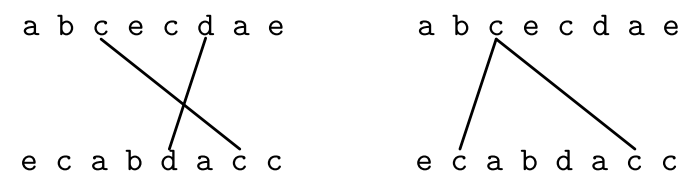

Dizemos que $(i, j)$ precede $(k, l)$ (ou $(k, l)$ sucede $(i, j)$ ) se $i<k$ e $j<l$, e denotamos isso por $(i, j) \prec(k, l)$. Isto é, $(i, j)$ não cruza com $(k, l)$ e está à esquerda de $(k, l)$ na representação gráfica.

É fácil ver que, dado um conjunto de casamentos $C=\left\{\left(i_{1}, j_{1}\right),\left(i_{2}, j_{2}\right), \ldots,\left(i_{k}, j_{k}\right)\right\}$, seus elementos não se cruzam dois a dois se e só se eles podem ser ordenados de forma que $\left(i_{l_{1}}, j_{l_{1}}\right) \prec$ $\left(i_{l_{2}}, j_{l_{2}}\right) \prec \ldots \prec\left(i_{l_{k}}, j_{l_{k}}\right)$, onde $\left(l_{1}, l_{2}, \ldots, l_{k}\right)$ é uma permutação de $\{1,2, \ldots, k\}$. Assim, dizemos que um conjunto de casamentos $C=\left\{\left(i_{1}, j_{1}\right),\left(i_{2}, j_{2}\right), \ldots,\left(i_{k}, j_{k}\right)\right\}$ com seus elementos ordenados de tal maneira é uma representação da subsequência comum $S=x_{i_{1}} x_{i_{2}} \ldots x_{i_{k}}=y_{j_{1}} y_{j_{2}} \ldots y_{j_{k}}$.

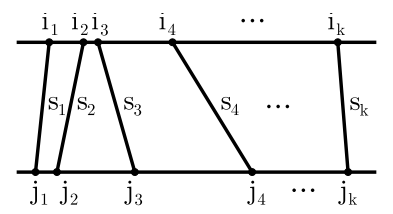

A figura seguinte ilustra a matriz de programação dinâmica $L$, que vimos na se,ão anterior, com os pares $x_{i}=y_{j}$ (casamentos) destacados. A figura à direita nos mostra, dado um casamento, as regiões na matriz em que estão os casamentos que cruzam com ele. Isto é, uma vez que escolhemos um certo casamento para estar em uma subsequência comum, não podemos escolher os casamentos nas regiões sombreadas. 

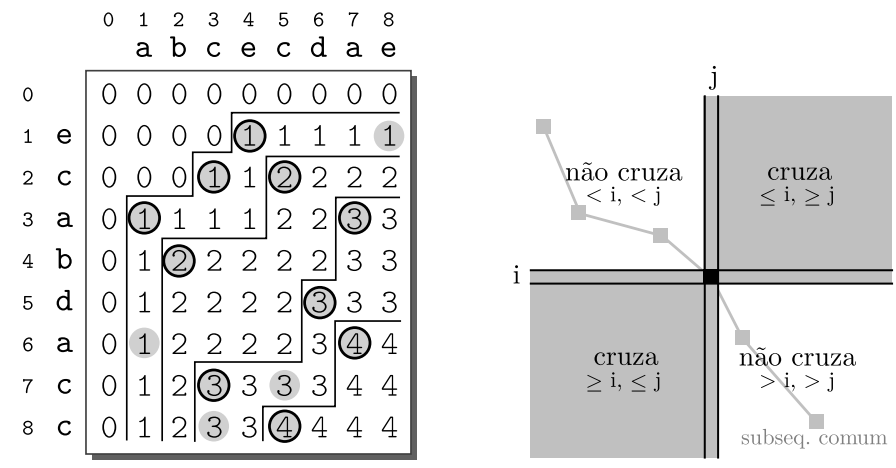

Note que a matriz é definida inteiramente pela posição dos casamentos. Eles formam "cantos" nos contornos que definem cada região de valores. Ainda mais, nem todos casamentos formam esses "cantos", e tais casamentos são desnecessários para definir a matriz. Esta observação é fundamental para alguns dos algoritmos descritos neste texto. Os casamentos que definem as regiões (isto é, que formam os "cantos"), marcados com uma borda circular preta, são chamados de casamentos dominantes (definiremos esse conceito formalmente quando for necessário mais adiante). Vale observar também que os casamentos que fazem parte de um mesmo contorno se cruzam e que, para cada contorno, existe no máximo um dominante por linha e por coluna. Tudo isso será revisto mais formalmente quando empregarmos essas propriedades para desenvolver os algoritmos.

É interessante ver o problema do LCS sob o ponto de vista de grafos.

Tome as posições da matriz $L$ como vértices de um grafo orientado tal que cada vértice $(i, j)$ tem um arco para $(i+1, j)$ e para $(i, j+1)$ se existirem e, se $(i, j)$ for um casamento, existe um arco de $(i-1, j-1)$ para $(i, j)$. A primeira figura seguinte ilustra esse grafo e lembra um pouco a matriz $B$ do algoritmo de programação dinâmica.
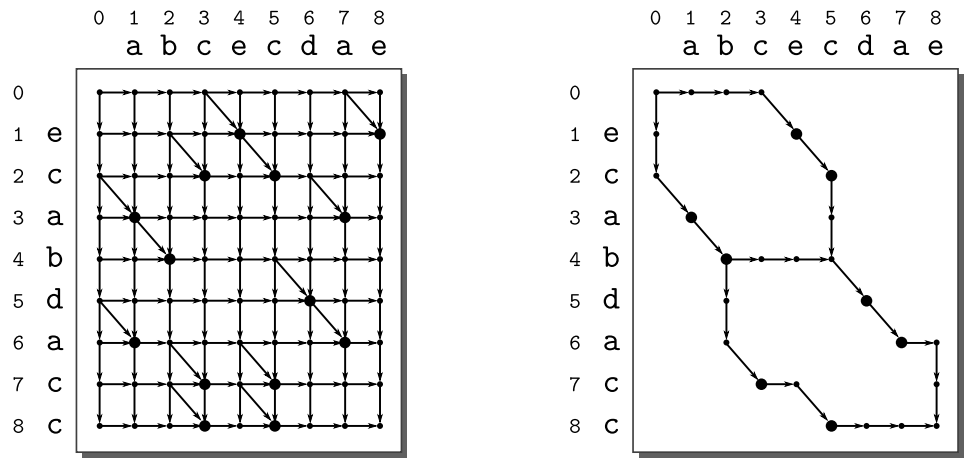

Podemos obter um LCS encontrando nesse grafo orientado um caminho mínimo que começa em $(0,0)$ e termina em $(m, n)$. De fato, usando apenas os arcos horizontais e verticais, o comprimento de um caminho de $(0,0)$ a $(m, n)$ é sempre $m+n$, mas usar um arco diagonal serve como um atalho diminuindo esse comprimento em 1. Então um caminho mínimo nesse grafo usa o maior número de arcos diagonais possível, cada um relacionado a um casamento. Assim, como o grafo garante que dois casamentos (dados pelos arcos diagonais) em um mesmo caminho não se cruzam, os arcos 
diagonais que um caminho mínimo contém definem os casamentos de um LCS. A figura à direita mostra os arcos e vértices dos caminhos que definem LCSs.

Considere agora um outro grafo orientado onde os vértices são os casamentos e existe um arco de $\left(c_{i}, c_{j}\right)$ para $\left(d_{i}, d_{j}\right)$ se $\left(c_{i}, c_{j}\right) \prec\left(d_{i}, d_{j}\right)$ (é importante notar que $\left(c_{i}, c_{j}\right)$ e $\left(d_{i}, d_{j}\right)$ não se cruzam). A primeira figura a seguir ilustra esse grafo.
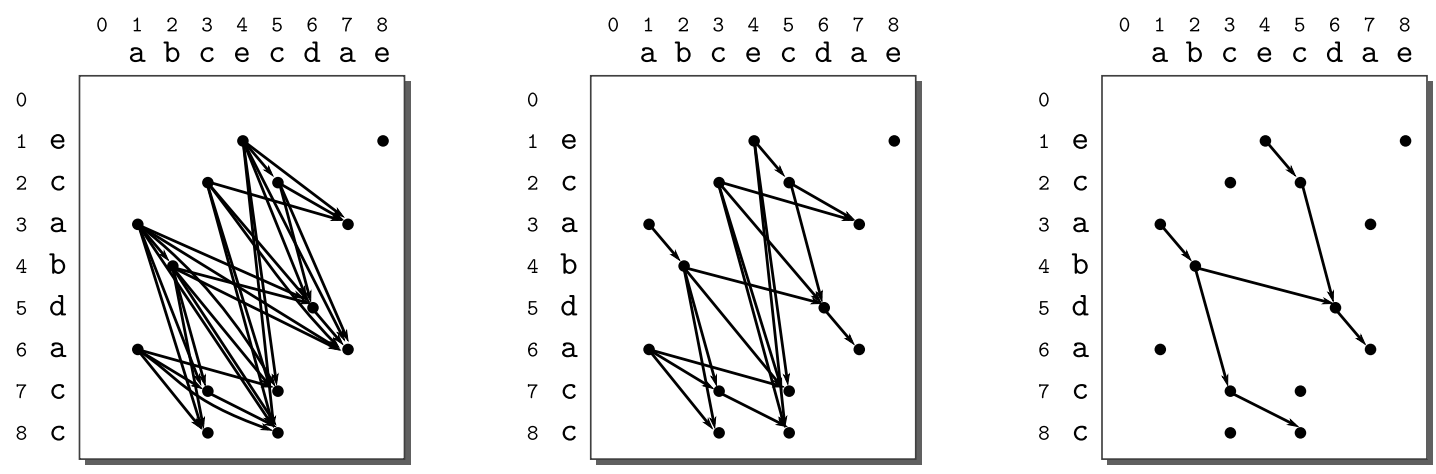

Nesse grafo acíclico, um LCS é um caminho máximo, já que queremos escolher o número máximo de casamentos $\left(i_{t}, j_{t}\right)$ para os quais existe a ordenação $\left(i_{1}, j_{1}\right) \prec\left(i_{2}, j_{2}\right) \prec \ldots \prec\left(i_{k}, j_{k}\right)$. Isso ainda vale se eliminarmos os arcos transitivos como na segunda figura $(\operatorname{arcos}(c, e)$ tais que existem $(c, d)$ e $(d, e))$, pois, para todo arco transitivo $(c, d)$, existe um outro caminho maior de $c$ a $d$. A terceira figura mostra os arcos e vértices dos caminhos que definem LCSs.

Vale observar que o grafo acima sem orientação é um grafo de comparabilidade por definição: as arestas são definidas por uma ordem parcial (estrita). No grafo não orientado, o problema de encontrar um LCS se torna o problema de encontrar um clique máximo, já que queremos o maior conjunto de casamentos que não se cruzam dois a dois. Esse é um problema difícil para grafos em geral mas resolvível em tempo polinomial para grafos de comparabilidade [15].

Tendo em mente essa visão dos casamentos em uma matriz, referiremos ao longo do texto, como um pouco de abuso de notação, à linha e à coluna de um casamento $(i, j)$ como sendo $i$ e $j$ respectivamente, ou simplesmente linha e coluna como índices de $X$ e $Y$ respectivamente.

Nas próximas seções, mostraremos algoritmos para o LCS. A tendência dos algoritmos diferentes do de programação dinâmica é se especializarem em certas classes de instâncias e boa parte deles se relacionam de uma forma ou outra com a matriz de programação dinâmica. O algoritmo assintoticamente mais rápido consome tempo $O(m n / \log n)$, mas tem uma natureza mais teórica do que prática (Seção 7.9). Dentre os algoritmos implementados, o algoritmo mais rápido na prática (para instâncias grandes aleatórias com distribuição de símbolos uniforme) é o algoritmo de Hunt e Szymanski, descrito na seção seguinte.

\subsection{Algoritmo por limiares de Hunt e Szymanski}

O algoritmo Hunt-Szymanski [22], de 1977, foi um dos primeiros algoritmos para o LCS diferentes do algoritmo clássico de programação dinâmica. Essencialmente, ele é um algoritmo que organiza a matriz de programação dinâmica $L$ de forma mais compacta e propõe-se a encontrar o valor equivalente a $L[m, n]$. 
A ideia deste algoritmo é calcular uma matriz $T$ onde $T[i, k]$ é o menor $j$ de forma que $X[1 . . i]$ e $Y[1 . . j]$ contenham uma subsequência comum de comprimento $k$, ou é $\infty$ se não existir (na prática, consideraremos $\infty$ como $n+1$ ). O número de colunas de $T$ seria o comprimento de um LCS, mas como não sabemos esse valor de antemão, ele pode ser limitado por $m$ (supondo que $m \leq n$ ). Este conceito pode ser relacionado com a matriz de programação dinâmica $L$ vista anteriormente, como exemplificado pela figura abaixo.

\begin{tabular}{|c|c|c|c|c|c|c|c|c|c|c|c|c|c|c|c|c|c|c|}
\hline $\mathrm{L}$ & 0 & $\begin{array}{l}1 \\
\mathrm{a}\end{array}$ & $\begin{array}{l}2 \\
\mathrm{~b}\end{array}$ & $\begin{array}{ll}3 & 4 \\
\mathrm{C} & \mathrm{e}\end{array}$ & $\begin{array}{l}5 \\
C\end{array}$ & $\begin{array}{l}6 \\
d\end{array}$ & & & $\mathrm{~T}$ & & 0 & 1 & 2 & 3 & 4 & 5 & 6 & 7 \\
\hline 0 & 0 & 0 & 0 & 00 & 0 & 0 & 0 & 0 & 0 & & 0 & $\infty$ & $\infty$ & $\infty$ & $\infty$ & $\infty$ & & 80 \\
\hline $\mathrm{e}$ & 0 & 0 & $\mathrm{O}_{3}$ & ${ }_{3} 0 \mid 1$ & 1 & 1 & 1 & 1 & & & 0 & 4 & $\infty$ & $\infty$ & $\infty$ & $\infty$ & $\infty$ & D \\
\hline C & 0 & ${ }_{1}^{0}$ & 01 & $\begin{array}{ll}1 & 1\end{array}$ & 2 & 2 & 2 & 2 & & & 0 & 3 & 5 & $\infty$ & $\infty$ & $\infty$ & D & $\infty$ \\
\hline a & 0 & 1 & 1 & 11 & 2 & 2 & 3 & 3 & 3 & $\mathrm{a}$ & 0 & 1 & 5 & 7 & $\infty$ & $\infty$ & 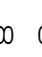 & $\infty$ \\
\hline b & 0 & 1 & 2 & 22 & 22 & 2 & 3 & 3 & 4 & b & 0 & 1 & 2 & 7 & $\infty$ & $\infty$ & $\infty$ & $\infty$ \\
\hline$d$ & 0 & 1 & 2 & 22 & 22 & 3 & 3 & 3 & & $\mathrm{~d}$ & 0 & 1 & 2 & 6 & $\infty$ & $\infty$ & o & o \\
\hline $\mathrm{a}$ & 0 & 1 & 2 & 22 & 22 & $3 \mid$ & 4 & 4 & & $\mathrm{a}$ & 0 & 1 & 2 & 6 & 7 & $\infty$ & Do & D \\
\hline C & 0 & 1 & $2 \mid$ & 33 & 33 & 3 & 4 & 4 & & c & 0 & 1 & 2 & 3 & 7 & $\infty$ & o & o \\
\hline C & 0 & $|1|$ & $2 \mid$ & 33 & $\left.3\right|^{5} 4$ & 4 & 4 & 4 & & c & 0 & 1 & 2 & 3 & 5 & $\infty$ & $\infty$ & \\
\hline
\end{tabular}

Em termos de $L, T(i, k)$ é o menor índice $j$ das colunas de $L$ para o qual vale $L(i, j)=k$ se existir, ou $\infty$ caso contrário. Faz sentido definir $T(i, 0)=0$ para todo $i \geq 0$ e $T(0, j)=\infty$ para todo $j>0$. Chamamos os valores de $T$ de limiares.

Observe que podemos obter $T$ a partir de $L$ e vice-versa, e $T$ pode ser visto como uma representação compacta de $L$, especialmente se usarmos, por exemplo, listas para representá-la. Neste algoritmo, no entanto, veremos $T$ como uma matriz mesmo.

Note que o maior $k$ tal que $T[m, k]$ esteja definido é o comprimento de um LCS de $X$ e $Y$. A ideia do algoritmo é calcular a matriz $T$ linha por linha de 1 até $m$ para encontrar esse $k$. Os dois lemas a seguir descrevem uma propriedade da matriz $T$ que nos permite computá-la (sem ter $L$ ).

Lema 7.4.1. Para valores definidos, $T[i-1, k-1]<T[i, k] \leq T[i-1, k]$.

Prova. Por definição, $X[1 . . i-1]$ e $Y[1 . . T[i-1, k]]$ têm uma subsequência comum de comprimento $k$. Logo, $X[1 . . i]$ e $Y[1 . . T[i-1, k]]$ também a têm. Portanto, $T[i, k] \leq T[i-1, k]$.

Também por definição, $X[1 . . i]$ e $Y[1 . . T[i, k]]$ têm uma subsequência comum de comprimento $k$. Se removermos o último símbolo de cada uma dessas sequências, essa subsequência comum perde no máximo um símbolo (na verdade, exatamente um símbolo pela definição de $T$ ). Então $X[1 . . i-1] \mathrm{e}$ $Y[1 . . T[i, k]-1]$ têm uma subsequência comum de comprimento $k-1$. Assim, $T[i-1, k-1] \leq T[i, k]-1$, isto é, $T[i-1, k-1]<T[i, k]$.

Um corolário direto desse lema é que os valores em cada linha são estritamente crescentes, isto é, para valores definidos, $T[i, k-1]<T[i, k]$.

O lema seguinte especifica como podemos computar $T[i, k]$ usando $T[i-1, k-1]$ e $T[i-1, k]$. Tendo em mente o que são limiares na matriz $L$, não é difícil de perceber intuitivamente que o valor do limiar $T[i, k]$ é o menor índice $j$ em que $(i, j)$ é um casamento e que está no intervalo do lema 
anterior, e, se não houver um, então é o maior possível nesse intervalo. O próximo lema enuncia isso. A figura a seguir ilustra isso em um pedaço da matriz $L$, com as barras representando os limiares e o retângulo representando a região onde podemos encontrá-lo.

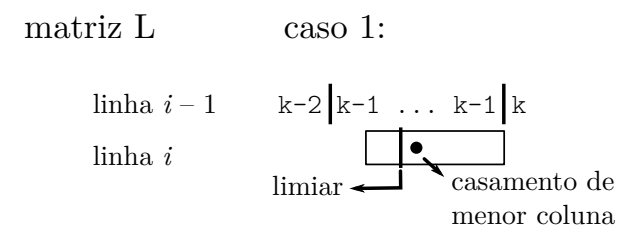

$$
\text { caso 2: }
$$

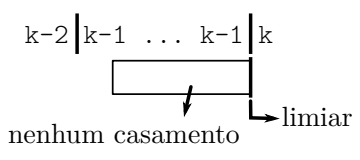

\section{Lema 7.4.2.}

$$
T[i, k]=\left\{\begin{array}{l}
\text { menor } j \text { tal que } x_{i}=y_{j} \text { e } T[i-1, k-1]<j \leq T[i-1, k], \text { ou } \\
T[i-1, k], \text { se tal } j \text { não existe. }
\end{array}\right.
$$

Prova. Primeiro, suponha que o $j$ descrito no lema existe, isto é, existe um $j$ tal que $x_{i}=y_{j}$ e $T[i-1, k-1]<j \leq T[i-1, k]$ e é o menor possível. Pela definição de $T$, existe uma subsequência comum de comprimento $k-1$ para $X[1 . . i-1]$ e $Y[1 . . T[i-1, k-1]]$. Como $j>T[i-1, k-1]$, podemos adicionar o casamento $(i, j)$ a essa subsequência (concatenar $x_{i}$ a ela) e obter uma subsequência comum de comprimento $k$ para $X[1 . . i]$ e $Y[1 . . j]$. Logo, $T[i, k] \leq j$.

Suponha por contradição que $T[i, k]<j$. O Lema 7.4.1 mais essa suposição dizem que $T[i-1, k-1]<T[i, k]<j$. Porém, não existe casamento $\left(i, j^{\prime}\right) \operatorname{com} T[i-1, k-1]<j^{\prime}<j$, pois $j$ é mínimo em sua definição. Portanto, não existe casamento $(i, T[i, k])$. Mantenha essa constatação de lado por um momento.

Suponha agora que o $j$ descrito no lema não existe. Então, não existe casamento $\left(i, j^{\prime}\right)$ tal que $T[i-1, k-1]<j^{\prime} \leq T[i-1, k]$. Logo, como o Lema 7.4.1 diz que $T[i-1, k-1]<T[i, k] \leq T[i-1, k]$, não existe casamento $(i, T[i, k])$.

Assim, se $T[i, k]<j$ ou se $j$ não existir, $(i, T[i, k])$ não é um casamento. Além disso, como $T[i, k]$ é minimal, qualquer subsequência comum de comprimento $k$ de $X[1 . . i]$ e $Y[1 . . T[i, k]]$ deve ter $y_{T[i, k]}$ como seu último elemento. Porém, como $x_{i} \neq y_{T[i, k]}$, podemos remover o último elemento de $X[1 . . i]$ que ainda continuamos com uma subsequência comum de comprimento $k$. Isto é, $X[1 . . i-1]$ e $Y[1 . . T[i, k]]$ têm uma subsequência comum de comprimento $k$. Portanto, $T[i-1, k] \leq T[i, k]$. Juntando com o Lema 7.4.1, $T[i, k]=T[i-1, k]$.

No caso em que $j$ não existe, é isso que queríamos provar. Se $T[i, k]<j$, devemos chegar em uma contradição pois queremos provar que $T[i, k]=j$. De fato, pela suposição e pela definição de $j$, $T[i, k]<j \leq T[i-1, k]$ e, logo, $T[i, k]<T[i-1, k]$, o que contradiz com a afirmação do parágrafo anterior. Portanto, $T[i, k] \geq j$ e, com o resultado do primeiro parágrafo da prova, $T[i, k]=j$.

Esse lema nos revela uma maneira de construir uma linha da matriz $T$ apenas com os valores da linha anterior. Para aplicá-lo em uma linha $i$ fixa, percorremos todos os casamentos $(i, j)$ procurando o $k$ em que $T[i-1, k-1]<j \leq T[i-1, k]$ e atribuindo $j$ a $T[i, k]$. As posições $T[i, k]$ não atribuídas são iguais às $T[i-1, k]$, e tomamos, para todo $i, T[i, 0]=0$ e $T[i, k]=n+1$ para valores indefinidos de $T[i, k]$. Para garantir a condição de que $T[i, k]$ é o menor $j$ com aquelas restrições, basta percorrer 
os casamentos em ordem decrescente de $j$, atribuindo assim o menor $j$ por último, sobreescrevendo as atribuições anteriores.

Como cada linha precisa apenas da linha anterior para ser calculada, é suficiente alocar um vetor $t$ de comprimento $m$ ao invés da matriz $T$ de tamanho $m \times m$ inteira, inicializando-a com $t[0]=0$ e $t[k]=n+1$ para todo $k>0$. Assim, basta aplicar as operações descritas no próprio vetor, sem se preocupar com as posições não atribuídas pois elas manterão os mesmos valores da iteração anterior $i-1$. Uma inspeção mais detalhada nos mostra que a ordem das operações nos garante que $t[k]=T[i, k]$ ao fim da iteração $i$ para todo $k$.

Uma outra nota importante é que gostaríamos que a busca pelo $k$ em que $t[k-1]<j \leq t[k]$ seja eficiente. Segundo o Lema 7.4.1, o vetor $t$ é sempre estritamente crescente para valores definidos. Então, dado um $j$, podemos realizar uma busca binária em tempo $O(\log m)$ para encontrar o $k$ tal que $t[k-1]<j \leq t[k]$, em $t[1 . . k m a x+1]$, onde $k$ max é o maior $k$ tal que $t[k] \neq n+1$.

Para que o algoritmo fique eficiente, precisamos usar uma estrutura de dados conveniente para percorrer os casamentos. Suponha que o alfabeto $\Sigma$ é $\{1,2, \ldots,|\Sigma|\}$. Seja $\operatorname{Pos} Y \operatorname{Dec}[1 . .|\Sigma|]$ um vetor tal que $\operatorname{Pos} Y \operatorname{Dec}[\sigma]$ é uma lista ligada contendo os índices das ocorrências do símbolo $\sigma$ em Y em ordem decrescente. Essa estrutura de dados pode ser construída percorrendo $Y$ uma vez, ou seja, sua construção consome tempo $O(n)$. A estrutura de dados em si ocupa espaço $O(n)$. Ela permite obter todos os casamentos de um dado índice $i$ em X, que são os $(i, j)$ para todo $j$ da lista $\operatorname{Pos} Y \operatorname{Dec}\left[x_{i}\right]$.

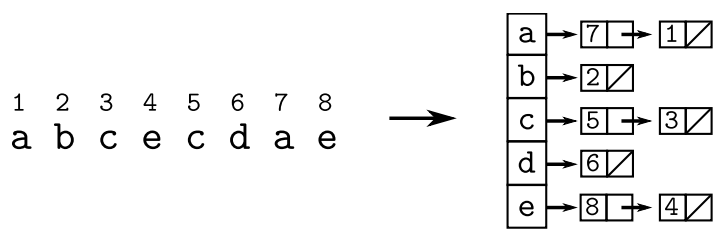

Uma última observação é como recuperar um LCS. Considere um vetor $\operatorname{link}[0 . . l]$, onde $l$ é o comprimento de um LCS (limitado por $m$ ). Construiremos link de forma que link $[k]$ é o primeiro nó de uma lista ligada formada por casamentos que representam uma subsequência comum de comprimento $k$, em ordem inversa (o nó link $[k]$ em si armazena o $k$-ésimo casamento dessa subsequência comum). O elemento link[0] é vazio por definição. A figura da página seguinte exemplifica link.

Para construir link, suponha que no instante que encontramos um casamento $(i, j)$ e um $k$ tal que $t[k-1]<j \leq t[k]$, a definição vale para link $[k-1]$ e ele armazena o casamento $\left(i^{\prime}, j^{\prime}\right)$. Então $i>i^{\prime}$ pois iteramos $i$ de 1 a $m$ e os maiores $k$ s são encontrados primeiro em uma mesma linha, e $j>j^{\prime}$ pois $j^{\prime} \leq t[k-1]<j$ pelo Lema 7.4.2. Logo, $\left(i^{\prime}, j^{\prime}\right)$ precede $(i, j)$ e, portanto, se $\operatorname{link}[k]$ armazenar $(i, j)$ e apontar para link $[k-1]$, temos que link $[k]$ satisfaz sua definição. Note que é seguro ignorar o caso $j=t[k]$, pois existe um outro casamento de mesmo $j$ e menor $i$ que é o último elemento de uma subsequência comum de comprimento $k$.

Um detalhe de implementação é que os nós criados para isso devem ser armazenados separadamente para que possam ser liberados da memória no término do algoritmo, pois os elementos de link são constantemente sobreescritos e as referências para os nós podem ser perdidas. Os nós relevantes para a recuperação de um LCS sempre são mantidas na lista link $[k]$ para o maior $k$ possível. 


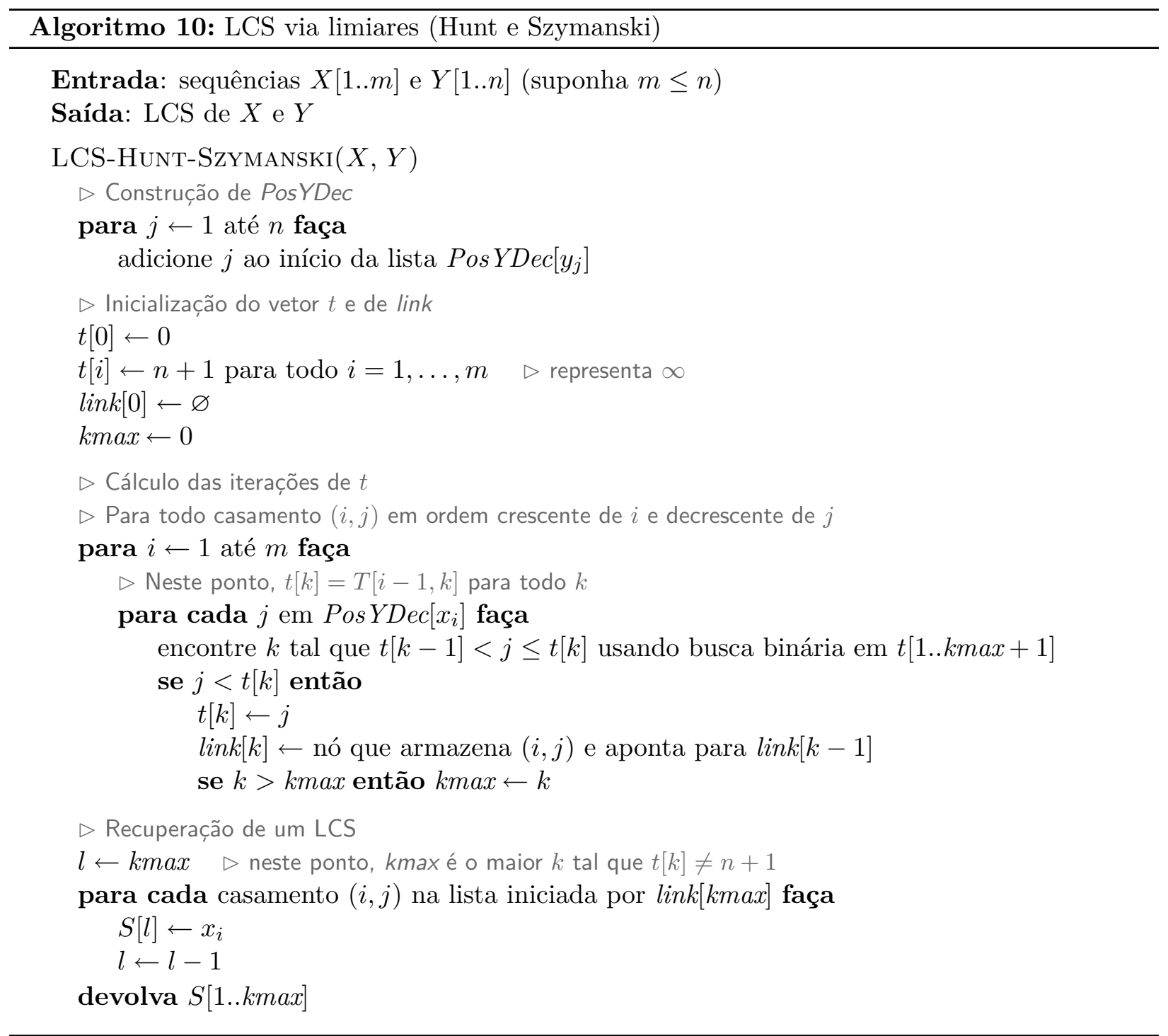

\section{$\mathrm{T}$}

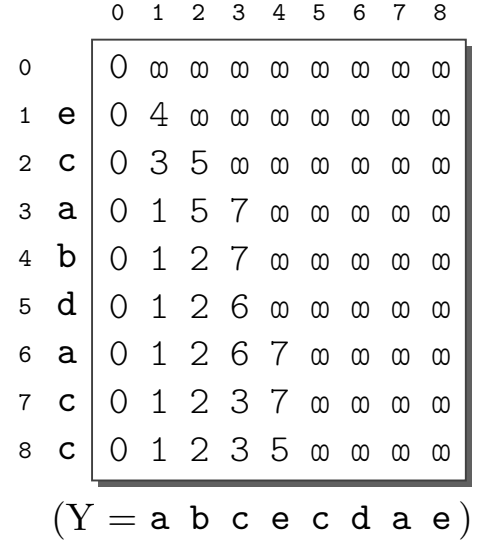

link

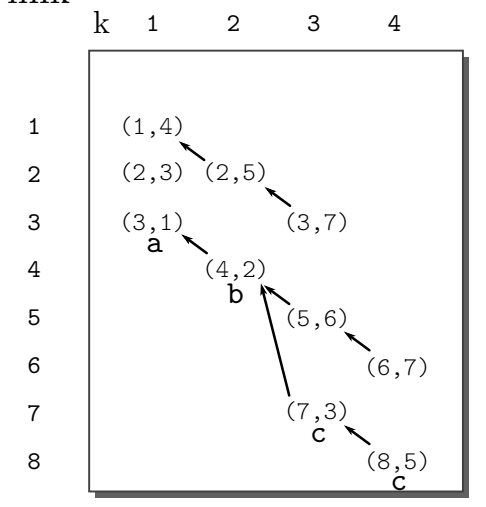


Analisaremos o consumo de tempo e espaço deste algoritmo. Sejam $r$ o número de casamentos em $X$ e $Y$ e $p$ o comprimento de um LCS de $X$ e $Y$, e lembremos que estamos supondo $m \leq n$. A construção de PosYDec consome tempo e espaço $O(n)$. As inicializações consomem tempo $O(m)$. Depois, para cada um dos $r$ casamentos, realizamos uma busca binária que consome tempo $O(\log p)$, gastando $O(m+r \log p)$ pois iteramos $i$ de 1 a $m$ para encontrar os casamentos. Nessa parte também gastamos tempo e espaço $O(r)$ para construir os nós da lista link e depois para liberá-los no término do algoritmo. Na recuperação do LCS, gastamos tempo $O(p)$. Assim, no total, gastamos tempo $O(n+r \log p)$ e espaço $O(n+r)$.

\subsubsection{Modificação por Kuo e Cross}

Kuo e Cross [29] propuseram em 1989 uma modificação ao algoritmo de Hunt e Szymanski que altera sua complexidade de tempo para $O(r+m p)$, onde $p$ é o comprimento de um LCS da instância. Eles notam que um elemento de $T$ pode ser sobreescrito várias vezes e o objetivo da modificação é remover essa redundância.

As modificações são as seguintes:

- O algoritmo utiliza a lista de casamentos Pos Y, equivalente a Pos YDec, mas com os casamentos em ordem crescente ao invés de decrescente.

- Como, dada uma linha $i$, o algoritmo preenche $T[i, k]$ do menor para o maior $k$, ele deve considerar que o $j$ do Lema 7.4.2 (o $j$ tal que $T[i, k-1]<j \leq T[i, k]$ ) deve ser mínimo. Portanto, ao encontrar um $k$ tal que a condição para $j$ valha, devemos pular todos os valores da lista entre $j$ e o $T[i, k]$ original, inclusive.

- A busca desse $k$ é linear em vez de binária, e ela é sempre iniciada a partir do $k$ anterior, pois os índices de Pos $Y$ estão em ordem crescente.

- Um cuidado adicional deve ser tomado quanto ao vetor link para recuperar um LCS. Lembremos que $\operatorname{link}[k]$ deve sempre apontar para o $\operatorname{lin} k[k-1]$ relacionado a uma linha anterior para garantir que o casamento de $\operatorname{link}[k-1]$ gere o de $l i n k[k]$. Isso não é garantido se procuramos link $[k] \mathrm{s}$ em ordem crescente de $k$, pois alguns deles podem apontar para um casamento da mesma linha. Uma maneira de contornar isso é guardar o link $[k]$ anterior para que o próximo possa apontar para ele se os $k$ s diferirem de 1.

O código a seguir substitui o pedaço do algoritmo anterior entre os comentários "Cálculo das iterações de $t$ " e "Recuperação de um LCS". O resto do algoritmo é feito como no de Hunt e Szymanski, com exceção da construção de $\operatorname{Pos} Y$ (anteriormente Pos YDec) que deve ser construída em ordem crescente ao invés de decrescente, e de kmax que não é mais necessário nessa parte mas ainda deve ser computado após ela. 


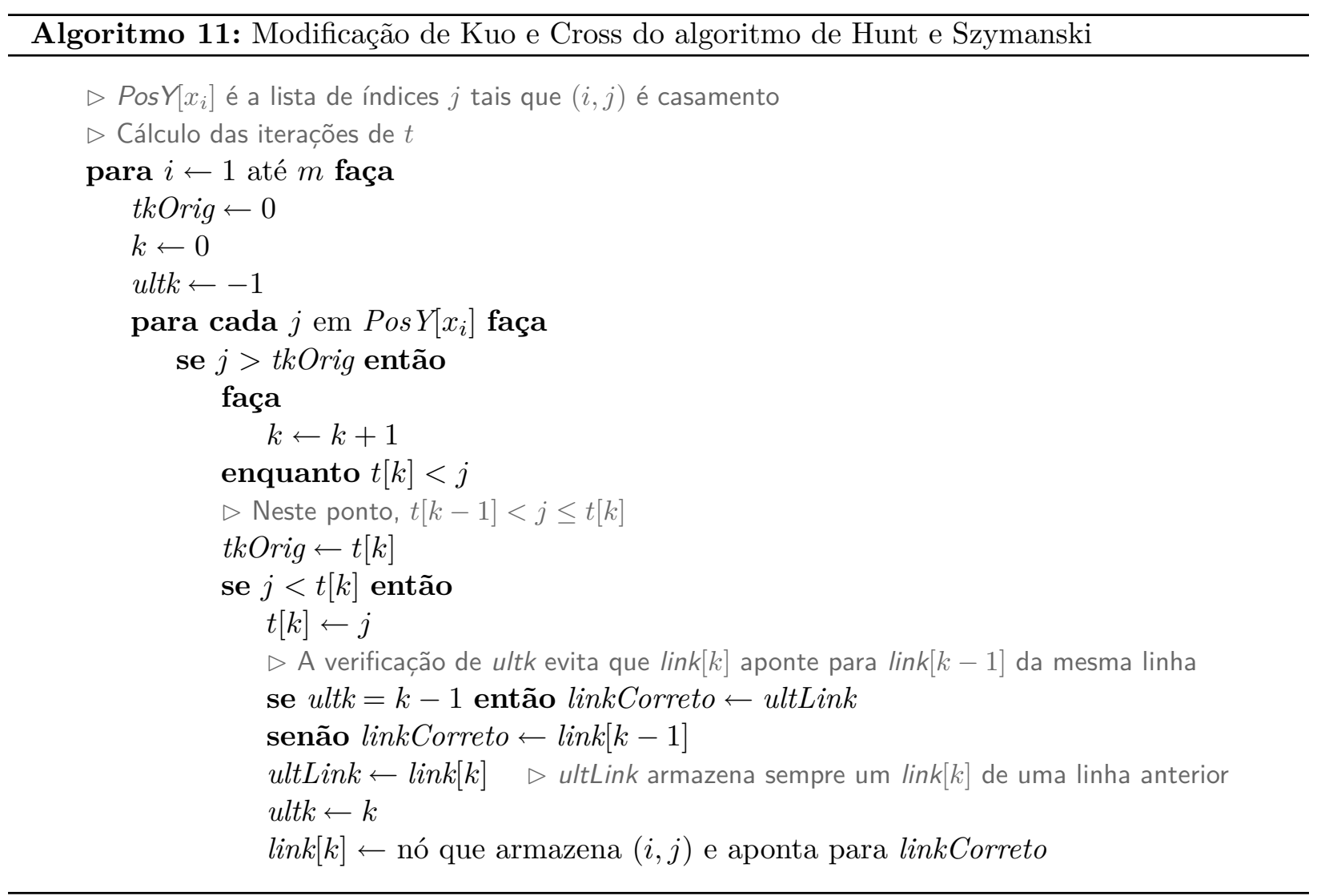

Como o $k$ acima é limitado pelo comprimento $p$ de um LCS e levando em conta que visitamos cada casamento uma vez, o código consome tempo $O(r+m p)$. Ele substitui a parte $O(m+r \log m)$ do algoritmo de Hunt-Szymanski e, juntando com o resto do algoritmo, a complexidade de tempo deste algoritmo continua sendo $O(r+m p)$. A de espaço também permanece $O(n+r)$.

\subsection{Algoritmo por contornos de Hirschberg}

Lembremos que $L[i, j]$ é o comprimento de um LCS de $X[1 . . i]$ e $Y[1 . . j]$ e que os valores dessa matriz definem regiões que podem ser representadas por contornos.

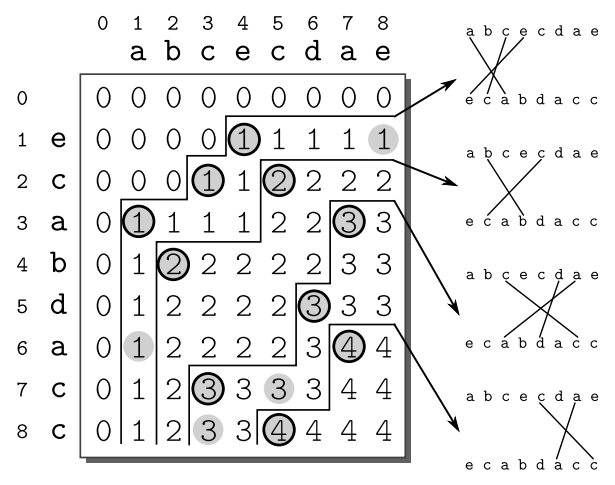


Hirschberg [20] propôs em 1977 um algoritmo que encontra cada um desses contornos um por vez, do primeiro até o $p$-ésimo contorno, onde $p$ é o comprimento de um LCS. O algoritmo, na verdade, encontra os casamentos que definem esses contornos, que ficam nos "cantos" e estão destacados com uma borda preta na figura anterior, e estão representados também nas figuras nas sequências à direita da matriz. Esses contornos existem sem se sobrepor ou cruzar pois $L$ é não-decrescente tanto para linhas como para colunas, seus valores são inteiros não-negativos e os vizinhos de seus elementos diferem em no máximo 1.

Definiremos primeiro algumas ideias básicas para nos ajudar a encontrar esses contornos. Um casamento $(i, j)$ é um $k$-casamento para $k \geq 2$ se existe um $(k-1)$-casamento $\left(i^{\prime}, j^{\prime}\right)$ tal que $\left(i^{\prime}, j^{\prime}\right) \prec(i, j)$ (isto é, $i^{\prime}<i$ e $\left.j^{\prime}<j\right)$. Neste caso, dizemos que $\left(i^{\prime}, j^{\prime}\right)$ gera $(i, j)$. Todo casamento é um 1-casamento por definição.

Mostraremos a seguir uma característica de $k$-casamentos que soa natural.

Lema 7.5.1. Seja $(i, j)$ um casamento. Para $k \geq 1,(i, j)$ é um $k$-casamento se e somente se existe uma subsequência comum de $X[1 . . i]$ e $Y[1 . . j]$ de comprimento $k$ (ou seja, $L[i, j] \geq k$ ).

Prova. Se $(i, j)$ é um casamento, então ele é um $k$-casamento se e só se ele é o último casamento de uma sequência de $k$ casamentos que pode ser ordenada em ordem de precedência, isto é, se e só se existe uma representação de cardinalidade $k$ cujo último casamento é $(i, j)$, o que vale se e só se existe uma subsequência comum de $X[1 . . i]$ e $Y[1 . . j]$ de comprimento $k$.

Gostaríamos de um conceito mais forte de $k$-casamento. Queremos apenas os $k$-casamentos que definem os contornos, como no exemplo no início desta seção.

Sejam $\left(i_{1}, j_{1}\right)$ e $\left(i_{2}, j_{2}\right) k$-casamentos. O casamento $\left(i_{1}, j_{1}\right)$ domina $\left(i_{2}, j_{2}\right)$ se $i_{1} \leq i_{2}$ e $j_{1} \leq j_{2}$. Dizemos que um $k$-casamento é dominante (ou minimal) se não existe $k$-casamento que o domina. É importante observar que se $\left(i_{1}, j_{1}\right)$ domina $\left(i_{2}, j_{2}\right)$, então qualquer $(k+1)$-casamento gerado por $\left(i_{2}, j_{2}\right)$ pode também ser gerado por $\left(i_{1}, j_{1}\right)$, tornando $\left(i_{2}, j_{2}\right)$ redundante nesse sentido.

Lema 7.5.2. Seja $C_{k}=\left\{\left(i_{1}, j_{1}\right),\left(i_{2}, j_{2}\right), \ldots,\left(i_{q}, j_{q}\right)\right\}$ o conjunto de todos os $k$-casamentos dominantes para um dado $k$. Então existe uma ordenação desse conjunto $\left(\left(i_{t_{1}}, j_{t_{1}}\right),\left(i_{t_{2}}, j_{t_{2}}\right), \ldots,\left(i_{t_{q}}, j_{t_{q}}\right)\right)$ tal que $i_{t_{1}}<i_{t_{2}}<\ldots<i_{t_{q}}$ e $j_{t_{1}}>j_{t_{2}}>\ldots>j_{t_{q}}$.

Prova. Sejam dois casamentos $(i, j)$ e $\left(i^{\prime}, j^{\prime}\right)$ de $C_{k}$ e suponha, sem perda de generalidade, que $i \leq i^{\prime}$. Vale que $i<i^{\prime}$ e $j>j^{\prime}$, pois, caso contrário, um dominaria o outro.

A ideia do algoritmo é manter um conjunto de casamentos $\left\{c_{1}, c_{2}, \ldots, c_{p}\right\}$ tal que cada casamento $c_{k}$ é um $k$-casamento dominante que gera $c_{k+1}$ se existir. Esse conjunto é uma representação de um LCS de comprimento $p$, pois nenhum casamento se cruza (cada um gera o próximo). Descreveremos agora uma maneira de encontrar tais $k$-casamentos dominantes.

Para o lema seguinte, considere um 0-casamento artificial $(0,0)$ que gera todos 1-casamentos.

Lema 7.5.3. Dados $1 \leq i \leq m$ e $k \geq 1$, suponha que existe um $(k-1)$-casamento $\left(i^{\prime}, j^{\prime}\right)$ com $i^{\prime}<i$. Então um casamento $(i, j)$ é um $k$-casamento dominante se e só se $j$ é o menor valor tal que $j_{k-1}(i)<j<j_{k}(i)$, onde $j_{k}(i)=\min \{\hat{\jmath} \mid(\hat{\imath}, \hat{\jmath})$ é um $k$-casamento e $\hat{\imath}<i\}$ para $k \geq 1$ e $j_{0}(i)=0$.

Se o limitante superior não existir, então é ilimitado superiormente. O limitante inferior sempre existe (por causa da suposição inicial). 
Prova. Dividimos esta prova em duas partes.

Seja $(i, j)$ um casamento. Veremos primeiro que $(i, j)$ é um $k$-casamento se e só se $j_{k-1}(i)<j$.

O casamento $(i, j)$ é um $k$-casamento se e só se existe um $(k-1)$-casamento $\left(i^{\prime}, j^{\prime}\right)$ que gera $(i, j)$ (isto é, $i^{\prime}<i$ e $j^{\prime}<j$ ), e podemos supor, sem perda de generalidade, que $j^{\prime}$ é mínimo. Isso é o mesmo que dizer que existe o $(k-1)$-casamento $\left(i^{\prime}, j^{\prime}\right)$ com $j^{\prime}=j_{k-1}(i)$, e vale que $j^{\prime}<j$. Sabemos que esse $(k-1)$-casamento existe pela suposição do lema. Assim, isso é o mesmo que afirmar simplesmente que $j_{k-1}(i)<j$. Logo, $(i, j)$ é um $k$-casamento se e só se $j_{k-1}(i)<j$.

Agora, seja $(i, j)$ um $k$-casamento e suponha que $j_{k}(i)$ existe. Veremos que $(i, j)$ é dominante (em relação a $k$ ) se e só se $j$ é mínimo entre os $k$-casamentos da linha $i$ e $j<j_{k}(i)$.

Por definição, o $k$-casamento $(i, j)$ é dominante se e só se não existe um outro $k$-casamento $\left(i^{\prime}, j^{\prime}\right)$ que domina $(i, j)$ (isto é, $i^{\prime} \leq i$ e $j^{\prime} \leq j$ ). Isso vale se e só se para qualquer $k$-casamento $\left(i^{\prime}, j^{\prime}\right)$ com $i^{\prime}<i$, vale $j^{\prime}>j$, e, entre os $k$-casamentos com $i^{\prime}=i, j$ é mínimo. Essa afirmação é equivalente a dizer que $j$ é mínimo entre os $k$-casamentos da linha $i$ e que vale $j<j_{k}(i)$ se o limitante $j_{k}(i)$ existir (se não existir, então $j$ não tem limitante superior).

O lema anterior nos dá uma região onde podemos procurar um $k$-casamento dominante de uma linha $i$, como ilustrado na figura seguinte.

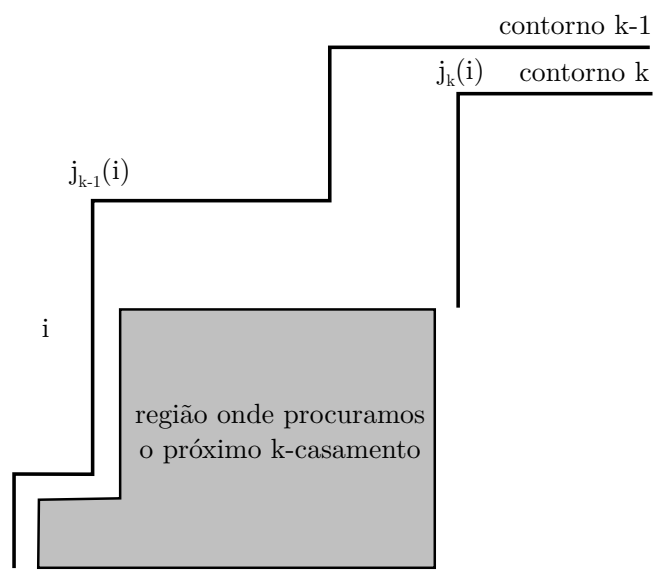

A ideia principal do algoritmo é construir uma matriz $D$ para armazenar os $k$-casamentos dominantes $(i, j)$ para cada $i$, lembrando que temos no máximo um deles para cada $i$ pelo Lema 7.5.2. Assim, definimos $D$ da seguinte forma:

$$
D[k, i]= \begin{cases}j & \text { se existe o } k \text {-casamento dominante }(i, j) \\ 0 & \text { se não existe tal } k \text {-casamento dominante }\end{cases}
$$

Precisamos aqui também considerar um 0-casamento artificial $(0,0)$ como consideramos no Lema 7.5.3. Então, $D[0, i]=0$ para todo $i$, que funciona como um 0 -casamento artificial $(D[k, 0]$ para $k>0$ não é usado). A matriz tem $p+1$ linhas $(0$ até $p)$ e $m+1$ colunas $(0$ até $m)$, onde $p$ é o comprimento de um LCS de $X$ e $Y$. Não conhecemos $p$ de antemão, mas $p$ é limitado por $m$ (lembrando a suposição $m \leq n$ ). A figura a seguir ilustra um exemplo da matriz $D$. 

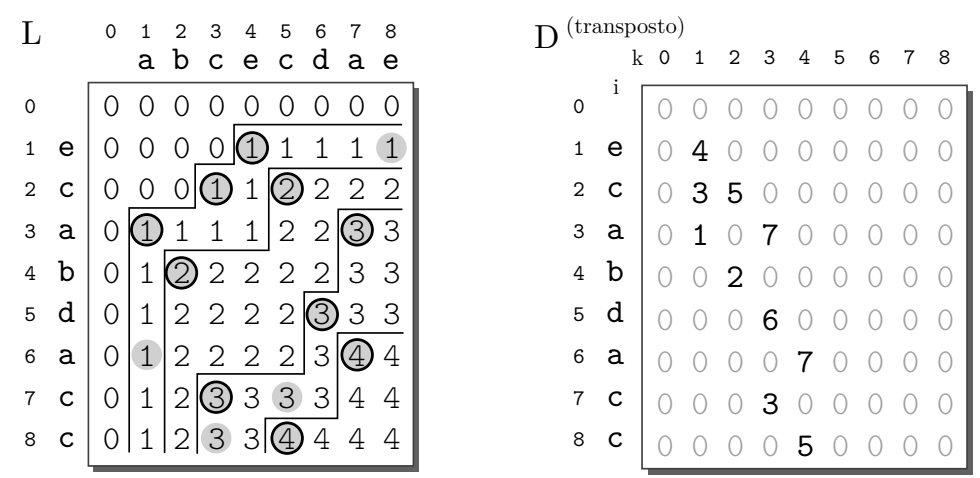

O algoritmo constrói a matriz $D$ linha por linha, para $k$ de 1 até $p$. Isto é, ele procura os conjuntos de 1-casamentos dominantes, 2-casamentos dominantes, assim em diante até $p$-casamentos dominantes, parando ao não encontrar $(p+1)$-casamentos dominantes. Fixado um $k$, para encontrar os $k$-casamentos dominantes, o algoritmo procura em cada linha o $j$ que satisfaz o Lema 7.5.3. É suficiente procurar $k$-casamentos começando da linha seguinte ao $(k-1)$-casamento dominante de menor linha (o pseudocódigo mais adiante chama essa linha de infi), pois todo $k$-casamento deve ser gerado por algum $(k-1)$-casamento.

A seguinte proposição é útil para mantermos os valores de $j_{k-1}(i)$ e $j_{k}(i)$ atualizados.

Proposição 7.5.4. O valor $j_{k}(i)$ é igual a $D\left[k, i^{\prime}\right]$ para o maior $i^{\prime}<i$ tal que $D\left[k, i^{\prime}\right]>0$ se existir.

Prova. Por definição, $j_{k}(i)$ é a menor coluna possível entre os $k$-casamentos de linha menor que $i$. Podemos supor que $j_{k}(i)$ é a coluna de um $k$-casamento dominante, pois, se não for, existe um dominante de mesma coluna. Pelo Lema 7.5.2, entre os $k$-casamentos dominantes, o de menor coluna é o que tem maior linha. Portanto, $j_{k}(i)$ é a coluna do $k$-casamento dominante da linha $i^{\prime}$ tal que $i^{\prime}$ é máxima mas $i^{\prime}<i$, isto é, é $D\left[k, i^{\prime}\right]$ para o maior $i^{\prime}<i$ tal que $D[k, i]>0$.

No pseudocódigo mais adiante, chamamos $j_{k-1}(i)$ de $i n f j$ e $j_{k}(i)$ de $s u p j$, e mantemos eles sempre atualizados com o valor descrito na proposição acima, ou com $n+1$ se não existir.

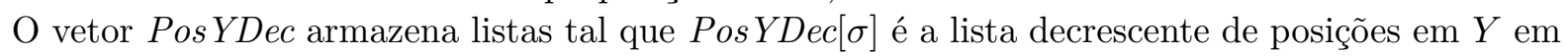
que o símbolo $\sigma$ aparece e ainda com 0 no fim de cada lista, que servem como valores sentinelas (é o mesmo PosYDec do algoritmo de Hunt e Szymanski da Seção 7.4, mas com zeros no fim). A busca do $j$ tal que $j_{k-1}(i)<j<j_{k}(i)$ será feita em PosYDec. Um marcador busca para cada lista de PosYDec (isto é, para cada símbolo $\sigma$ em $\Sigma$ ) ajuda a manter a busca eficiente.

Podemos recuperar um LCS em ordem inversa encontrando uma sequência $S^{r}=s_{p} s_{p-1} \ldots s_{1}$ tal que $s_{k}$ é um $k$-casamento dominante gerado por $s_{k-1}$. Para garantir que $s_{k}$ seja gerado por um $(k-1)$-casamento dominante a ser escolhido $s_{k-1}$, podemos escolher como $s_{k-1}$ o $(k-1)$-casamento dominante de maior linha menor que a linha de $s_{k}$. De fato, pelo Lema 7.5.2, isso garante que a coluna de $s_{k-1}$ seja mínima e, portanto, menor que a de $s_{k}$, lembrando que todo $k$-casamento deve ser gerado por algum $(k-1)$-casamento. Logo, $s_{k-1}$ gera $s_{k}$ e $s_{1} s_{2} \ldots s_{p}$ é um LCS. As figuras após o algoritmo ilustram a recuperação e também uma simulação do algoritmo. 


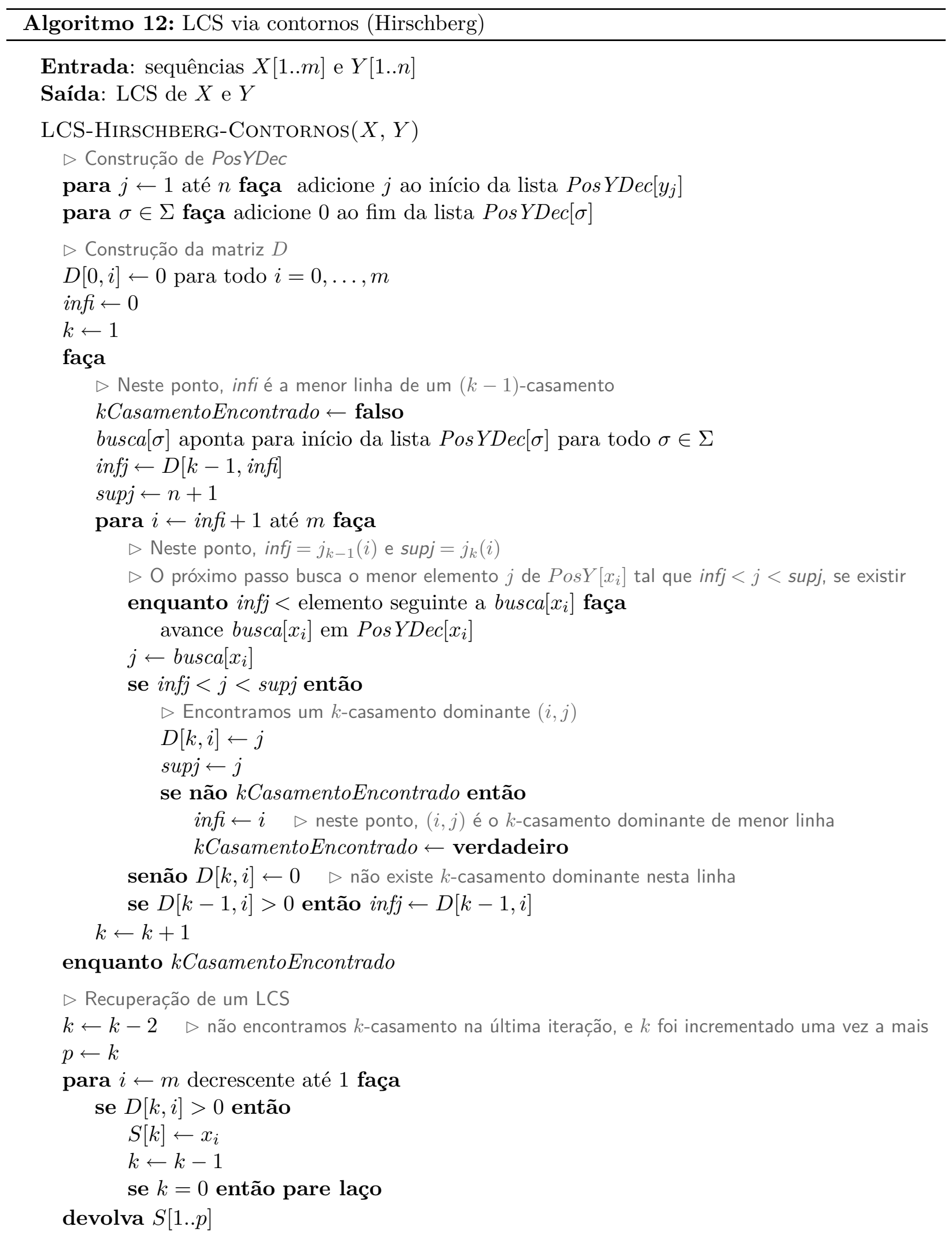



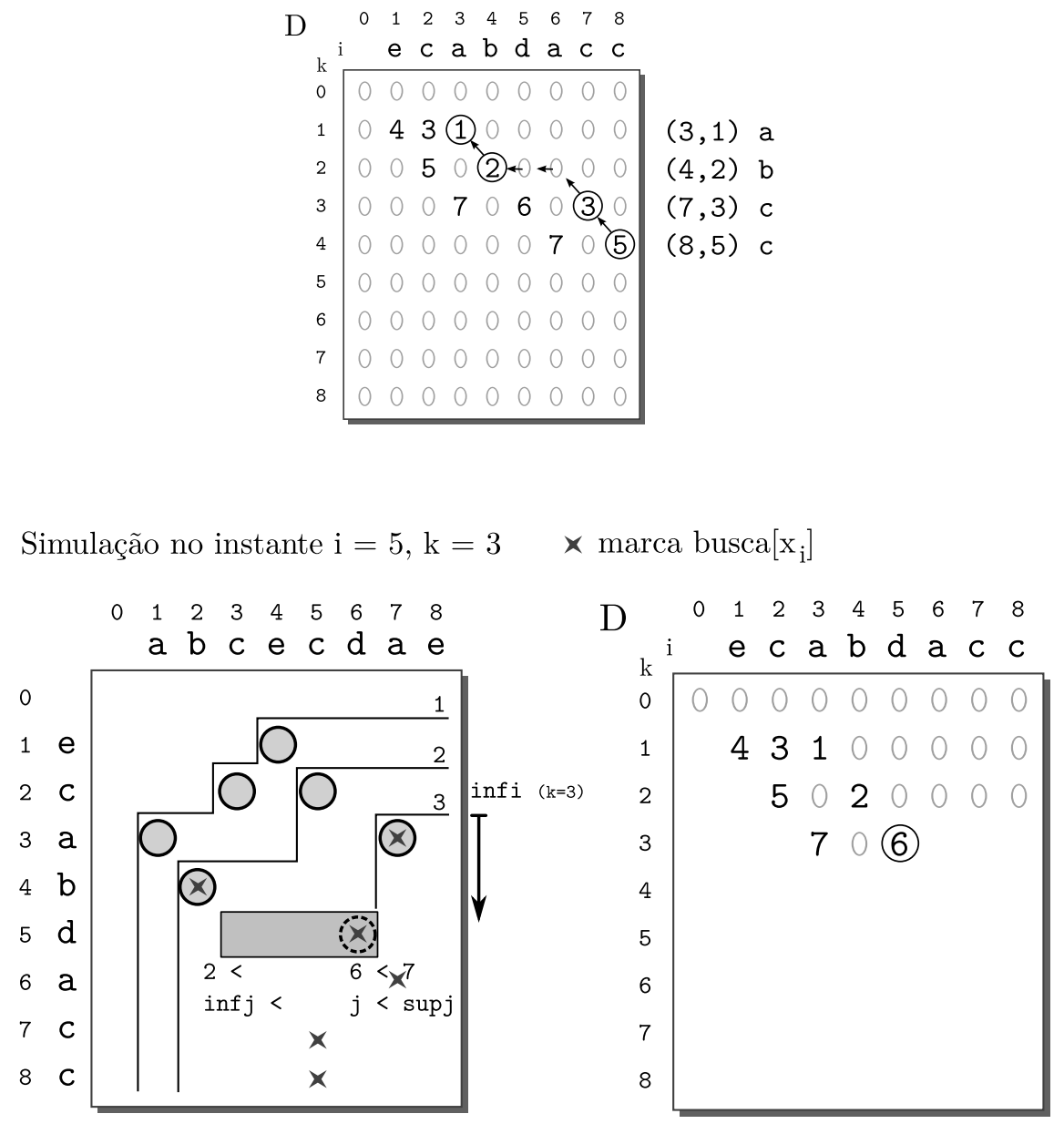

A inicialização é feita em tempo $O(n)$. Cada iteração de $k$ consome tempo $O(n)$, pois, em cada iteração de $k$, são feitas no máximo $m$ iterações de $i$ nas quais as buscas consomem tempo $O(n)$ no total de todas as iterações, já que os marcadores do vetor busca percorrem todos os $O(n)$ elementos de PosYDec uma vez no pior caso (lembremos que estamos supondo $m \leq n$ ). O restante das operações feitas dentro de uma iteração de $i$ é constante. Logo, a construção da matriz $D$ consome tempo $O(p n)$, onde $p$ é o comprimento de um LCS da instância. A recuperação de um LCS consome tempo $O(m)$.

Assim, o algoritmo consome tempo $O(p n)$. O espaço consumido pelo algoritmo é $O\left(m^{2}+n\right)$ devido à matriz $D$ e ao vetor PosYDec.

\subsection{Modificações dos algoritmos de Hirschberg e de Hunt-Szymanski por Apostolico e Guerra}

Apostolico e Guerra [2] sugeriram em 1987 dois algoritmos baseados nos algoritmos de Hirschberg e de Hunt-Szymanski. 


\subsubsection{Modificação do algoritmo de Hirschberg}

Assim como o algoritmo de Hirschberg da Seção 7.5, o primeiro algoritmo encontra todos os $k$-casamentos dominantes iterando em $k$, usando como base o Lema 7.5.3 do algoritmo de Hirschberg. Este algoritmo modifica o consumo de tempo do algoritmo de Hirschberg de $O(p n)$ para $O(p m+|\Sigma| n)$ ou $O(p m \log |\Sigma|+n)$, lembrando que $m \leq n$ e que $p$ é o comprimento de um LCS da entrada.

O algoritmo utiliza o vetor de listas ligadas $\operatorname{Pos} Y$ (como na Seção 7.4.1), a variante crescente de Pos YDec. Isto é, Pos $Y[\sigma]$ é uma lista ligada com os índices das ocorrências de $\sigma$ em $Y$ em ordem crescente.

Para cada linha $i$, o algoritmo guarda um marcador que denotaremos por marcador (Apostolico e Guerra o chamam de pebble) que aponta para alguma célula de $\operatorname{Pos} Y\left[x_{i}\right]$, ou seja, para um casamento na linha $i$. Eles têm um objetivo parecido com as referências busca $[\sigma]$ do algoritmo de Hirschberg e são armazenados em uma lista ligada listaMarcador crescente em ordem de $i$ para que eles possam ser removidos conforme eles deixam de ser necessários.

Lembremos do Lema 7.5.3 do algoritmo de Hirschberg: um casamento $(i, j)$ é um $k$-casamento dominante se e só se $j$ é o menor valor tal que $j_{k-1}(i)<j<j_{k}(i)$, onde $j_{k}(i)=\min \{\hat{\jmath} \mid(\hat{\imath}, \hat{\jmath})$ é um $k$-casamento e $\hat{\imath}<i\}$ para $k \geq 1$ e $j_{0}(i)=0$ (supondo a existência de $j_{k-1}(i)$ ).

$\mathrm{O}$ algoritmo realiza dois passos fundamentais, a cada iteração $k$, para cada marcador $_{i}$ em listaMarcador (marcador $i$ é o marcador para o índice $i$ ):

1. O algoritmo verifica se marcador $_{i}<j_{k}(i)$. Se sim, então ele guarda ( $i$, marcador $\left._{i}\right)$ como um $k$-casamento dominante em uma lista $\operatorname{rank}[k]$. Note que estamos verificando apenas o limitante superior do Lema 7.5.3; as outras condições do lema são garantidas pelo item seguinte.

2. Depois, o algoritmo move marcador $_{i}$ para o menor $j$ tal que $j_{k}(i)<j$ (se não houver, marcador $_{i}$ é removido da lista listaMarcador). Isso garante a invariante de que, no início da cada iteração $k>1$, ele aponta para o menor $j$ tal que $j_{k-1}(i)<j$ (se ele não foi removido).

Os dois itens acima são uma aplicação direta do Lema 7.5.3. O limitante $j_{k}(i)$ pode ser obtido da mesma maneira que no algoritmo de Hirschberg: armazenando a coluna do último $k$-casamento dominante encontrado em uma iteração $k$ (ela será referida no pseudocódigo como limiar). Para garantir o segundo passo para $k=1$, devemos, antes das iterações em $k$, inicializar marcador como o primeiro casamento da linha $i$ (a primeira célula de Pos $Y\left[x_{i}\right]$ ).

A dificuldade maior deste algoritmo é mover marcador $_{i}$ para o menor $j$ tal que $j>$ limiar de forma eficiente. Suporemos por enquanto que existe uma função ProxPosY que devolve justamente esse $j$, ou $n+1$ se não existir. Essa função será detalhada após o pseudocódigo. Um pequeno detalhe é que, como ProxPosY devolve um índice e não uma referência a uma célula, é necessário um vetor celula $[1 . . n]$ tal que celula $[j]$ aponta para a célula em $\operatorname{Pos} Y\left[y_{j}\right]$ de valor $j$, para tornar possível a recuperação da célula a partir do índice $j$.

A recuperação de um LCS neste algoritmo é similar à recuperação no algoritmo de Hirschberg. 


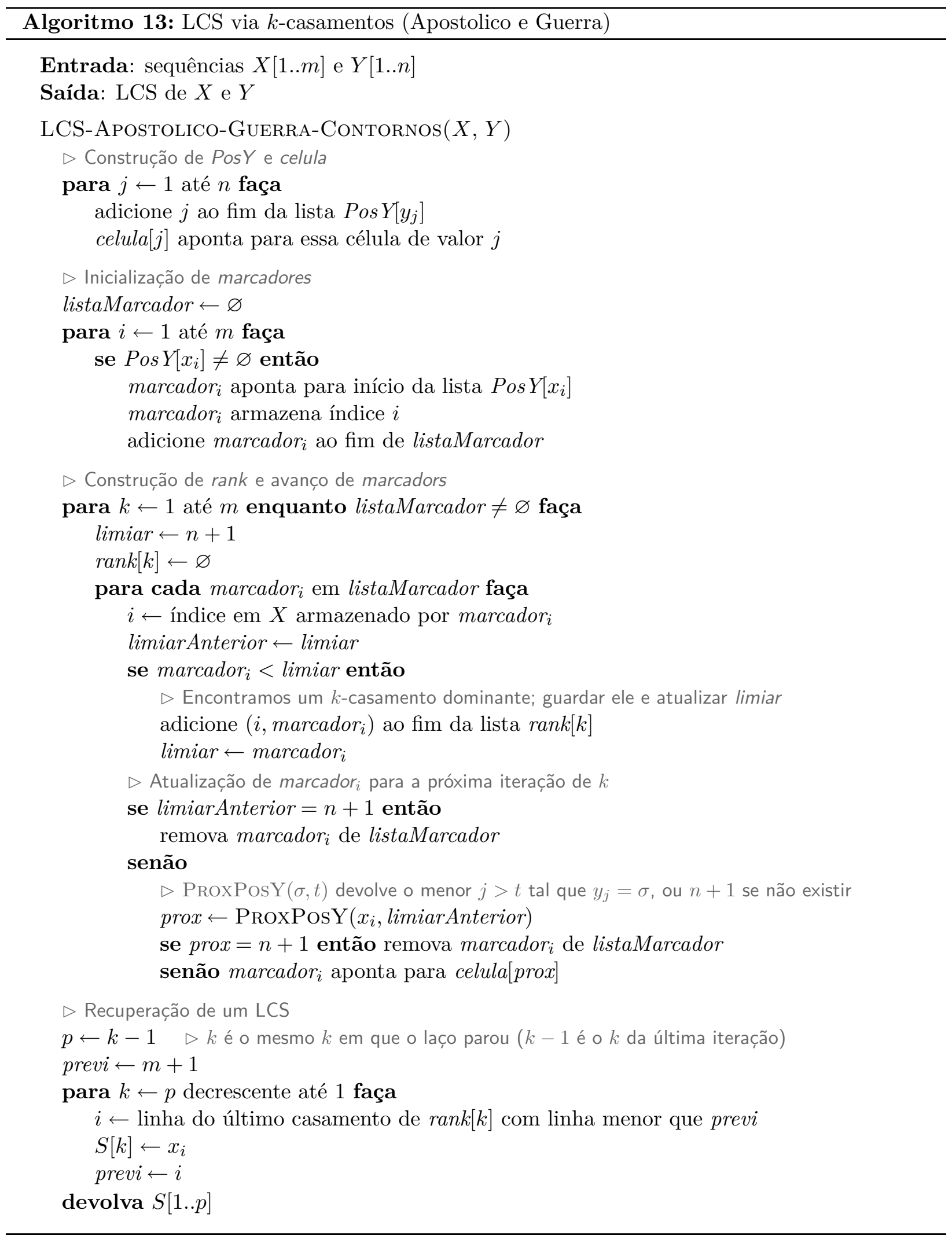


Se ProxPosY consome tempo $O(f(m, n))$, então este algoritmo consome tempo $O(p m f(m, n))$. De fato, o laço externo itera $k$ de 1 a $p$, onde $p$ é o comprimento de um LCS, e o interno itera em listaMarcador, que tem, no pior caso, m marcadores. Dentro do laço interno, as operações consomem tempo constante com exceção da função ProxPosY, que não conhecemos ainda.

Quanto à função ProxPosY (chamado de closest no artigo original), podemos implementá-la de duas maneiras.

A primeira, mais óbvia, é construir uma tabela proxPos $Y$ no início do algoritmo tal que o elemento proxPos $Y[\sigma, t]$ seja o menor $j$ maior que $t$ de forma que $y_{j}=\sigma$, ou $n+1$ se não existir, e a função simplesmente checa essa tabela e devolve o valor correspondente. Na figura abaixo, os elementos circulados são tais que $y_{j}=\sigma$.

\begin{tabular}{|c|c|c|c|c|c|c|c|}
\hline \multicolumn{8}{|c|}{ proxPosY } \\
\hline & & & 4 & & 6 & & \\
\hline & $a b$ & C & e & c & d & $\mathrm{a}$ & e \\
\hline a & (7) 7 & 7 & 7 & 7 & 7 & & 9 \\
\hline b & 29 & 9 & 9 & 9 & 9 & 9 & 9 \\
\hline C & 33 & (5) & 5 & & 9 & 9 & 9 \\
\hline d & 66 & 6 & 6 & & (9) & & 9 \\
\hline e & 44 & 4 & (8) & 8 & 8 & 8 & (9) \\
\hline
\end{tabular}

A construção dessa tabela é fácil: basta inicializar a tabela com $n+1$ e, para cada $j$ iterando de 1 a $n$, atribuir $j$ a proxPos $Y\left[y_{j}, j^{\prime}\right]$ para todo $j^{\prime}$ de $j-1$ decrescente até $\hat{\jmath}$, onde $\hat{\jmath}$ é o menor índice tal que proxPos $Y\left[y_{j}, \hat{\jmath}\right]$ ainda não foi preenchido após a inicialização (isto é, é igual a $n+1$ ). Esse processo consome tempo $\Theta(|\Sigma| n)$, tornando o consumo de tempo do algoritmo $O(p m+|\Sigma| n)$.

Entretanto, se $n$ for muito maior que $m$, e $|\Sigma|$ for grande, pode ser que o termo $|\Sigma| n$ atrapalhe. O segundo método de implementar ProxPosY foi proposto para remover o $n$ da complexidade de tempo (com exceção do $n$ na construção de $P o s Y$ ).

O segundo método envolve construir no início do algoritmo um vetor proxPosYDiv[1..n] que contém uma parte de proxPosY: proxPos YDiv $[j]=\operatorname{proxPos} Y\left[\sigma_{j}, j\right]$ onde $\left(\sigma_{j}-1\right) \equiv(j-1)(\bmod |\Sigma|)$, supondo $\Sigma=\{1, \ldots,|\Sigma|\}$. O $-1 \mathrm{em}$ ambos os lados aparece apenas porque nossos índices começam em 1 e não em 0 . O exemplo a seguir ilustra esse vetor.

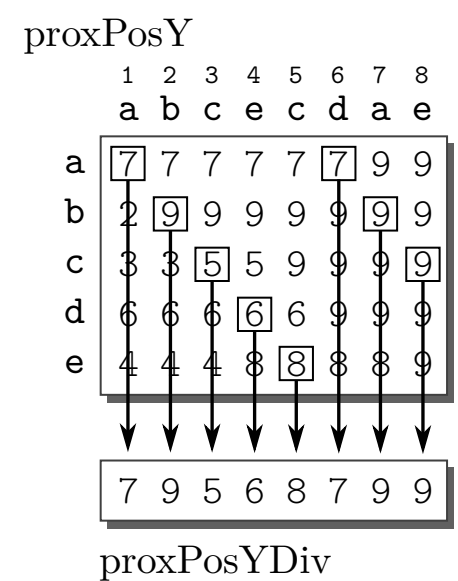


Não é difícil construir o vetor proxPos YDiv em tempo $\Theta(n)$ percorrendo Pos $Y[\sigma]$ uma vez para cada $\sigma$ e, para os $j$ tal que $(\sigma-1) \equiv(j-1)(\bmod |\Sigma|)$, preenchendo proxPosYDiv $[j]$ com o menor elemento maior que $j$ presente em $\operatorname{Pos} Y[\sigma]$, ou $n+1$ se não existir. No entanto, a chamada de ProxPosY $(\sigma, t)$, descrita a seguir, se torna mais complicada. Um detalhe importante é que, no algoritmo seguinte, usamos busca binária em $\operatorname{Pos} Y[\sigma]$ para algum $\sigma$ em $\Sigma$ e, portanto, Pos $Y[\sigma]$ deve ser um vetor em vez de uma lista, o que não muda muito no algoritmo. Nesse caso, celula $[j]$ armazena o índice $k$ tal que $\operatorname{Pos} Y\left[y_{j}\right][k]=j$.

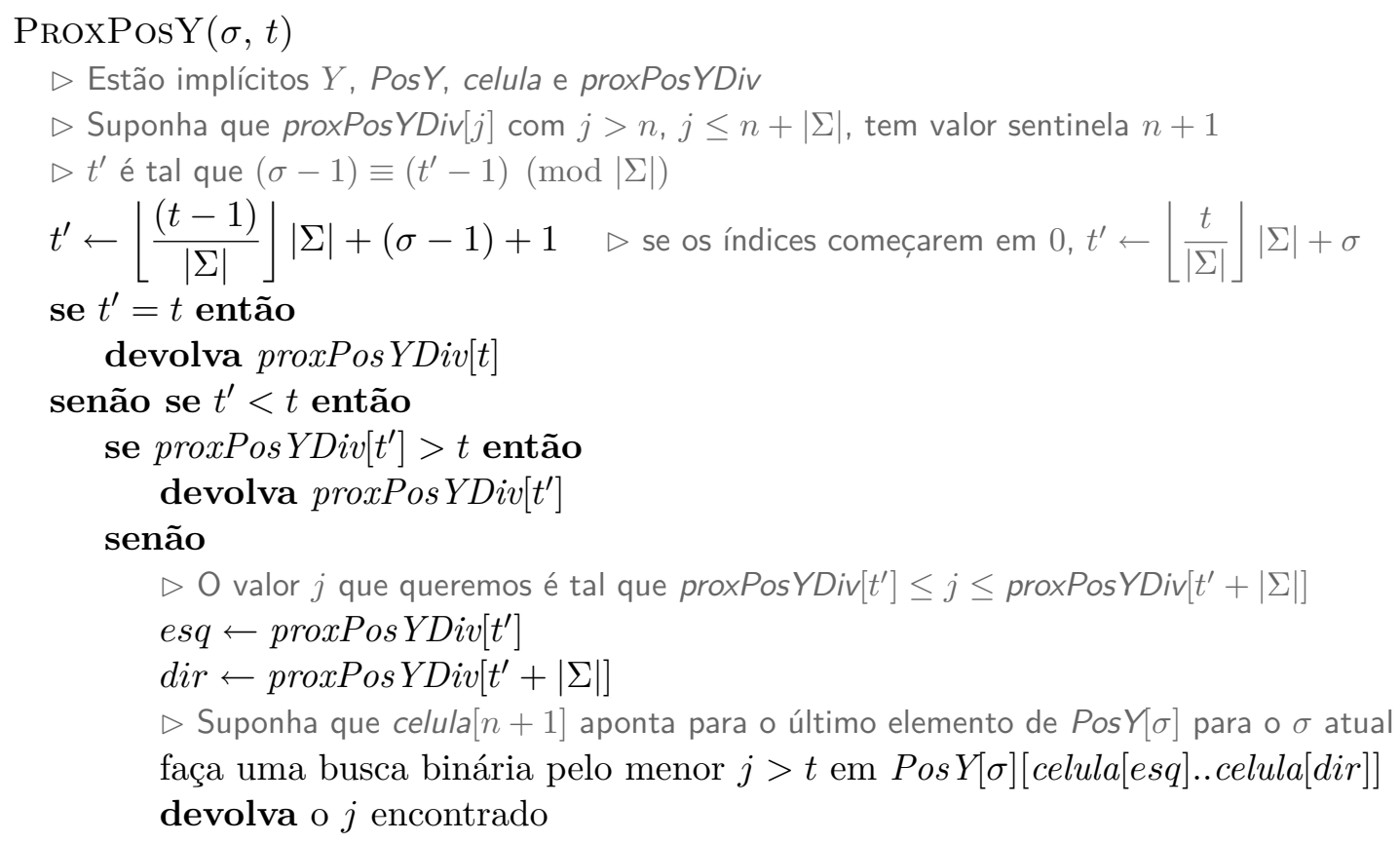

O pseudocódigo acima consome tempo $O(\log |\Sigma|)$ por causa da busca binária, então o consumo total de tempo do algoritmo de Apostolico e Guerra baseado em contornos é $O(p m \log |\Sigma|+n)$. Assintoticamente, este algoritmo vale mais a pena que o algoritmo de Hirschberg se o $m$ for significativamente menor que $n$, e se o tamanho do alfabeto $\Sigma$ não for muito grande.

O consumo de espaço do algoritmo é $O(n+d+|\Sigma| n)$ com a primeira versão de ProxPosY, ou $O(n+d)$ com a segunda, onde $d$ é o número total de $k$-casamentos dominantes para qualquer $k$.

\subsubsection{Modificação do algoritmo de Hunt-Szymanski}

O segundo algoritmo proposto por Apostolico e Guerra é baseado no algoritmo de Hunt e Szymanski da Seção 7.4. A ideia principal do algoritmo é percorrer, por linha, apenas $k$-casamentos dominantes para algum $k$, trocando a complexidade de tempo de $O(r \log p)$ do algoritmo de Hunt e Szymanski para $O(d \log n)$, onde $r$ é o número de casamentos, $p$ é o comprimento de um LCS e $d$ é o número de $k$-casamentos dominantes para algum $k$. 
Na verdade, a base deste algoritmo é a mesma do algoritmo de Kuo e Cross, da Seção 7.4.1, que não repetiremos aqui. Existem apenas duas modificações ao algoritmo de Kuo e Cross:

1. O algoritmo é reescrito em termos de buscas, inserções, remoções e atribuições de valores em Pos $Y$ e $t$. Ele usa árvores de busca balanceadas (árvores 2-3 ou AVL, por exemplo), e cada uma dessas operações consome tempo $O(\log n)$, onde $n$ é o número de elementos da estrutura de dados.

2. O algoritmo considera apenas $k$-casamentos dominantes para algum $k$. O algoritmo de Kuo e Cross não considera $k$-casamentos dominados que estão na mesma coluna de um dominante. Para considerar isso, removemos temporariamente de Pos $Y$ os índices que representam limiares, recolocando-os quando eles deixam de representar limiares.

Escrevemos a parte principal do algoritmo abaixo.

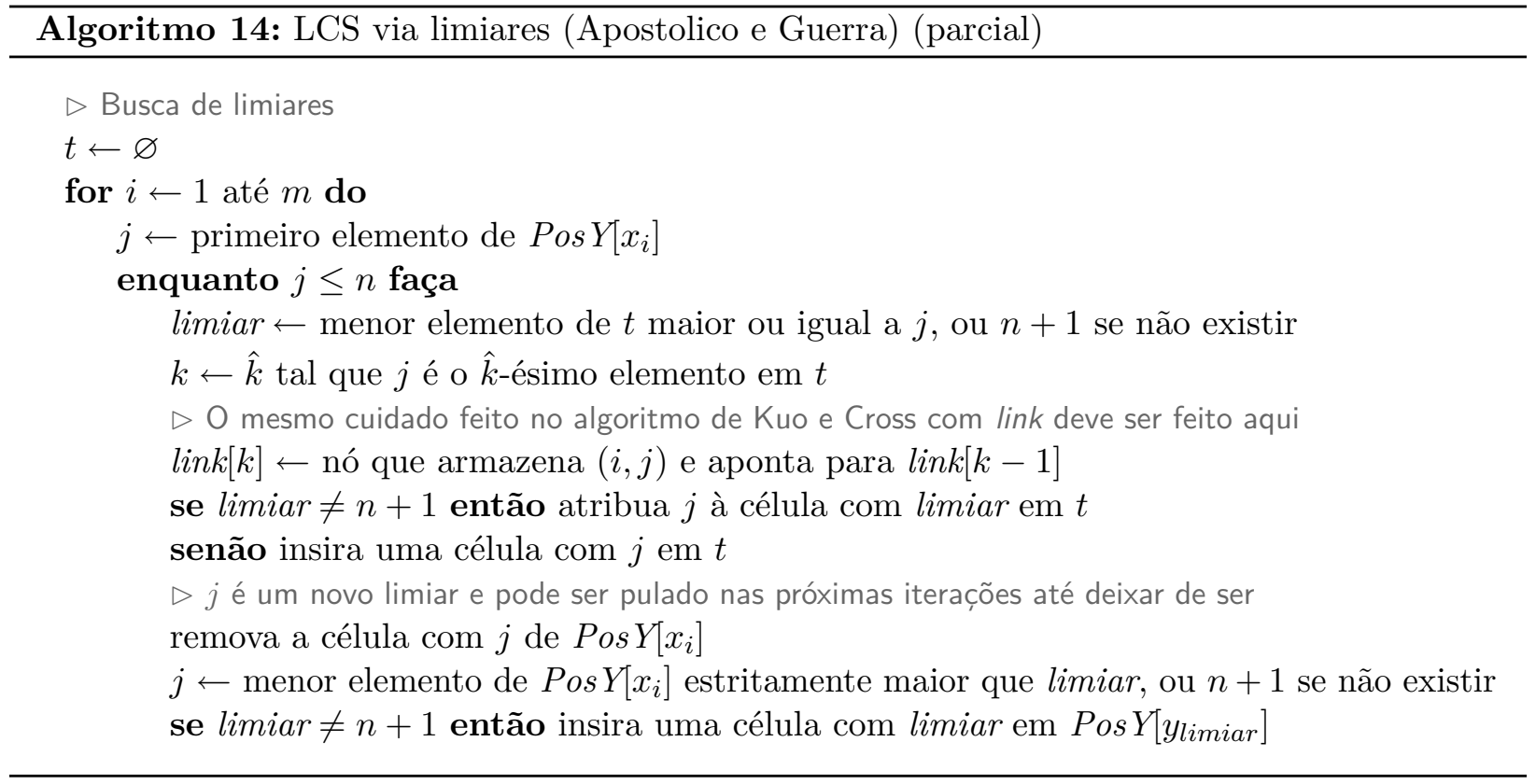

O algoritmo executa, no total, $\Theta(d)$ buscas, atribuições, inserções e remoções, onde $d$ é o número total de $k$-casamentos dominantes para algum $k$. O restante do algoritmo consome tempo $O(n)$ no total. Então, com árvores de busca balanceadas, o algoritmo consome tempo $O(d \log n+n)$. A complexidade de espaço continua sendo $O(n+r)$.

\subsection{Algoritmo por preenchimento de diagonais de Nakatsu, Kam- bayashi e Yajima}

Nakatsu, Kambayashi e Yajima [34] propuseram um algoritmo para o LCS em 1982 cujo objetivo é ser eficiente para casos em que sabemos que o comprimento de um LCS é grande. A complexidade de tempo deste algoritmo é $O(n(m-p))$, onde $p$ é o comprimento de um LCS da entrada. Assim como todos os algoritmos anteriores, este algoritmo se apoia no conceito da matriz de programação dinâmica $L$. Ele usa uma matriz $T^{s}$, que é similar à matriz $T$ do algoritmo de Hunt e Szymanski da Seção 7.4, mas considera sufixos ao invés de prefixos. 
A matriz $T^{s}$ é tal que $T^{s}[i, k]$ é o maior $j$ tal que $X[i . . m]$ e $Y[j . . n]$ possuem um LCS de comprimento $k$. Comparando com a definição da matriz $T$ de Hunt e Szymanski, trocamos "menor $j$ " por "maior $j$ ", e "X[1..i] e $Y[1 . . j]$ " (prefixos que terminam em $(i, j)$ ) por " $X[i . . m]$ e $Y[j . . n]$ " (sufixos que iniciam em $(i, j))$. Se não existir tal $j$ para $T^{s}[i, k]$, ele é indefinido para os critérios dos dois lemas mais adiante, mas será conveniente defini-lo como 0 . Faz sentido também $T^{s}[i, 0]$ ser $\infty$, ou, na prática, $n+1$.

A figura abaixo à esquerda mostra uma matriz $L^{s}$ análoga a $L$, mas para sufixos: $L^{s}[i, j]$ é o comprimento de um LCS de $X[i . . m]$ e $Y[j . . n](X[m+1 . . m]$ representa uma sequência vazia). A maneira de calculá-la é análoga à maneira de computar $L$. Dela, é fácil derivar $T^{s}$ (exemplificado na figura à direita), assim como obtivemos a matriz $T$ a partir de $L$ na Seção 7.4.

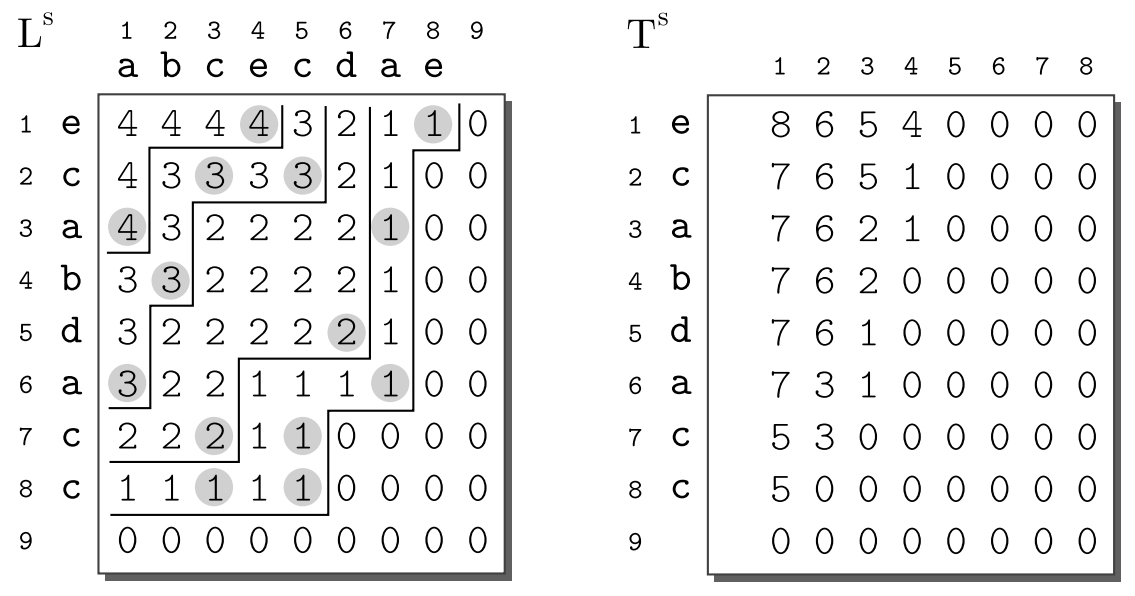

Os dois lemas a seguir são análogos aos lemas 7.4.1 e 7.4.2 de Hunt e Szymanski. Suas provas também são análogas e, portanto, não as escrevemos aqui.

Lema 7.7.1. Para valores definidos, $T^{s}[i+1, k] \leq T^{s}[i, k]<T^{s}[i+1, k-1]$.

Um corolário direto desse lema é que as linhas são estritamente decrescentes, isto é, vale que $T^{s}[i, k-1]>T^{s}[i, k]$ para valores definidos. Também vale que $T^{s}[i, k]>T^{s}[i-1, k+1]$, ou seja, as diagonais na direção para cima e direita $(\nearrow$ ) são estritamente decrescentes para valores definidos (não nulos). Além disso, se $T^{s}[i, k]=0$, então $T^{s}[i-1, k+1]=0$, pois se não existe LCS de comprimento $k$ para $X[i . . m]$ e $Y[j . . n]$, então não existe LCS de comprimento $k+1$ para $X[i-1 . . m]$ e $Y[j . . n]$. Podemos então dizer que as diagonais são decrescentes e se atingirem 0 , continuam em 0.

Lema 7.7.2.

$$
T^{s}[i, k]=\left\{\begin{array}{l}
\text { maior } j \text { tal que } x_{i}=y_{j} \text { e } T^{s}[i+1, k] \leq j<T^{s}[i+1, k-1] \text {, ou } \\
T^{s}[i+1, k], \text { se tal } j \text { não existe. }
\end{array}\right.
$$

Assim como no algoritmo de Hunt e Szymanski, a base deste algoritmo é preencher elementos de $T^{s}$ conforme o Lema 7.7.2. Porém, enquanto o algoritmo de Hunt e Szymanski constrói a matriz $T$ linha por linha, este algoritmo constrói a matriz $T^{s}$ diagonal por diagonal $(\nearrow)$. Com um critério de parada esperto, essa ordem economiza o cálculo de vários elementos de $T^{s}$ especialmente se o comprimento de um LCS for grande. A figura seguinte mostra essa ordem. 


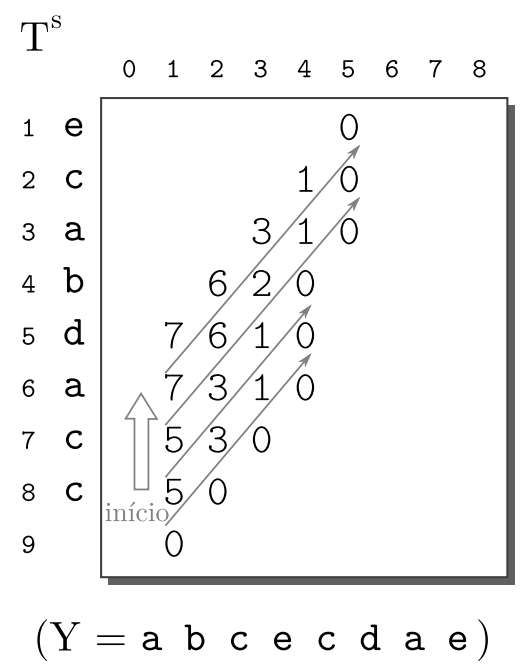

A ordem em que calculamos $T^{s}$, como ilustrada na figura acima, é a seguinte: iniciamos em $T^{s}[m, 1]$ e percorremos as diagonais decrescendo a linha e crescendo a coluna. Quando batemos em uma borda da matriz $(i=0)$ ou encontramos um valor $T^{s}[i, k]=0$, não há mais o que calcular nessa diagonal e passamos para a próxima, a diagonal acima dela, iniciando-a da coluna $k=1$ (lembrando que as diagonais são decrescentes até 0 ).

Observe que, nessa ordem, ao calcular $T^{s}[i, k]$, temos sempre à disposição $T^{s}[i+1, k-1] \mathrm{e}$ quase sempre $T^{s}[i+1, k]$, que são os dois elementos que precisamos para calcular $T^{s}[i, k]$ segundo o Lema 7.7.2. Apenas não temos à disposição $T^{s}[i+1, k]$ se estamos calculando um elemento da coluna $k$ pela primeira vez. No entanto, nesse caso ele sempre vale 0 . De fato, se estivermos na primeira diagonal iniciada em $T^{s}[m, 1]$, sabemos que $T^{s}[m+1,1]=0$ por definição, o que implica que todos os elementos da diagonal abaixo da primeira são iguais a 0. Se não estivermos na primeira diagonal e $T^{s}[i+1, k]$ não estiver preenchido, deve valer $T^{s}[i+2, k-1]=0$ pois, senão, o cálculo da diagonal anterior teria continuado para a coluna $k$. Isso implica que $T^{s}[i+1, k]=0$.

Dados $i$ e $k$, a busca para encontrar o maior $j$ tal que $x_{i}=y_{j}$ e $T^{s}[i+1, k] \leq j<T^{s}[i+1, k-1]$ (isto é, aplicar o Lema 7.7.2) é feita linearmente. Com essas observações, temos um processo para calcular os elementos da matriz $T^{s}$ por completo, mas falta pensar no critério de parada para evitar calcular elementos da matriz $T^{s}$ desnecessariamente.

Se conhecemos o comprimento $k$ de uma subsequência comum de $X$ e $Y$, então a computação da diagonal que inicia em $T^{s}\left[k^{\prime}, 1\right]$ para qualquer $k^{\prime} \leq k$ não resultará no conhecimento de uma subsequência comum de comprimento maior que $k$, pois essa diagonal termina no máximo em $T^{s}\left[1, k^{\prime}\right]$. Logo, ao encontrarmos a primeira diagonal desse tipo, podemos finalizar o algoritmo, pois, pela ordem que preenchemos as diagonais, qualquer outra diagonal que ainda não foi preenchida é também desse tipo. Assim, o maior $k$ encontrado até esse ponto é o comprimento de um LCS.

Para recuperar um LCS de $T^{s}$, basta realizar o caminho inverso da última diagonal calculada, lembrando que podem haver casos em que $\left(i, T^{s}[i, k]\right)$ não é um casamento. Porém, nesses casos, $T^{s}[i, k]=T^{s}[i+1, k]$, então basta sempre escolher o maior $i^{\prime}$ tal que $T^{s}\left[i^{\prime}, k\right]=T^{s}[i, k]$, pois $\left(i^{\prime}, T^{s}\left[i^{\prime}, k\right]\right)$ é um casamento. Assim, como as diagonais são crescentes na direção inversa, escolhemos casamentos com ambas linhas e colunas em ordem crescente, o que implica que os casamentos escolhidos não se cruzam e, portanto, representam uma subsequência comum (na ordem correta). 


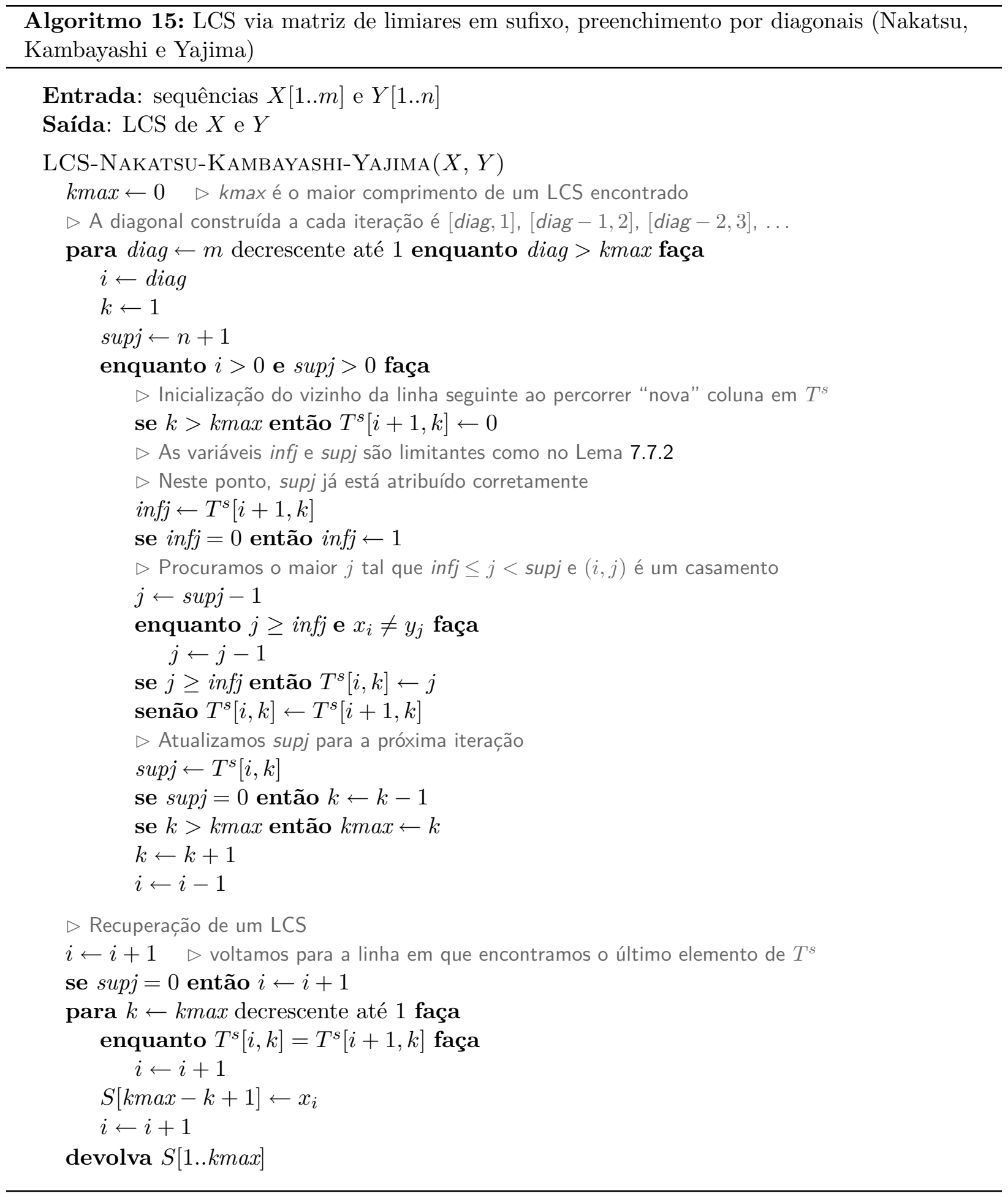


O número de diagonais que computamos é exatamente $m-p$ quando $p<m$, ou 1 quando $p=m$, pois o laço principal termina quando diag (que inicia em $m$ e decresce) é igual a $p$. Para computar cada diagonal, percorremos a sequência $Y$ inteira. Portanto, consumimos tempo $O(n(m-p))$ para encontrar os elementos da matriz $T^{s}$ que desejamos. Contando posições com zeros, calculamos $m-p+1$ diagonais com no máximo $p+1$ elementos cada, isto é, calculamos no máximo $(p+1)(m-p+1)$ elementos de $T^{s}$. A matriz $T^{s}$ pode ser mapeada para vetores de comprimento total $(m+1)(m-p+1)$ : a cada vez que começamos a calcular uma diagonal nova, alocamos um vetor de comprimento $m+1$ (o pseudocódigo anterior deve ser adaptado para isso). A recuperação de um LCS consome tempo $O(m)$. Logo, o algoritmo consome tempo $O(n(m-p))$ e espaço $O(m(m-p))$.

\subsection{Algoritmo de divisão e conquista de Hirschberg em espaço linear}

Nos algoritmos até a seção anterior, nos preocupamos mais em obter uma complexidade de tempo menor que a tradicional $O(m n)$. Embora essa preocupação valha a pena, em muitos casos práticos da resolução do LCS, o espaço é um gargalo maior do que o tempo. Por causa disso, um dos primeiros algoritmos para o LCS, desenvolvido em 1975 por Hirschberg [19], propõe-se a reduzir assintoticamente o consumo de espaço do algoritmo tradicional de programação dinâmica da Seção 7.2 sem aumentar assintoticamente o consumo de tempo.

Antes de descrevermos o algoritmo de espaço linear de Hirschberg, discutiremos um caso mais fácil. Digamos que estamos interessados apenas no comprimento de um LCS e não em um LCS em si. Nesse caso, é simples modificar o algoritmo de programação dinâmica para devolver apenas o comprimento de um LCS consumindo espaço linear. Observe que para gerar a linha $i$ da matriz de programação dinâmica $L$, precisamos apenas da linha anterior $i-1$. Ainda mais, se estamos calculando a linha $i$ a partir da coluna $j$, não precisamos da linha $i-1$ inteira; precisamos apenas da coluna $j-1$ em diante. O pseudocódigo a seguir descreve como determinar $L[m, n]$ usando espaço linear.

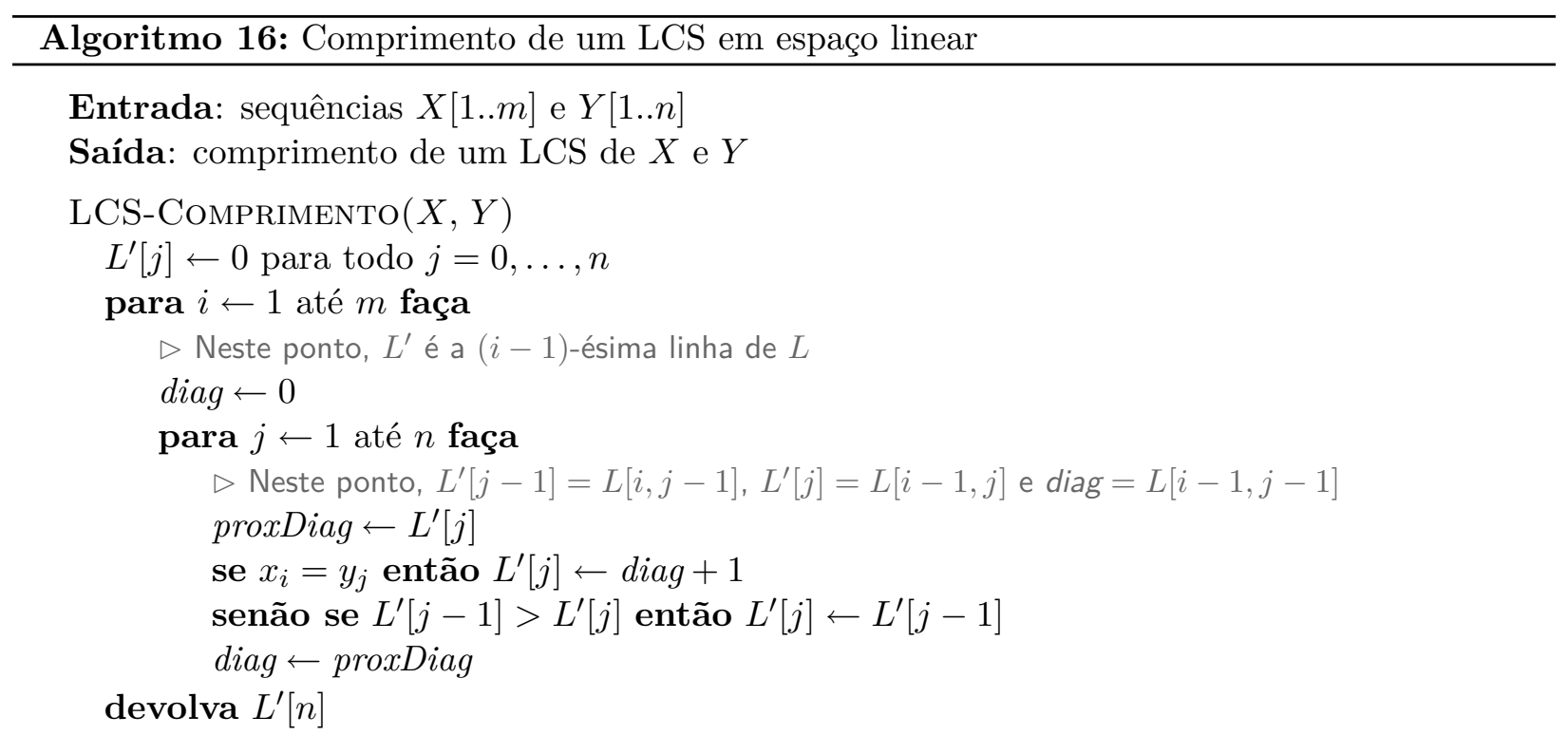


O algoritmo anterior itera em $i$ e em $j$ para computar os elementos da matriz $L$ assim como no algoritmo de programação dinâmica da Seção 7.2, aplicando a mesma recorrência. Ele consome tempo $O(m n)$ pois ainda calcula todos os valores da matriz $L$. A vantagem dele é que ele consome apenas espaço $O(n)$. Infelizmente, não é possível recuperar um LCS dessa maneira.

No entanto, sabendo que o algoritmo anterior pode devolver qualquer linha inteira de $L$ com uma pequena modificação, ele pode ser usado em um algoritmo de divisão e conquista que constrói um LCS em espaço linear. Esse algoritmo foi proposto por Hirschberg e será detalhado a seguir.

Seja $L^{s}[i, j]$ o comprimento de um LCS dos sufixos de $X$ e $Y$ com inícios em $i+1$ e $j+1$ respectivamente, isto é, um LCS de $X[i+1 . . m]$ e $Y[j+1 . . n]$.

Lema 7.8.1. Para qualquer $0 \leq i \leq m$,

$$
L[m, n]=\max _{0 \leq j \leq n}\left\{L[i, j]+L^{s}[i, j]\right\}
$$

Prova. Provaremos primeiro que $L[m, n] \geq \max _{0 \leq j \leq n}\left\{L[i, j]+L^{s}[i, j]\right\}$. Dados $i$ e $j$, um LCS de $X[1 . . i]$ e $Y[1 . . j]$ concatenado com um LCS de $X[i+1 . . m]$ e $Y[j+1 . . n]$ é uma subsequência comum de $X$ e $Y$ de comprimento $L[i, j]+L^{s}[i, j]$. Logo, $L[i, j]+L^{s}[i, j] \leq L[m, n]$ para quaisquer $i$ e $j$.

Veremos agora que $L[m, n] \leq \max _{0 \leq j \leq n}\left\{L[i, j]+L^{s}[i, j]\right\}$. Seja $Z$ um LCS de $X$ e $Y$. Para qualquer $i, Z$ pode ser dividido em dois de forma que $Z=Z_{1} Z_{2}$, onde $Z_{1}$ é uma subsequência de $X[1 . . i]$ e $Z_{2}$ de $X[i+1 . . m]$. Então existe um $j$ tal que $Z_{1}$ seja subsequência de $Y[1 . . j]$ e $Z_{2}$ de $Y[j+1 . . n]$, e vale que $\left|Z_{1}\right| \leq L[i, j]$ e $\left|Z_{2}\right| \leq L^{s}[i, j]$. Assim, $L[m, n]=|Z|=\left|Z_{1}\right|+\left|Z_{2}\right| \leq$ $\max _{0 \leq j \leq n}\left\{L[i, j]+L^{s}[i, j]\right\}$.

Portanto, $L[m, n]=\max _{0 \leq j \leq n}\left\{L[i, j]+L^{s}[i, j]\right\}$.

Um corolário direto desse lema é que, para quaisquer $i$ e $j$ tais que $j$ maximiza $L[i, j]+L^{s}[i, j]$, um LCS de $X[1 . . i]$ e $Y[1 . . j]$ (de comprimento $L[i, j]$ ) concatenado com um LCS de $X[i+1 . . m] \mathrm{e}$ $Y[j+1 . . n]$ (de comprimento $L^{s}[i, j]$ ) é um LCS de $X$ e $Y$ (de comprimento $L[m, n]$ ).

A ideia do algoritmo é fixar um índice $i$ de $X$ (digamos, metade do comprimento de $X$ ), encontrar um $j$ que maximiza $L[i, j]+L^{s}[i, j]$, resolver os subproblemas recursivamente para $X[1 . . i]$ e $Y[1 . . j]$, e $X[i+1 . . m]$ e $Y[j+1 . . n]$, e depois concatenar os resultados. A figura seguinte ilustra um passo desse processo, detalhado melhor pelo pseudocódigo na página seguinte.

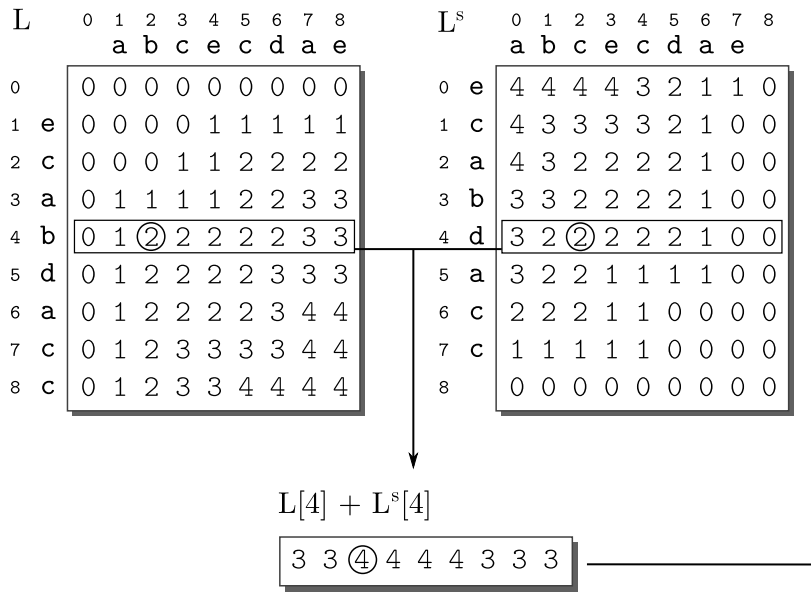

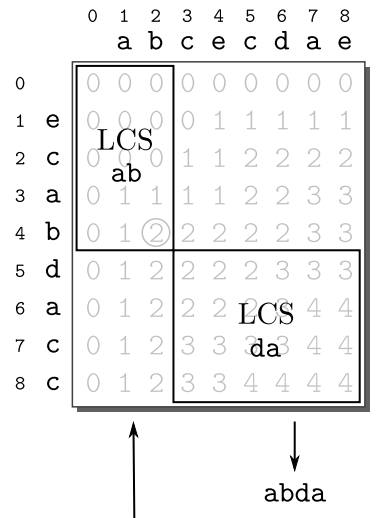


Defina $X^{r}$ como o reverso da sequência $X: X^{r}=x_{m} x_{m-1} \ldots x_{2} x_{1}$. É claro que $L^{s}[i, j]$ também é o comprimento de um LCS de $X^{r}[m . . i+1]$ e $Y^{r}[n . . j+1]$.

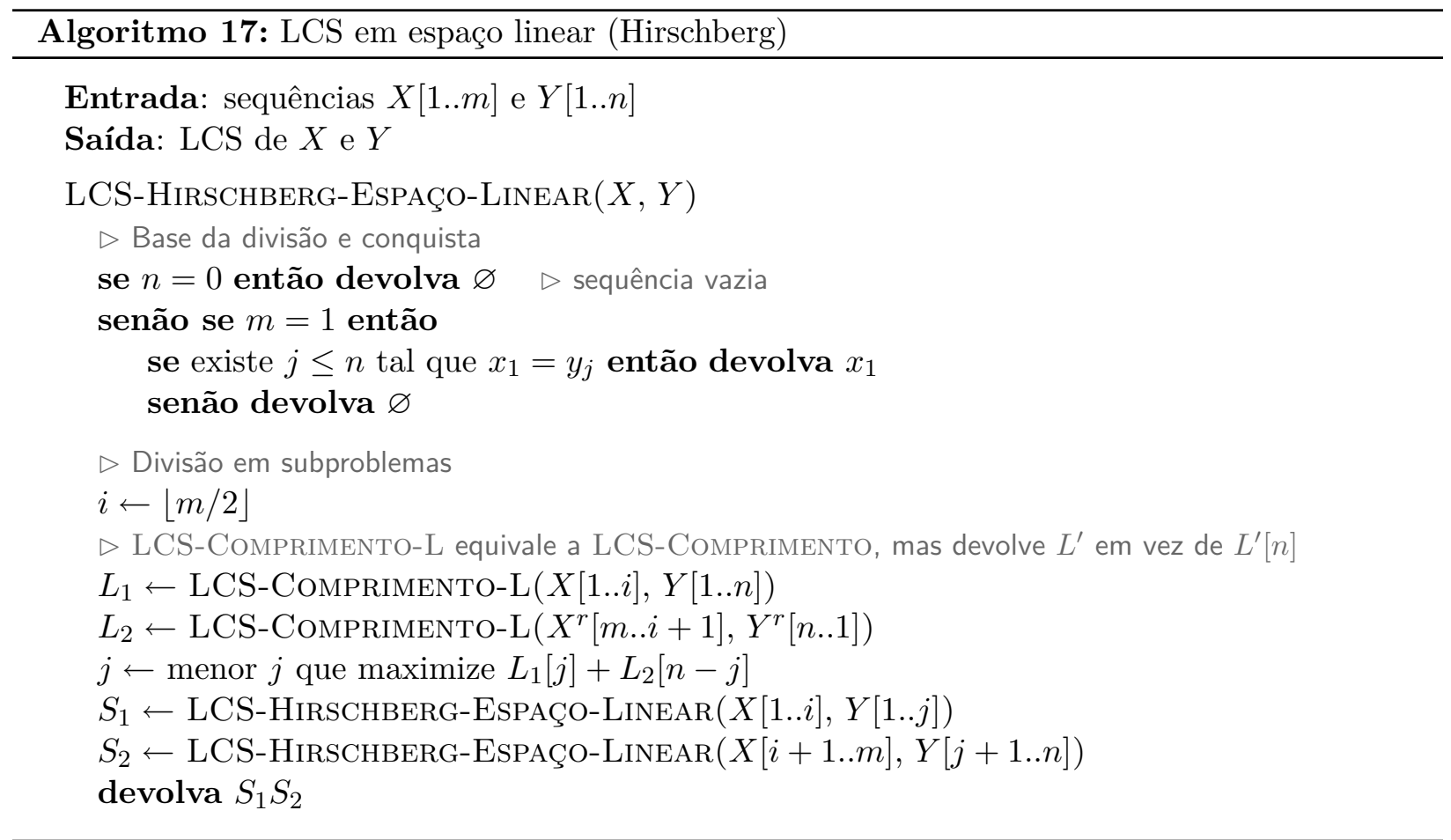

A base da divisão e conquista está correta por definição. Mostraremos agora a corretude da subdivisão em problemas.

Por definição, $L_{1}[j]$ é o comprimento de um LCS de $X[1 . . i]$ e $Y[1 . . j]$, e $L_{2}[j]$ é o comprimento de um LCS de $X^{r}[m . . i+1]$ e $Y^{r}[n . . n-j+1]$. Então $L_{2}[n-j]$ é o comprimento de um LCS de $X[i+1 . . m]$ e $Y[j+1 . . m]$. Portanto, $L_{1}[j]=L[i, j]$ e $L_{2}[n-j]=L^{s}[i, j]$. Pelo corolário do Lema 7.8.1, se $j$ maximiza $L[i, j]+L^{s}[i, j]=L_{1}[j]+L_{2}[n-j]$, então um LCS $S_{1}$ de $X[1 . . i]$ e $Y[1 . . j]$ concatenado com um LCS $S_{2}$ de $X[i+1 . . m]$ e $Y[j+1 . . n]$ é um LCS de $X$ e $Y$. Logo, o algoritmo devolve um LCS de $X$ e $Y$.

Os vetores $L_{1}$ e $L_{2}$ ocupam espaço $O(n)$ e são calculados com o algoritmo LCS-ComPRIMENTO-L, que opera em espaço $O(n)$ para ambos os casos. A sequência $S_{1} S_{2}$ também sempre ocupa espaço $O(n)$. Assim, se alocarmos espaço apenas no momento que for necessário para cada sequência devolvida, a alocação dessas sequências no algoritmo inteiro consome espaço $O(n)$. Com exceção da recursão, o resto do algoritmo gasta espaço constante. Ao entrar na recursão, não precisamos mais manter $L_{1}$ e $L_{2}$ e podemos liberá-los e, portanto, o algoritmo gasta espaço $O(n)$.

As duas chamadas a LCS-COMPRIMENTO-L equivalem aproximadamente, em termos de tempo, a calcular a matriz de programação dinâmica inteira, gastando tempo $c m n$ juntas para alguma constante $c$. O resto do algoritmo, a menos da recursão, consome tempo $O(n)$, então consideraremos apenas as chamadas a LCS-COMPRIMENTO-L e a recursão para analisar seu consumo de tempo. Observe que, a cada nível de recursão, estamos chamando LCS-HIRSCHBERG-ESPAÇO-LINEAR uma vez com sequências de comprimentos $m / 2$ e $j$, e outra vez com comprimentos $m / 2$ e $n-j$, para algum $j$. Então, no segundo nível da recursão, por exemplo, gastamos tempo $c m j / 2+c m(n-j) / 2=c m n / 2$. No $i$-ésimo nível da recursão, gastamos tempo $\mathrm{cmn} / 2^{i-1}$, pois nesse nível, cada subproblema $t$ envolve sequências de comprimentos $m / 2^{i-1}$ e $j_{t}$ tal que a soma dos $j_{t}$ s para todo subproblema $t$ seja $n$. A 
recursão tem $\lceil\lg m\rceil$ níveis e, então, o tempo total gasto é $\sum_{i=1}^{\lceil\lg m\rceil} \mathrm{cmn} / 2^{i-1} \leq 2 \mathrm{cmn}$ (lembrando que cmn é aproximadamente o consumo de tempo do algoritmo de programação dinâmica). Logo, o algoritmo consome (aproximadamente) no máximo duas vezes do tempo que o algoritmo de programação dinâmica consome. Isto é, o algoritmo consome tempo $O(m n)$.

\subsection{Algoritmo de subdivisão de matriz de Masek e Paterson}

O algoritmo de Masek e Paterson [32], de 1980, baseia-se em um método para acelerar algoritmos de programação dinâmica desenvolvido por Arlazarov, Dinic, Kronrod e Faradzev [3] e conhecido como a técnica Quatro-Russos ${ }^{1}$. A ideia desse método é dividir uma matriz de programação dinâmica em submatrizes pequenas (com índices contíguos) e precomputar todas as possibilidades para essas submatrizes. Dependendo da escolha do tamanho dessas submatrizes, isso pode resultar em um algoritmo assintoticamente mais eficiente - em particular, este algoritmo tem complexidade de tempo de $O\left(n^{2} / \log n\right)$ supondo tamanho do alfabeto constante, embora ele tenha um caráter mais teórico do que prático. Na prática, os algoritmos previamente discutidos podem funcionar melhor que este. Um bom resumo deste algoritmo pode ser encontrado em um livro de Gusfield [17].

Considere a matriz de programação dinâmica $L$ da Seção 7.2. Observe que a primeira linha e a primeira coluna de qualquer submatriz (contígua) dessa matriz, junto com os segmentos das duas sequências associadas a ela, determinam o resto da submatriz (basta executar o algoritmo de programação dinâmica). Isto é, se essa submatriz tem tamanho $k \times k$, os $2 k-1$ valores nas bordas superior e esquerda e as duas sequências de comprimento $k$ associadas a ela determinam, em particular, os $2 k-1$ valores nas bordas inferior e direita, como na figura abaixo.

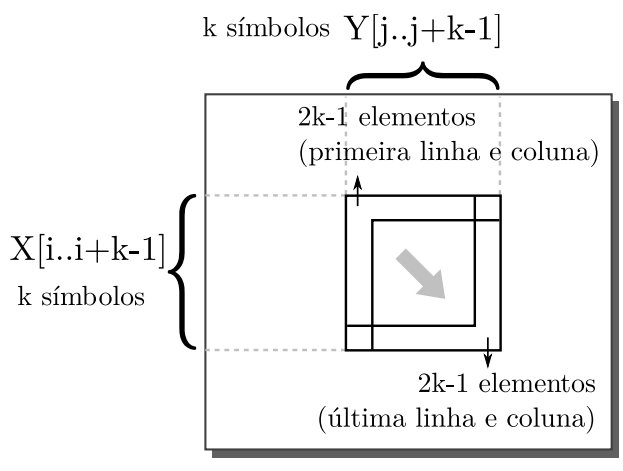

A ideia do algoritmo é enumerar todas as possíveis submatrizes de tamanho $k \times k$ e pré-computálas. O número de possíveis submatrizes é duas vezes o número de combinações possíveis de sequências de comprimento $k$ (para $X$ e para $Y$ ), mais o número de combinações possíveis da primeira linha e primeira coluna da submatriz, já que o resto da submatriz é determinado por esses valores. Temos $|\Sigma|^{2 k}$ possibilidades para as sequências $X[i . . i+k-1]$ e $Y[j . . j+k-1]$. Já o número de possibilidades para os valores nas bordas superior e esquerda depende não só de $k$, mas também de $m$, já que eles podem ser qualquer valor inteiro de 0 a $\mathrm{m}$. No entanto, podemos torná-lo dependente apenas de $k$.

Sai diretamente da recorrência do LCS que, para toda célula de valor $v$ da matriz $L$, o valor da célula à sua esquerda (se existir) é ou $v$, ou $v-1$. Podemos então reescrever a matriz como uma matriz binária, onde o valor de cada posição é 0 se, na matriz original, a célula à esquerda tem

\footnotetext{
${ }^{1}$ Embora apenas um dos autores seja russo.
} 
valor igual, ou 1 se, na matriz original, a célula à esquerda tem valor um a menos. A figura a seguir ilustra essa matriz. Observe que podemos facilmente recuperar a matriz original a partir da binária realizando um processo inverso.

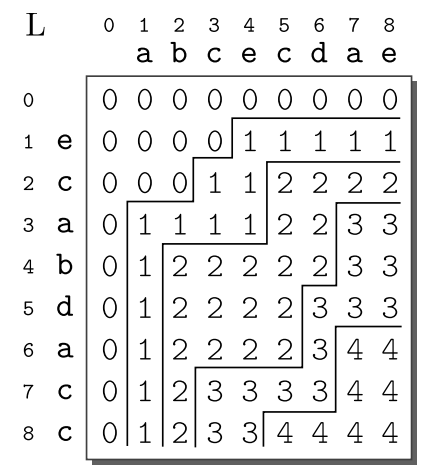

\begin{tabular}{|c|c|c|c|c|c|c|c|c|c|}
\hline & 0 & $\begin{array}{l}1 \\
\mathrm{a}\end{array}$ & $\begin{array}{l}2 \\
b\end{array}$ & $\begin{array}{l}3 \\
c\end{array}$ & $\begin{array}{l}4 \\
\mathrm{e}\end{array}$ & $\begin{array}{l}5 \\
\mathrm{C}\end{array}$ & $\begin{array}{l}6 \\
\mathrm{~d}\end{array}$ & & $\begin{array}{l}8 \\
\mathrm{e}\end{array}$ \\
\hline & 0 & 0 & 0 & 0 & 0 & 0 & 0 & 0 & 0 \\
\hline e & 0 & 0 & 0 & 0 & 1 & 0 & 0 & 0 & 0 \\
\hline C & 0 & 0 & 0 & 1 & 0 & 1 & 0 & 0 & 0 \\
\hline a & 0 & 1 & 0 & 0 & 0 & 1 & 0 & 1 & 0 \\
\hline$b$ & 0 & 1 & 1 & 0 & 0 & 0 & 0 & 1 & 0 \\
\hline$d$ & 0 & 1 & 1 & 0 & 0 & 0 & 1 & 0 & 0 \\
\hline $\mathrm{a}$ & 0 & 1 & 1 & 0 & 0 & 0 & 1 & & 0 \\
\hline C & 0 & 1 & 1 & 1 & 0 & 0 & 0 & 1 & 0 \\
\hline C & 0 & 1 & 1 & 1 & 0 & 1 & 0 & 0 & 0 \\
\hline
\end{tabular}

Agora, considerando essa matriz binária, temos $2^{2 k-1}$ possibilidades para os valores nas bordas superior e esquerda (cada elemento pode ser 0 ou 1 ). Assim, temos $|\Sigma|^{2 k} 2^{2 k-1}$ submatrizes possíveis.

Suponha, por simplicidade, que a sequência $X$ tem comprimento $m=m^{\prime}(k-1)$ e a $Y$ tem comprimento $n=n^{\prime}(k-1)$ para algum $m^{\prime}$ e $n^{\prime}$. Caso contrário, para cada sequência que não o tem, basta preencher o final dela com ocorrências de um símbolo novo que não pertence ao alfabeto até ela ter um comprimento múltiplo de $k-1$.

Iremos definir o $k$ apropriadamente depois. O algoritmo para uma constante $k$ é o seguinte:

1. Pré-calcule os valores nas bordas inferior e direita para todas as $|\Sigma|^{2 k} 2^{2 k+1}$ submatrizes $k \times k$ possíveis.

2. Cubra a matriz com várias submatrizes $k \times k$ de forma que a borda inferior de uma submatriz se sobreponha com a borda superior da submatriz de baixo (se existir), e a borda direita de uma submatriz se sobreponha com a borda esquerda da submatriz à direita (se existir). Temos então uma matriz de $\left(\frac{m}{k-1}\right) \times\left(\frac{n}{k-1}\right)$ submatrizes.

3. Inicialize a primeira linha e a primeira coluna com zeros.

4. Percorrendo as submatrizes por linha, use os valores precalculados para determinar suas bordas inferior e direita. Como as submatrizes se sobrepõem, elas serão as bordas superior e esquerda das matrizes adjacentes.

5. Devolva a soma dos valores da última linha.

O algoritmo tem duas etapas principais: pré-calcular as submatrizes (item 1) e calcular a matriz usando as submatrizes (item 4). A primeira etapa consiste em computar o LCS usando o algoritmo tradicional de programação dinâmica para $|\Sigma|^{2 k} 2^{2 k-1}$ matrizes $k \times k$. Esse processo consome tempo e espaço $O\left(|\Sigma|^{2 k} 2^{2 k-1} k^{2}\right)=O\left((2|\Sigma|)^{2 k} k^{2}\right)$. Tomando $k=\left\lfloor\left(\log _{2|\Sigma|} n\right) / 2\right\rfloor$, temos que a etapa consome tempo e espaço $O\left(n \log ^{2} n\right)$, supondo tamanho do alfabeto constante. Na segunda etapa, para cada uma das $\left(\frac{m}{k-1}\right)\left(\frac{n}{k-1}\right)$ submatrizes, olhamos para $O(k)$ elementos para encontrar a submatriz para a qual estamos olhando. Supondo que podemos acessar as submatrizes pré-calculadas em tempo constante, essa etapa consome tempo $O\left(k\left(\frac{m}{k-1}\right)\left(\frac{n}{k-1}\right)\right)=O(m n / \log n)$. Assim, como $O\left(n \log ^{2} n\right)$ é $O\left(n^{2} / \log n\right)$, o algoritmo consome tempo $O\left(n^{2} / \log n\right)$. 


\subsection{Algoritmo por limiares e saltos para casamentos}

Vimos na Seção 7.6.1 uma matriz $|\Sigma| \times n$ que chamamos de $\operatorname{proxPos} Y$, proposta por Apostolico e Guerra, tal que proxPos $Y[\sigma, j]$ é o índice da próxima ocorrência de $\sigma$ em $Y$ depois de $j$, ou $n+1$ se não existir (supondo $m \leq n$ ). Essa matriz consome $O(|\Sigma| n)$ de espaço e tempo para ser construída. Eles também sugerem uma maneira esperta de obter o mesmo resultado construindo apenas um vetor de tamanho $n$ em vez da matriz $|\Sigma| \times n$, mas com a desvantagem de que cada consulta ProxPosY consome tempo $O(\log |\Sigma|)$. Eles adaptam o algoritmo de Hirschberg usando essa técnica, mas eles não a usam para adaptar o de Hunt e Szymanski. Descrevemos uma maneira natural de aplicar essa ideia ao algoritmo de Hunt e Szymanski (Seção 7.4) que não foi encontrada na literatura estudada.

A alteração no algoritmo de Hunt e Szymanski é simples: basta, em vez de percorrer os casamentos $(i, j)$ em ordem decrescente de $j$, usar ProxPosY para escolher sempre o primeiro casamento que vem após o último limiar encontrado, como ilustrado na figura seguinte.

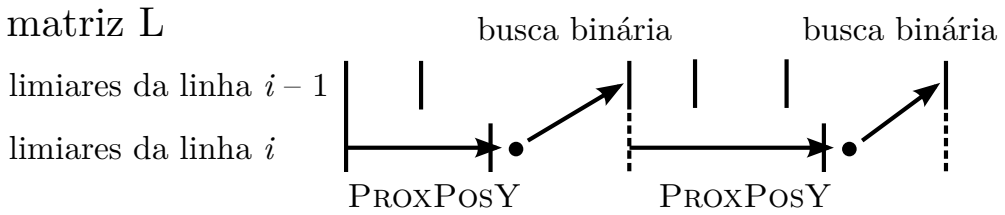

A maneira de recuperar um LCS neste algoritmo é igual à do algoritmo de Hunt e Szymanski, mas com o cuidado descrito na Seção 7.4.1 por percorrer os casamentos em ordem crescente de coluna. No pseudocódigo seguinte, omitimos a recuperação de um LCS. Assim como no algoritmo de Hunt e Szymanski, preenchemos um vetor $t$ tal que $t[k]$ é o valor $T(i, k)$ (descrito na Seção 7.4) para a linha atual $i$.

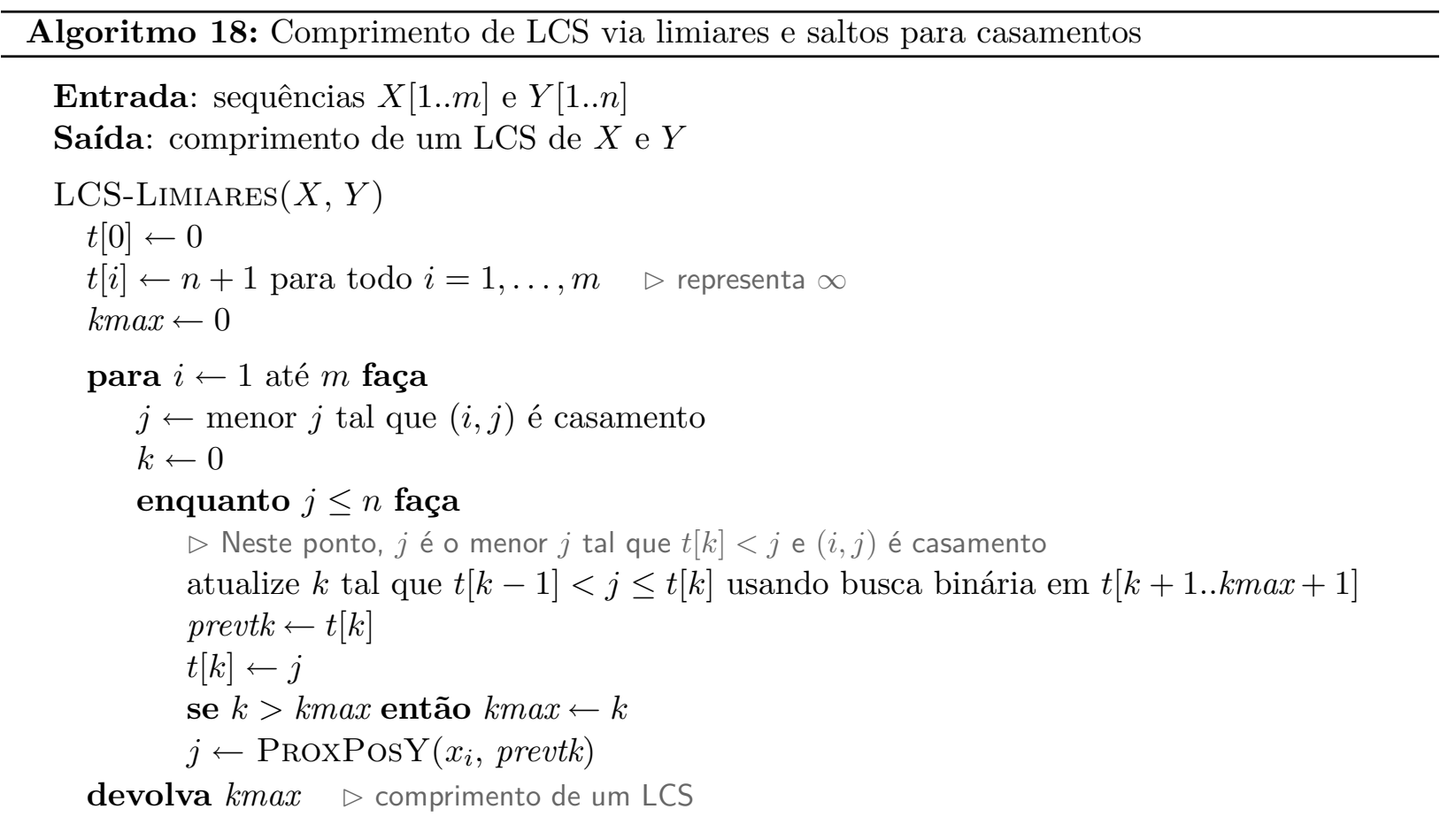


A complexidade de tempo do algoritmo é $O(|\Sigma| n+r \log p)$ com a versão de tabela de ProxPosY e $O(n+r(\log p+\log |\Sigma|))$ com a de vetor, onde $r$ é o número de casamentos e $p$ é o comprimento de um LCS, pois para cada casamento realizamos no máximo uma busca binária (em no máximo $p+1$ elementos) e uma consulta a ProxPosY. A complexidade de espaço é $O(|\Sigma| n+r)$ com tabela e $O(n+r)$ com vetor (precisamos de espaço $O(r)$ para armazenar a estrutura que nos permite recuperar uma solução). Em termos de consumo de tempo assintótico, no pior caso, este algoritmo é pior que o de Hunt e Szymanski, mas vale ressaltar que nem todos casamentos são percorridos, e as buscas binárias são feitas em vetores menores.

Uma característica interessante do algoritmo anterior é que a recursividade da busca binária para encontrar limiares pode ser incorporada também para encontrar casamentos. Fixada uma linha, podemos pensar em olhar para seus limiares como se fosse uma árvore binária, como ilustrado a seguir, e tratar os limiares nessa ordem.

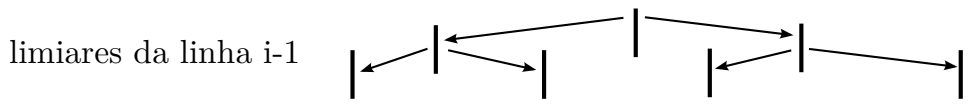

A figura seguinte ilustra como lidar com os limiares de uma linha $i$ recursivamente se tivermos sempre o primeiro casamento (casamento $(i, j)$ de menor $j$ ) da região que estamos considerando.

Caso 1: primeiro casamento após o meio

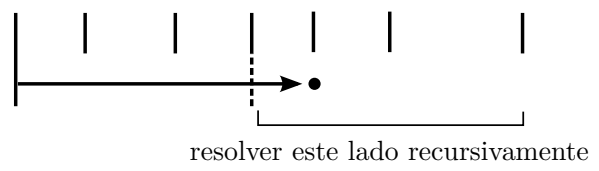

Caso 2: primeiro casamento antes do meio

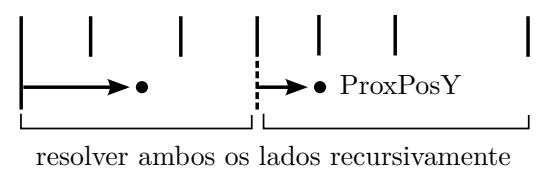

O pseudocódigo seguinte descreve uma função recursiva que aplica a ideia da figura acima. Ele recebe um vetor $t$ que contém a linha $i-1$ da matriz $T$, e atualiza $t$ de forma que, ao fim da recursão, ela contenha a linha $i$ da matriz $T$. 


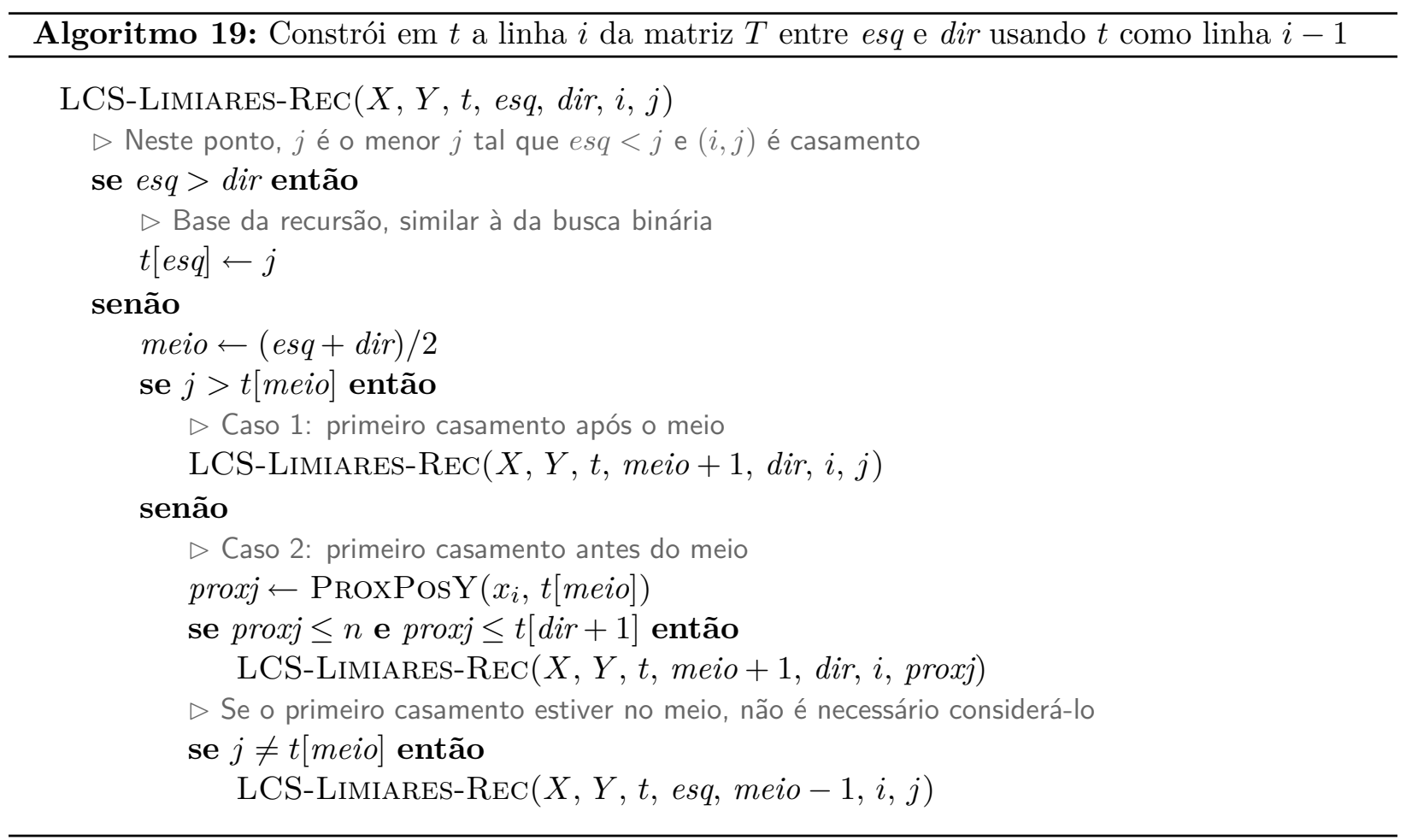

Dado que $p$ é o comprimento de um LCS, a função acima com $e s q=1$ e dir $=k \max$ (onde $k$ max é como no algoritmo anterior) consome tempo $O(p)$ com ProxPosY como tabela e $O(p \log |\Sigma|)$ com vetor, pois a cada linha temos no máximo $p$ limiares, e o pior caso é passar por todos eles realizando sempre uma consulta a PROxPosY. Portanto, o algoritmo que usa a função anterior para computar as linhas de $T$ consome tempo $O(|\Sigma| n+m p)$ com tabela e $O(n+m p \log |\Sigma|)$ com vetor. Já a complexidade de espaço do algoritmo continua sendo $O(|\Sigma| n+r)$ com tabela e $O(n+r)$ com vetor. Na prática, no entanto, esta modificação parece não fazer muita diferença, como veremos na seção seguinte.

\subsection{Resultados computacionais}

Implementamos todos os algoritmos descritos neste capítulo exceto a modificação do algoritmo de Hunt e Szymanski por Apostolico e Guerra e o algoritmo de Masek e Paterson. Executamos os algoritmos para sequências com distribuição uniforme de símbolos dado o tamanho do alfabeto e o comprimento das sequências. Cada valor dos gráficos indica o tempo médio de 10 execuções do algoritmo. A segunda versão do algoritmo de saltos para casamentos foi implementada de forma iterativa.

Para construir o gráfico a seguir, procuramos, manualmente e de forma pouco rígida, comprimentos de sequência para cada algoritmo que resultassem em um consumo de memória perto de $1 \mathrm{~GB}$ ou em um consumo de tempo razoável, e testamos para entradas até esses valores. O alfabeto usado é sempre a metade do comprimento. 
LCS (alfabeto $\mathrm{n} / 2$ )

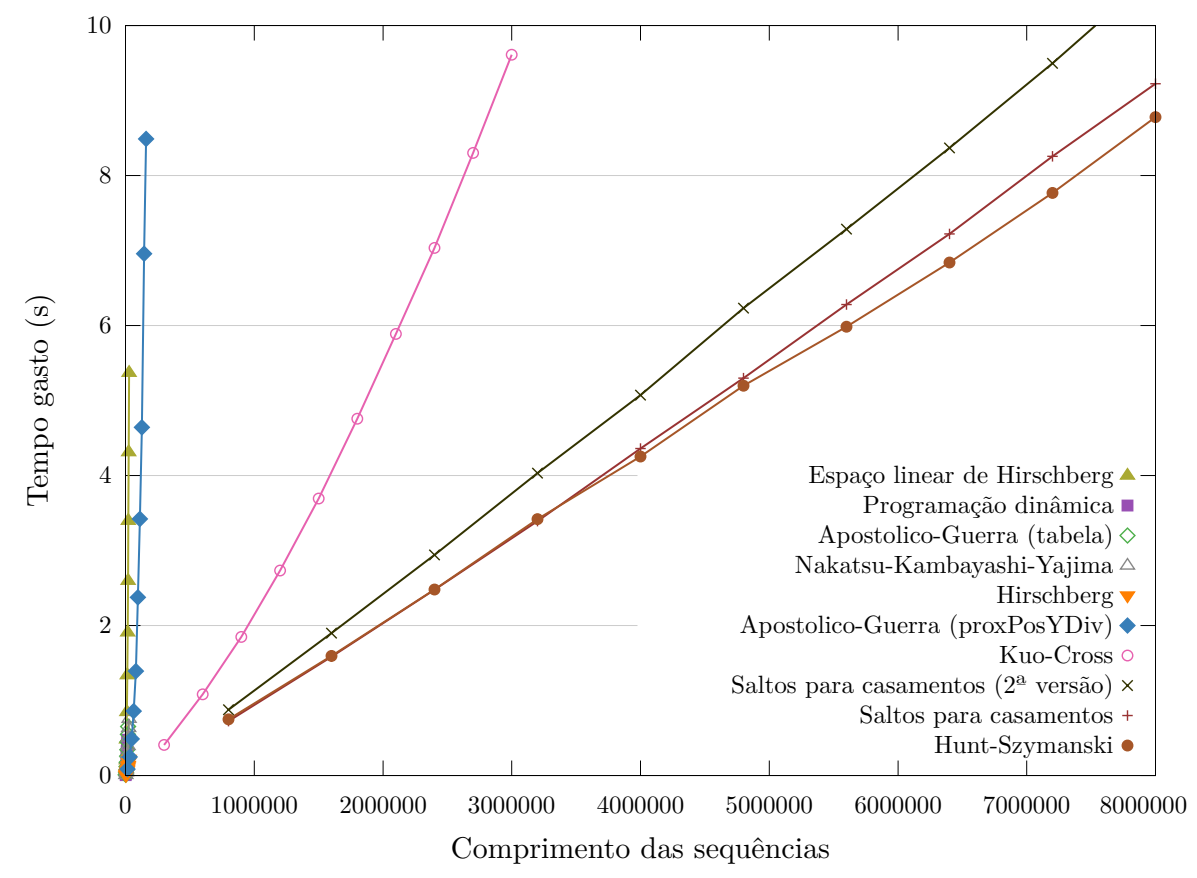

Do gráfico anterior, é bem claro que os algoritmos com base no de Hunt e Szymanski funcionam bem para o caso em que a entrada é uniformemente gerada e grande. O próximo gráfico ilustra melhor os que não têm base no de Hunt e Szymanski.

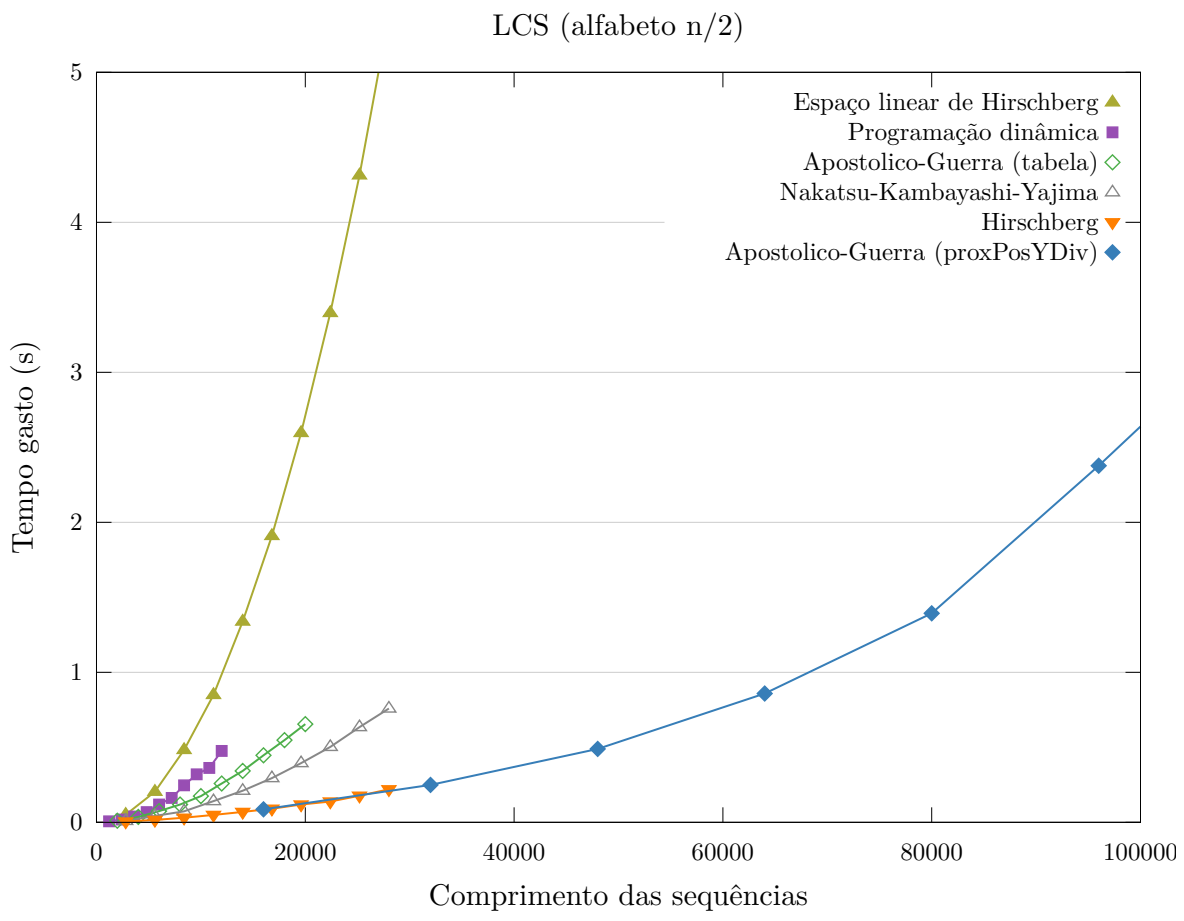


Vale a pena observar também o desempenho dos algoritmos conforme o alfabeto. O próximo gráfico fixa o comprimento das sequências em 10000 e varia o alfabeto. A escala no eixo $x$ (alfabeto) é logarítmica para facilitar a visualização do gráfico.

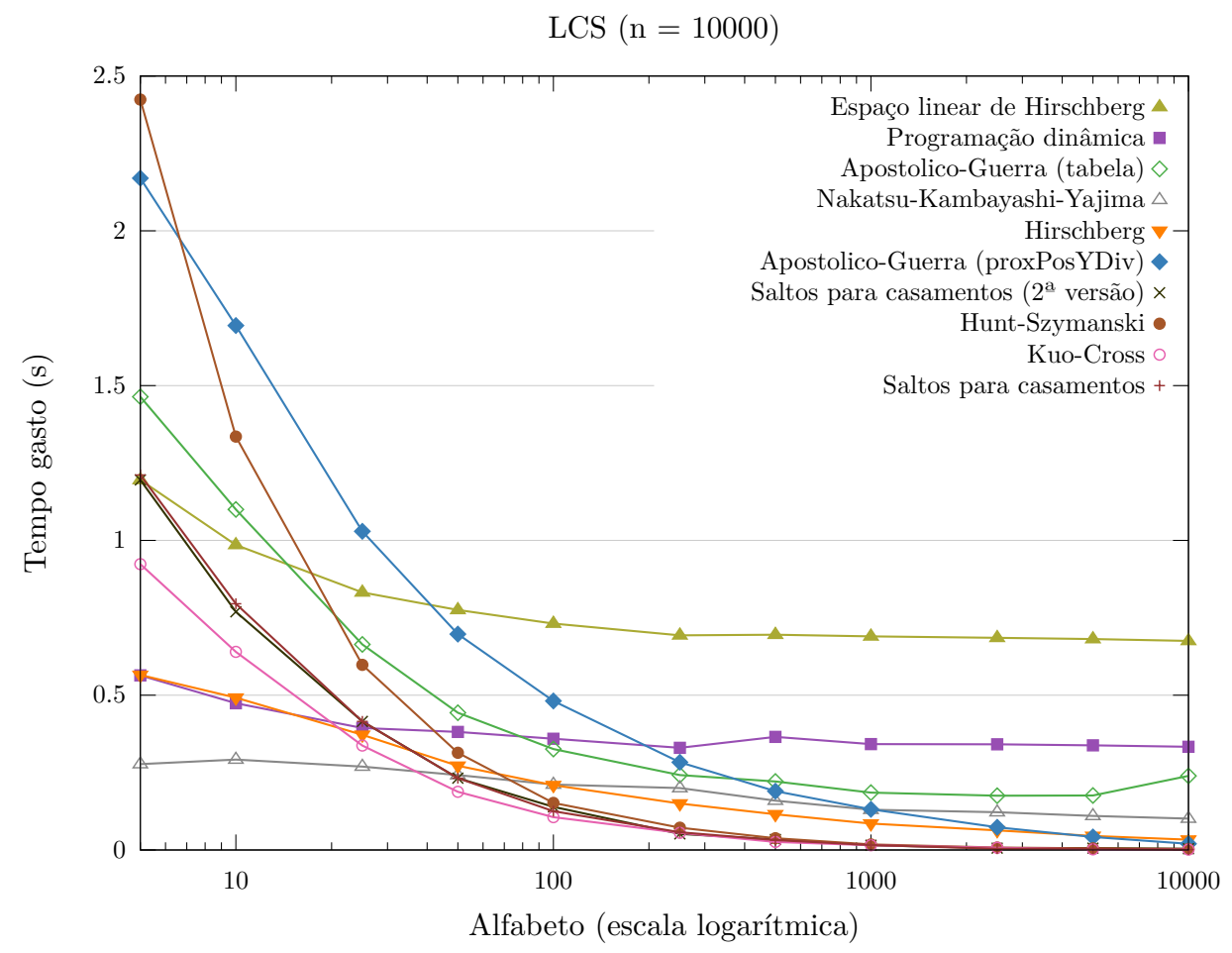

A primeira observação que se pode fazer é a dificuldade da maioria dos algoritmos em lidar com alfabetos pequenos. Isso decorre do fato de que o desempenho de muitos deles depende do número de casamentos, que é inversamente proporcional ao tamanho do alfabeto para entradas uniformemente geradas.

Podemos perceber que, com alfabeto muito pequeno para entradas uniformemente geradas, o algoritmo de Hunt e Szymanski tem o maior consumo de tempo, e o de Nakatsu, Kambayashi e Yajima tem o menor. Podemos reparar também que o algoritmo de programação dinâmica e o de espaço linear por Hirschberg não sofrem muita influência do alfabeto, como esperado.

Outra observação é que o algoritmo da seção anterior tem a vantagem de funcionar bem para entradas grandes, e ainda não sofrer muito no desempenho com alfabeto pequeno. Nesse sentido, ele é uma espécie de um algoritmo intermediário entre o de Kuo e Cross e o de Hunt e Szymanski.

\subsection{Resumo}

A tabela seguinte lista as complexidades de tempo e de espaço de todos os algoritmos descritos neste capítulo. Lembremos que $m$ e $n$ são os comprimentos da sequências $X$ e $Y$ respectivamente (com $m \leq n), r$ é o número de casamentos, $d$ é o número de casamentos dominantes e $p$ é o comprimento de um LCS. 


\begin{tabular}{lcllcc}
\hline Algoritmo & Ano & Tempo & Espaço & Seção & Ref. \\
\hline Programação dinâmica & 1974 & $O(m n)$ & $O(m n)$ & 7.2 & {$[45]$} \\
Hunt-Szymanski (limiares) & 1977 & $O(n+r \log p)$ & $O(n+r)$ & 7.4 & {$[22]$} \\
$\rightarrow$ Mod. Apostolico-Guerra & 1987 & $O(n+d \log n)$ & $O(n+r)$ & 7.6 .2 & {$[2]$} \\
$\rightarrow$ Mod. Kuo-Cross & 1989 & $O(r+m p)$ & $O(n+r)$ & 7.4 .1 & {$[29]$} \\
$\rightarrow$ Mod. saltos para casamentos & - & $O(n+r(\log p+\log |\Sigma|))$ & $O(n+r)$ & 7.10 & - \\
& & $O(n+m p \log |\Sigma|)$ & $O(n+r)$ & & \\
Hirschberg (contornos) & 1977 & $O(p n)$ & $O\left(m^{2}+n\right)$ & 7.5 & {$[20]$} \\
$\rightarrow$ Mod. Apostolico-Guerra & 1987 & $O(p m \log |\Sigma|+n)$ & $O(n+d)$ & 7.6 .1 & {$[2]$} \\
& & $O(p m+|\Sigma| n)$ & $O(n+d+|\Sigma| n)$ & & \\
Nakatsu-Kambayashi-Yajima & 1982 & $O(n(m-p))$ & $O(m(m-p))$ & 7.7 & {$[34]$} \\
(diagonais) & & & & & \\
Hirschberg (espaço linear) & 1975 & $O(m n)$ & $O(n)$ & & \\
Masek-Paterson (subdivisão) & 1980 & $O\left(n^{2} / \log _{|\Sigma|} n\right)$ & $O\left(n \log _{|\Sigma|}^{2} n\right)$ & 7.9 & {$[32]$} \\
\hline
\end{tabular}

É interessante observar que todos os algoritmos acima se baseiam na matriz de programação dinâmica de uma forma ou outra. Estes não são os únicos algoritmos para o problema do LCS na literatura; existem muitos outros. 
Capítulo 7. Algoritmos para LCS 


\section{CAPÍtulo 8}

\section{Conclusão}

Nesta dissertação, exploramos de forma abrangente e detalhada os problemas do LCS e do RFLCS. O problema do RFLCS tem a característica peculiar de ser, em essência, um problema fácil com uma restrição aparentemente simples a mais, mas que torna o problema computacionalmente difícil. É interessante notar as características contrastantes da dificuldade do problema. Por um lado, o problema do clique máximo no grafo associado ao problema, o grafo de conflito, é resolvível em tempo polinomial (essencialmente, é o algoritmo de separação sem considerar pesos), mas, por outro, o problema do conjunto independente máximo nesse mesmo grafo (o problema do RFLCS em si) é computacionalmente difícil. Por um lado, se o alfabeto é constante, então o problema é resolvível em tempo linear (usando o algoritmo de programação dinâmica da Seção 6.3), mas, por outro, o problema é APX-difícil mesmo quando o número máximo de ocorrências de cada símbolo em cada sequência é limitado por dois.

Um dos temas focados nesta dissertação foi o desenvolvimento de algoritmos para resolver o problema do RFLCS na prática, apoiado em um estudo do problema do LCS. Descrevemos formulações para ambos os problemas e exploramos suas estruturas poliédricas. Construímos algoritmos de aproximação e heurísticas para o problema do RFLCS, que foram adaptados para contribuir ao algoritmo exato baseado na técnica branch-and-cut. Desenvolvemos um algoritmo de separação eficiente e outras técnicas para melhorar o algoritmo exato. O algoritmo nos permite resolver instâncias de tamanho 1000 em um tempo razoável se não houver muitas repetições nas sequências de entrada. Além disso, apresentamos nesta dissertação uma resenha dos algoritmos para o problema do LCS, que é independente do resto do texto.

Como trabalho futuro, ainda existem algumas perguntas sobre o problema do RFLCS que podem ser respondidas. Seria interessante tentar provar se o problema do RFLCS está em APX ou não (isto é, se existe algum algoritmo de aproximação de razão constante). Também seria de interesse conhecer um gap de integralidade mais justo que o gap simples apresentado neste texto, especialmente dado que muitas vezes é possível construir um algoritmo de aproximação com essencialmente a mesma razão que o gap. Uma outra possível tarefa seria explorar, da mesma maneira que fizemos neste texto, a variante do problema do RFLCS em que permitimos reversões nas sequências. 
Capítulo 8. Conclusão 


\section{APÊNDICE A}

\section{Técnicas não usadas no algoritmo branch-and-cut}

Descrevemos neste apêndice uma classe de inequações e duas técnicas implementadas que não contribuíram para a melhoria do algoritmo, mas que são interessantes mesmo assim.

\section{A.1 Algoritmo de separação para circuito ímpar}

Nesta seção, consideramos a separação de um outro tipo de inequação para o problema do RFLCS. Considere o grafo de conflito (os vértices são dados pelos casamentos e as arestas pelos conflitos). Lembremos da inequação de buraco ímpar (um buraco ímpar é um circuito induzido de comprimento ímpar maior ou igual a 5), descrita na Seção 3.3.1:

$$
\sum_{(i, j) \in B} z_{i j} \leq \frac{|B|-1}{2} \text { para todo buraco ímpar } B \subseteq \mathcal{C} .
$$

Como existe um número exponencial de restrições de buraco ímpar, é necessário um algoritmo de separação para tal tipo de restrição. Uma opção é relaxar a restrição e considerar circuitos ímpares (isto é, que não precisam ser induzidos). É claro que a mesma restrição é válida para circuitos ímpares, pois apenas acrescentamos mais arestas, o que não aumenta nenhum valor $z_{v}$ para qualquer vértice $v$ pertencente ao circuito ímpar. Para o caso do circuito ímpar, existe um algoritmo de separação eficiente descrito em [16], que descrevemos nesta seção. Existe também um outro algoritmo que separa diretamente inequações de buraco ímpar que não implementamos [21].

O problema da separação do circuito ímpar é, dada uma solução $z$, encontrar um circuito ímpar $C \subseteq \mathcal{C}$ para qual a inequação $\sum_{c \in C} z_{c} \leq \frac{|C|-1}{2}$ é falsa, ou garantir que ela é verdadeira para qualquer circuito ímpar $C$. Para resolver esse problema, é conveniente considerar uma variável nova $y$.

Seja $y_{e}=1-z_{u}-z_{v}$ para todo par de casamentos $\{u, v\}$ que conflitam entre si. Note que $y_{e} \geq 0$ pois $z_{u}+z_{v} \leq 1$. Então, manipulando a inequação $\sum_{v \in C} z_{v} \leq \frac{|C|-1}{2}$ para algum $C \in \mathcal{C}$, obtemos $\sum_{v \in C}\left(1-2 z_{v}\right) \geq 1$. Se $C$ for um circuito ímpar com conjunto de arestas $E^{\prime}$, então a última inequação pode ser trocada por $\sum_{u v \in E^{\prime}}\left(1-z_{u}-z_{v}\right) \geq 1$, que equivale a $\sum_{e \in E^{\prime}} y_{e} \geq 1$.

Portanto, podemos resolver o problema da separação encontrando um circuito ímpar de peso mínimo nas arestas, onde o peso de cada aresta $u v$ é 1 menos o peso de suas pontas $z_{u}$ e $z_{v}$. Se ele for menor que 1, então o circuito ímpar nos leva a uma inequação violada pela solução atual. Caso 
contrário, não existe inequação de circuito ímpar violada, pois o peso do circuito que encontramos é mínimo.

Para encontrar um circuito ímpar de peso mínimo nas arestas, podemos trocar todo vértice $u$ por $u_{1}$ e $u_{2}$, e trocar toda aresta $u v$ por $u_{1} v_{2}$ e $u_{2} v_{1}$. Então, para todo vértice $u$, basta encontrar um caminho de peso mínimo de $u_{1}$ para $u_{2}$, pois ele garantidamente passará por um número ímpar de arestas. Isso pode ser feito implementando, por exemplo, o algoritmo de Dijkstra para caminhos de peso mínimo.

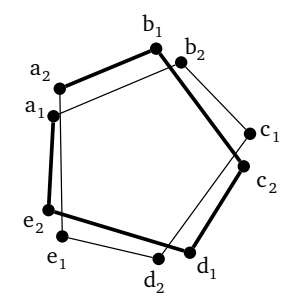

Implementamos o método descrito acima e vimos que, na prática, a separação descrita acima é pouco eficiente em comparação com a separação da restrição de estrela estendida, como evidenciado pela tabela seguinte. Nos testes da tabela, fixamos o comprimento das sequências em 200 e variamos o alfabeto. Foi tirada a média de 5 execuções. O "sem" é a execução do algoritmo de branch-and-cut apenas com a separação de estrelas estendidas e o "com" é com as duas separações. O algoritmo foi rodado sem as heurísticas para que elas não interferissem.

\begin{tabular}{lllll}
\hline & \multicolumn{2}{l}{ \#nós } & branch & \multicolumn{2}{c}{ tempo gasto (s) } \\
\cline { 2 - 5 } alfabeto & sem & com & sem & com \\
\hline 50 & 45.8 & 31.8 & 38.60 & 804.93 \\
60 & 11.8 & 7.4 & 10.13 & 93.47 \\
70 & 8.2 & 8.2 & 4.01 & 26.94 \\
80 & 8.6 & 7.0 & 3.53 & 14.05 \\
90 & 8.2 & 6.2 & 2.04 & 9.23 \\
100 & 7.0 & 5.4 & 1.56 & 4.84 \\
\hline
\end{tabular}

De fato, a separação de circuitos ímpares reduziu o número de nós da árvore de branch-and-cut como esperado, mas o tempo total gasto pelo algoritmo aumentou bastante. Por isso, em geral, não parece valer a pena incluir as restrições de circuito ímpar, embora seja possível que elas sejam úteis para outras classes de instâncias.

É possível que, usando a implementação de Hoffman e Padberg [21], essas inequações valham a pena, mas isso não foi experimentado. Em linhas gerais, o algoritmo de Hoffman e Padberg escolhe um vértice $r$ do grafo, classifica os vértices do grafo de acordo com a distância mínima deles até $r$ e, para cada par de vértices $u$ e $v$ que estão na mesma classe, procura dois caminhos, um de $u$ a $r$ e outro de $v$ a $r$, escolhendo apenas vértices de classe menor até $r$ de forma que, no caminho de $v$ a $r$, não sejam escolhidos vértices adjacentes a algum vértice do caminho de $u$ a $r$. 


\section{A.2 Pool de inequações}

Uma técnica associada ao método branch-and-cut é o pool de inequações. Conforme planos de corte são adicionados ao programa linear em um algoritmo branch-and-cut, o número de restrições pode crescer demais, tornando a resolução do programa linear lenta. No entanto, ocorre que algumas dessas restrições não mais satisfazem a solução atual com igualdade e, em um certo sentido, elas estão relaxadas em relação a essa solução. Se isso vem ocorrendo com alguma restrição por um certo número de iterações, é possível que valha a pena removê-las do programa inteiro para acelerar sua resolução. Porém, muitas vezes encontrar uma restrição violada pela solução atual é lento, então gostaríamos de armazená-la de modo que possamos recuperá-la facilmente caso ela seja violada novamente.

O conceito de pool de inequações é esse: colocar de lado as restrições mais "velhas", no sentido de que a idade de uma restrição é o número de iterações nas quais ela não é satisfeita pela solução viável da iteração com igualdade, e, a cada iteração (ou menos frequentemente), olhar novamente no pool para ver se alguma dessas restrições volta a ser violada pela solução viável atual.

Infelizmente, os resultados da implementação foram pouco favoráveis, mesmo variando a idade em que as inequações são postas de lado. Já que encontrar a restrição de estrela estendida mais violada é relativamente rápido, não houve melhoria significativa (essa técnica foi testada com o algoritmo de separação de programação dinâmica).

\section{A.3 Atualização da matriz de programação dinâmica no algoritmo de separação}

Antes do algoritmo de separação por limiares estar desenvolvido, exploramos a ideia de atualizar apenas os valores necessários da matriz de programação dinâmica do primeiro algoritmo de separação a cada execução dele.

Nos baseamos na observação de que nem sempre o valor da solução ótima da relaxação se altera muito de uma iteração para outra. Portanto, parece interessante aproveitar um pedaço da matriz de programação dinâmica de uma iteração para a próxima.

Em linhas gerais, o processo é o seguinte. Primeiro, verificamos quais casamentos tiveram seu peso alterado e, para cada linha da matriz, anotamos os índices das colunas desses casamentos. Para cada linha, iniciando no primeiro desses índices, recalculamos elementos andando para a direita. Se encontramos um valor que é igual ao novo valor, passamos para o próximo casamento da linha (se já não passamos por ele) ou para a próxima linha. Mantemos esses índices para a próxima linha, até o valor antigo no índice da coluna do próprio casamento ser igual ao novo valor. Além disso, para tratar os blocos, ao observar um casamento, devemos marcar que precisamos atualizar casamentos com o mesmo símbolo que vêm depois dele na matriz (maior linha e maior coluna).

A implementação possui vários outros detalhes pequenos, inclusive detalhes de operações de ponto flutuante. No entanto, o uso dessa técnica não resultou em uma diferença significativa no consumo de tempo do algoritmo. 
Apêndice A. Técnicas não usadas no algoritmo branch-and-cut 


\section{APÊNDICE B}

\section{Comparação entre resultados computacionais usando CPLEX e GLPK}

Nesta dissertação, utilizamos a biblioteca de código aberto GLPK (versão 4.41) [14], que lida com a resolução de programas lineares e oferece um framework para a implementação de um algoritmo baseado em branch-and-cut. Implementamos os algoritmos que usam formulações de cruzamentos, de estrelas estendidas (incluindo o uso de heurísticas e eliminação de variáveis) e de símbolos distintos também usando a biblioteca comercial CPLEX (versão 12.1) [23], que é, em geral, conhecida por ser uma biblioteca poderosa (particularmente em comparação com bibliotecas de código aberto). Porém, com a exceção do primeiro caso, a implementação com GLPK teve um desempenho melhor do que com a implementação com CPLEX, como evidenciado pelos gráficos seguintes (é possível que um ajuste de parâmetros da implementação com CPLEX a leve a um desempenho melhor).
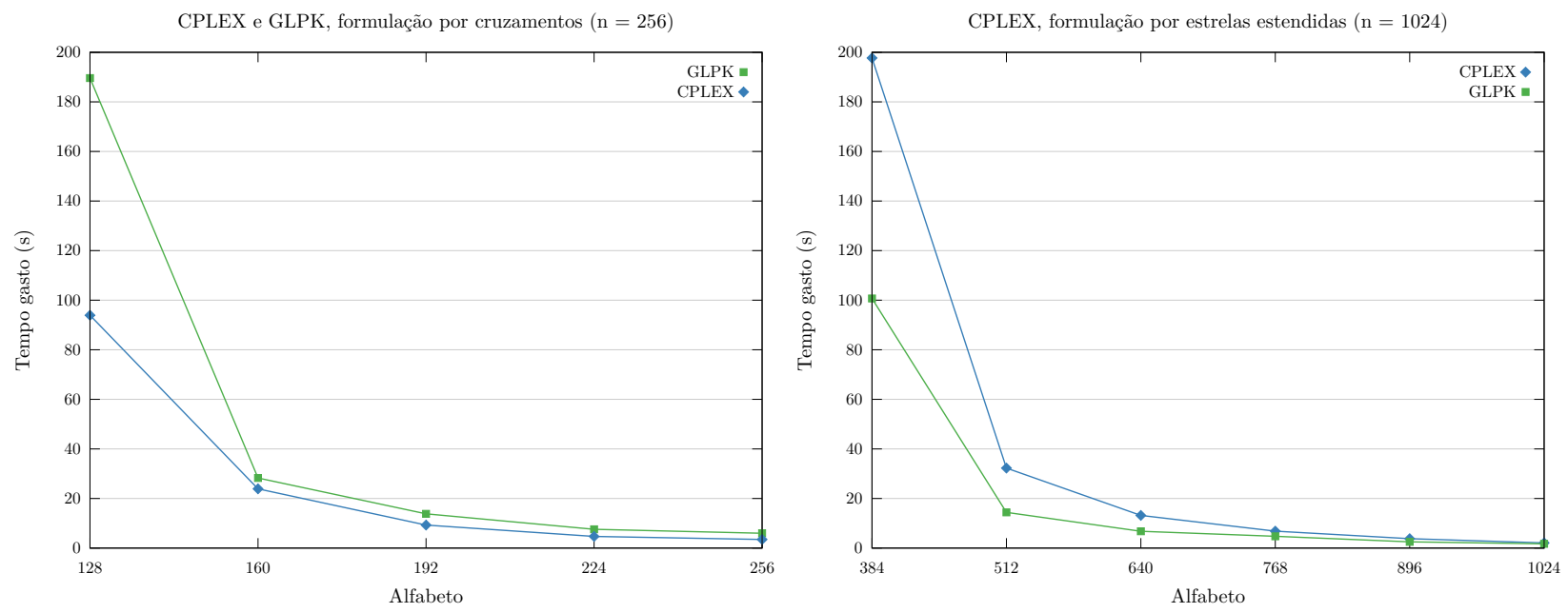


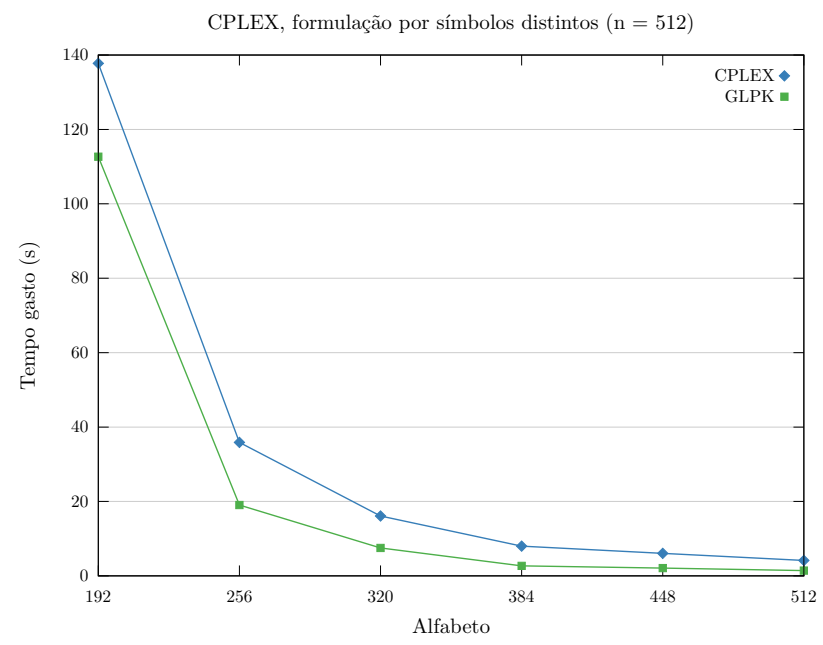

\begin{tabular}{|c|c|c|c|c|c|}
\hline \multirow[b]{3}{*}{$|\Sigma|$} & \multicolumn{5}{|c|}{$\mathrm{n}=256$ (form. por cruzamentos) } \\
\hline & \multicolumn{2}{|c|}{ Tempo gasto (s) } & \multicolumn{3}{|c|}{ Número de cortes (CPLEX) } \\
\hline & CPLEX & GLPK & Clique & Zero-half & $\begin{array}{r}\text { Gomory } \\
\text { frac. }\end{array}$ \\
\hline 256 & 3.447 & 5.972 & 546.8 & 6.4 & 0.1 \\
\hline 224 & 4.711 & 7.583 & 801.3 & 6.9 & 0.3 \\
\hline 192 & 9.282 & 13.797 & 308.4 & 2.0 & 0.0 \\
\hline 160 & 23.883 & 28.280 & 642.8 & 2.6 & 0.0 \\
\hline 128 & 93.923 & 189.620 & 239.5 & 1.0 & 0.0 \\
\hline 96 & 417.939 & $\geq 1091.517$ & 270.9 & 1.3 & 0.0 \\
\hline 64 & $\geq 1800.000$ & $\geq 1800.000$ & $\geq 949.7$ & $\geq 10.5$ & $\geq 0.0$ \\
\hline 32 & $\geq 1466.217$ & $\geq 1800.000$ & $\geq 400.5$ & $\geq 6.9$ & $\geq 0.0$ \\
\hline
\end{tabular}

$\mathbf{n}=1024$ (form. por estrelas estendidas)

\begin{tabular}{|c|c|c|c|c|c|c|}
\hline \multirow[b]{2}{*}{$|\Sigma|$} & \multicolumn{2}{|c|}{ Tempo gasto (s) } & \multicolumn{3}{|c|}{ Número de cortes (CPLEX) } & \multirow{2}{*}{$\begin{array}{r}\begin{array}{r}\text { Cortes } \\
(\text { GLPK })\end{array} \\
\begin{array}{r}\text { Estrela } \\
\text { estendida }\end{array}\end{array}$} \\
\hline & CPLEX & GLPK & $\begin{array}{r}\text { Estrela } \\
\text { estendida }\end{array}$ & Zero-half & $\begin{array}{r}\text { Gomory } \\
\text { frac. }\end{array}$ & \\
\hline 1024 & 2.089 & 1.699 & 133.6 & 2.8 & 0.1 & 140.0 \\
\hline 896 & 3.801 & 2.493 & 172.9 & 2.6 & 0.0 & 172.0 \\
\hline 768 & 6.845 & 4.724 & 257.5 & 2.7 & 0.1 & 251.9 \\
\hline 640 & 13.181 & 6.789 & 297.6 & 0.3 & 0.0 & 306.0 \\
\hline 512 & 32.261 & 14.375 & 454.9 & 0.0 & 0.0 & 470.0 \\
\hline 384 & 197.725 & 100.673 & 1041.8 & 0.0 & 0.0 & 1145.1 \\
\hline 256 & $\geq 1800.000$ & $\geq 1793.710$ & $\geq 2199.4$ & 0.0 & 0.0 & $\geq 3075.5$ \\
\hline 128 & $\geq 1800.000$ & $\geq 1800.000$ & $\geq 787.7$ & 0.0 & 0.0 & $\geq 235.9$ \\
\hline
\end{tabular}

$\mathrm{n}=\mathbf{5 1 2}$ (form. por símbolos distintos)

\begin{tabular}{|c|c|c|c|c|c|c|c|}
\hline \multirow[b]{2}{*}{$|\Sigma|$} & \multicolumn{2}{|c|}{ Tempo gasto (s) } & \multicolumn{4}{|c|}{ Número de cortes (CPLEX) } & \multirow{2}{*}{$\begin{array}{r}\begin{array}{r}\text { Cortes } \\
(\text { GLPK) }\end{array} \\
\begin{array}{r}\text { Estrela } \\
\text { especial }\end{array}\end{array}$} \\
\hline & CPLEX & GLPK & $\begin{array}{r}\text { Estrela } \\
\text { especial }\end{array}$ & Clique & Zero-half & $\begin{array}{r}\text { Gomory } \\
\text { frac. }\end{array}$ & \\
\hline 512 & 4.146 & 1.423 & 231.8 & 0.0 & 0.0 & 0.0 & 244.8 \\
\hline 448 & 6.054 & 2.077 & 280.8 & 0.0 & 0.1 & 0.0 & 290.9 \\
\hline 384 & 8.001 & 2.706 & 332.6 & 0.0 & 0.0 & 0.0 & 336.8 \\
\hline 320 & 16.098 & 7.506 & 440.1 & 0.0 & 0.0 & 0.0 & 493.1 \\
\hline 256 & 35.862 & 19.033 & 630.4 & 0.0 & 0.0 & 0.0 & 680.4 \\
\hline 192 & 137.771 & 112.666 & 1201.1 & 0.0 & 0.0 & 0.0 & 1558.5 \\
\hline 128 & $\geq 1414.090$ & $\geq 1574.471$ & $\geq 3180.8$ & 0.0 & 0.0 & 0.0 & $\geq 4941.6$ \\
\hline 64 & $\geq 1800.000$ & $\geq 1800.000$ & $\geq 914.0$ & 0.0 & 0.0 & 0.0 & $\geq 771.8$ \\
\hline
\end{tabular}




\section{APÊNDICE C}

\section{Dados numéricos dos resultados computacionais}

As tabelas deste apêndice mostram os valores numéricos dos resultados computacionais realizados.

\section{C.1 Algoritmos de aproximação e heurísticas}

As tabelas a seguir mostram o consumo médio de tempo e o comprimento médio da solução obtida pelos algoritmos de aproximação e heurísticas das Seções 4.2 e 4.3.

Legenda:

- LCS-RR: LCS e remove repetições;

- RR-LCS: remove repetições e LCS;

- RR-LCS1: remove repetições e LCS com 1 valor aleatório;

- GS: guloso simples;

- GS (v): guloso simples (variante);

- MC: guloso por menor número de conflitos;

- LC (s): guloso por limitante de casamento simples;

- LC: guloso por limitante de casamento.

\begin{tabular}{|c|c|c|c|c|c|c|c|c|}
\hline \multirow[b]{2}{*}{$n$} & \multicolumn{7}{|c|}{ Alfabeto $\mathrm{n} / 2$} & \multirow[b]{2}{*}{ LC } \\
\hline & $\begin{array}{c}\text { LCS- } \\
\text { RR }\end{array}$ & $\begin{array}{l}\text { RR- } \\
\text { LCS }\end{array}$ & $\begin{array}{r}\text { RR- } \\
\text { LCS1 }\end{array}$ & GS & GS (v) & MC & LC (s) & \\
\hline 1000 & 0.003 & 0.004 & 0.004 & 0.001 & 0.000 & 0.045 & 0.009 & 0.263 \\
\hline 2000 & 0.016 & 0.014 & 0.006 & 0.003 & 0.002 & 0.182 & 0.048 & 1.619 \\
\hline 3000 & 0.031 & 0.023 & 0.024 & 0.014 & 0.000 & 0.395 & 0.108 & 4.345 \\
\hline 4000 & 0.053 & 0.042 & 0.044 & 0.023 & 0.000 & 0.687 & 0.195 & 9.111 \\
\hline 5000 & 0.085 & 0.070 & 0.077 & 0.038 & 0.000 & 1.072 & 0.316 & 15.968 \\
\hline 6000 & 0.127 & 0.096 & 0.085 & 0.048 & 0.003 & 1.558 & 0.433 & 25.462 \\
\hline 7000 & 0.164 & 0.114 & 0.144 & 0.074 & 0.006 & 2.119 & 0.592 & 38.271 \\
\hline 8000 & 0.226 & 0.144 & 0.144 & 0.089 & 0.004 & 2.769 & 0.779 & 54.453 \\
\hline 9000 & 0.262 & 0.214 & 0.206 & 0.117 & 0.004 & 3.501 & 0.994 & 72.216 \\
\hline 10000 & 0.338 & 0.231 & 0.244 & 0.146 & 0.006 & 4.344 & 1.237 & 95.168 \\
\hline 11000 & 0.412 & 0.304 & 0.301 & 0.172 & 0.004 & 5.215 & 1.474 & 120.714 \\
\hline 12000 & 0.466 & 0.360 & 0.315 & 0.204 & 0.005 & 6.221 & 1.727 & 150.166 \\
\hline 13000 & 0.536 & 0.394 & 0.427 & 0.247 & 0.010 & 7.243 & 2.050 & 181.220 \\
\hline 14000 & 0.629 & 0.498 & 0.492 & 0.282 & 0.010 & 8.404 & 2.372 & 221.670 \\
\hline 15000 & 0.725 & 0.540 & 0.550 & 0.325 & 0.012 & 9.664 & 2.718 & 263.591 \\
\hline
\end{tabular}


Apêndice C. Dados numéricos dos resultados computacionais

\begin{tabular}{|c|c|c|c|c|c|c|c|c|c|}
\hline \multicolumn{10}{|c|}{ Alfabeto $n / 2$} \\
\hline \multirow[b]{2}{*}{$n$} & \multicolumn{9}{|c|}{ Solução } \\
\hline & $\begin{array}{c}\text { LCS- } \\
\text { RR }\end{array}$ & $\begin{array}{l}\text { RR- } \\
\text { LCS }\end{array}$ & $\begin{array}{l}\text { RR- } \\
\text { LCS1 }\end{array}$ & GS & GS (v) & MC & LC (s) & LC & $\begin{array}{r}\text { LCS } \\
\text { (1. sup.) }\end{array}$ \\
\hline 1000 & 74.6 & 57.6 & 57.7 & 62.4 & 57.0 & 67.1 & 73.0 & 76.1 & 80.3 \\
\hline 2000 & 109.7 & 86.1 & 84.5 & 94.7 & 82.7 & 98.3 & 108.0 & 112.8 & 116.4 \\
\hline 3000 & 135.5 & 106.1 & 106.1 & 115.6 & 102.1 & 116.1 & 133.7 & 139.5 & 142.3 \\
\hline 4000 & 160.3 & 125.6 & 122.7 & 134.2 & 122.3 & 133.5 & 157.7 & 162.9 & 166.5 \\
\hline 5000 & 180.1 & 140.7 & 137.2 & 143.9 & 132.1 & 152.1 & 172.1 & 183.5 & 187.8 \\
\hline 6000 & 198.5 & 155.5 & 151.0 & 168.7 & 152.3 & 171.2 & 188.3 & 202.1 & 205.4 \\
\hline 7000 & 215.8 & 167.3 & 165.5 & 177.4 & 162.1 & 184.6 & 209.0 & 220.2 & 224.1 \\
\hline 8000 & 236.0 & 181.7 & 178.6 & 195.7 & 173.9 & 202.0 & 232.4 & 239.4 & 242.7 \\
\hline 9000 & 246.7 & 190.1 & 185.8 & 202.6 & 186.0 & 210.5 & 230.9 & 250.0 & 254.6 \\
\hline 10000 & 264.5 & 200.9 & 198.4 & 216.1 & 198.3 & 222.1 & 256.4 & 267.6 & 271.9 \\
\hline 11000 & 276.0 & 208.9 & 209.4 & 223.2 & 203.7 & 232.1 & 261.6 & 280.8 & 284.6 \\
\hline 12000 & 287.1 & 219.9 & 217.2 & 231.5 & 214.1 & 241.9 & 273.4 & 291.0 & 295.5 \\
\hline 13000 & 299.3 & 230.1 & 224.7 & 243.0 & 218.0 & 252.1 & 276.5 & 303.4 & 306.9 \\
\hline 14000 & 317.4 & 237.9 & 233.6 & 251.3 & 232.9 & 261.3 & 308.1 & 319.2 & 323.3 \\
\hline 15000 & 325.8 & 246.2 & 242.7 & 265.0 & 235.4 & 268.8 & 307.5 & 328.4 & 332.2 \\
\hline
\end{tabular}

\begin{tabular}{|c|c|c|c|c|c|c|c|c|}
\hline \multirow[b]{2}{*}{$n$} & \multicolumn{8}{|c|}{ Alfabeto $\mathbf{n} / 8$} \\
\hline & $\begin{array}{c}\text { LCS- } \\
\text { RR }\end{array}$ & $\begin{array}{l}\text { RR- } \\
\text { LCS }\end{array}$ & $\begin{array}{c}\text { RR- } \\
\text { LCS1 }\end{array}$ & GS & GS (v) & MC & LC (s) & LC \\
\hline 1000 & 0.003 & 0.000 & 0.001 & 0.001 & 0.000 & 0.011 & 0.415 & 0.143 \\
\hline 2000 & 0.013 & 0.003 & 0.007 & 0.008 & 0.000 & 0.041 & 1.718 & 1.688 \\
\hline 3000 & 0.028 & 0.011 & 0.015 & 0.011 & 0.000 & 0.083 & 3.847 & 4.842 \\
\hline 4000 & 0.061 & 0.027 & 0.029 & 0.024 & 0.001 & 0.145 & 6.942 & 10.339 \\
\hline 5000 & 0.083 & 0.036 & 0.040 & 0.034 & 0.001 & 0.204 & 10.817 & 18.331 \\
\hline 6000 & 0.100 & 0.053 & 0.057 & 0.049 & 0.002 & 0.301 & 15.611 & 29.225 \\
\hline 7000 & 0.155 & 0.072 & 0.062 & 0.061 & 0.003 & 0.395 & 21.367 & 43.424 \\
\hline 8000 & 0.211 & 0.080 & 0.105 & 0.086 & 0.003 & 0.492 & 27.817 & 60.446 \\
\hline 9000 & 0.273 & 0.114 & 0.113 & 0.111 & 0.003 & 0.634 & 35.524 & 81.941 \\
\hline 10000 & 0.332 & 0.133 & 0.150 & 0.137 & 0.001 & 0.776 & 43.453 & 107.325 \\
\hline 11000 & 0.407 & 0.165 & 0.176 & 0.171 & 0.005 & 0.926 & 52.447 & 135.795 \\
\hline 12000 & 0.491 & 0.211 & 0.178 & 0.206 & 0.005 & 1.148 & 62.644 & 170.189 \\
\hline 13000 & 0.530 & 0.226 & 0.231 & 0.236 & 0.003 & 1.295 & 73.478 & 209.393 \\
\hline 14000 & 0.636 & 0.275 & 0.285 & 0.272 & 0.003 & 1.529 & 85.337 & 252.561 \\
\hline 15000 & 0.734 & 0.293 & 0.314 & 0.313 & 0.005 & 1.675 & 98.111 & 298.969 \\
\hline
\end{tabular}

\begin{tabular}{|c|c|c|c|c|c|c|c|c|c|}
\hline \multicolumn{10}{|c|}{ Alfabeto $n / 8$} \\
\hline \multirow[b]{2}{*}{$n$} & \multicolumn{9}{|c|}{ Solução } \\
\hline & $\begin{array}{c}\text { LCS- } \\
\text { RR }\end{array}$ & $\begin{array}{l}\text { RR- } \\
\text { LCS }\end{array}$ & $\begin{array}{c}\text { RR- } \\
\text { LCS1 }\end{array}$ & GS & GS (v) & MC & LC (s) & $\mathrm{LC}$ & $\begin{array}{r}\text { LCS } \\
\text { (1. sup.) }\end{array}$ \\
\hline 1000 & 90.3 & 55.2 & 45.3 & 92.3 & 87.2 & 95.2 & 98.0 & 102.3 & 157.2 \\
\hline 2000 & 150.8 & 82.8 & 74.0 & 149.8 & 140.5 & 152.1 & 155.4 & 172.9 & 228.8 \\
\hline 3000 & 198.7 & 105.2 & 92.4 & 192.9 & 178.5 & 203.4 & 202.0 & 226.8 & 287.3 \\
\hline 4000 & 245.4 & 123.6 & 108.7 & 233.4 & 211.2 & 242.8 & 239.6 & 273.6 & 333.1 \\
\hline 5000 & 281.9 & 140.8 & 115.4 & 260.9 & 238.5 & 291.7 & 270.5 & 315.2 & 377.3 \\
\hline 6000 & 323.5 & 153.2 & 133.6 & 297.3 & 268.2 & 317.3 & 298.9 & 348.3 & 412.8 \\
\hline 7000 & 352.6 & 167.7 & 148.0 & 323.5 & 296.1 & 359.8 & 326.4 & 384.8 & 448.5 \\
\hline 8000 & 378.8 & 180.4 & 157.0 & 351.3 & 319.7 & 363.8 & 360.5 & 417.6 & 478.8 \\
\hline 9000 & 408.2 & 190.5 & 163.2 & 373.2 & 333.5 & 412.7 & 379.7 & 447.4 & 511.0 \\
\hline 10000 & 443.1 & 200.9 & 179.4 & 398.7 & 361.6 & 419.0 & 397.1 & 476.3 & 537.9 \\
\hline 11000 & 463.0 & 214.7 & 188.9 & 418.1 & 374.3 & 456.2 & 418.3 & 501.7 & 563.3 \\
\hline 12000 & 488.6 & 219.8 & 187.3 & 433.1 & 394.3 & 479.5 & 446.7 & 525.5 & 590.7 \\
\hline 13000 & 515.9 & 234.6 & 206.1 & 461.5 & 417.7 & 491.6 & 473.4 & 556.4 & 617.9 \\
\hline 14000 & 541.3 & 242.4 & 203.9 & 478.6 & 425.0 & 536.9 & 489.7 & 577.6 & 644.4 \\
\hline 15000 & 557.8 & 250.0 & 212.9 & 488.2 & 446.4 & 540.1 & 501.2 & 602.3 & 666.8 \\
\hline
\end{tabular}


Apêndice C. Dados numéricos dos resultados computacionais

\begin{tabular}{|c|c|c|c|c|c|c|c|c|c|}
\hline \multirow[b]{2}{*}{$|\Sigma|$} & \multicolumn{9}{|c|}{$\begin{aligned} \mathrm{n}= & 1000 \\
& \text { Solução }\end{aligned}$} \\
\hline & $\begin{array}{c}\text { LCS- } \\
\text { RR }\end{array}$ & $\begin{array}{l}\text { RR- } \\
\text { LCS }\end{array}$ & $\begin{array}{c}\text { RR- } \\
\text { LCS1 }\end{array}$ & GS & GS (v) & MC & LC (s) & LC & $\begin{array}{r}\text { LCS } \\
\text { (1. sup.) }\end{array}$ \\
\hline 25 & 25.0 & 24.8 & 21.9 & 25.0 & 25.0 & 25.0 & 25.0 & 25.0 & 323.4 \\
\hline 50 & 49.7 & 42.1 & 33.3 & 50.0 & 50.0 & 49.9 & 50.0 & 50.0 & 240.0 \\
\hline 75 & 70.0 & 47.5 & 39.0 & 74.2 & 73.0 & 73.7 & 74.7 & 74.4 & 201.5 \\
\hline 100 & 83.8 & 53.3 & 42.9 & 89.2 & 85.2 & 91.7 & 93.1 & 93.4 & 175.2 \\
\hline 125 & 90.3 & 55.2 & 45.3 & 92.3 & 87.2 & 95.2 & 98.0 & 102.3 & 157.2 \\
\hline 150 & 92.9 & 56.0 & 50.2 & 91.9 & 87.1 & 96.7 & 97.0 & 107.0 & 144.4 \\
\hline 175 & 93.8 & 60.3 & 50.7 & 91.2 & 85.9 & 96.1 & 93.7 & 105.7 & 134.7 \\
\hline 200 & 93.0 & 60.2 & 53.3 & 88.0 & 82.0 & 93.9 & 91.0 & 104.0 & 125.4 \\
\hline 225 & 92.3 & 59.9 & 54.2 & 88.0 & 79.3 & 94.8 & 90.5 & 100.1 & 118.2 \\
\hline 250 & 90.2 & 62.1 & 57.3 & 81.8 & 75.7 & 92.6 & 87.0 & 99.3 & 113.7 \\
\hline 300 & 86.4 & 60.6 & 58.5 & 81.3 & 72.2 & 85.3 & 81.7 & 94.1 & 103.8 \\
\hline 350 & 85.1 & 61.1 & 58.7 & 75.0 & 71.0 & 84.1 & 79.6 & 87.7 & 96.0 \\
\hline 400 & 80.0 & 59.3 & 59.7 & 69.9 & 62.7 & 78.8 & 73.7 & 83.4 & 88.5 \\
\hline 450 & 77.9 & 60.1 & 59.4 & 65.9 & 60.2 & 76.4 & 69.4 & 81.4 & 84.8 \\
\hline 500 & 74.6 & 57.6 & 57.7 & 62.4 & 57.0 & 73.0 & 67.1 & 76.1 & 80.3 \\
\hline 600 & 67.7 & 57.2 & 56.1 & 57.9 & 51.9 & 66.4 & 60.5 & 70.4 & 72.3 \\
\hline 700 & 64.2 & 55.4 & 54.8 & 56.0 & 50.9 & 63.3 & 58.0 & 65.5 & 67.2 \\
\hline 800 & 61.3 & 53.9 & 54.0 & 52.2 & 45.3 & 59.0 & 53.3 & 61.2 & 63.0 \\
\hline 900 & 56.8 & 51.1 & 51.2 & 49.8 & 43.2 & 53.7 & 49.7 & 57.6 & 59.1 \\
\hline 1000 & 54.1 & 49.5 & 49.6 & 45.9 & 41.9 & 52.3 & 48.6 & 54.8 & 55.4 \\
\hline
\end{tabular}

\begin{tabular}{|c|c|c|c|c|c|c|c|c|c|}
\hline \multirow[b]{3}{*}{$|\Sigma|$} & \multicolumn{9}{|c|}{$\mathrm{n}=10000$} \\
\hline & \multicolumn{9}{|c|}{ Solução } \\
\hline & $\begin{array}{c}\text { LCS- } \\
\text { RR }\end{array}$ & $\begin{array}{l}\text { RR- } \\
\text { LCS }\end{array}$ & $\begin{array}{c}\text { RR- } \\
\text { LCS1 }\end{array}$ & GS & GS (v) & MC & LC (s) & LC & $\begin{array}{r}\text { LCS } \\
\text { (1. sup.) }\end{array}$ \\
\hline 250 & 247.8 & 161.1 & 135.9 & 250.0 & 250.0 & 249.8 & 250.0 & 249.8 & 1175.6 \\
\hline 500 & 407.3 & 184.0 & 153.6 & 443.3 & 417.5 & 450.2 & 454.2 & 473.8 & 838.9 \\
\hline 750 & 453.9 & 192.0 & 163.0 & 450.4 & 413.8 & 468.2 & 456.9 & 524.6 & 690.7 \\
\hline 1000 & 452.6 & 196.7 & 172.1 & 426.9 & 384.0 & 464.4 & 433.4 & 504.0 & 601.0 \\
\hline 1250 & 443.1 & 200.9 & 179.4 & 398.7 & 361.6 & 419.0 & 397.1 & 476.3 & 537.9 \\
\hline 1500 & 421.4 & 202.7 & 182.7 & 367.6 & 334.2 & 411.1 & 382.3 & 449.5 & 492.3 \\
\hline 1750 & 400.0 & 204.5 & 188.9 & 352.1 & 315.2 & 391.1 & 357.2 & 424.2 & 455.3 \\
\hline 2000 & 383.4 & 210.0 & 196.0 & 330.2 & 297.4 & 368.2 & 334.7 & 401.6 & 427.7 \\
\hline 2250 & 365.5 & 210.0 & 197.1 & 310.5 & 280.2 & 354.3 & 320.3 & 381.3 & 400.8 \\
\hline 2500 & 353.4 & 211.0 & 203.1 & 296.4 & 269.6 & 345.5 & 305.1 & 365.5 & 380.5 \\
\hline 3000 & 326.6 & 209.0 & 201.1 & 273.3 & 252.0 & 315.2 & 279.7 & 336.7 & 347.0 \\
\hline 3500 & 307.9 & 208.9 & 204.7 & 254.8 & 230.6 & 295.2 & 262.2 & 315.6 & 322.5 \\
\hline 4000 & 291.0 & 206.4 & 204.0 & 241.8 & 217.1 & 280.4 & 244.7 & 295.9 & 301.7 \\
\hline 4500 & 275.3 & 203.4 & 198.9 & 226.4 & 205.6 & 266.8 & 224.8 & 279.2 & 285.2 \\
\hline 5000 & 264.5 & 200.9 & 198.4 & 216.1 & 198.3 & 256.4 & 222.1 & 267.6 & 271.9 \\
\hline 6000 & 242.5 & 194.7 & 193.0 & 192.9 & 177.4 & 234.6 & 200.4 & 244.9 & 246.9 \\
\hline 7000 & 223.6 & 186.0 & 185.1 & 180.4 & 167.6 & 205.6 & 192.6 & 225.7 & 227.4 \\
\hline 8000 & 209.4 & 178.4 & 178.5 & 171.8 & 157.8 & 199.1 & 172.3 & 210.1 & 212.1 \\
\hline 9000 & 198.4 & 173.9 & 172.0 & 161.5 & 148.0 & 193.9 & 160.9 & 199.4 & 200.4 \\
\hline 10000 & 188.6 & 169.4 & 169.6 & 152.3 & 140.7 & 182.0 & 159.3 & 189.6 & 191.0 \\
\hline
\end{tabular}


Apêndice C. Dados numéricos dos resultados computacionais

\begin{tabular}{|c|c|c|c|c|c|c|c|c|}
\hline \multirow[b]{2}{*}{$|\Sigma|$} & \multicolumn{8}{|c|}{$\begin{array}{l}\mathrm{n}=10000 \\
\text { Tempo gasto }(\mathrm{s})\end{array}$} \\
\hline & $\begin{array}{c}\text { LCS- } \\
\text { RR }\end{array}$ & $\begin{array}{l}\text { RR- } \\
\text { LCS }\end{array}$ & $\begin{array}{c}\text { RR- } \\
\text { LCS1 }\end{array}$ & GS & GS (v) & MC & LC (s) & LC \\
\hline 250 & 0.347 & 0.113 & 0.096 & 0.175 & 0.066 & 0.836 & 905.095 & 2.560 \\
\hline 500 & 0.314 & 0.110 & 0.127 & 0.133 & 0.002 & 0.778 & 238.813 & 31.335 \\
\hline 750 & 0.336 & 0.120 & 0.119 & 0.138 & 0.002 & 0.721 & 111.716 & 119.366 \\
\hline 1000 & 0.309 & 0.137 & 0.137 & 0.137 & 0.005 & 0.729 & 65.568 & 112.737 \\
\hline 1250 & 0.310 & 0.135 & 0.142 & 0.139 & 0.007 & 0.769 & 43.362 & 107.432 \\
\hline 1500 & 0.330 & 0.161 & 0.149 & 0.143 & 0.003 & 0.783 & 31.354 & 103.513 \\
\hline 1750 & 0.322 & 0.179 & 0.159 & 0.137 & 0.006 & 0.812 & 23.768 & 101.761 \\
\hline 2000 & 0.329 & 0.176 & 0.185 & 0.133 & 0.006 & 0.851 & 18.811 & 99.938 \\
\hline 2250 & 0.310 & 0.171 & 0.185 & 0.138 & 0.004 & 0.878 & 15.384 & 99.506 \\
\hline 2500 & 0.327 & 0.189 & 0.188 & 0.137 & 0.008 & 0.907 & 12.839 & 98.965 \\
\hline 3000 & 0.338 & 0.202 & 0.200 & 0.140 & 0.004 & 0.978 & 9.511 & 98.139 \\
\hline 3500 & 0.315 & 0.221 & 0.215 & 0.134 & 0.006 & 1.029 & 7.424 & 97.540 \\
\hline 4000 & 0.314 & 0.216 & 0.232 & 0.138 & 0.002 & 1.102 & 6.025 & 97.243 \\
\hline 4500 & 0.326 & 0.225 & 0.225 & 0.143 & 0.007 & 1.160 & 5.010 & 97.491 \\
\hline 5000 & 0.312 & 0.246 & 0.271 & 0.142 & 0.006 & 1.204 & 4.269 & 95.375 \\
\hline 6000 & 0.333 & 0.249 & 0.262 & 0.132 & 0.005 & 1.266 & 3.331 & 89.769 \\
\hline 7000 & 0.309 & 0.277 & 0.281 & 0.146 & 0.005 & 1.339 & 2.757 & 84.543 \\
\hline 8000 & 0.331 & 0.277 & 0.264 & 0.143 & 0.009 & 1.360 & 2.306 & 78.513 \\
\hline 9000 & 0.318 & 0.290 & 0.290 & 0.146 & 0.007 & 1.405 & 2.093 & 73.711 \\
\hline 10000 & 0.328 & 0.309 & 0.304 & 0.141 & 0.007 & 1.410 & 1.880 & 67.693 \\
\hline
\end{tabular}

\section{C.2 Algoritmos de separação de estrela estendida}

As duas primeiras tabelas a seguir são relativas a uma execução de cada algoritmo de separação da Seção 5.2, fora do algoritmo de branch-and-cut, e a terceira é relativa à execução do algoritmo branch-and-cut usando cada algoritmo de separação, sem o uso de heurísticas ou eliminação de variáveis através de limitantes de casamento.

\begin{tabular}{crr}
\hline \multicolumn{3}{c}{$\mathbf{n}=\mathbf{2 0 0 0}$} \\
& \multicolumn{2}{c}{ Tempo gasto $(\mathbf{s})$} \\
\cline { 2 - 3 }$|\Sigma|$ & PD & limiares \\
\hline 50 & 166.639 & 0.933 \\
100 & 7.009 & 0.207 \\
150 & 1.310 & 0.124 \\
200 & 0.434 & 0.096 \\
250 & 0.219 & 0.066 \\
300 & 0.148 & 0.056 \\
400 & 0.108 & 0.044 \\
500 & 0.088 & 0.034 \\
600 & 0.083 & 0.032 \\
700 & 0.080 & 0.029 \\
800 & 0.070 & 0.026 \\
900 & 0.077 & 0.027 \\
1000 & 0.071 & 0.024 \\
1100 & 0.068 & 0.019 \\
1200 & 0.069 & 0.023 \\
1300 & 0.060 & 0.018 \\
1400 & 0.069 & 0.017 \\
1500 & 0.065 & 0.020 \\
1600 & 0.064 & 0.016 \\
1700 & 0.065 & 0.015 \\
1800 & 0.066 & 0.019 \\
1900 & 0.066 & 0.016 \\
2000 & 0.064 & 0.014 \\
\hline
\end{tabular}

\begin{tabular}{crr}
\hline & \multicolumn{3}{c}{ Alfabeto n/2 } \\
& Tempo gasto (s) \\
\cline { 2 - 3 }$n$ & PD & limiares \\
\hline 500 & 0.005 & 0.003 \\
1000 & 0.013 & 0.008 \\
1500 & 0.033 & 0.016 \\
2000 & 0.078 & 0.022 \\
2500 & 0.114 & 0.030 \\
3000 & 0.152 & 0.050 \\
3500 & 0.187 & 0.053 \\
4000 & 0.246 & 0.062 \\
4500 & 0.316 & 0.082 \\
5000 & 0.397 & 0.113 \\
5500 & 0.491 & 0.114 \\
6000 & 0.574 & 0.121 \\
6500 & 0.666 & 0.154 \\
7000 & 0.740 & 0.147 \\
7500 & 0.882 & 0.184 \\
8000 & 1.016 & 0.200 \\
8500 & 1.082 & 0.213 \\
9000 & 1.170 & 0.249 \\
9500 & 1.410 & 0.247 \\
10000 & 1.462 & 0.294 \\
\hline
\end{tabular}

\begin{tabular}{crr}
\hline \multicolumn{3}{c}{$\begin{array}{c}\text { Alfabeto n/2 } \\
\text { (no algoritmo) }\end{array}$} \\
& \multicolumn{2}{c}{ Tempo gasto (s) } \\
\cline { 2 - 3 }$n$ & PD & \multicolumn{1}{c}{ limiares } \\
\hline 64 & 0.025 & 0.021 \\
128 & 0.124 & 0.125 \\
256 & 0.962 & 0.987 \\
384 & 3.355 & 2.754 \\
512 & 11.093 & 8.561 \\
640 & 15.676 & 14.223 \\
768 & 21.815 & 17.877 \\
896 & 45.682 & 42.271 \\
1024 & 91.263 & 86.019 \\
\hline
\end{tabular}




\section{C.3 Heurísticas no branch-and-cut}

As tabelas seguintes relacionam-se à execução do algoritmo branch-and-cut comparando o uso de cada heurística da Seção 5.3, sem o uso de eliminação de variáveis através de limitantes de casamento.

\begin{tabular}{|c|c|c|c|c|c|c|c|}
\hline \multirow[b]{2}{*}{$n$} & \multicolumn{7}{|c|}{ Alfabeto $n / 2$} \\
\hline & Nenhuma & RR-LCS & LCS-RR & Guloso & LC & Todas & $\begin{array}{l}\text { Todas s/ } \\
\text { RR-LCS }\end{array}$ \\
\hline 64 & 0.021 & 0.018 & 0.010 & 0.011 & 0.012 & 0.016 & 0.013 \\
\hline 128 & 0.124 & 0.114 & 0.080 & 0.089 & 0.081 & 0.090 & 0.085 \\
\hline 256 & 0.962 & 0.855 & 0.524 & 0.596 & 0.567 & 0.534 & 0.511 \\
\hline 384 & 2.811 & 2.887 & 1.883 & 1.794 & 1.759 & 1.867 & 1.788 \\
\hline 512 & 9.010 & 10.253 & 6.144 & 6.304 & 6.227 & 6.160 & 6.045 \\
\hline 640 & 15.934 & 17.418 & 12.751 & 12.447 & 12.600 & 12.657 & 12.043 \\
\hline 768 & 22.033 & 21.43 & 14.089 & 12.452 & 12.457 & 12.821 & 12.161 \\
\hline 896 & 47.554 & 51.624 & 33.626 & 31.485 & 31.574 & 29.235 & 28.603 \\
\hline 1024 & 97.678 & 95.004 & 63.314 & 58.207 & 58.825 & 58.509 & 56.382 \\
\hline
\end{tabular}

Alfabeto $\mathrm{n} / 2$

Número de cortes

\begin{tabular}{crrrrrrr}
$n$ & & & & & & Todas S/ \\
$n$ & Nenhuma & RR-LCS & LCS-RR & Guloso & LC & Todas & RR-LCS \\
\hline 64 & 63.7 & 53.5 & 36.7 & 38.8 & 36.2 & 36.2 & 36.2 \\
128 & 125.5 & 112.1 & 85.7 & 85.3 & 85.8 & 84.7 & 84.7 \\
256 & 253.0 & 222.2 & 162.6 & 175.3 & 174.5 & 161.8 & 161.8 \\
384 & 351.1 & 332.4 & 262.1 & 251.8 & 251.8 & 251.5 & 251.5 \\
512 & 512.3 & 512.3 & 392.6 & 395.0 & 393.2 & 392.6 & 392.6 \\
640 & 598.3 & 598.3 & 527.2 & 524.2 & 524.2 & 524.2 & 524.2 \\
768 & 632.3 & 618.9 & 477.6 & 471.6 & 458.9 & 458.7 & 458.7 \\
896 & 803.9 & 803.9 & 644.4 & 652.3 & 653.7 & 626.2 & 626.2 \\
1024 & 1013.7 & 998.6 & 808.1 & 799.9 & 799.9 & 796.8 & 796.8 \\
\hline \multicolumn{7}{r}{} \\
\hline
\end{tabular}

$\mathrm{n}=\mathbf{2 5 6}$

Tempo gasto (s)

\begin{tabular}{rrrrrrrr} 
& & & & & & Todas s/ \\
R & Nenhuma & RR-LCS & LCS-RR & Guloso & LC & Todas & \begin{tabular}{c} 
RR-LCS \\
\hline 256
\end{tabular} \\
224 & 0.119 & 0.145 & 0.095 & 0.090 & 0.077 & 0.097 & 0.086 \\
192 & 0.119 & 0.145 & 0.111 & 0.103 & 0.099 & 0.111 & 0.101 \\
160 & 0.209 & 0.225 & 0.160 & 0.139 & 0.127 & 0.169 & 0.141 \\
128 & 1.0414 & 0.262 & 0.243 & 0.236 & 0.222 & 0.271 & 0.240 \\
96 & 2.570 & 0.860 & 0.525 & 0.563 & 0.576 & 0.573 & 0.538 \\
64 & 31.596 & 30.435 & 1.752 & 1.681 & 1.665 & 1.743 & 1.635 \\
32 & $\geq 900.016$ & $\geq 900.015$ & $\geq 900.016$ & $\geq 691.547$ & $\geq 678.809$ & $\geq 667.113$ & $\geq 667.982$ \\
\hline
\end{tabular}


Apêndice C. Dados numéricos dos resultados computacionais

\begin{tabular}{|c|c|c|c|c|c|c|c|}
\hline \multirow[b]{2}{*}{$|\Sigma|$} & \multicolumn{7}{|c|}{$\begin{array}{l}\quad n=256 \\
\text { Número de cortes }\end{array}$} \\
\hline & Nenhuma & RR-LCS & LCS-RR & Guloso & $\mathbf{L C}$ & Todas & $\begin{array}{l}\text { Todas s/ } \\
\text { RR-LCS }\end{array}$ \\
\hline 256 & 107.3 & 107.3 & 79.1 & 78.4 & 68.1 & 67.9 & 67.9 \\
\hline 224 & 108.8 & 105.1 & 85.4 & 83.6 & 78.0 & 76.9 & 76.9 \\
\hline 192 & 139.0 & 133.5 & 97.8 & 98.9 & 85.5 & 85.5 & 85.5 \\
\hline 160 & 153.1 & 138.0 & 119.6 & 121.3 & 115.3 & 114.8 & 115.2 \\
\hline 128 & 253.0 & 222.2 & 162.6 & 175.3 & 174.5 & 161.8 & 161.8 \\
\hline 96 & 373.9 & 370.8 & 275.3 & 277.0 & 277.0 & 274.9 & 274.9 \\
\hline 64 & 1142.2 & 1102.2 & 825.0 & 791.7 & 791.7 & 791.7 & 791.7 \\
\hline 32 & $\geq 315.6$ & $\geq 316.0$ & $\geq 315.6$ & $\geq 292.9$ & $\geq 289.7$ & $\geq 293.9$ & $\geq 294.5$ \\
\hline
\end{tabular}

\section{C.4 Variáveis fixadas através de limitantes de casamento}

As tabelas a seguir consideram o consumo médio de tempo e o número de cortes de execuções do algoritmo branch-and-cut sem e com o uso de eliminação de variáveis através de limitantes de casamento, usando as heurísticas (exceto RR-LCS) em todos os casos.

\begin{tabular}{|c|c|c|c|c|c|}
\hline \multicolumn{6}{|c|}{ alfabeto $n / 2$} \\
\hline \multirow[b]{2}{*}{$n$} & \multicolumn{2}{|c|}{ Tempo gasto (s) } & \multicolumn{2}{|c|}{ Número de cortes } & \multirow[b]{2}{*}{$\begin{array}{r}\% \text { de variáveis } \\
\text { fixadas (\%) }\end{array}$} \\
\hline & Sem & Com & Sem & Com & \\
\hline 128 & 0.086 & 0.058 & 84.7 & 70.2 & 48.36 \\
\hline 256 & 0.555 & 0.257 & 162.6 & 116.1 & 63.53 \\
\hline 384 & 1.902 & 0.745 & 251.5 & 170.4 & 72.02 \\
\hline 512 & 6.516 & 1.732 & 392.6 & 236.9 & 73.52 \\
\hline 640 & 13.122 & 3.627 & 524.2 & 344.4 & 71.38 \\
\hline 768 & 13.470 & 3.122 & 468.8 & 262.6 & 77.02 \\
\hline 896 & 30.543 & 7.459 & 626.2 & 377.8 & 76.05 \\
\hline 1024 & 62.540 & 12.064 & 796.8 & 470.0 & 76.13 \\
\hline \multicolumn{6}{|c|}{ alfabeto $\mathrm{n} / 4$} \\
\hline & \multicolumn{2}{|c|}{ Tempo gasto (s) } & \multicolumn{2}{|c|}{ Número de cortes } & \\
\hline$n$ & Sem & Com & Sem & Com & $\begin{array}{r}\% \text { de variáveis } \\
\text { fixadas (\%) }\end{array}$ \\
\hline 128 & 2.026 & 1.062 & 305.3 & 277.9 & 22.94 \\
\hline 256 & 22.271 & 12.303 & 791.7 & 683.5 & 33.88 \\
\hline 384 & 275.675 & 155.268 & 2160.9 & 1965.0 & 35.81 \\
\hline
\end{tabular}

\section{C.5 Resultados gerais do algoritmo branch-and-cut}

As tabelas a seguir mostram uma visão geral da execução do algoritmo branch-and-cut.

Legenda:

- EV: eliminação de variáveis através de limitante de casamento;

- HP: heurísticas primais (LCS-RR, guloso e limitante de casamento);

- Sep. PD: separação através de programação dinâmica (sem EV/HP);

- Nós: número de nós da árvore de branch-and-cut;

- Cortes: número de cortes de estrela estendida;

- Raiz: valor ótimo da relaxação no nó raiz. 
Apêndice C. Dados numéricos dos resultados computacionais

\begin{tabular}{|c|c|c|c|c|c|c|c|c|}
\hline \multirow[b]{2}{*}{$|\Sigma|$} & \multirow[b]{2}{*}{ Solução } & \multicolumn{5}{|c|}{$\mathrm{n}=512$} & $\mathbf{E V}+\mathbf{H P}$ & \multirow[b]{2}{*}{ Raiz } \\
\hline & & $\mathbf{E V}+\mathbf{H P}$ & HP & Sem EV/HP & Sep. PD & Nós & Cortes & \\
\hline 512 & 38.0 & 0.456 & 0.819 & 0.997 & 1.522 & 1.0 & 98.8 & 38.0 \\
\hline 448 & 40.7 & 0.584 & 1.241 & 1.663 & 2.598 & 1.0 & 116.3 & 40.8 \\
\hline 384 & 43.0 & 0.531 & 1.518 & 2.050 & 3.143 & 1.0 & 96.0 & 43.0 \\
\hline 320 & 46.5 & 1.423 & 3.453 & 5.079 & 6.879 & 1.0 & 187.1 & 46.5 \\
\hline 256 & 54.2 & 2.566 & 7.596 & 9.783 & 13.412 & 1.2 & 236.9 & 54.4 \\
\hline 192 & 59.8 & 12.469 & 32.299 & 53.560 & 53.505 & 3.6 & 549.7 & 60.4 \\
\hline 128 & 69.4 & 543.323 & 752.400 & 847.435 & $\geq 994.444$ & 29.5 & 2654.5 & 71.2 \\
\hline 64 & $56.9-63.9$ & $\geq 1800.000$ & $\geq 1800.000$ & $\geq 1800.000$ & $\geq 1800.000$ & $\geq 1.0$ & $\geq 527.3$ & $\leq 63.9$ \\
\hline
\end{tabular}

\begin{tabular}{|c|c|c|c|c|c|c|c|c|}
\hline \multirow[b]{2}{*}{$|\Sigma|$} & \multirow[b]{2}{*}{ Solução } & \multicolumn{4}{|c|}{$\mathbf{n}=1024$} & \multicolumn{2}{|c|}{$\mathbf{E V}+\mathbf{H P}$} & \multirow[b]{2}{*}{ Raiz } \\
\hline & & $\mathbf{E V}+\mathbf{H P}$ & HP & Sem EV/HP & Sep. PD & Nós & Cortes & \\
\hline 1024 & 56.9 & 1.699 & 5.025 & 5.495 & 10.307 & 1.0 & 140.0 & 56.9 \\
\hline 896 & 59.2 & 2.493 & 8.454 & 9.782 & 17.300 & 1.0 & 172.0 & 59.2 \\
\hline 768 & 64.1 & 4.724 & 15.039 & 19.072 & 28.105 & 1.0 & 251.9 & 64.1 \\
\hline 640 & 70.2 & 6.789 & 25.775 & 30.851 & 53.552 & 1.0 & 306.0 & 70.2 \\
\hline 512 & 78.1 & 14.375 & 63.984 & 78.752 & 106.518 & 1.4 & 470.0 & 78.3 \\
\hline 384 & 89.5 & 100.673 & 406.354 & 506.547 & 533.532 & 5.6 & 1145.1 & 90.2 \\
\hline 256 & $95.7-105.6$ & $\geq 1793.710$ & $\geq 1800.000$ & $\geq 1800.000$ & $\geq 1800.000$ & $\geq 3.9$ & $\geq 3075.5$ & $\leq 107.3$ \\
\hline 128 & $95.3-127.7$ & $\overline{\geq} 1800.000$ & $\overline{\geq} 1800.000$ & $\geq 1800.000$ & $\overline{\geq} 1800.000$ & $\overline{\geq} 1.0$ & $\geq 235.9$ & $\overline{\leq} 127.7$ \\
\hline
\end{tabular}

\begin{tabular}{|c|c|c|c|c|c|c|c|c|}
\hline \multirow[b]{3}{*}{$|\Sigma|$} & \multirow[b]{3}{*}{ Solução } & \multicolumn{6}{|c|}{$\mathrm{n}=1536$} & \multirow[b]{3}{*}{ Raiz } \\
\hline & & \multicolumn{4}{|c|}{ Tempo gasto (s) } & \multicolumn{2}{|c|}{$\mathbf{E V}+\mathbf{H P}$} & \\
\hline & & $\mathbf{E V}+\mathbf{H P}$ & HP & Sem EV/HP & Sep. PD & Nós & Cortes & \\
\hline 1536 & 71.0 & 4.775 & 18.58 & 19.184 & 33.425 & 1.0 & 179.4 & 71.0 \\
\hline 1344 & 76.0 & 5.189 & 24.095 & 25.993 & 43.253 & 1.0 & 168.9 & 76.0 \\
\hline 1152 & 81.4 & 10.309 & 43.313 & 50.965 & 79.398 & 1.0 & 265.3 & 81.4 \\
\hline 960 & 88.2 & 27.691 & 120.997 & 189.851 & 237.747 & 1.2 & 534.6 & 88.5 \\
\hline 768 & 98.4 & 63.570 & 347.947 & 532.176 & 555.320 & 4.4 & 755.0 & 98.7 \\
\hline 576 & 112.3 & 430.371 & $\geq 1444.602$ & $\geq 1578.908$ & $\geq 1574.156$ & 5.9 & 1669.4 & $\leq 113.2$ \\
\hline 384 & $121.2-139.2$ & $\geq 1800.000$ & $\overline{\geq} 1800.000$ & $\geq 1800.000$ & $\geq 1800.000$ & $\geq 2.1$ & $\geq 2008.6$ & $\leq 142.7$ \\
\hline 192 & $126.0-192.0$ & $\geq 1800.000$ & $\geq 1800.000$ & $\geq 1800.000$ & $\geq 1800.000$ & $\geq 1.0$ & $\geq 190.6$ & $\overline{\leq} 192.0$ \\
\hline
\end{tabular}

$$
\mathrm{n}=\mathbf{2 0 4 8}
$$

Tempo gasto (s)

\begin{tabular}{|c|c|c|c|c|c|c|c|c|}
\hline \multirow[b]{2}{*}{$|\Sigma|$} & \multirow[b]{2}{*}{ Solução } & & & & & & \multirow[b]{2}{*}{ Raiz } \\
\hline & & $\mathbf{E V}+\mathbf{H P}$ & HP & Sem EV/HP & Sep. PD & Nós & Cortes & \\
\hline 2048 & 82.7 & 5.233 & 44.802 & 44.324 & 71.519 & 1.0 & 119.3 & 82.7 \\
\hline 1792 & 89.2 & 12.959 & 70.728 & 72.682 & 105.848 & 1.0 & 247.2 & 89.2 \\
\hline 1536 & 95.2 & 22.198 & 140.183 & 153.518 & 196.652 & 1.0 & 315.0 & 95.2 \\
\hline 1280 & 102.6 & 32.817 & 208.035 & 296.675 & 316.615 & 1.0 & 433.1 & 102.6 \\
\hline 1024 & 116.0 & 206.650 & $\geq 834.925$ & $\geq 1033.834$ & $\geq 1072.482$ & 2.4 & 913.4 & $\leq 116.6$ \\
\hline 768 & $129.9-130.3$ & $\geq 774.912$ & $\geq 1791.638$ & $\geq 1800.000$ & $\geq 1800.000$ & $\geq 4.8$ & $\geq 1952.1$ & $\leq 133.4$ \\
\hline 512 & $143.2-168.6$ & $\geq 1761.192$ & $\geq 1800.000$ & $\geq 1800.000$ & $\geq 1800.000$ & $\geq 1.0$ & $\geq 1630.6$ & $\leq 172.6$ \\
\hline 256 & $154.6-255.9$ & $\overline{\geq} 1800.000$ & $\overline{\geq} 1800.000$ & $\geq 1800.000$ & $\overline{\geq} 1800.000$ & $\overline{\geq} 1.0$ & $\geq 184.0$ & $\leq 255.9$ \\
\hline
\end{tabular}




\section{C.6 Formulação por símbolos distintos}

A tabela abaixo compara a execução de um algoritmo branch-and-cut que usa formulação de símbolos distintos (SD) da Seção 3.3.2, incluindo restrições de estrelas especiais, com a que usa a formulação de estrelas estendidas (EE), sem o uso de heurísticas ou eliminação de variáveis através de limitantes de casamento.

\begin{tabular}{rrrrr}
\hline \multicolumn{5}{c}{$\mathbf{n}=\mathbf{5 1 2}$} \\
& & \multicolumn{2}{c}{ Tempo gasto $(\mathbf{s})$} & \\
\cline { 3 - 4 }$|\Sigma|$ & Nós & SD & EE & Cortes \\
\hline 512 & 2.0 & 1.423 & 0.997 & 244.8 \\
448 & 2.0 & 2.077 & 1.663 & 290.9 \\
384 & 3.0 & 2.706 & 2.050 & 336.8 \\
320 & 6.6 & 7.506 & 5.079 & 493.1 \\
256 & 8.8 & 19.033 & 9.783 & 680.4 \\
192 & 41.4 & 112.666 & 53.560 & 1558.5 \\
128 & $\geq 73.8$ & $\geq 1574.471$ & 847.435 & $\geq 4941.6$ \\
64 & $\geq 1.0$ & $\geq 1800.000$ & $\geq 1800.000$ & $\geq 771.8$ \\
\hline
\end{tabular}

\section{C.7 Formulação por cruzamentos}

As duas tabelas seguintes revelam o consumo médio de tempo da execução de um algoritmo branchand-cut usando apenas as restrições de cruzamento e de apenas um casamento por símbolo (primeira formulação da Seção 3.3.1). Foram aplicados todos os cortes gerados pelo GLPK, inclusive os de clique. A versão do GLPK usada foi 4.31, pois as versões posteriores limitam o número de cortes de clique por iteração, o que reduz o desempenho do algoritmo.

\begin{tabular}{crr}
\hline \multicolumn{3}{c}{$\mathbf{n}=\mathbf{2 5 6}$} \\
$|\Sigma|$ & Nós & Tempo (s) \\
\hline 256 & 1.0 & 5.972 \\
224 & 1.6 & 7.583 \\
192 & 1.0 & 13.797 \\
160 & 1.2 & 28.280 \\
128 & 74.0 & 189.620 \\
96 & $\geq 235.4$ & $\geq 1091.517$ \\
64 & $\geq 51.5$ & $\geq 1800.000$ \\
32 & $\geq 0.0$ & $\geq 1800.000$ \\
\hline
\end{tabular}

\begin{tabular}{rrr}
\hline & \multicolumn{2}{c}{$\mathbf{n = 5 1 2}$} \\
$|\Sigma|$ & Nós & Tempo (s) \\
\hline 512 & 25.2 & 115.830 \\
448 & 96.0 & 320.178 \\
384 & 124.0 & 588.796 \\
320 & $\geq 131.1$ & $\geq 1283.711$ \\
256 & $\geq 58.3$ & $\geq 1694.430$ \\
192 & $\geq 1.0$ & $\geq 1800.000$ \\
128 & $\geq 1.0$ & $\geq 1800.000$ \\
64 & $\geq 5.3$ & $\geq 1800.000$ \\
\hline
\end{tabular}

\begin{tabular}{crr}
\hline \multicolumn{3}{c}{ Alfabeto n/2 } \\
$n$ & Nós & Tempo (s) \\
\hline 64 & 12.6 & 0.695 \\
128 & 15.4 & 8.460 \\
192 & 17.0 & 43.777 \\
256 & 74.0 & 175.717 \\
320 & $\geq 116.6$ & $\geq 956.670$ \\
384 & $\geq 46.3$ & $\geq 1279.590$ \\
448 & $\geq 15.6$ & $\geq 1577.368$ \\
512 & $\geq 18.8$ & $\geq 1736.506$ \\
\hline
\end{tabular}

\section{C.8 Algoritmos de decomposição em subproblemas}

As tabelas a seguir comparam os consumos médios de tempo dos algoritmos de enumeração das Seções 6.1 e 6.2 . 
Apêndice C. Dados numéricos dos resultados computacionais

\begin{tabular}{|c|c|c|}
\hline \multirow[b]{2}{*}{$|\Sigma|$} & \multicolumn{2}{|c|}{$\begin{array}{c}\quad n=60 \\
\text { Tempo gasto (s) }\end{array}$} \\
\hline & Simples & $\begin{array}{l}\text { Com branch- } \\
\text { and-bound }\end{array}$ \\
\hline 5 & 0.167 & 0.001 \\
\hline 10 & 11.767 & 0.073 \\
\hline 15 & 5.401 & 2.247 \\
\hline 20 & 4.707 & 2.070 \\
\hline 25 & 0.677 & 0.117 \\
\hline 30 & 0.046 & 0.012 \\
\hline 35 & 0.009 & 0.003 \\
\hline 40 & 0.005 & 0.000 \\
\hline 45 & 0.001 & 0.003 \\
\hline 50 & 0.000 & 0.001 \\
\hline 55 & 0.000 & 0.000 \\
\hline 60 & 0.000 & 0.001 \\
\hline
\end{tabular}

\begin{tabular}{crr}
\hline & \multicolumn{2}{c}{ Alfabeto $\mathbf{n / 2}$} \\
& \multicolumn{2}{c}{ Tempo gasto (s) } \\
\cline { 2 - 3 }$n$ & Simples & $\begin{array}{r}\text { Com } \text { branch- } \\
\text { and-bound }\end{array}$ \\
\hline 10 & 0.000 & 0.000 \\
20 & 0.000 & 0.000 \\
30 & 0.000 & 0.000 \\
40 & 0.004 & 0.002 \\
50 & 0.022 & 0.005 \\
60 & 0.046 & 0.009 \\
70 & 0.535 & 0.057 \\
80 & 2.934 & 0.398 \\
90 & 12.033 & 0.335 \\
100 & 51.606 & 2.708 \\
110 & 283.311 & 12.284 \\
\hline
\end{tabular}

\section{C.9 Algoritmo de programação dinâmica}

As tabelas seguintes ilustram o consumo médio de tempo e de memória de execuções do algoritmo de programação dinâmica da Seção 6.3, sem o uso de pré-processamento das sequências.

\begin{tabular}{|c|c|c|c|c|c|c|c|}
\hline \multicolumn{4}{|c|}{$|\Sigma|=5$} & \multicolumn{4}{|c|}{$|\Sigma|=10$} \\
\hline$n$ & Solução & Tempo (s) & Memória (kB) & $n$ & Solução & Tempo (s) & Memória (kB) \\
\hline 3000000 & 5.0 & 1.374 & 444000.484 & 100000 & 10.0 & 1.841 & 413612.488 \\
\hline 6000000 & 5.0 & 2.575 & 888000.484 & 200000 & 10.0 & 3.670 & 827212.488 \\
\hline 9000000 & 5.0 & 3.860 & 1332000.484 & 300000 & 10.0 & 5.948 & 1240812.488 \\
\hline 12000000 & 5.0 & 5.116 & 1776000.484 & 400000 & 10.0 & 8.148 & 1654412.488 \\
\hline 15000000 & 5.0 & 6.548 & 2220000.484 & 500000 & 10.0 & 10.137 & 2068012.488 \\
\hline 18000000 & 5.0 & 7.622 & 2664000.484 & 600000 & 10.0 & 12.089 & 2481612.488 \\
\hline 21000000 & 5.0 & 8.757 & 3108000.484 & 700000 & 10.0 & 17.297 & 2895212.488 \\
\hline 24000000 & 5.0 & 10.029 & 3552000.484 & 800000 & 10.0 & 19.682 & 3308812.488 \\
\hline 27000000 & 5.0 & 11.551 & 3996000.484 & 900000 & 10.0 & 21.422 & 3722412.488 \\
\hline 30000000 & 5.0 & 12.353 & 4440000.484 & 1000000 & 10.0 & 22.528 & 4136012.488 \\
\hline \multicolumn{4}{|c|}{$|\Sigma|=15$} & \multicolumn{4}{|c|}{$|\Sigma|=20$} \\
\hline$n$ & Solução & Tempo (s) & Memória (kB) & $n$ & Solução & Tempo (s) & Memória (kB) \\
\hline 3200 & 15.0 & 2.456 & 420015.916 & 100 & 19.3 & 3.552 & 369082.794 \\
\hline 6400 & 15.0 & 5.531 & 839638.316 & 200 & 20.0 & 7.820 & 851460.112 \\
\hline 9600 & 15.0 & 8.664 & 1259260.716 & 300 & 20.0 & 10.917 & 1270898.512 \\
\hline 12800 & 15.0 & 11.878 & 1678883.116 & 400 & 20.0 & 15.368 & 1690336.912 \\
\hline 16000 & 15.0 & 14.135 & 2098505.516 & 500 & 20.0 & 18.749 & 2109775.312 \\
\hline 19200 & 15.0 & 16.485 & 2518127.916 & 600 & 20.0 & 22.552 & 2529213.712 \\
\hline 22400 & 15.0 & 22.324 & 2937750.316 & 700 & 20.0 & 25.750 & 2948652.112 \\
\hline 25600 & 15.0 & 26.938 & 3357372.716 & 800 & 20.0 & 31.775 & 3368090.512 \\
\hline 28800 & 15.0 & 28.334 & 3776995.116 & 900 & 20.0 & 34.000 & 3787528.912 \\
\hline 32000 & 15.0 & 34.962 & 4196617.516 & 1000 & 20.0 & 39.174 & 4206967.312 \\
\hline
\end{tabular}


Apêndice C. Dados numéricos dos resultados computacionais

\begin{tabular}{crrr}
\hline \multicolumn{3}{c}{$|\Sigma|=25$} \\
$n$ & Solução & Tempo (s) & Memória (kB) \\
\hline 9 & 1.5 & 0.371 & 268437.052 \\
18 & 4.4 & 0.372 & 268442.111 \\
27 & 6.2 & 0.705 & 268480.667 \\
36 & 8.7 & 2.569 & 268842.900 \\
45 & 11.1 & 5.720 & 271674.642 \\
54 & 13.6 & 10.553 & 290866.110 \\
63 & 15.9 & 12.881 & 424753.270 \\
72 & 17.2 & 18.071 & 786507.950 \\
81 & 18.8 & 23.708 & 1330135.579 \\
90 & 20.2 & 48.342 & 3047538.037 \\
\hline
\end{tabular}

\section{C.10 Algoritmos de conjunto independente}

As tabelas a seguir comparam o consumo médio de tempo dos algoritmos de clique máximo no grafo complementar ao de conflito (o mesmo que conjunto independente no grafo de conflito) com o algoritmo branch-and-cut.

\begin{tabular}{|c|c|c|c|}
\hline \multicolumn{4}{|c|}{$\mathrm{n}=\mathbf{5 1 2}$} \\
\hline$|\Sigma|$ & Östergard & $\begin{array}{l}\text { Konc e } \\
\text { Janežič }\end{array}$ & $\begin{array}{r}\text { branch-and- } \\
\text { cut }\end{array}$ \\
\hline 512 & 0.062 & 0.059 & 0.456 \\
\hline 448 & 0.048 & 0.086 & 0.584 \\
\hline 384 & 0.073 & 0.135 & 0.531 \\
\hline 320 & 0.068 & 0.286 & 1.423 \\
\hline 256 & 10.671 & 0.638 & 2.566 \\
\hline 192 & 357.614 & 3.633 & 12.469 \\
\hline 128 & - & 1053.535 & 543.323 \\
\hline \multicolumn{4}{|c|}{$n=1536$} \\
\hline$|\Sigma|$ & Östergard & $\begin{array}{l}\text { Konc e } \\
\text { Janežič }\end{array}$ & $\begin{array}{r}\text { branch-and- } \\
\text { cut }\end{array}$ \\
\hline 1536 & 3.005 & 2.538 & 4.775 \\
\hline 1344 & 58.044 & 4.999 & 5.189 \\
\hline 1152 & 55.750 & 10.446 & 10.309 \\
\hline 960 & 2234.097 & 31.366 & 27.691 \\
\hline 768 & - & 87.323 & 63.570 \\
\hline 576 & - & 3641.843 & 430.371 \\
\hline
\end{tabular}

\begin{tabular}{crrr}
\hline \multicolumn{4}{c}{$\mathbf{n = 1 0 2 4}$} \\
$|\Sigma|$ & Östergard & $\begin{array}{r}\text { Konc e } \\
\text { Janežič }\end{array}$ & $\begin{array}{r}\text { branch-and- } \\
\text { cut }\end{array}$ \\
\hline 1024 & 0.156 & 0.578 & 1.699 \\
896 & 0.364 & 1.013 & 2.493 \\
768 & 1.210 & 1.880 & 4.724 \\
640 & 9.726 & 4.600 & 6.789 \\
512 & - & 14.791 & 14.375 \\
384 & - & 151.828 & 100.673 \\
& & & \\
\hline
\end{tabular}

\begin{tabular}{crrr}
\hline \multicolumn{5}{c}{$\mathbf{n}=\mathbf{2 0 4 8}$} \\
$|\Sigma|$ & Östergard & $\begin{array}{r}\text { Konc e } \\
\text { Janežič }\end{array}$ & $\begin{array}{r}\text { branch-and- } \\
\text { cut }\end{array}$ \\
\hline 2048 & 1.004 & 8.403 & 5.233 \\
1792 & 20.468 & 18.445 & 12.959 \\
1536 & 44.141 & 28.541 & 22.198 \\
1280 & - & 77.280 & 32.817 \\
1024 & - & 373.692 & 206.650 \\
& & & \\
\hline
\end{tabular}

\section{C.11 Algoritmos para o LCS}

As tabelas seguintes ilustram os consumos médios de tempo de execuções de algoritmos para o problema do LCS, descritos no Capítulo 7.

Legenda:

- AG(p): Apostolico-Guerra (proxPosYDiv)

- AG(t): Apostolico-Guerra (tabela)

- PD: Programação dinâmica

- Hirsch.: Hirschberg

- Lin. H: Espaço linear de Hirschberg

- HS: Hunt-Szymanski

- KC: Kuo-Cross

- NKY: Nakatsu-Kambayashi-Yajima

- SC: Saltos para casamentos

- $\mathbf{S C}(2)$ : Saltos para casamentos $\left(2^{\mathrm{a}}\right.$ versão $)$ 
Apêndice C. Dados numéricos dos resultados computacionais

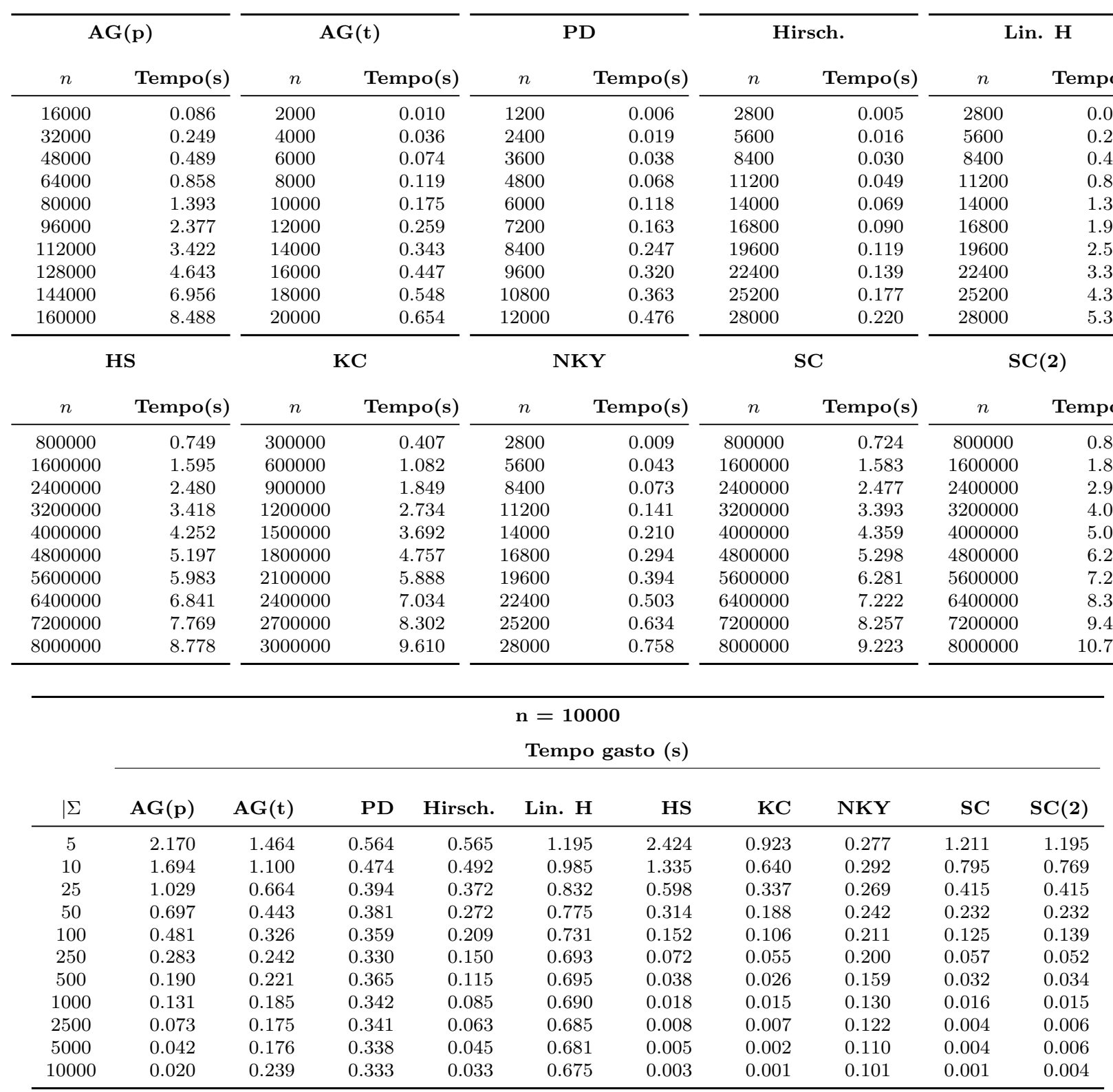


Apêndice C. Dados numéricos dos resultados computacionais 


\section{Créditos}

Esta dissertação abrange todo o conteúdo sobre o problema do RFLCS estudado pelo autor tanto em um projeto de mestrado como um de iniciação científica antes dele. Este trabalho aproveitou-se bastante do auxílio de diversas fontes (professores e artigos), especialmente em sua primeira metade cronológica, e o propósito desta parte é atribuir os créditos para cada resultado desta dissertação, mencionar em que publicação cada tópico aparece e indicar o que foi feito durante a iniciação científica e o que foi feito durante o mestrado.

Não podemos atribuir créditos sem primeiro destacar os três professores do Instituto de Matemática e Estatística que ajudaram diretamente a atingir o objetivo deste trabalho. Todos os tópicos deste trabalho foram proveitosamente discutidos com o prof. Carlos Eduardo Ferreira, o orientador do autor deste texto, que proveu muitas das ideias descritas neste texto durante essas discussões. Além disso, tanto a prof. ${ }^{a}$ Cristina Gomes Fernandes, que também participou dessas discussões durante a iniciação científica, como a prof. ${ }^{a}$ Yoshiko Wakabayashi contribuíram bastante para os resultados deste trabalho.

Separamos os créditos por capítulo.

Capítulo 2: Os problemas e suas estruturas. A maioria dos conceitos desse capítulo foi herdada ou adaptada de conceitos existentes para problema do LCS. A visão do problema em termos de grafos foi desenvolvida durante a iniciação científica.

Capítulo 3: Formulações e poliedros. As formulações por cruzamentos e sua variante foram construídas para uma versão anterior (de conferência) do artigo por Adi et al. (Adi, Braga, Fernandes, Ferreira, Martinez, Sagot, Stefanes, Tjandraatmadja e Wakabayashi, 2007/2009) [1]. Estendemos essas formulações durante a iniciação científica, o que resultou nas formulações por estrelas e por estrelas estendidas. A prova 1 do Teorema 3.2.3 (integralidade do poliedro do LCS) foi desenvolvida pelo prof. Carlos, e a prova 2 foi observada pela prof. ${ }^{a}$ Yoshiko e pelo autor. Tudo isso, mais as provas de facetas (feitas pelo prof. Carlos), foram desenvolvidas na iniciação científica e compõem o artigo por Fernandes et al. (Fernandes, Ferreira, Tjandraatmadja e Wakabayashi, 2008) [12].

As simples observações de que a matriz de restrições da formulação por estrelas não é totalmente unimodular e de que inequações de buraco ímpar são válidas para o problema do RFLCS foram notadas durante o mestrado. A formulação por símbolos distintos e as provas de que suas inequações definem facetas (Seção 3.3.1) e os limitantes e gap de integralidade para o problema do RFLCS (Seção 3.4) também foram desenvolvidos durante o mestrado. 
Capítulo 4: Aproximabilidade e heurísticas para RFLCS. Os algoritmos de aproximação (Seção 4.2) foram desenvolvidos por Adi et al., sendo que o autor participou no processo apenas ao implementá-los durante a iniciação científica. As heurísticas gulosas (Seção 4.3) foram desenvolvidas e implementadas durante o mestrado e tiveram algumas influências: a heurística de escolha simples (Seção 4.3.1) foi apontada pelo prof. Marcos Kiwi [27] como uma heurística de espaço constante para o problema do LCS que poderia ser facilmente estendida para o do RFLCS, e a heurística de menor número de conflitos (Seção 4.3.2) foi adaptada de um algoritmo de aproximação para o problema do conjunto independente máximo [18].

A prova de que o problema do RFLCS é APX-difícil (Seção 4.5) foi desenvolvida por Adi et al., e o autor apenas a reescreveu nesta dissertação.

Capítulo 5: Algoritmo branch-and-cut para RFLCS. A implementação do algoritmo baseado em branch-and-cut foi iniciada durante a iniciação científica e aprofundada durante o mestrado. O primeiro algoritmo de separação para inequação de estrelas estendidas, que usa programação dinâmica (Seção 5.2.1), foi elaborado junto com o prof. Carlos e a prof. ${ }^{a}$ Cristina e implementado durante a iniciação científica, e está descrito também no artigo por Fernandes et al. O pré-processamento foi também desenvolvido durante a iniciação científica. A extensão desse algoritmo baseada no algoritmo de Hunt e Szymanski (Seção 5.2.2) foi usada para obter os resultados computacionais no artigo por Ferreira e Tjandraatmadja, 2010 [13]. Esse artigo também descreve as heurísticas (Seção 5.3) e a técnica de eliminação de variáveis usando limitantes de casamento (Seção 5.4), que foram desenvolvidas e implementadas durante o mestrado.

Capítulo 6: Algoritmos de enumeração para RFLCS. Os algoritmos desse capítulo foram concebidos no mestrado. O algoritmo de programação dinâmica (Seção 6.3) é baseado em um algoritmo por Bonizzoni et al. [7] para um problema mais geral, e as ideias para reduzir seu consumo de tempo são inspiradas por artigos de Hunt e Szymanski [22] e Apostolico e Guerra [2]. A implementação dos dois algoritmos de clique máximo (conjunto independente) são de Östergård [36] e de Konc e Janežič [28].

Capítulo 7: Algoritmos para LCS. A resenha e a implementação dos algoritmos foram feitas durante o mestrado. As referências de cada algoritmo para o problema do LCS estão em suas respectivas seções e também na última seção do capítulo. Desenvolvemos também um algoritmo não encontrado na literatura (Seção 7.10) que aplica uma técnica por Apostolico e Guerra no algoritmo de Hunt e Szymanski.

Um dos objetivos desse capítulo foi apresentar todos os algoritmos sob uma estrutura coesa e uma mesma notação, apesar dos vários pontos de vista e notações diferentes dos artigos. Em particular, descrevemos os algoritmos tendo sempre em mente como eles funcionam no contexto da matriz de programação dinâmica. Isso facilita tanto o entendimento dos algoritmos como a comparação das ideias dos algoritmos. 


\section{Referências Bibliográficas}

[1] S.S. Adi, M. Braga, C.G. Fernandes, C.E. Ferreira, F.V. Martinez, M.-F. Sagot, M.A. Stefanes, C. Tjandraatmadja, and Y. Wakabayashi. Repetition-free longest common subsequence. Discrete Applied Mathematics, 158(12):1315-1324, 2010. Traces from LAGOS'07 IV Latin American Algorithms, Graphs, and Optimization Symposium Puerto Varas - 2007.

[2] A. Apostolico and C. Guerra. The longest common subsequence problem revisited. Algorithmica, $2: 315-336,1987$.

[3] V.L. Arlazarov, E.A. Dinic, M.A. Kronrod, and I.A. Faradzev. On economic construction of the transitive closure of a directed graph [English translation]. Soviet Math. Dokl, 11:1209-1210, 1975.

[4] G. Ausiello, P. Crescenzi, G. Gambosi, V. Kann, A. Marchetti-Spaccamela, and M. Protasi. Complexity and Approximation: Combinatorial Optimization Problems and Their Approximability Properties. Springer, 1999.

[5] L. Bergroth, H. Hakonen, and T. Raita. A survey of longest common subsequence algorithms. In SPIRE'00: Proceedings of the Seventh International Symposium on String Processing Information Retrieval (SPIRE'00), page 39, Washington, DC, USA, 2000. IEEE Computer Society.

[6] P. Bonizzoni, G. Della Vedova, R. Dondi, G. Fertin, R. Rizzi, and S. Vialette. Exemplar longest common subsequence. IEEE/ACM Trans. Comput. Biol. Bioinformatics, 4(4):535-543, 2007.

[7] P. Bonizzoni, G. Della Vedova, R. Dondi, and Y. Pirola. Variants of constrained longest common subsequence. Information Processing Letters, 110(20):877-881, 2010.

[8] M.H. Carvalho, M.R. Cerioli, R. Dahab, P. Feofiloff, C.G. Fernandes, C.E. Ferreira, F.K. Miyazawa, J.C. de Pina, J. Soares, and Y. Wakabayashi. Uma Introdução Sucinta a Algoritmos de Aproximação. Publicações Matemáticas do IMPA, 2001.

[9] V. Chvátal. On certain polytopes associated with graphs. J. Combinatorial Theory Ser. B, 18:138-154, 1975.

[10] G.B. Dantzig. Maximization of a linear function of variables subject to linear inequalities. In Tj. C. Koopmans, editor, Activity Analysis of Production and Allocation, pages 339-347. Wiley, New York, 1951.

[11] R.P. Dilworth. A decomposition theorem for partially ordered sets. Annals of Mathematics, 51:161-166, 1950.

[12] C.G. Fernandes, C.E. Ferreira, C. Tjandraatmadja, and Y. Wakabayashi. A polyhedral investigation of the LCS problem and a repetition-free variant. In Proc. of the 8th Latin American Symposium on Theoretical Informatics (LATIN'08), volume 4957 of Lecture Notes in Computer Science, pages 329-338. Springer, 2008. 
[13] C.E. Ferreira and C. Tjandraatmadja. A branch-and-cut approach to the repetition-free longest common subsequence problem. Electronic Notes in Discrete Mathematics, 36:527-534, 2010. ISCO 2010 International Symposium on Combinatorial Optimization.

[14] GLPK (GNU Linear Programming Kit). http://www.gnu.org/software/glpk.

[15] M.C. Golumbic. Algorithmic Graph Theory and Perfect Graphs (Annals of Discrete Mathematics, Vol. 57). North-Holland Publishing Co., Amsterdam, The Netherlands, The Netherlands, 2004.

[16] M. Grötschel, L. Lovász, and A. Schrijver. Geometric Algorithms and Combinatorial Optimization. Springer, 2nd edition, 1993.

[17] D. Gusfield. Algorithms on Strings, Trees, and Sequences: Computer Science and Computational Biology. Cambridge Univ. Press, 2007.

[18] M. Halldórsson and J. Radhakrishnan. Greed is good: approximating independent sets in sparse and bounded-degree graphs. In STOC '94: Proceedings of the twenty-sixth annual ACM symposium on Theory of computing, pages 439-448, New York, NY, USA, 1994. ACM.

[19] D.S. Hirschberg. A linear space algorithm for computing maximal common subsequences. Commun. ACM, 18(6):341-343, 1975.

[20] D.S. Hirschberg. Algorithms for the longest common subsequence problem. J. ACM, 24(4):664-675, 1977.

[21] K.L. Hoffman and M. Padberg. Solving airline crew scheduling problems by branch-and-cut. Manage. Sci., 39(6):657-682, 1993.

[22] J.W. Hunt and T.G. Szymanski. A fast algorithm for computing longest common subsequences. Communications of the ACM, 20(5):350-353, 1977.

[23] IBM ILOG CPLEX. http://www.cplex.com.

[24] N. Karmarkar. A new polynomial-time algorithm for linear programming. Combinatorica, 4:373-395, 1984.

[25] R.M. Karp and C.H. Papadimitriou. On linear characterizations of combinatorial optimization problems. SIAM Journal on Computing, 11:620-632, 1982.

[26] L.G. Khachiyan. A polynomial algorithm for linear programming. Soviet Mathematical Doklady, 20:191-194, 1979.

[27] M. Kiwi. Comunicação pessoal, 2008.

[28] J. Konc and D. Janežič. An improved branch and bound algorithm for the maximum clique problem. MATCH Communications in Mathematical and in Computer Chemistry, 58:569-590, 2007.

[29] S. Kuo and G.R. Cross. An improved algorithm to find the length of the longest common subsequence of two strings. SIGIR Forum, 23(3-4):89-99, 1989.

[30] B.T. Lahn and D.C. Page. Four evolutionary strata on the human X chromosome. Science, 286:964-967, 1999.

[31] W.-H. Li, Z. Gu, H. Wang, and A. Nekrutenko. Evolutionary analyses of the human genome. Nature, 409:847-849, 2001.

[32] W.J. Masek and M. Paterson. A faster algorithm computing string edit distances. J. Comput. Syst. Sci., 20(1):18-31, 1980.

[33] R.R. Meyer. On the existence of optimal solutions to integer and mixed-integer programming problems. Mathematical Programming, 7(1):223-235, 1974. 
[34] N. Nakatsu, Y. Kambayashi, and S. Yajima. A longest common subsequence algorithm suitable for similar text strings. Acta Inf., 18:171-179, 1982.

[35] S.B. Needleman and C.D. Wunsch. A general method applicable to the search for similarities in the amino acid sequence of two proteins. J. Mol. Biol., 48(3):443-453, 1970.

[36] P.R.J. Östergård. A fast algorithm for the maximum clique problem. Discrete Appl. Math., 120(1-3):197207, 2002.

[37] M.W. Padberg. On the facial structure of set packing polyhedra. Mathematical Programming, 5:199-215, 1973.

[38] C.H. Papadimitriou and M. Yannakakis. Optimization, approximation and complexity classes. Journal of Computer and System Sciences, 43:425-440, 1991.

[39] D. Sankoff. Genome rearrangement with gene families. Bioinformatics, 15(11):909-917, 1999.

[40] D. Sankoff. Gene and genome duplication. Current Opinion in Genetics and Development, 11(6):681-684, 2001.

[41] D. Sankoff and N. El-Mabrouk. Genome rearrangement. In T. Jiang, T. Smith, Y. Xu, and M. Zhang, editors, Current Topics in Computational Biology, pages 135-155. MIT Press, 2002.

[42] D. Sankoff and J.B. Kruskal. Time Warps, String Edits, and Macromolecules: The Theory and Practice of Sequence Comparison. Addison-Wesley, 1983.

[43] A. Schrijver. Min-max results in combinatorial optimization. In A. Bachem, M. Grötschel, and B. Korte, editors, Mathematical Programming - The state of the Art, pages 439-500. Springer-Verlag, 1983.

[44] H. Skaletsky et al. The male-specific region of the human Y chromosome is a mosaic of discrete sequence classes. Nature, 423:825-837, 2003.

[45] R.A. Wagner and M.J. Fischer. The string-to-string correction problem. J. ACM, 21(1):168-173, 1974.

[46] L.A. Wolsey. Integer Programming. Wiley-Interscience, 1998. 